\title{
Uma Visão Sobre a Próxima \\ Geração de Abstrações de Pro- \\ cessos em Sistemas Operacionais
}

Rodrigo Siqueira Jordão

\author{
DiSSERTAÇÃO APRESENTADA AO \\ Instituto DE MATEMÁTICA E EstatísticA \\ DA UNIVERSidAde de SÃo PaUlo \\ PARA OBTENÇÃO DO TÍTULO DE \\ Mestre em CiênCIAS
}

Programa: Ciência da Computação

Orientador: Prof. Dr. Fabio Kon

Durante o desenvolvimento deste trabalho o autor recebeu auxílio do CNPq

São Paulo

5 de fevereiro de 2019 



\title{
Uma Visão Sobre a Próxima Geração de Abstrações de Pro- cessos em Sistemas Operacionais
}

\author{
Rodrigo Siqueira Jordão
}

Esta versão da dissertação contém as correções e alterações sugeridas pela Comissão Julgadora durante a defesa da versão original do trabalho, realizada em 5 de fevereiro de 2019.

Uma cópia da versão original está disponível no Instituto de Matemática e Estatística da Universidade de São Paulo.

Comissão Julgadora:

- Prof. Dr. Fabio Kon - IME-USP

- Prof. Dr. Emilio de Camargo Francesquini - UFABC

- Dr. João Moreira - Suse 

Dedico este trabalho para todo brasileiro que vem de camadas desprivilegiadas da sociedade, mas que com muito sacrifício nadam contra a maré de uma sociedade doente e conservadora. 



\section{Agradecimentos}

Se eu vi mais longe, foi por estar sobre ombros de gigantes. - Isaac Newton

Não existe outra forma de começar estes agradecimentos sem iniciar reconhecendo o grupo de pessoas que mais me apoiaram e apoiam até hoje a minha família. Se fiz coisas boas nesta vida, se fiz algo útil para a alguém, ou qualquer outra coisa digna de reconhecimento, devo tudo isso a duas mulheres extraordinárias que me inspiraram e inspiram até hoje; muito obrigado mãe (Simone Martins Siqueira) e avó/mãe (Maria Francelina Martins Siqueira), duas mães que com muito carinho, amor, paciência e ternura me moldaram. Sei que vocês passaram por dificuldades enormes nesta vida, tiveram que lutar firmemente contra todos aqueles que torciam contra, foram éticas e consistentes com os seus valores em todas as situações. Muito obrigado por tudo o que vocês fizeram por mim, por todas as batalhas travadas, em prol do meu enriquecimento intelectual. Agradeço a minha super irmã (Sophia Fiama), que tenho como uma filha, que me enche de orgulho e me inspira a sempre buscar o impossível. Por fim, agradeço muito a minha esposa (Jozzi Quezzia) que é sempre tão carinhosa, amável, paciente e companheira. Muito obrigado por ter ficado ao meu lado em tantos momentos de luta e sacrifício.Você é uma das poucas pessoas que sabem de fato o que foram esses últimos três anos de intensa luta. Sei que não foi fácil para você esses últimos anos mas quero que saiba que sou realmente muito grato em te ter na minha vida. Enfim, muito obrigado a todas as mulheres da minha vida que tanto me auxiliaram e incentivaram.

Agradeço também a minha "nova velha família" na qual a minha esposa me deu a honra de fazer parte ao se casar comigo. Obrigado seu José Eliziario e Dona Maria Aparecida por sempre me tratar com tanto carinho, pelas brincadeiras e por sempre me fazer esquecer um pouco dos problemas. Obrigado Bertineide por me tratar bem e por cuidar da minha esposa até hoje. Muito obrigado a todos vocês que vieram somar coisas boas na minha vida. 
Devo um grande agradecimento ao meu amigo Paulo Meirelles e toda a sua família por sempre tratarem eu e a minha esposa com tanto apreço. Obrigado Paulo por ter me ensinado como construir um projeto de software de verdade, por ter me ajudado a melhorar o meu "RH" e por me apresentar ao software livre; em especial agradeço por ter sido um grande exemplo de ética e trabalho. Muito obrigado Flavio e Patricia Kobayashi por todo suporte que vocês deram para mim e toda a minha família durante esses anos; admiro muito vocês. Também agradeço muito ao meu grande amigo Charles por sempre me dar bons conselhos, por me ajudar em momentos difíceis, por se preocupar comigo e por ser sempre o melhor companheiro de doritos com Bohemia. Agradeço ao meu amigo Paulo Márcio Rodrigues, que foi um grande companheiro durante a minha caminhada pelo mestrado fazendo companhia para mim nos fins de semana de trabalho no laboratório ou nas altas horas de trabalho.

Agradeço ao meu orientador Fabio Kon por ter aceitado o desafio de me orientar em uma área tão complexa. Obrigado por ter me ajudado a concluir essa fase da minha vida e por ter me dado o suporte necessário para que eu pudesse melhorar as minhas habilidades. Agradeço também ao super Nelson por todas as discussões que tivemos, por ter me ajudado com inúmeras discussões e revisões. Nelson, muito obrigado por todos os aconselhamentos, pelos ensinamentos e pelos bons momentos que você proporcionou no dia-a-dia de laboratório.

Obrigado Renan por todos os momentos que tivemos juntos durante o mestrado, por ter sido um grande amigo e pelas boas confusões que compartilhamos pelas filas dos bandejões da USP. Obrigado Arthur, Athos, Thallysman, Dylan, Mourão e Kanashiro por todas as nossas conversas referentes a pesquisa, debates sobre software livre e por toda "água" compartilhada. Agradeço também a Melissa Wen por todas as suas revisões e pelo time vencedor que montamos juntos. Obrigado Giuliano por sua amizade e companheirismo de lab; obrigado também por ter confiado nas minhas orientações. Agradeço a Isabel pelas suas várias tentativas desajeitadas e ligeiramente vagas, mas de coração, de me ajudar; apesar de tudo, você também fez parte deste ciclo.

Agradeço a USP e UnB por todas as oportunidades, sinto-me privilegiado por ter passado por essas instituições. Agradeço ao CNPq pelo investimento proporcionado a minha formação ao longo desses anos, e prometo que honrarei meu país, com os conhecimentos adquiridos com excelência e eficiência. Por fim, agradeço ao Senhor Josenaldo Ferreira Batista pelo excelente trabalho que vem desenvolvendo ao longo desses anos junto ao serviço de prestação de contas do $\mathrm{CNPq}$ durante todos esses anos, a pesquisa e os que fazem parte do corpo docente e discente só tem a agradecer. 


\section{Resumo}

Rodrigo Siqueira Jordão. Uma Visão Sobre a Próxima Geração de Abstrações de Processos em Sistemas Operacionais. Dissertação (Mestrado). Instituto de Matemática e Estatística, Universidade de São Paulo, São Paulo, 2019.

Nas últimas décadas, muitos pesquisadores dedicaram-se a avançar o modelo atual de abstração de processos, seja por meio da adição de camadas extras de segurança, seja em busca de melhorias de desempenho, ou ainda com o objetivo de fornecer suporte para novos recursos de hardware. Tais melhorias são relevantes porque abstrações de processos em SOs de propósito geral representam o ponto de encontro de diversos recursos de interesse dos usuários. Processos representam a convergência entre a aplicação dos usuários, os modelos de programação oferecidos pelo SO e a utilização dos recursos de hardware. Os esforços para expandir as capacidades dos SOs no nível da abstração de processos abrem uma nova área de pesquisa ainda pouco explorada. Nesta dissertação, após um levantamento preliminar dos trabalhos relacionados ao tema, nos concentramos em 9 pesquisas que foram selecionadas levando-se em consideração aspectos como as propostas de implementação adotadas por elas e o seu impacto na literatura da área. Desses trabalhos, derivamos um conjunto de características que consideramos importantes para guiar o desenvolvimento da próxima geração de abstrações de processos. Partindo de tais características, propomos um modelo teórico chamado de bead cujo o objetivo é ilustrar os desafios e vantagem em se expandir as abstrações de processos. Além disso, sugerimos uma coleção de microbenchmarks que podem ser utilizados para revelar parte dos impactos de novas abstrações de processos. Por fim, realizamos uma discussão sobre aplicações de uso cotidiano que podem ser utilizadas para a validação dessas propostas e que também possam delas se beneficiar.

Palavras-chave: Abstração de processos. Gerenciamento de processos. Processos. Sistemas Operacionais. SO. 



\begin{abstract}
Rodrigo Siqueira Jordão. An Outline for the Next Generation of Process Abstractions in Operating Systems. Thesis (Masters). Institute of Mathematics and Statistics, University of São Paulo, São Paulo, 2019.

In recent decades, many researchers committed to pushing forward the current model of process abstraction, either by adding extra layers of security or seeking performance improvements or even providing support for new hardware. Such enhancements are relevant because process abstractions in general-purpose OSes represent the meeting point of several aspects of users concern. Processes join together user applications, programming models provided by the OS and hardware resources access. Efforts to expand OS capabilities at the process abstraction level represent a new and underexplored research field. In this thesis, after a preliminary survey of the area, we selected nine works to focus on by considering aspects such as their implementation approach and their impact on the literature. From these works, we extracted a set of characteristics that we consider essential to guide the development of the next generation of process abstractions. Based on such characteristics, we propose a theoretical model called "bead", which illustrates the challenges and advantages of expanding process abstractions. Furthermore, we suggest a collection of microbenchmarks that can be used to reveal some of the impacts of new process abstractions. Finally, we discuss real-world applications that can be used to validate these proposals, and that could also benefit from them.
\end{abstract}

Keywords: Processes abstractions. Processes management. Processes. Operating Systems. OS. 



\title{
Lista de Abreviaturas
}

\author{
APR Apache Portable Runtime \\ CVE Common Vulnerabilities and Exposures \\ GC Garbage Collection \\ IP Instruction Pointer \\ MMP Mondrian Memory Protection \\ MMU Memory-Management Unit \\ MPM Multi-Processing Module \\ MPX Memory Protection Extensions \\ PCB Process Control Block \\ PD Protection Domain \\ PTE Page Table Entry \\ SB Secure binding \\ SGX Software Guard Extensions \\ SO Sistema Operacional \\ SSL Secure Sockets Layers \\ SSL Secure Sockets Layers \\ SSL Secure Sockets Layers \\ STW Stop the World \\ SVM Secure Virtual Machine \\ TLB Translation Lookaside Buffer \\ USP Universidade de São Paulo \\ VMA Virtual Memory AREA \\ VMCS Virtual-Machine Control Structure \\ VMM Virtual Machine Monitor
}




\section{Lista de Figuras}

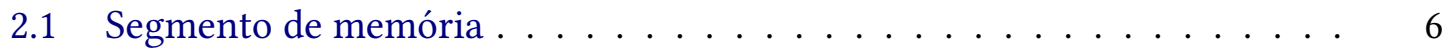

2.2 Alocação e desalocação de Stack frames considerando o padrão CDECL . 7

2.3 Única thread e multi-thread. . . . . . . . . . . . . . . . . . . 8

2.4 Um processo com uma thread e um processo com três threads . . . . . . 10

2.5 Do endereço lógico ao físico com o auxílio da MMU . . . . . . . . . . . . 11

2.6 Espaço de endereçamento virtual vs. físico . . . . . . . . . . . . . . . 12

2.7 Os elementos básicos presentes no modelo de paginação. . . . . . . . . . 13

2.8 Entrada da tabela de páginas . . . . . . . . . . . . . . . . . . 13

2.9 Passos do acesso a memória usando o modelo de paginação. . . . . . . . . 14

2.10 Comportamento do modelo de segmentação. . . . . . . . . . . . . . . . . 15

2.11 Ilustração de uma entrada da tabela de páginas utilizando novos bits . . . 15

2.12 VAS durante a troca de contexto . . . . . . . . . . . . . . . . . 17

2.13 Visão interna do gerenciamento da memória . . . . . . . . . . . . . . . . 18

2.14 Passos envolvidos na alocação de memória com malloc() . . . . . . . 18

2.15 Execução do user space até o kernel space . . . . . . . . . . . . . . . . 19

2.16 Tabela local e global de arquivos . . . . . . . . . . . . . . . . . 21

2.17 Fluxo do comportamento da tecnologia VT-x . . . . . . . . . . . . 26

3.1 Arquitetura do Dune . . . . . . . . . . . . . . . . . . . . . 32

3.2 Funcionamento geral do shreds . . . . . . . . . . . . . . 34

3.3 Cenários das aplicações . . . . . . . . . . . . . . . . . 38

3.4 Visão geral da arquitetura do Nooks . . . . . . . . . . . . . . . . . . . . 40

3.5 Acesso à memória do Nooks . . . . . . . . . . . . . . . . . . . . . 41

3.6 Representação dos domínios de proteção do Mondrix . . . . . . . . . . . 43

3.7 VAS e Memóra Física . . . . . . . . . . . . . . . . . . . . . . . . 44

3.8 Resolvendo o problema de endereçar memórias físicas grandes . . . . . . 45

3.9 VAS e MVAS . . . . . . . . . . . . . . . . . . . . . 46

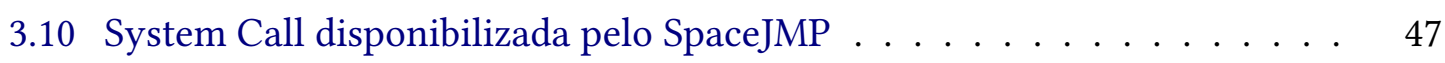

3.11 Exemplo do comportamento do lwC . . . . . . . . . . . . . . . . . 48 
4.1 Do cliente para o servidor Web. . . . . . . . . . . . . . . . 53

4.2 Exemplo de uma conexão feita sem keep-alive e outra com keep-alive . . 54

4.3 Arquitetura do servidor Apache HTTP . . . . . . . . . . . . . . . 55

4.4 Componentes do Servidor Apache HTTP . . . . . . . . . . . . . . . 55

4.5 Gerador de Conteúdo . . . . . . . . . . . . . . . . . . . . 56

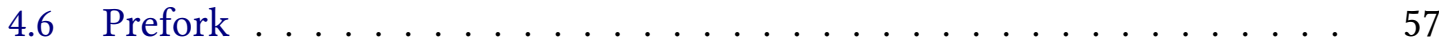

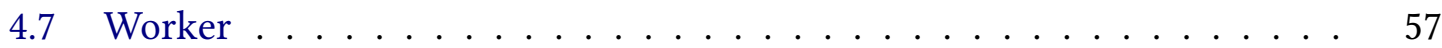

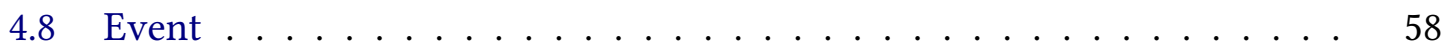

4.9 Nginx comportando-se como reverse-proxy . . . . . . . . . . . . . 58

4.10 Do cliente para o servidor Web . . . . . . . . . . . . . . . . . . 60

4.11 Arquitetura do OpenSSL . . . . . . . . . . . . . . . . . . 61

4.12 Camadas $\mathrm{SSH} \ldots \ldots \ldots \ldots \ldots \ldots$. . . . . . . . . . . . . . 62

4.13 Visão geral do funcionamento do Redis . . . . . . . . . . . . . . . . . . 64

4.14 Algoritmo de pintura da memória . . . . . . . . . . . . . . 65

4.15 Visão da memória durante a aplicação do algoritmo de GC . . . . . . . . 66

5.1 Visão geral da organização de aplicações utilizando servidores Web . . 71

5.2 Arquitetura do experimento . . . . . . . . . . . . . . . . 72

5.3 httpd com MVAS . . . . . . . . . . . . . . . . . . . . . 78

5.4 Arquivos estáticos: tempo gasto para servir o percentual de requisições . 81

5.5 Arquivos estáticos: O consumo de memória necessário para atender todas as requisições . . . . . . . . . . . . . . . . . . 82

5.6 Arquivos Dinâmicos: Tempo gasto por percentual de requisições . . . . . 83

5.7 Arquivos Dinâmicos: Consumo de memória necessário para servir as requisições .............................. 83

6.1 Decomposição do processo . . . . . . . . . . . . . . . . . 94

6.2 Ilustração do padrão configuração . . . . . . . . . . . . . . . . . . . . . . 100

6.3 Ilustração dos principais elemento envolvidos no padrão fotografia . . . 102

6.4 Ilustração dos elementos envolvidos no padrão virtualização . . . . . . . . 104

6.5 Funcionamento do padrão atualização em tempo de execução . . . . . . 106 


\section{Lista de Tabelas}

4.1 Relação aplicações e alvos . . . . . . . . . . . . . . . . . . 68

5.1 Configuração adotada para o MPM . . . . . . . . . . . . . 74

5.2 Configurações feitas no Kernel . . . . . . . . . . . . . . . . . . 75

5.3 Tamanho dos arquivos para serem transferidos . . . . . . . . . . 76

5.4 Carga principal aplicada . . . . . . . . . . . . . 76

5.5 Hardware .............................. 81

6.1 Potencial de adoção . . . . . . . . . . . . . . . . . . . . . . 89

6.2 Relação desacoplamento benefício . . . . . . . . . . . . . . . 93

\section{Lista de Programas}

2.1 Exemplo simples de threads . . . . . . . . . . . . . . . 9

2.2 Saída do exemplo de threads . . . . . . . . . . . . . . . . . . . . . . . . . . . . . .

5.1 Alteração no Apache Server . . . . . . . . . . . . . . . 78 


\section{Lista de Pseudocódigo}

6.1 Função de controle das propriedades do bead . . . . . . . . . . . . . . . 98

6.2 Estrutura de dados utilizada pelo bead para troca de dados do espaço de usuário com o de kernel (vice-versa) . . . . . . . . . . . . . . 99

6.3 Código ilustrando o processo de manipular as configurações dobead . . . 99

6.4 Padrão fotografia . . . . . . . . . . . . . . . . . . . 101

6.5 Padrão Virtualização Controlada . . . . . . . . . . . . . . . . . . . . . . . 103

6.6 Padrão Persistência ． . . . . . . . . . . . . . . . . . . . . . . . . . . . 105

6.7 Padrão Atualização em Tempo Real . . . . . . . . . . . . . . . . . . . 107

6.8 Padrão compartimento . . . . . . . . . . . . . . . . . . . . . 108

6.9 libbead: Padrão fotografia . . . . . . . . . . . . . . . . . . . . . . 110

6.10 libbead: Padrão Virtualização Controlada ． . . . . . . . . . . . . . . . . . 110

6.11 libbead: Padrão Atualização em Tempo Real . . . . . . . . . . . . . . . . 111 



\section{Sumário}

1 Introdução 1

1.1 Avaliação de Novas Abstrações de Processos . . . . . . . . . . . . . . . . 2

1.2 Objetivos ........................ 3

2 Fundamentação Teórica $\quad 5$

2.1 Uma Breve Jornada Sobre os Processos . . . . . . . . . . . . . . . . 6

2.2 Gerenciamento da Memória Relacionada aos Processos . . . . . . . . . . 11

2.2.1 O Modelo de Paginação . . . . . . . . . . . . . . . . . . . . . 12

2.2.2 Modelo de Segmentação . . . . . . . . . . . . . . . . . . . . . . 14

2.2 .3 Proteção da Memória . . . . . . . . . . . . . . . . . . . . . 15

2.2.4 Exemplo Prático Usando o GNU/Linux . . . . . . . . . . . . . . . 16

2.3 Chamadas de Sistema . . . . . . . . . . . . . . . . . . . . . . . 19

2.4 Troca de Contexto . . . . . . . . . . . . . . . . . . . . . 20

2.5 Descritores de Arquivo . . . . . . . . . . . . . . . . . . . . . . 21

2.6 Modelos de Programação . . . . . . . . . . . . . . . . . . . . . . . 22

2.7 Aspectos de Implementação . . . . . . . . . . . . . . . . . . . . . . . 22

2.8 Gerenciamento de Recursos _ . . . . . . . . . . . . . . . . . . . 22

2.9 Outros Conceitos Indiretamente Relacionados a Abstração de Processos . 23

2.9 .1 Device Drivers . . . . . . . . . . . . . . . . . 23

2.9 .2 Virtualização . . . . . . . . . . . . . . . . . . 23

2.10 Considerações Finais _ . . . . . . . . . . . . . . . . . . 27

3 Trabalhos Analisados $\quad 29$

3.1 Dune . . . . . . . . . . . . . . . . . . . . . 30

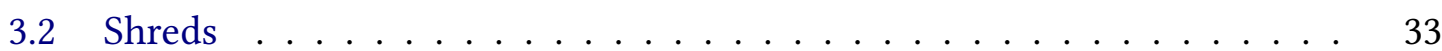

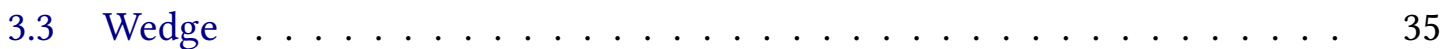

3.4 Resource Container . . . . . . . . . . . . . . . . . . . . . 37

3.5 Nooks . . . . . . . . . . . . . . . . . . . . . . . . 39

3.6 Mondrian Memory Protection e Mondrix . . . . . . . . . . . . . . . . 42 


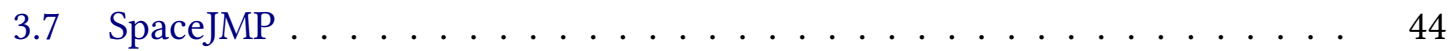

3.8 Light-weight Contexts . . . . . . . . . . . . . . . . . . . 47

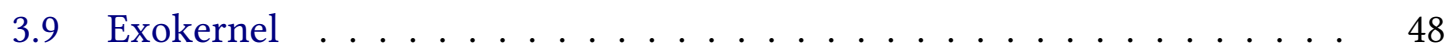

3.10 Considerações Finais . . . . . . . . . . . . . . . . 50

4 Validação de Novas Abstrações de Processos

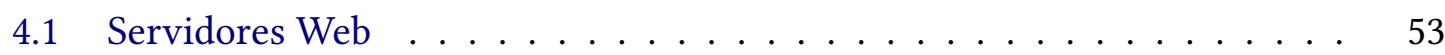

4.1 .1 Servidor Apache HTTPD . . . . . . . . . . . . 54

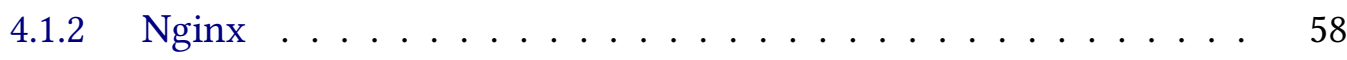

4.2 Ferramentas de Comunicação Criptografada . . . . . . . . . . . . . . 59

$4.2 .1 \quad$ OpenSSL . . . . . . . . . . . . . . . . . . 59

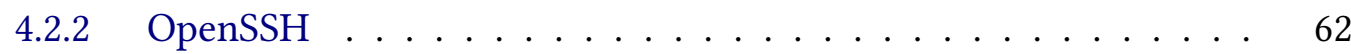

4.3 Outras Aplicações . . . . . . . . . . . . . . . . . . . . . 63

$4.3 .1 \quad$ Redis . . . . . . . . . . . . . . . . 63

4.3.2 Coleta Automática de Lixo (GC) . . . . . . . . . . . . . . 64

4.4 Discussão Sobre as Aplicações . . . . . . . . . . . . . . . . . . . . . . 66

4.5 Microbenchmarks . . . . . . . . . . . . . . . 68

4.6 Discussão . . . . . . . . . . . . . . . . . . . . . . . . 70

5 Estudo de Caso $\quad 71$

5.1 Metodologia . . . . . . . . . . . . . . . . . 71

5.2 Customizações no Servidor Apache e no GNU/Linux . . . . . . . . . . . 73

5.3 Cenários . . . . . . . . . . . . . . . . . . . . 75

5.4 MVAS Dentro do GNU/Linux e Apache HTTP Server . . . . . . . . . . . 77

5.4.1 MVAS Dentro do Apache HTTP Server . . . . . . . . . . . . . . 77

5.5 Resultados . . . . . . . . . . . . . . . . . . . 80

5.5.1 Existe alguma diferença significativa de desempenho entre o apache HTTP trabalhando com processos e threads? . . . . . . . . 81

5.5.2 Qual a Diferença de Desempenho do Apache Utilizando MVAS Quando Comparado com as Estratégias Baseadas em Processos e Threads? . . . . . . . . . . . . . . . . . 84

5.6 Discussão Sobre os Experimentos . . . . . . . . . . . . . . . 84

6 Análise Sobre Abstrações de Processos $\quad 87$

6.1 Potenciais e Dificuldades Para a Adoção de Novas Abstrações de Processos 87

6.2 Extração de Conceitos Derivados das Pesquisas em Abstrações de Processos 90

6.3 Bead: Um Modelo Teórico Para a Próxima Geração de Abstrações de Processos 92

6.3 .1 A API Bead . . . . . . . . . . . . . . . . . . . . . 94 
6.3.2 Padrões de Utilização . . . . . . . . . . . . . . . . . . . . . . . . 97

6.3 .3 A Biblioteca libbead . . . . . . . . . . . . . . . . 110

6.4 Sumário . . . . . . . . . . . . . . . . . . . . . 111

7 Conclusões 113

7.1 Trabalhos Futuros . . . . . . . . . . . . . . . . . . . . . . 114

7.2 Outras Contribuições deste Mestrado . . . . . . . . . . . . . . . . 115

$\begin{array}{ll}\text { Referências } & 117\end{array}$

Índice Remissivo 123 



\section{Capítulo 1}

\section{Introdução}

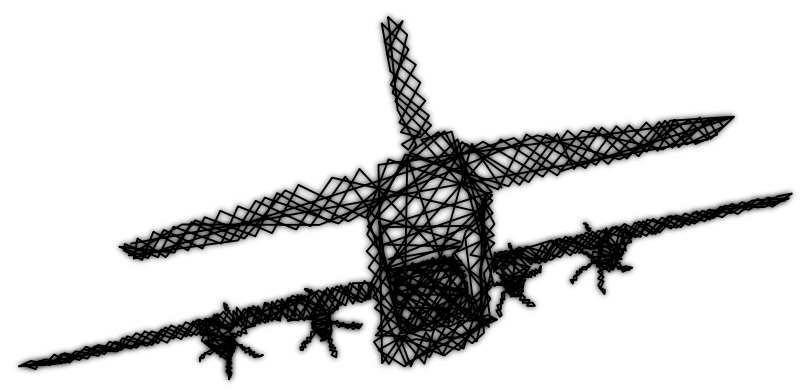

Sistemas Operacionais (SO) são projetos de software grandes e complexos em que cada uma das suas partes é estritamente definida baseada nas entradas, saídas e funcionalidades esperadas (Silberschatz et al., 2010). Coletivamente, essas partes representam um conjunto de abstrações construídas sobre o hardware (p.ex., processadores, memórias e dispositivos de armazenamento) para fornecer recursos para os usuários - tanto desenvolvedores de aplicações quanto usuários finais. Dentre os conceitos empregados pelos SOs modernos destacam-se processos, escalonadores, gerenciadores de memória e sistemas de arquivo (TANEnBAum e Bos, 2015).

Uma das abstrações mais antigas fornecida pelos SOs é o conceito de processos. Estes dão a noção de virtualização do processador, pois oferecem a ilusão de múltiplos programas executando simultaneamente (Love, 2010; TANenbaum e Bos, 2015). Os SOs de propósito geral possuem grande dependência do conceito de processos, sendo esse o principal mecanismo de interação com os demais recursos oferecidos. Dado o papel central de tal abstração nos SOs modernos, fica evidente que alterações nessa área reverberam em todo tipo de usuário. Por esse motivo, é comum observar que os conceitos de processos evoluem de forma a atender novas demandas de hardware, segurança, escalabilidade, modelos de programação e desempenho.

Melhorar a abstração de processos para atender novos requisitos é uma tarefa delicada. Em um SO voltado para produção (p.ex., GNU/Linux e FreeBSD), uma mudança incorreta na abstração de processos pode comprometer completamente a estabilidade do $\mathrm{SO}$ e, consequentemente, afetar diversos sistemas em todo o mundo. Assim, identificar e implementar novos atributos dentro dos processos normalmente demanda muito esforço e, portanto, raramente isso é feito a não ser em alguns poucos contextos na comunidade científica. Dessa maneira, para tornar as pesquisas nessa área mais robustas e com maior potencial de adoção por parte dos SOs mais amplamente utilizados, novas propostas tipicamente precisam abordar três aspectos: apresentar uma implementação viável, avaliar o desempenho e demonstrar benefícios para as aplicações.

Inspirados pelas diversas propostas de novas extensões nas abstrações de processos sugeridas pela academia nas últimas décadas, nós buscamos investigá-las com o objetivo de compilar o estado da arte verificando características interessantes para os SOs usados 
em produção. Dado o foco pretendido nas abstrações relativas a processos, examinamos as diferentes pesquisas excluindo outros aspectos eventualmente introduzidos pelos pesquisadores.

\subsection{Avaliação de Novas Abstrações de Processos}

Dentre o conjunto dos diversos trabalhos na área de processos é possível realizar sua categorização de acordo com a abordagem adotada. Além do mais, essas pesquisas normalmente são avaliadas de duas formas diferentes: (1) microbenchmark ${ }^{1}$ e (2) utilizando uma aplicação como exemplo. Nesse contexto, podemos avaliar de forma direta uma proposta baseada na sua categoria e de forma mais profunda verificar como ela valida os seus resultados.

De forma a explorar as característica de uma abordagem e buscando ter um guia para selecionar os trabalhos, nos utilizamos três categorias para realizar a seleção:

Implementação Estrutural Pesada consiste em melhorar um SO bem estabelecido e amplamente utilizado (p.ex., GNU/Linux), através de modificações em seu núcleo;

Implementação Estrutural Leve consiste na implementação das novas abstrações em um sistema já consolidado, mas evitando mudanças diretas no núcleo;

Implementação Independente consiste na criação de um SO totalmente novo. Normalmente, esse tipo de trabalho introduz inovações em diferentes áreas, contudo, neste texto estamos interessados nas propostas relacionadas às abstrações de processos.

Esses critérios foram selecionados com o intuito de facilmente fornecer pistas das consequências de cada proposta em termos do impacto no projeto de um SO. Cada uma dessas abordagens oferece um balanceamento entre o escopo das propostas de modificação, o esforço necessário para o desenvolvimento e a facilidade em integrar com SOs de uso cotidiano. No Capítulo 3 apresentamos uma das contribuições desta dissertação ao detalhar e discutir os diversos trabalhos que orbitam o tema de abstrações de processos utilizando os critérios citados acima.

Depois que uma implementação se torna funcional, os pesquisadores comumente utilizam um conjunto de microbenchmarks para avaliar o desempenho das suas propostas. A peculiaridade de cada trabalho é evidenciada na grande pluralidade de estratégias de microbenchmarks encontrada em diversos artigos. De forma geral, os cientistas selecionam um conjunto de procedimentos para mostrar os prós e contras da sua abordagem. Contudo, identificar um bom conjunto de microbenchmarks que comprove um comportamento particular é uma tarefa que requer certa experiência por parte do pesquisador.

O uso de microbenchmarks como forma de comprovação de algum resultado serve como indicador parcial de bons resultados mas pode ser perigoso, uma vez que pode induzir o pesquisador a acreditar em um resultado positivo negligenciando outros potenciais impactos. Assim, para validar as propostas e verificar o impacto delas em um cenário

\footnotetext{
${ }^{1}$ Microbenchmarks têm por objetivo mensurar e fornecer meios para analisar uma única característica do objeto de estudo.
} 
minimamente realista, os pesquisadores comumente selecionam uma aplicação utilizada em certos contextos para testar as modificações feitas. No entanto, selecionar um software para realização de testes representa uma tarefa complicada devido às características singulares de cada aplicação. Por exemplo, um software pode utilizar muita memória e consumir boa parte dos recursos da CPU, o que é desejável para demonstrar o uso de novas abstrações de processos em uma situação de estresse. Ainda assim, pode não revelar nada de útil relacionado a melhorias de segurança.

\subsection{Objetivos}

No cenário atual, notamos uma falta de unificação e validação das diferentes propostas de mudanças nas abstrações dos processos, aspectos esses que são importantes para justificar sua implementação em um SO de produção. Nesta dissertação, temos como objetivo avaliar iniciativas que melhoram as abstrações de processos levando em consideração a implementação, as questões que a nova proposta visa resolver e os impactos gerais no SO. Fizemos essa avaliação por meio da análise de 15 trabalhos, onde buscamos responder as seguintes questões de pesquisa:

QP1: "Quais são as características desejáveis para a próxima geração de abstrações de processos?"

QP2: "Quais são os principais desafios em se implementar a próxima geração de abstrações de processos?"

QP3: "Quais aplicações podem ser utilizadas para avaliar as novas abstrações adicionadas a um SO?"

QP4: "Qual conjunto de microbenchmarks pode ser utilizado para auxiliar a entender os impactos de uma nova característica adicionada às abstrações de processos?”

Dos 15 trabalhos que analisamos, a maior parte faz uso de SOs baseados no núcleo do Linux. Por isso, no Capítulo 2 exploramos conceitos gerais sobre SOs e também descrevemos alguns desse conceitos usando o GNU/Linux como exemplo. Para responder a questão RQ1, identificamos as principais características propostas por vários pesquisadores e extraímos o conceito central desses vários trabalhos, descritos no Capítulo 3 e 6. Para responder a RQ2, investigamos diferentes técnicas de implementação levando-se em consideração a categorização feita sobre as abordagens descritas no Capítulo 3. Para responder a RQ3, extraímos dos trabalhos uma coleção de programas que podem se beneficiar das modificações, levando vantagens para o usuário final (Capítulo 4). Para responder a RQ4, nós analisamos diversos microbenchmarks utilizados pelos pesquisadores e selecionamos um subconjuntos de características úteis para avaliar uma proposta (Capítulo 4). Por fim, no Capítulo 6, discutimos um novo horizonte para a próxima geração de abstrações de processos com o objetivo de auxiliar na construção de um novo modelo. 



\section{Capítulo 2}

\section{Fundamentação Teórica}

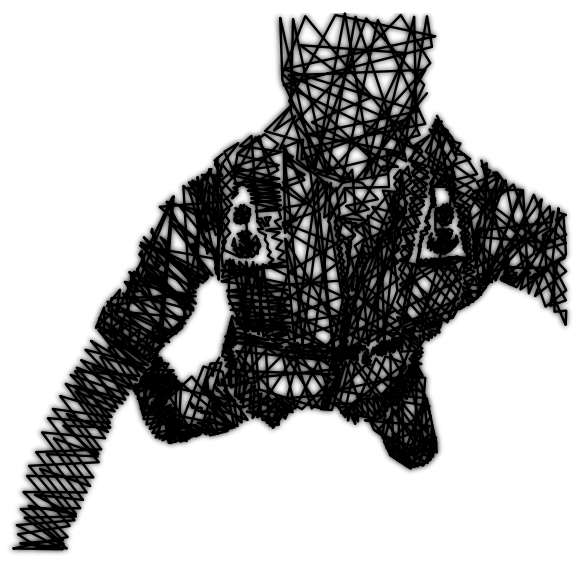

Neste capítulo, visitamos vários conceitos consolidados relativos à abstrações de processos e outras indiretamente relacionadas (threads, fork, representação na memória, virtualização, dentre outros). Introduzimos conceitos que são indiretamente ligados à abstrações de processos, portanto não habitualmente explicitados na bibliografia padrão. A maioria dos conceitos apresentados nesta seção são baseadas em sistemas Unix (especialmente GNU/Linux) e no padrão POSIX, uma vez que esses são amplamente documentados e adotados.

As informações apresentadas aqui representam a prática tradicional de sistemas operacionais e, portanto, são bem conhecidas, sendo objeto de estudo básico na formação em ciência da computação. Consequentemente, mantemos a discussão dentro do escopo necessário para a compreensão dos capítulos posteriores, pois há bastante material didático e de referência sobre o tema. Em particular, utilizamos como fundamentos para esta seção os seguintes livros:

- Operating system concepts (Silberschatz et al., 2010);

- Modern operating system (TAnenbaum e Bos, 2015);

- Operating systems: a design-oriented approach (CROwLEY, 1996);

- Understanding the Linux kernel (Bovet e CesATI, 2006);

- Linux Kernel Development (Love, 2010).

Neste trabalho, queremos elucidar potenciais melhorias nas abstrações de processos, consequentemente descrever as principais abstrações agregadas ao conceito de processos que podem ser modificadas. Começamos com a descrição do processo de carga, representação na memória e controle de execução de um processo e, em seguida, falamos sobre as diferentes técnicas de gestão de memória, um tema muito importante devido ao elevado acoplamento que os SOs modernos tem com a memória. Discutimos também como o processo em execução interage com o SO, que é importante por causa de segurança, desempenho, estabilidade e confiabilidade. A seguir, observamos o papel do SO em for- 
necer a infraestrutura para diferentes modelos de programação, o que é importante no contexto de diversas tecnologias e técnicas que vêm tomando força nos últimos anos (p.ex., Machine Learning, IoT, e big data). Finalmente, abordamos dois temas tradicionalmente independentes de processos (controladores de dispositivos e virtualização) que possibilitam expandir o conceito das abstrações de processos de forma a melhorar o desempenho de alguns tipos de aplicação, flexibilizar o uso de alguns recursos, melhorar a separação de processos, dentre outros.

\subsection{Uma Breve Jornada Sobre os Processos}

$\mathrm{O}$ arquivo binário de um programa tem um conjunto de metadados inseridos pelo compilador logo no início do arquivo que recebe o nome de cabeçalho (ou header), ele possibilita o SO a executá-lo de forma correta. Quando o SO carrega o executável do disco para a memória com o objetivo de criar um novo processo, ele realiza a leitura desses metadados e utiliza tais informações para criar os segmentos de memória pertencentes ao processo. Cada um desses segmentos tem um propósito específico que habilita o SO a gerir o processo.

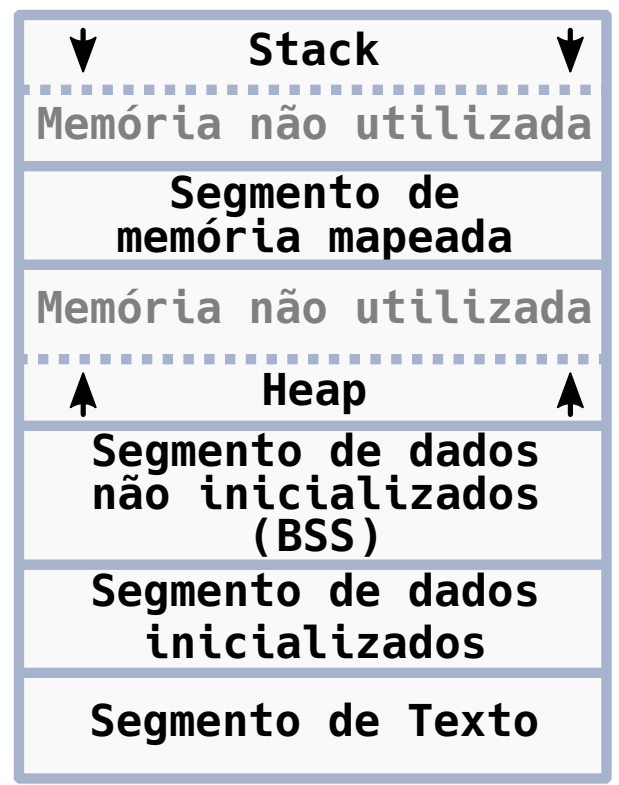

Figura 2.1: Segmento de memória

A Figura 2.1 ilustra seis segmentos de memória diferentes representando o leiaute típico de um processo após sua criação (essa estrutura pode variar a depender do SO e do compilador utilizado). O segmento de texto (text segment) representa a região da memória que mantém a cópia em memória do código executável (compartilhável e apenas para leitura). O segmento de dados inicializados (initialized data segment) e o segmento de dados não inicializados (uninitialized data segment) ${ }^{1}$ são responsáveis pelas variáveis estáticas. O segmento de memória mapeada (memory mapping segment)

\footnotetext{
${ }^{1} \mathrm{O}$ segmento de dados não inicializável também é comumente conhecido como block started by symbol (BSS) por causa de um antigo operador usado pelos montadores (Memory Layout And The Stack 2018).
} 
é a região na qual o SO mapeia arquivos diretamente na memória (p.ex., bibliotecas dinâmicas ou arquivos especificados pelo programador). O segmento de pilha (stack segment) compreende os dados usados pelo programa durante a execução, como por exemplo, valores de parâmetros de função, endereços de retorno e variáveis locais (dados temporários) (Silberschatz et al., 2010). Por fim, o segmento do monte (heap segment mantém a memória dinamicamente alocada durante a execução do programa; repare que a pilha e o heap crescem em direções opostas da memória na imagem, contudo isso pode ser configurável em algumas arquiteturas.

O primeiro passo realizado pelo SO quando ele lê o arquivo executável é processar o header, obtendo as informações sobre o tamanho dos segmentos de texto e dados e criando um novo espaço de endereçamento (address space). O próximo passo consiste em alocar a memória inicialmente necessária e copiar toda a região de código e dados lidas do arquivo binário do programa executável ou bibliotecas para essa memória recém alocada. Em seguida, é feita a inicialização da PCB (descrita mais adiante) e os devidos ajustes no stack pointer $^{2}$ e no instruction pointer (IP), que é ajustado para a o ponto de início do programa, por exemplo, a função main em um programa na linguagem C (PATterson e Hennessy, 2007). Por fim, quando o SO termina de inicializar todos os elementos necessários para que o processo possa executar, ele insere o novo processo na fila do escalonador.
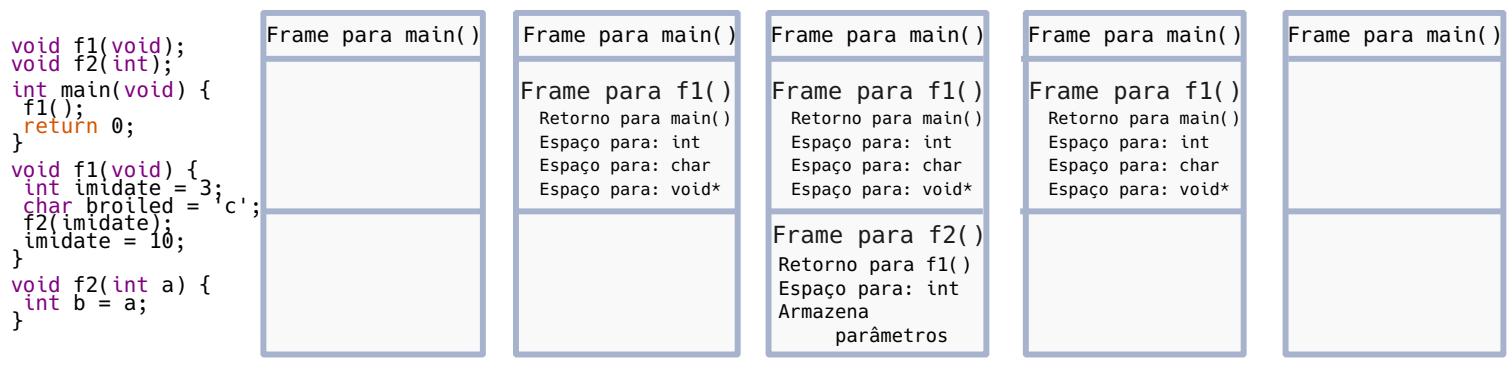

Figura 2.2: Alocação e desalocação de Stack frames considerando o padrão CDECL (PATTERSON e HENNESSY, 2007)

A pilha é organizada em uma coleção de stack frames, que são estruturas de dados inseridas no topo da pilha e que contêm informações como o endereço de retorno da função, argumentos recebidos, variáveis locais, dentre outros. Toda vez que uma função é chamada, uma nova estrutura de dados frame é criada e preenchida com as informações relacionadas à função. A Figura 2.2 ilustra a alocação e desalocação de frames em um simples programa (Memory Layout And The Stack 2018). No começo, só existe um stack frame associado à função main. Conforme cada função local é chamada, o SO aloca um novo stack frame, que é inserido logo após o frame da função anterior. Esse procedimento permite que a execução do processo ocorra de forma consistente, uma vez que basta desempilhar o frame para retomar ao contexto da função anterior. No fim da execução da função, a execução retorna para o ponto na qual a função foi invocada e o processo de preencher e esvaziar a pilha continua.

Todos os processos são descritos por meio de uma estrutura de dados chamada Process Control Block (PCB), responsável por manter informações referentes ao estado do

\footnotetext{
${ }^{2}$ Um stack pointer é um registrador que armazena o endereço do último acesso feito pelo programa para à pilha.
} 
processo, program counter (PC), registradores da CPU, informações sobre escalonamento, dados sobre contas de usuários, estado de operações de E/S, dentre outros (SilBERSCHATZ et al., 2010). Uma dos principais motivos para a PCB existir é permitir a troca de contexto, o mecanismo pelo qual processos se alternam no uso da CPU. Por exemplo, se o usuário possui vários processos executando concorrentemente, o SO deve alternar entre todos eles para que cada um tenha a oportunidade de executar por um intervalo de tempo. O SO realiza esse processo de troca em duas etapas: (1) salvamento do estado atual do processo em sua PCB e (2) carregamento dos dados da PCB do outro processo. A troca de contexto deve ser rápida para não prejudicar o desempenho das aplicações.

O conceito apresentado acima revela uma característica de isolamento associada com a forma na qual os processos funcionam, promovendo segurança e estabilidade. Por outro lado, existem situações que demandam que os processos cooperem entre si e, nesses casos, é possível notar algumas das desvantagens inerentes da estratégia de processos atual (e.g., necessidade de mecanismos complexos para possibilitar a comunicação, controle do consumo de memória, dentre outros). Para resolver parte desse problema, algumas bibliotecas ou chamadas de sistema são fornecidas como interfaces para coordenar a interação entre processos executando simultaneamente, oferecendo mecanismos de Comunicação entre processos (Interprocess Communication) ou simplesmente IPC. Desenvolvedores podem utilizar IPC para compartilhar dados, melhorar o desempenho das aplicações, refinar a modularidade da aplicação ou por alguma questão de conveniência da sua aplicação. Os mecanismos de IPC têm três limitações principais: elevam o consumo de memória, adicionam custos extras de comunicação e apresentam uma certa complexidade para serem implementados. Essas limitações são proibitivas em aplicações com grande demanda computacional.

Por muito tempo, buscou-se formas de elevar o desempenho das aplicações por meio de melhorias no grau de paralelismo. No entanto, como mencionado, o paralelismo tem seus próprios custos. Como resultado direto do esforço em minimizá-los, surgiu o conceito de um único processo com múltiplas threads compartilhando praticamente todos os elementos básicos de sua estrutura com exceção da pilha e do PC. A Figura 2.3 mostra um processo com uma thread e outro com múltiplas threads.
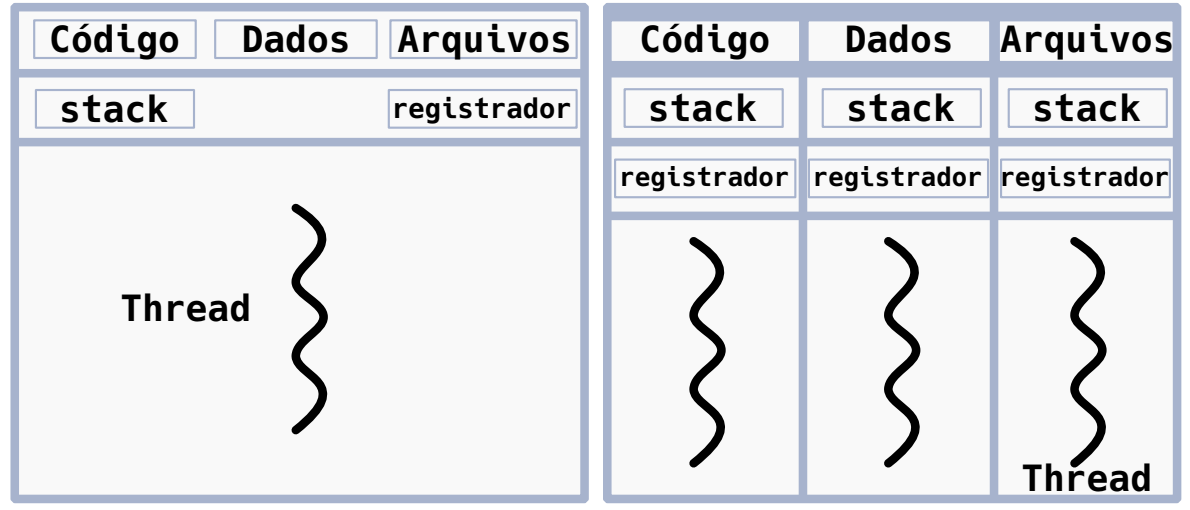

Figura 2.3: Unica thread e multi-thread. Note o isolamento da pilha e do registrador (PC) (SILBERSCHATZ et al., 2010)

Com o objetivo de ilustrar o comportamento descrito até agora sobre a execução de 
múltiplas threads em um mesmo processo, apresentamos um código simples que tem por objetivo criar duas novas threads, cada uma mostrando uma mensagem diferente. $\mathrm{O}$ Código 2.1 ilustra o comportamento básico das threads por meio de uma biblioteca chamada de POSIX Thread Library (Pthread). A função thread_kernel() tem as operações que são executadas por cada nova thread criada na função principal. Note que thread_kernel() recebe um ponteiro genérico, converte-o para um tipo char * e mostra o seu valor no final.

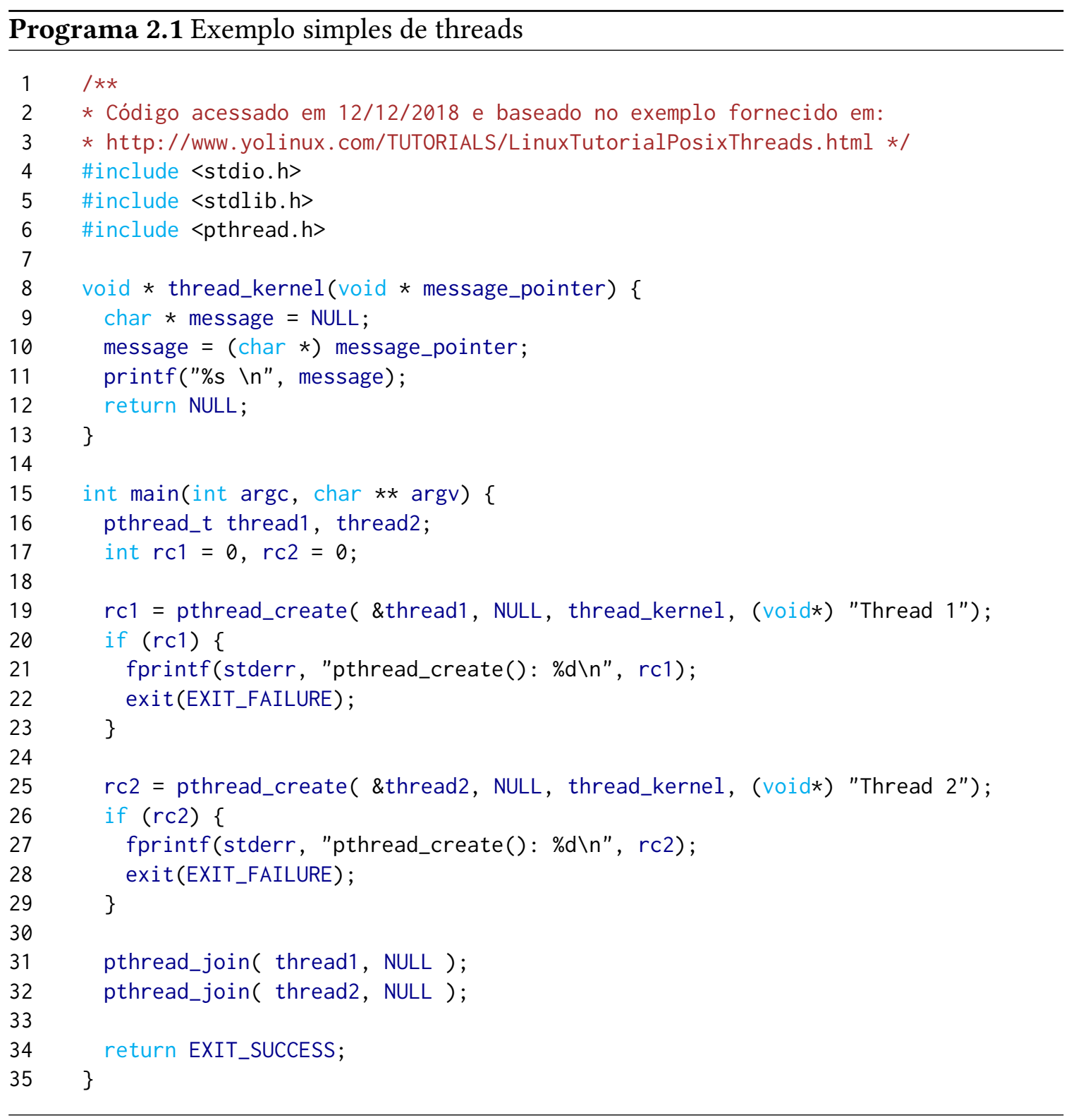

A função main() declara duas variáveis do tipo pthread_t, que são responsáveis por manter as informações referentes às threads. Adicionalmente, são declaradas duas strings diferentes para serem mostradas posteriormente dentro das threads criadas de forma a tornar claro o paralelismo. Quando o PC atinge a função pthread_create(), a biblioteca solicita ao SO a criação de uma nova thread que executa a função thread_kernel() em paralelo. Em seguida, pthread_create() é chamada novamente e cria uma segunda 
thread de execução baseada na função thread_kernel(), contudo, com outra mensagem associada com ela. Note que nesse momento da execução, temos três threads: a primeira thread criada durante a inicialização do processo e outras duas threads criadas por meio da função pthread_create(). O código termina com a função pthread_join(), que mantém a thread principal esperando que as duas threads terminem a sua execução. Uma das possíveis saídas desse programa é ilustrada na Figura 2.2. Ela mostra que as duas threads executam em paralelo, o que é evidenciado pela sequência não determinística da saída: A diferença na sequência é explicada pela variação imposta pelo escalonador.

Programa 2.2 Saída do exemplo de threads

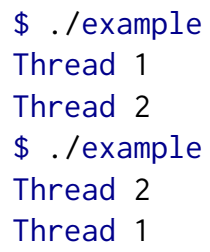

Vamos analisar com um pouco mais de detalhes como o SO trata o Código 2.1 durante a sua execução. A Figura 2.4 ilustra o que acontece internamente quando novas threads são criadas. Como esperado, o segmento de texto e dados são compartilhados entre as threads, como ilustrado na parte inferior da figura. A principal mudança na organização de memória pode ser observada no segmento da pilha, pois toda vez que uma nova thread é criada um novo segmento de pilha é gerado (a Figura 2.4 mostra que a pilha é preenchida aos poucos); a independência entre threads é assegurada pelas múltiplas pilha isoladas. Cada thread tem seu próprio stack pointer e demais registradores; toda vez que a thread em execução muda, o stack pointer e os registradores são atualizados. Repare que o uso de threads melhora o desempenho uma vez que reduz os impactos na memória cache (detalharemos mais sobre esse aspectos nas próximas seções).
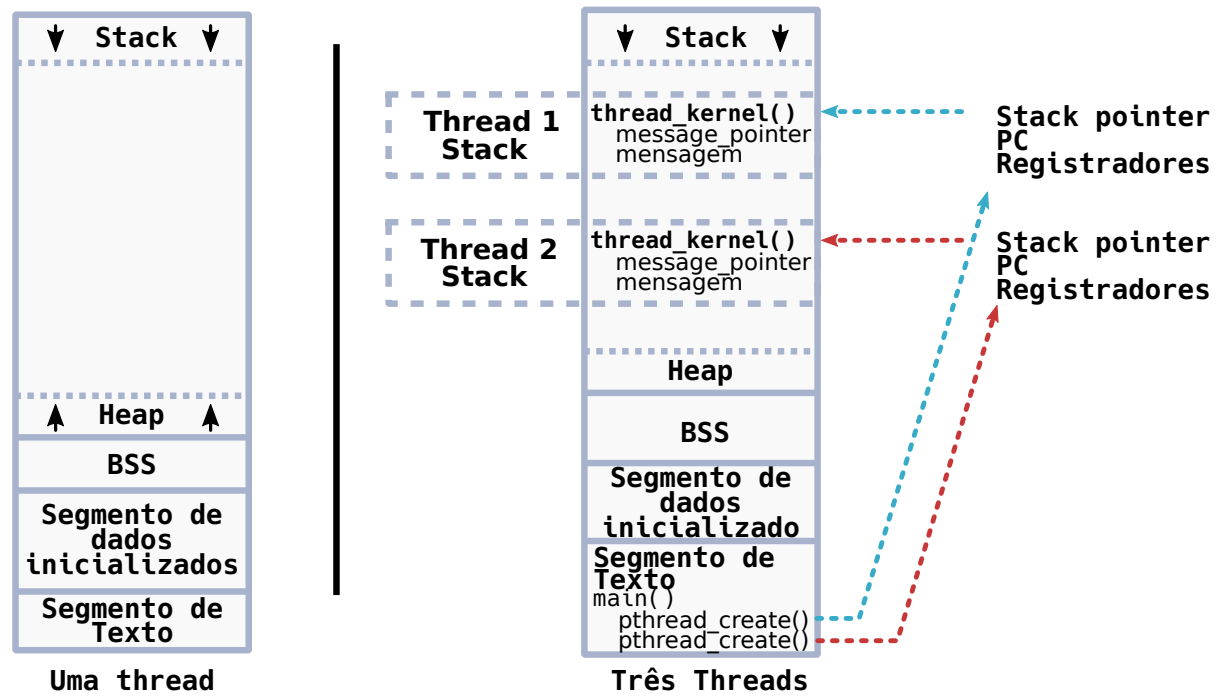

Figura 2.4: Um processo com uma thread (esquerda) e um processo com três threads (direita) 


\subsection{Gerenciamento da Memória Relacionada aos Processos}

Fazer com que a memória do sistema esteja disponível e utilizável para uma aplicação é uma das principais responsabilidade de um SO de propósito geral. A maioria dos SOs modernos oferece a ilusão de que toda a memória está acessível para cada processo, o que é possível graças ao desacoplamento entre a memória física e como o processo a vê. Processos só veem o Virtual Address Space (VAS) que, por sua vez, é mapeado pelo SO (com auxílio de hardware) para a memória física, garantindo um bom isolamento entre processos. Além da ilusão de que a memória está inteiramente disponível para cada processo, esse mecanismo também permite que (1) a memória alocada para um dado processo não seja necessariamente contígua, permitindo uma melhor utilização dos recursos, (2) trechos de memória iguais em processos diferentes, como o segmento de texto, possam ser compartilhados, economizando espaço, e (3) seja possível liberar memória temporariamente, associando um trecho de memória virtual com uma área de disco.

Quando o software começa a sua execução, significa que a CPU está executando as instruções descritas no binário, dentre elas as tentativas de acesso a certos endereços na memória. Todo endereço utilizado pela CPU nesse contexto recebe o nome de endereço virtual ou endereço lógico; por sua vez, o conjunto desses endereços recebe o nome de espaço de endereçamento virtual (Virtual Address Space) ou simplesmente VAS. Esses endereços não são válidos da perspectiva da memória física, i.e., são apenas endereços usados pela aplicação mas que não correspondem ao endereço real dessa memória física. Os endereços reais da memória são chamados de endereços físicos e o conjunto de todos os endereços da memória são chamados de espaço de endereçamento físico. Agora você deve estar se perguntando: qual a relação entre esses dois tipos de endereços? Eis que surge um terceiro elemento entre elas, a Memory-Management Unit (MMU). Veja a Figura 2.5 ilustrando como a MMU se interpõe entre o endereço lógico e o físico.

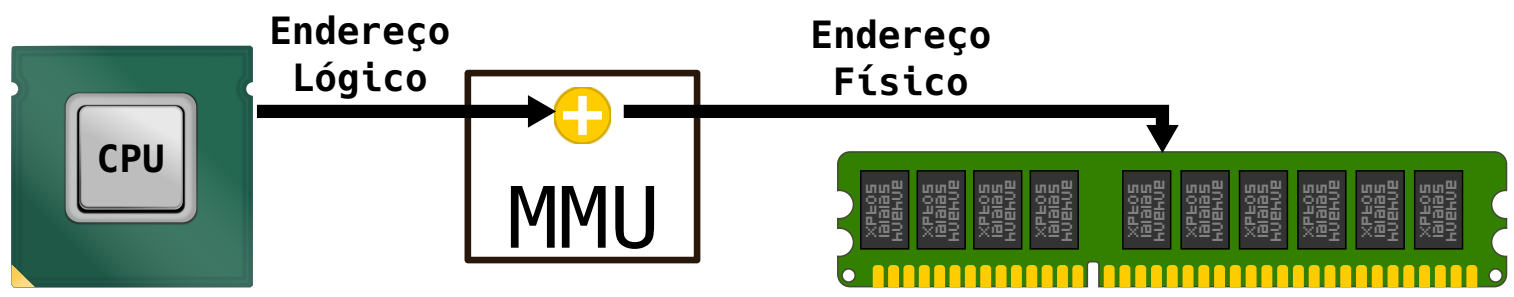

Figura 2.5: Do endereço lógico ao físico com o auxílio da $M M U$

A MMU é um hardware usado para fazer o mapeamento do endereço virtual para o endereço físico em tempo de execução. A Figura 2.5 mostra a CPU gerando um endereço lógico que é imediatamente entregue para a MMU. Esta converte o endereço recebido em um endereço físico e procede com o acesso à memória.

Qual o tamanho máximo da memória de um sistema? No caso da memória virtual, o endereçamento começa em 0 e vai até um valor máximo definido em um conjunto de bits chamado de virtual bits. Durante muito tempo, o padrão adotado para o virtual bits era de 32 bits, gerando um limite superior de endereçamento de $4 \mathrm{GiB}$; hoje em dia é relativamente comum encontrar CPUs que fornecem 48 bits, produzindo uma VAS de 256 
TiB. Na prática, isso significa que um software executado em um SO moderno tem a ilusão de que pode acessar todos os endereços fornecidos pela VAS. Por enquanto, sabemos que isso não é verdade, pois dificilmente conseguimos fornecer tanta memória. Por esse motivo, e como ilustrado na Figura 2.6, notamos que o endereço virtual pode ser várias vezes maior do que o endereço físico. Além disso, repare que a memória física deve ser compartilhada entre vários processos em execução no $\mathrm{SO}$ (todos eles acreditam que tem toda a memória disponível).

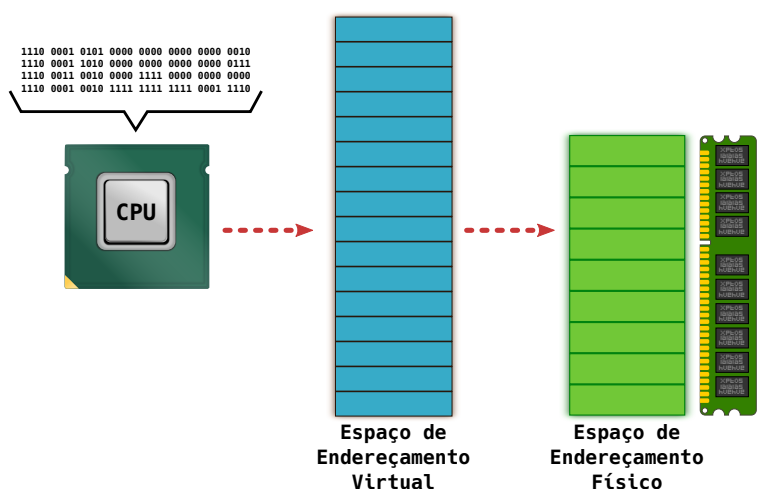

Figura 2.6: Espaço de endereçamento virtual vs. físico

Não obstante, como fazer para traduzir um endereço VAS para um endereço físico? Não é viável ter uma tabela de tradução byte-a-byte (ela ocuparia toda a memória) nem supor que a memória de um processo é contígua. A solução é dividir a memória em blocos e manter, para cada processo, uma tabela mapeando cada bloco dentro do VAS para um bloco correspondente na memória física. Há duas estratégias comuns para isso: o modelo de paginação e o modelo de segmentação.

\subsubsection{O Modelo de Paginação}

Para implementar o modelo de páginação, é preciso dividir o espaço de endereçamento virtual em páginas e o físico em frames. Uma vez que ambos os espaços de endereçamentos são subdivididos, é necessário ter um mecanismo para saber o que está presente ou não na memória. Para ter uma visão de como todo o modelo de paginação funciona, veja a Figura 2.7.

Na Figura 2.7 observamos que a CPU gera um endereço lógico, subdividido em duas partes: page e um offset. O page comporta-se como um índice corresponde a uma entrada em uma estrutura de dados chamada tabela de paginação. Essa tabela faz parte da abstração de processos e tem uma entrada especificada na $\mathrm{PCB}$, ou seja, todo processo possui uma tabela associada a si. Cada entrada na tabela corresponde ao endereço de início de um frame na memória associado ao processo. Para ilustrar melhor esse conceito, imagine um programa que aloca espaço na memória. Em termos práticos, o SO cria uma nova entrada na tabela e retorna o endereço virtual para a aplicação. Depois que o valor referente ao índice é recuperado a MMU soma o offset da segunda parte do endereço virtual e, finalmente, o acesso a memória física ocorre.

Toda vez que um acesso à memória é feito, a tabela de páginas do processo é consultada. Cada entrada dessa tabela é descrita por uma série de metadados que descreve a região 


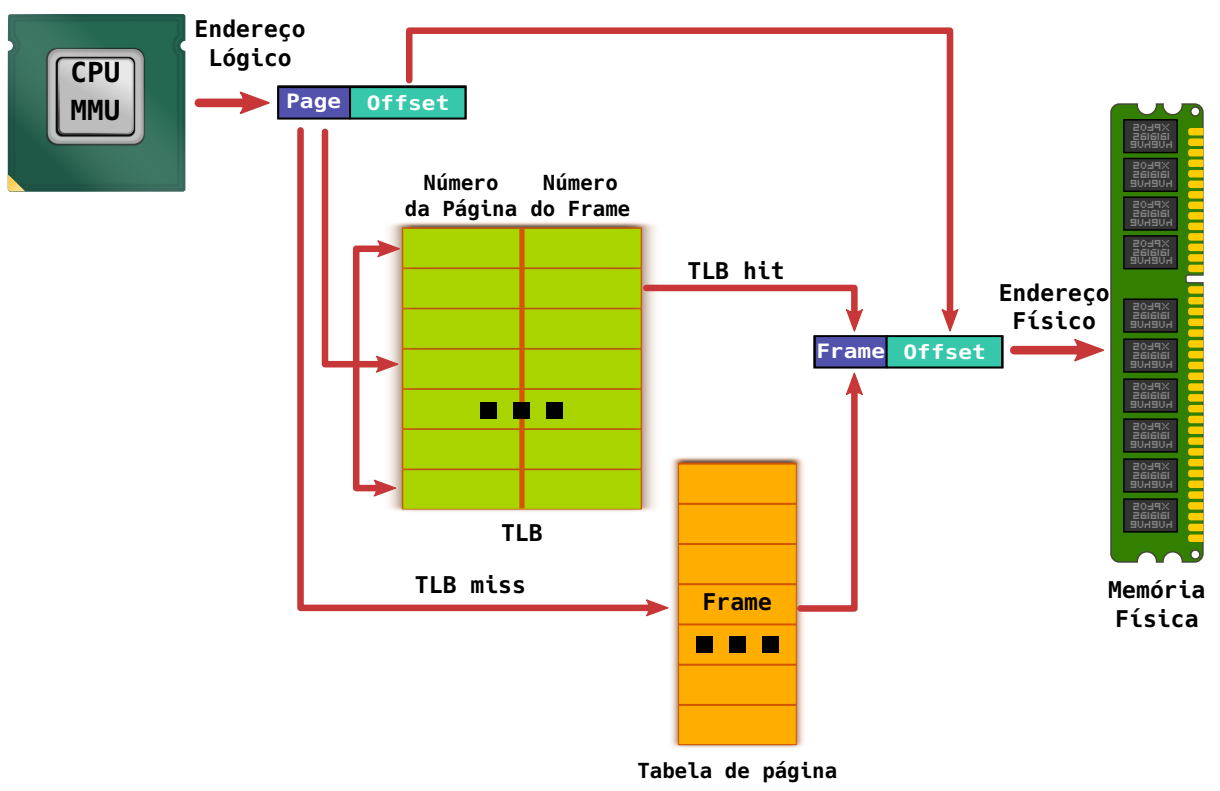

Figura 2.7: Os elementos básicos presentes no modelo de paginação. Note que a busca na TLB e na tabela de página ocorre em paralelo

\begin{tabular}{|c|c|c|c|c|c|c|}
\hline & & bits(1) & bits(1) & bits(2) & bits(1) & bits(1) \\
\hline $\begin{array}{c}\text { Endereço Físico Base } \\
\text { da página }\end{array}$ & Vago & $\begin{array}{l}\text { Página } \\
\text { alterada }\end{array}$ & $\begin{array}{l}\text { Página } \\
\text { acessada }\end{array}$ & $\begin{array}{l}\text { User/ } \\
\text { root }\end{array}$ & $\begin{array}{l}\text { Leitura/ } \\
\text { escrita }\end{array}$ & Presente \\
\hline
\end{tabular}

Figura 2.8: Entrada da tabela de páginas

de memória e recebe o nome de entrada da tabela de páginas (Page Table Entry) ou simplesmente PTE. A Figura 2.8 ilustra como a entrada pode ser representada ${ }^{3}$. Sem entrar em detalhes referentes aos campos (a figura é autoexplicativa), podemos concluir que uma página virtual é a unidade mínima de proteção da memória, por que todos os bytes dela compartilham os bits User/Root e Leitura/Escrita.

A Figura 2.9 exemplifica o processo completo de converter um endereço virtual até o acesso na memória física. Repare que são necessários vários acessos à memória para construir o endereço físico e finalmente conseguir acessar a palavra de dados, o que faz com que essa técnica não seja eficiente. Nesse sentido, existe um mecanismo que busca reduzir esses acessos por meio de uma tabela chamada de translation look-aside buffer (TLB). Essa tabela salva os últimos acessos (coluna e valor) feitos à tabela de páginas evitando que a memória seja consultada inúmeras vezes. Na Figura 2.7, é possível ver a TLB sendo usada para acelerar o acesso aos dados: se uma consulta for encontrada na TLB, ocorre o chamado acerto na TLB (TLB hit); do contrário, falta na TLB (TLB miss). Note que no exemplo ilustrado pela Figura 2.9 a busca na memória sempre é feita, o que significa que, no pior caso (TLB miss), a busca na memória já foi iniciada (na prática, nem sempre a busca na memória é feita). Além disso, o mecanismo de paginação facilita a operação de realizar o compartilhamento de dados entre os processos; o SO orquestra um conjunto de páginas com a mesma visibilidade (indicada pelo programa no espaço de usuário) para ser compartilhado entre processos.

\footnotetext{
${ }^{3}$ Cada arquitetura implementa a PTE à sua maneira.
} 


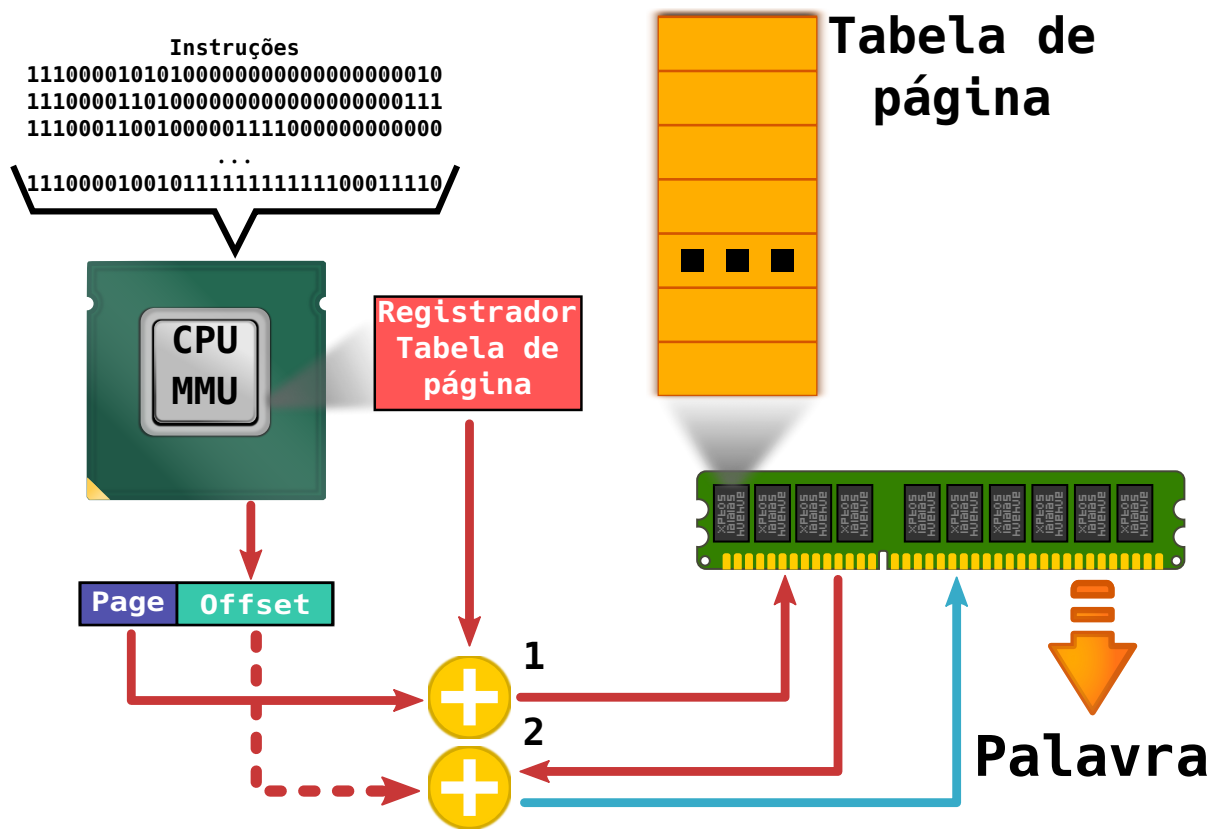

Figura 2.9: Passos do acesso a memória usando o modelo de paginação. A figura ilustra o caso simples na qual pelo menos dois acessos a memória são necessários

\subsubsection{Modelo de Segmentação}

Além do mecanismo de gerenciamento de memória fornecido pela paginação, também existe uma alternativa chamada de segmentação. Esse modelo decompõe a memória referente ao programa em segmentos de acordo com as suas seções; por exemplo, uma área para o text, outra para os dados, pilha, etc. Os tamanhos de cada segmento podem ser variáveis, o que leva a uma visão bidimensional da memória uma vez que os endereços passam a ser construídos como uma tupla: <número do segmento, offset> (SilbersCHATz et al., 2010). Apesar dessa visão bidimensional, a memória continua sendo linear e, por isso, é necessário converter os endereços.

O modelo de segmentação depende de um elemento fundamental chamado tabela de segmentos. A tabela de segmentos é o elemento central para a conversão de um endereço lógico em um endereço físico, ela mantém o mapeamento das referências para o começo de cada segmento do programa. Cada entrada dessa tabela é dividida em dois pedaços chamados de limite e base. O limite é um componente com duas responsabilidades, (1) ele é o índice de um elemento na tabela e (2) o seu valor indica o tamanho máximo do segmento. Por sua vez, o limite está associado a um segundo valor chamado de endereço base (ou simplesmente base) que representa o início do segmento na memória física.

A Figura 2.10 mostra como a segmentação funciona com o suporte de hardware. Repare que o endereço lógico utilizado pela CPU é dividido em duas partes; a primeira parte do endereço corresponde ao limite e a segunda a um offset. Como ilustrado na figura, o valor do limite é utilizado para acessar a tabela de segmentos e recuperar o valor base. O limite é o tamanho máximo do segmento e é usado para verificar se o offset passado é valido. Se a verificação do limite for válida, então o endereço base é lido e usado em conjunto com o offset para gerar o endereço físico. 


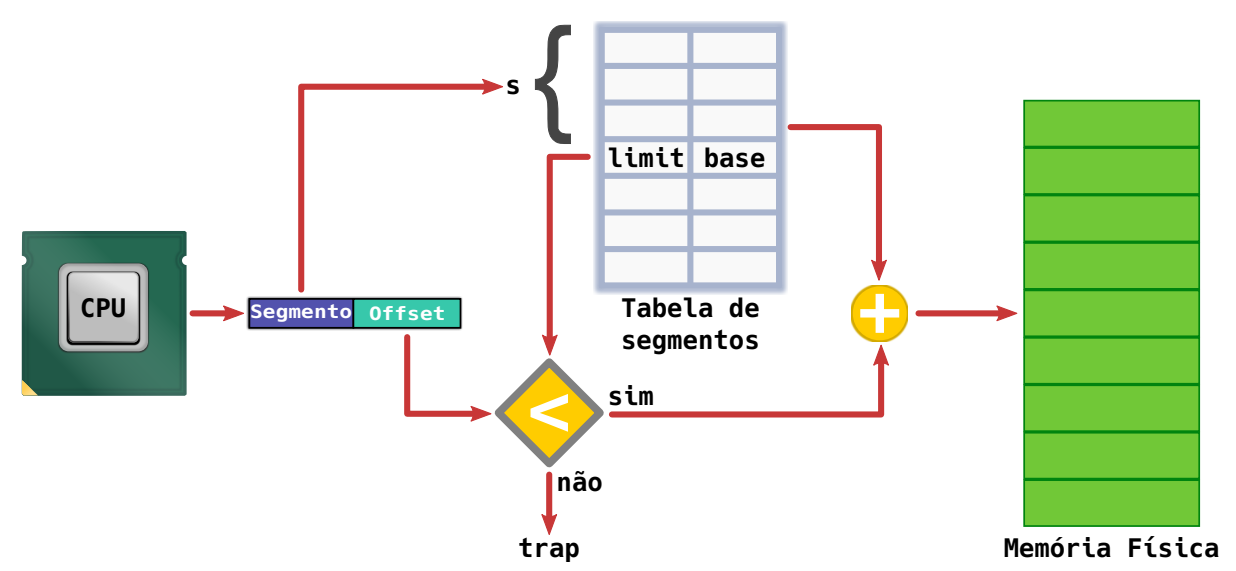

Figura 2.10: Comportamento do modelo de segmentação. Note que a tabela de segmento é acessada para obter o valor base e esse é sempre verificado para evitar acessos indevidos a outras regióes da memória

Tanto o modelo de segmentação quanto o de paginação têm suporte de hardware. Tradicionalmente o Microsoft Windows fez uso do modelo de segmentação, enquanto o MacOS e o GNU/Linux usam a paginação. Como a CPU costuma dar suporte para ambos os esquemas, os SOs podem utilizar esses mecanismos para executar aplicações de outros SOs. Por exemplo, o Wine ${ }^{4}$ executa aplicações Windows no Linux utilizando parte dos recursos de segmentação fornecidos pela CPU.

\subsubsection{Proteção da Memória}

A Seção 2.2.1 descreveu a forma como o mecanismo de paginação funciona, em especial, apresentamos uma ilustração de uma PTE na Figura 2.8. A PTE define um certo nível de proteção da memória uma vez que temos bits que servem para verificar se a página é acessível ou não pelo programa. Contudo, as CPUs modernas estão evoluindo de forma a fornecer novos recursos de controle de acesso à memória. Em especial as CPUs Intel e ARM já oferecem uma funcionalidade chamada de Chave de Proteção da Memória (Memory Protection Key).

Essa nova funcionalidade permite que um processo tenha mais opções de controle de acesso a memória, i.e., o processo pode restringir o acesso dele mesmo a certas regiões da memória. Para possibilitar que tal mecanismo seja implementado, as CPUs passaram a oferecer um mecanismo que faz uso de quatro bits da PTE que não eram utilizados. A Figura 2.11 ilustra uma PTE utilizando esses bits, em última instancia esse é mais um recurso atrelado à tabela de tradução. No total, esses 4 bits representam um conjunto de 16 possíveis domínios de acesso.

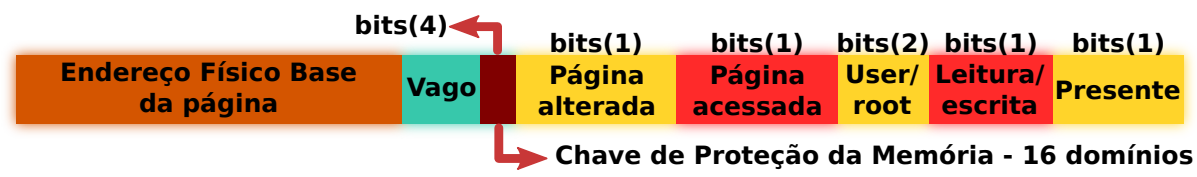

Figura 2.11: Ilustração de uma entrada da tabela de páginas utilizando novos bits

\footnotetext{
${ }^{4}$ https://www.winehq.org/
} 
Cada região de memória definida na tabela de tradução é controlada por um dos 16 domínios existentes (Limited, 2001). O aspecto mais interessante em se utilizar domínios está nos possíveis comportamentos que eles apresentam caso ocorra alguma tentativa de acesso à memória, dentre eles: o acesso pode ser permitido se o conjunto de permissões presentes na tabela permitir e gerar falta de domínio. A MMU procede com algumas verificações, que consistem em três passos:

1. A MMU verifica o número do domínio encontrado na tabela de tradução;

2. Com base no número obtido do passo anterior, a MMU verifica a permissão de acesso no registrador de controle de acesso;

3. De acordo com o valor encontrado no registrador de domínio de acesso, a MMU pode tomar as seguintes decisões: permitir o acesso, bloquear o acesso e verificar a permissão de acesso em uma tabela de tradução.

Assim, o SO precisa decidir, para cada aplicação se o acesso à diferentes áreas de memória deve ser permitido ou negado. Além disso, o SO pode mudar permissões de acesso para um grande número de regiões simultaneamente. Note que o mecanismo de domínios é um recurso adicional ao tradicional modelo de controle da memória adotado pelos SOs, ou seja, é um recurso não fundamental mas que oferece novos recursos aos desenvolvedores. Na Seção 3.2, discutimos a utilização deste conceito no Shreds.

\subsubsection{Exemplo Prático Usando o GNU/Linux}

Nesta seção, revisitamos e expandimos alguns dos conceitos discutidos da perspectiva do Linux, já que a maioria dos trabalhos analisados faz uso de SOs baseados nele. Iniciamos a nossa análise por um fato interessante sobre VAS no Linux em uma arquitetura x86: uma vez que a VAS é habilitada, todo sistema é afetado, incluindo o próprio kernel. Por esse motivo, uma porção da VAS é reservada para o Linux; contudo, ela recebe um tratamento especial, uma vez que o acesso a ela é restrito e o kernel está presente na memória física. Por outro lado, as VASes dos processos comportam-se como o esperado, ou seja, são movidas constantemente de acordo com a troca de contexto e podem ser acessadas pela aplicação. A Figura 2.12 busca ilustrar o mapeamento da VAS levando-se em consideração o espaço reservado para o Kernel (destacado no topo da figura) e os processos. O lado esquerdo da figura mostra de forma genérica como o Kernel e uma aplicação coexistem na memória. Repare que o processo tem todos os seus segmentos alocados da memória e a ilusão de que tem total domínio sobre ela, i.e., comporta-se como descrito na Seção 2.1. Por outro lado, o processo não tem acesso ao intervalo de endereços reservados para o Kernel. Por fim, do lado direito da figura, é mostrado como a troca de contexto ocorre entre dois processos; repare que a VAS dos processos são substituídas mas o kernel permanece constante.

Note que, até esse momento, temos uma visão de uma sequência padrão para os segmentos do processo descrita pela ordem: text, dados inicializados, BSS, heap, mapeamento de memória e a pilha. Esse tipo de informação torna o sistema mais vulnerável, uma vez que um atacante que conheça tal sequência terá uma forma de encontrar dados na memória explorando uma eventual falha de segurança. Como uma resposta a essa situação, o Kernel 

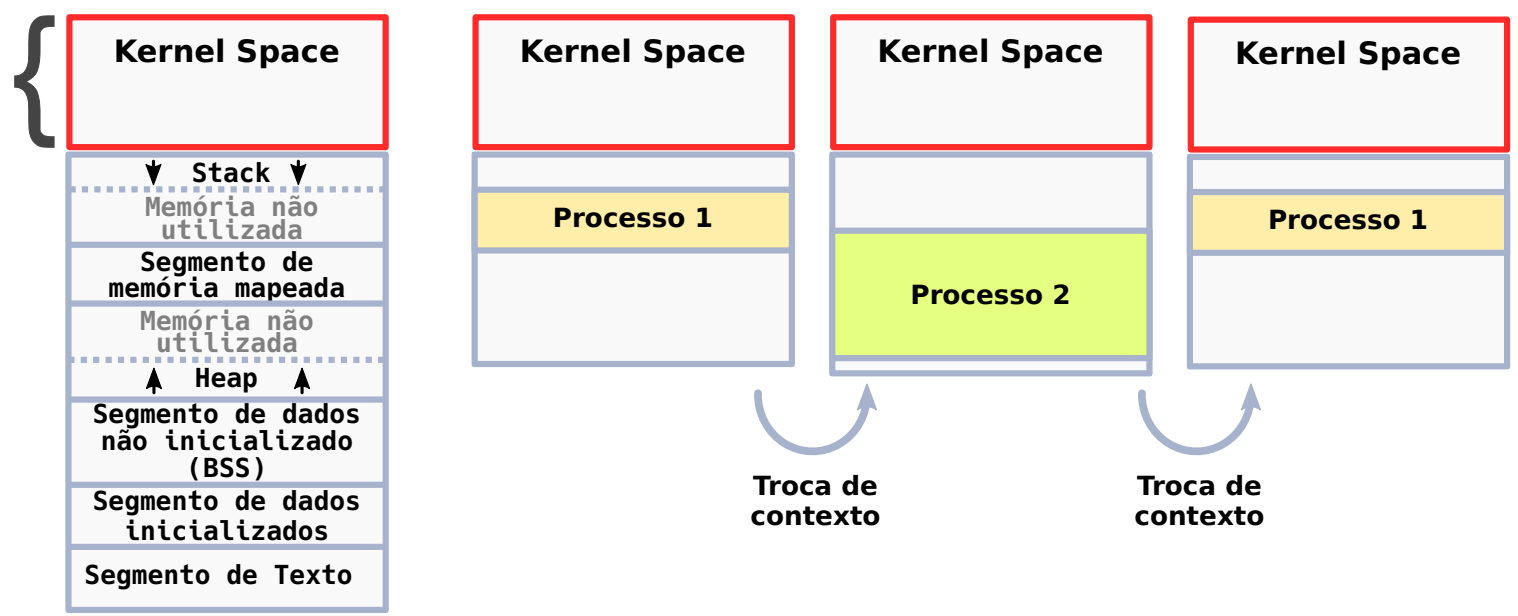

Figura 2.12: VAS durante a troca de contexto (DUARTE, 2009b)

implementa uma série de mecanismos de embaralhamento conhecidos como ASLR ${ }^{5}$, KASLR e KARL (Gruss et al., 2017). Dentre as áreas a que o Linux aplica a aleatorização, destacamse os segmentos dos processos. Portanto, toda vez que um processo é inicializado o seu leiaute na memória é embaralhado aleatoriamente, dificultando um eventual ataque.

Ainda na Figura 2.12, tenha em mente que o programa em execução faz alocações na pilha durante a sua execução, como explicado na Seção 2.1. No Linux, essa pilha começa com um tamanho pré-definido $(8 \mathrm{Mb})$ que normalmente é o suficiente para a maioria das aplicações; contudo, esse limite pode ser ultrapassado. Se o tamanho máximo da pilha for atingido, o Kernel fornece meios para expandir o tamanho da pilha. Vale observar que depois que a pilha é aumentada ela não pode ser encolhida. Por fim, na Figura 2.12, repare que o processo possui um conjunto de segmentos que mapeia arquivos diretamente na memória para rápido acesso; esse segmento recebe o nome de segmento de memória mapeada. O Kernel define esse segmento como uma área de mapeamento anônimo, que é utilizado pelos programas para obter mais espaço para dados. Contudo, o seu principal uso é para fazer o mapeamento de bibliotecas dinâmicas ${ }^{6}$.

A Figura 2.13 detalha como o Kernel manipula as estruturas de dados da PCB. Vamos explorar essa imagem de duas perspectivas: primeiramente, observando os segmentos do processo e, depois, examinando a implementação. Começamos nosso estudo pelo heap ${ }^{7}$; por uma questão de otimização, todo processo inicia com um pequeno espaço de memória previamente alocado para o heap (esse pode ser manipulado via libc), já que a maioria dos processos vai alocar memória mas que não vai precisar de muito espaço. Contudo, se o programa demandar mais memória, então uma chamada de sistema para brk ()$^{8}$ é feita com o intuito de que expandir o tamanho do heap. Por fim, em último caso, se o usuário solicitar uma porção muito grande de memória, o SO utiliza mmap para alocar a memória.

\footnotetext{
${ }^{5}$ https://lwn.net/Articles/330866/

${ }^{6} \mathrm{~A}$ biblioteca $\mathrm{C}(l i b c)$ utiliza esse recurso como uma forma de otimizar grandes alocações solicitadas via malloc(): ela cria um mapeamento anonimo para tais casos.

${ }^{7} \mathrm{O}$ heap é comumente manipulado através das funções malloc() e free() na maior parte do tempo

${ }^{8} \mathrm{~A}$ libc encapsula essa chamada
} 
Note na Figura 2.13 que o BSS é um segmento anônimo, uma vez que ele armazena variáveis estáticas não inicializadas (valores não disponíveis no código fonte). Ao contrário do BSS, a região Data (dados inicializados) mapeia uma parte do arquivo, uma vez que esse mantém o conteúdo das variáveis estáticas (i.e., pode ser mapeado do código fonte). A mesma ideia é válida para a região do text.

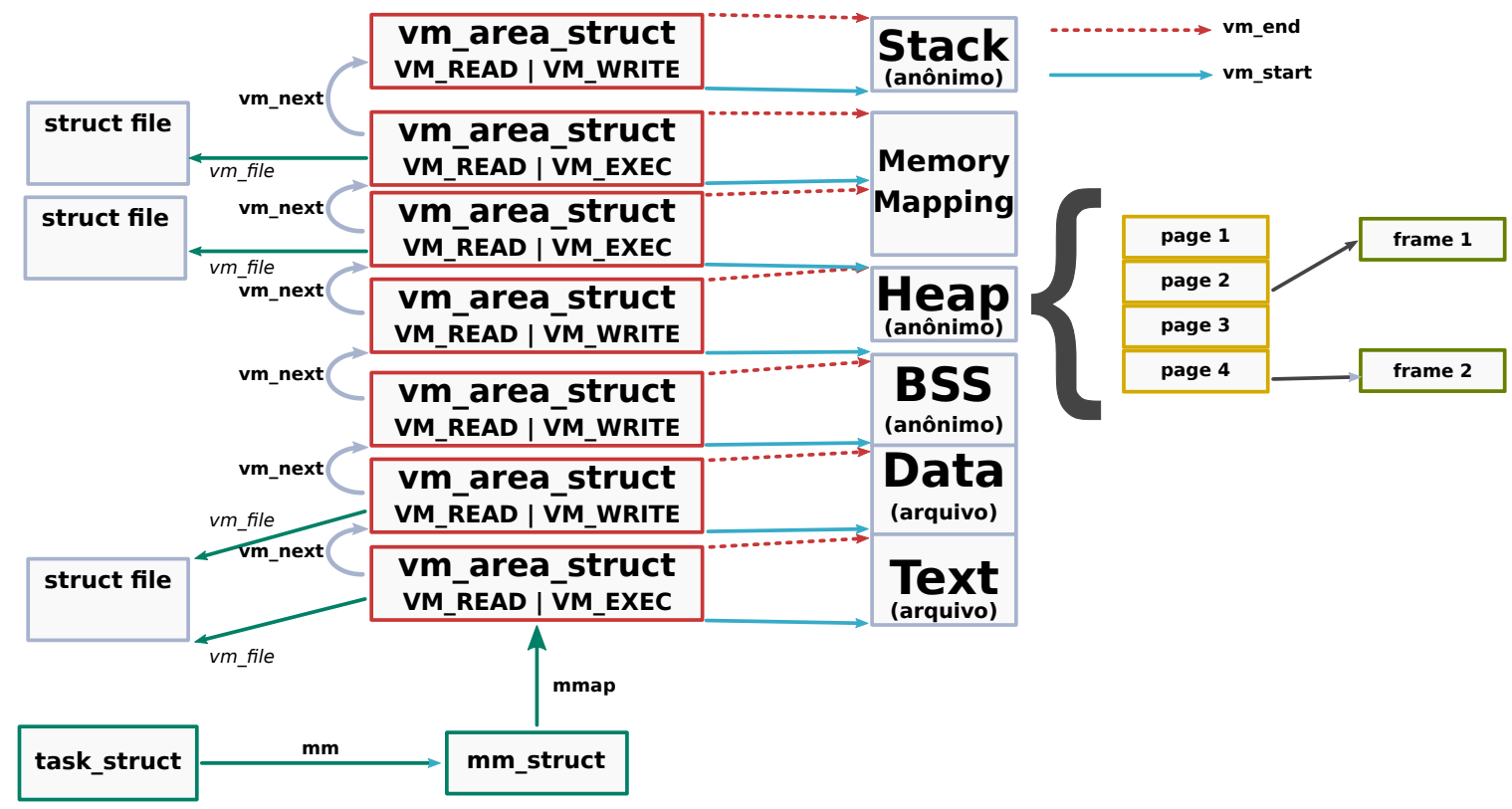

Figura 2.13: Visão interna do gerenciamento da memória (DUARTE, 2009b)

Observando a Figura 2.13 sob a ótica da implementação, temos as estruturas de dados usadas pelo Linux e suas ligações. No Kernel, a estrutura responsável por manter todas as informações do processo (i.e., PCB) chama-se task_struct. Ela tem um ponteiro para outra estrutura de dados chamada de mm_struct, que mantém uma lista ligada para estruturas do tipo vm_area_struct (ou virtual memory area - VMA). Uma VMA consiste em um intervalo de endereços virtuais contíguos e sem sobreposição; elas também possuem algumas flags de controle de acesso associadas. A informação se a VMA é anônima ou não vem do campo vm_file (se ele estiver vazio, então a área é anônima). Repare na figura que cada segmento corresponde a uma VMA; a única exceção são os segmentos de mapeamento de memória, que podem ter mais de um VMA. Lembre-se que a VAS é dividida em páginas, por isso o tamanho de uma VMA deve ser múltiplo do tamanho de uma página. De forma geral, a VMA, em conjunto com a tabela de páginas, orquestra o gerenciamento do programa na memória no Linux.
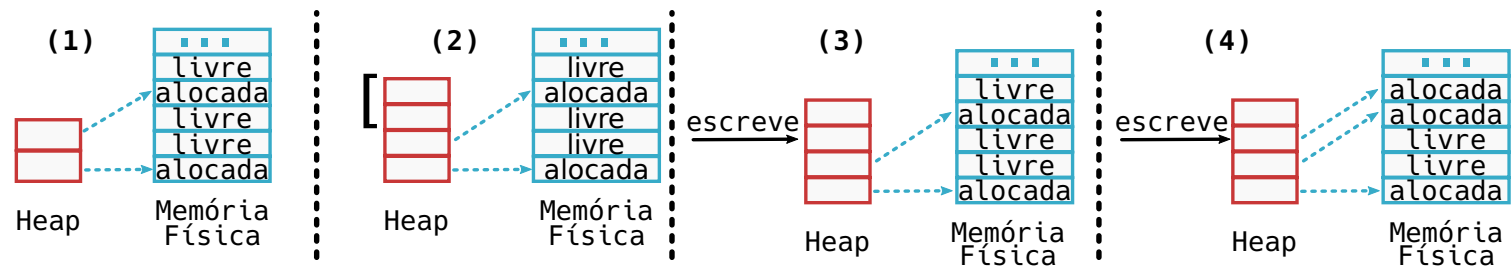

Figura 2.14: Passos envolvidos na alocação de memória com malloc() (imagem baseada em DUARTE, 2009a) 
Por fim, para exemplificar como esses mecanismos estão relacionados do kernel ao espaço do usuário, veja a Figura 2.14. Na figura, temos um programa com algumas páginas já mapeadas para uma memória física. A aplicação decide alocar mais memória por meio da função malloc(), e por sua vez, uma chamada para brk() é feita. O kernel atualiza o VMA do heap com o tamanho solicitado e fornece o ponteiro para a aplicação. Na prática, nenhum endereço físico foi alocado e, enquanto o programa não acessar a região alocada, nenhum frame é criado. Na primeira tentativa de acesso, ocorre uma falha de página e a função do_page_fault() é chamada. Se o processo atender à permissões indicadas na PTE, então o kernel aloca e associa o frame à página.

\subsection{Chamadas de Sistema}

Silberschatz et al. (2010) apresenta diversas perspectivas sobre SOs. Dentre elas, destaca-se a ideia de que um SO fornece serviços para tornar as tarefas de programação mais simples para os desenvolvedores. Partindo de tal concepção, podemos notar os seguintes serviços: controle sobre a execução de um programa, operações de E/S, manipulação de sistemas de arquivos, comunicação via rede, detecção de erros, alocação de recursos, dentre outros. Dada a vasta quantidade de serviços oferecidos, levantamos a questão de qual mecanismo é utilizado pelo SO para fornecer acesso a eles? A resposta é simples: chamadas de sistema (também conhecidas por system calls ou syscalls).

Uma chamada de sistema consiste em uma operação de API de baixo nível que permite que uma aplicação executando no espaço de usuário (user space) faça uma requisição para o SO. Por sua vez, esse pedido é rigorosamente validado pelo SO, que pode executar a operação até o fim, devolvendo o que a aplicação solicitou, ou pode se negar a executá-la, caso encontre algum impedimento. Na prática, esse tipo de operação consiste em uma simples chamada de função que é tratada pelo SO. Normalmente, cada syscall tem um número associado a si, através do qual o SO consulta uma tabela que identifica a função que deve ser executada. Além disso, passar parâmetros para esse tipo de função pode depender da arquitetura e de outros detalhes. Para tentar esconder toda a complexidade por trás desse tipo de operação, muitas vezes são escritas bibliotecas que encapsulam esse tipo de chamada. O exemplo mais emblemático é a libc que oculta vários detalhes de baixo nível, como a leitura e escrita de um arquivo.

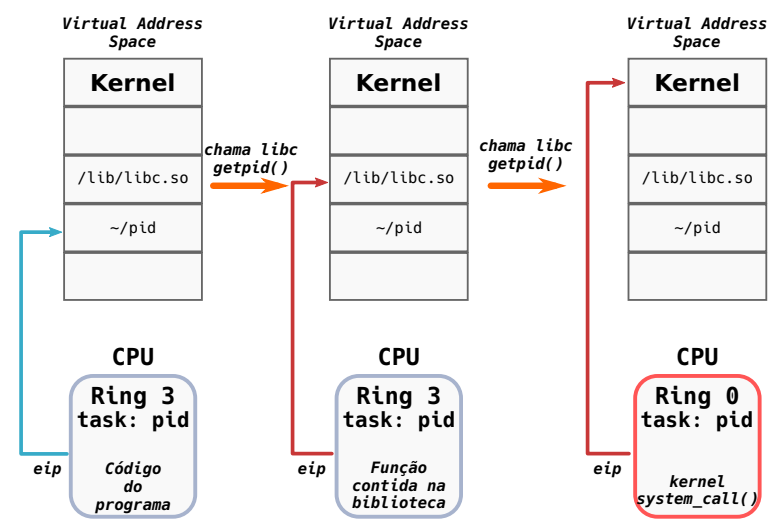

Figura 2.15: Execução do user space até o kernel space 
Para ilustrar como esse conceito funciona na prática, veja a Figura 2.15. Nela, um programa pede o seu PID para o SO (exemplo baseado em DUARTE, 2014). O programa executado está na memória e tem o seu Address Space devidamente inicializado; ao invocar a função getpid(), o seu fluxo de execução é levado para a libc. Por sua vez, a libc faz algumas operações, tal como alocar espaço na memória para fazer cache do PID. Quando a libc está pronta, ela finalmente faz a chamada para o sistema. Note que nessa etapa ocorre uma mudança de um modo de execução menos privilegiado (ring 3) para um modo privilegiado ( ring 0 ). Nesse momento, o SO tem total controle sobre o pedido feito e faz a verificação dos parâmetros e permissões. Se tudo correr bem, o SO se encarrega de copiar a informação pós-processada do espaço do Kernel para o espaço do usuário. Por fim, a libc salva o valor do seu cache, evitando a necessidade do SO intervir no futuro e a aplicação finalmente recebe o seu PID.

\subsection{Troca de Contexto}

Em um SO de propósito geral, um processo executa por um intervalo de tempo; quando esse tempo acaba outro processo é inserido na $\mathrm{CPU}$, esse procedimento ocorre na escala das centenas de processos. A troca tem início quando uma interrupção vinda do hardware ocorre, seja ela porque o tempo de CPU do processo terminou ou por qualquer outro motivo. O primeiro passo necessário consiste em salvar o estado do processo em execução e, em seguida, carregar o estado do novo processo na CPU. Repare que o tempo gasto na troca de processo não produz nenhum trabalho útil, ou seja, é um overhead (SilBERSCHATZ et al., 2010).

Na prática, a troca de contexto é bem mais complexa. Por exemplo, vamos olhar de perto e de forma breve a troca de contexto no GNU/Linux em uma arquitetura x86. Primeiramente, todos os processos precisam compartilhar os registradores da CPU. Por esse motivo, o kernel deve assegurar que todos os registradores sejam carregados com os valores de quando o processo foi suspenso. O conjunto de todos os dados dos registradores que devem ser carregados recebe o nome de contexto de hardware (Bovet e CesATI, 2006), que pode ser visto como um subconjunto do contexto do processo. No Linux, o contexto de hardware é armazenado na própria estrutura do processo, enquanto as demais partes são salvas em uma interna pilha do kernel. Toda troca de processo precisa armazenar o contexto de hardware, por isso a task_struct inclui um campo chamado thread_struct, que armazena o contexto do hardware (dependente da arquitetura de hardware).

Para realizar a troca de processos, o Kernel Linux realiza duas operações (Bovet e Cessati, 2006): (1) Instala o novo espaço de endereço e (2) Muda a pilha do domínio do Kernel e o contexto de hardware. A operação de troca é extremamente dependente da arquitetura de hardware, pois precisa ser executada de forma rápida e, por isso, o Linux tenta tirar proveito de todo recurso disponibilizado pela $\mathrm{CPU}^{9}$.

\footnotetext{
${ }^{9}$ Note que é preciso levar em consideração os registradores que lidam com pontos flutuantes, o que faz a troca de contexto ainda mais pesada
} 


\subsection{Descritores de Arquivo}

Normalmente, quando um processo deseja ler ou escrever um dado em um arquivo, ele precisa passar por algumas camadas. O processo interage com o sistema de arquivos, que é responsável por fornecer um mecanismo simplificado para o processo localizar, escrever e recuperar dados. Por sua vez, os sistemas de arquivos atuam com outras camadas responsáveis por manter a organização e meta-dados dos aquivos. Por fim, as operações de alto nível são convertidas para instruções de baixo nível passadas para os discos que de fato realizam as operações solicitadas.

Em GNU/Linux e outros sistemas POSIX, existe uma estrutura de dados utilizada para controlar o bloco de dados em disco e que é usada para leitura ou escrita, o inode. Um inode contém diversas informações, dentre elas: permissão, datas, dono do arquivo, tamanho, dentre outros. Quando um arquivo é criado, uma estrutura de dados como o inode é criada e então o arquivo é salvo.

Quando um processo abre um arquivo, ele faz uma chamada para open(), acionando o sistema de arquivos para encontrar o arquivo solicitado. Para isso, open() primeiro procura em uma tabela global de arquivos para verificar se o arquivo solicitado já está aberto. Se o arquivo estiver presente na tabela global, uma nova entrada em uma tabela local de arquivos dos processos é feita e nela é armazenada uma nova entrada com a posição referente ao arquivo na tabela global. A tabela global é atualizada com a informação de que um novo processo abriu o arquivo (basicamente, um contador é incrementado para representar a informação). Por outro lado, se não existe uma entrada para o arquivo solicitado na tabela global, ele é carregado e a tabela global atualizada. A Figura 2.16 ilustra a operação descrita.

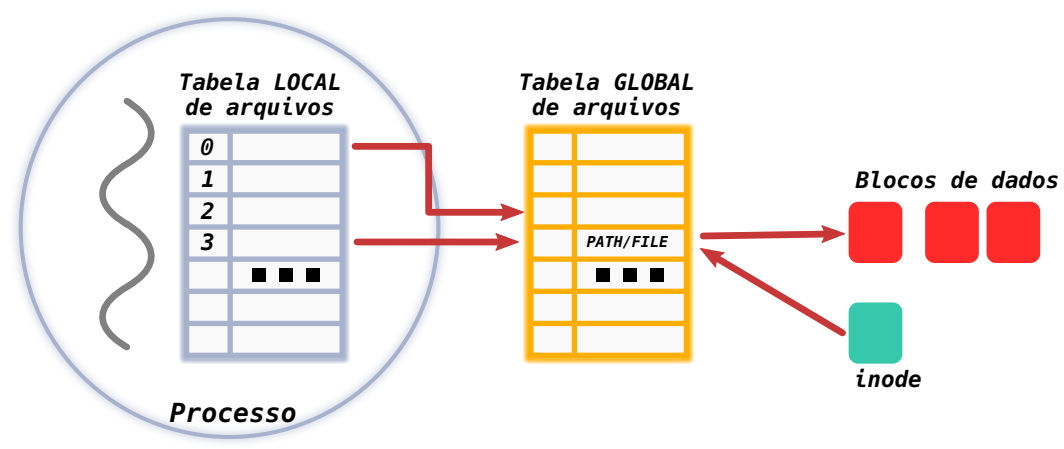

Figura 2.16: Tabela local e global de arquivos

Quando um arquivo é aberto por meio da função open(), ela devolve um número chamado de descritor de arquivo (file descriptor - fd), que nada mais é do que a posição da entrada na tabela local de processos. Quando o processo fecha um arquivo, a entrada na tabela local é removida e o contador de processos presente na tabela global é decrementado. Quando o contador zera, o bloco de dados referente ao arquivo aberto é finalmente atualizado. 


\subsection{Modelos de Programação}

Além da manipulação de dispositivos de hardware, os SOs fornecem vários recursos adicionais para o espaço de usuário, tal qual file locking e primitivas de segurança. Para fazer uso de tais recursos, a aplicação precisa ser capaz de acessá-los por meio de um modelo de programação coerente, i.e., um conjunto bem estabelecido de abstrações interligadas. Um dado SO implementa um dado modelo de programação através de uma API própria. Por exemplo, tanto o GNU/Linux quanto Windows fornecem diferentes APIs de threading (pthreads e WindowsThreads), mas ambos correspondem ao modelo de programação de paralelismo.

Atualmente, a maioria dos SOs dá suporte a um grande número de modelos de programação e suas respectivas APIs. Contudo, as aplicações mudam ao longo dos anos e criam demandas para melhorias em áreas como camadas de segurança, opções de otimização e simplificação de código; esses aspectos são problemas reais. Consequentemente, propostas para expandir as abstrações de processos visando introduzir novos modelos de programação são recorrentes e representam uma interessante área para inovações.

\subsection{Aspectos de Implementação}

As abstrações de processos são o ponto central no projeto de um SO moderno de propósito geral, mapeando outras abstrações para ele. Assim, outros serviços são oferecidos pelo SO com a intenção de fornecer os mecanismos necessários para orquestrar todas as operações dos processos (p.ex., escalonador e gerenciamento de memória). Toda estrutura necessária para gerir processos tem o lado negativo de utilizar CPU (overhead); para tentar mitigar essa situação, os SOs empregam um vasto número de otimizações de hardware e software.

Mudanças em uma abstração de processos normalmente têm impactos no desempenho e as consequências podem variar de acordo com a proposta de modificação. Por exemplo, uma verificação adicional em uma camada pode elevar a sobrecarga no sistema devido a uma nova característica implementada. Contudo, enquanto extensões de processos podem degradar o desempenho, elas também podem trazer benefícios de desempenho explorando alguma característica do hardware.

\subsection{Gerenciamento de Recursos}

Toda aplicação em execução em um SO consome recursos do sistema. Frequentemente, elas realizam boa parte do trabalho no espaço de usuário, o que requer pouca intervenção do SO. Por exemplo, uma aplicação que faz cálculos complexos não precisa de muita intervenção do SO. Contudo, existe uma grande quantidade de software que demanda significativa participação do SO para atingir os seus objetivos, estendendo assim o seu consumo de recursos para o sistema. Por exemplo, uma aplicação que utiliza recursos de rede tem várias partes das suas atividades conduzidas pelo SO quando um pacote chega. 
Esse cenário no qual a aplicação solicita que o SO execute algo em seu favor, faz com que o consumo de recursos por parte da aplicação atravesse do espaço de usuário para o espaço do kernel. Essa situação pode gerar problemas devido ao controle indireto e descontrolado do uso de recursos; ataques de negação de serviço (Denial-of-service) representam um exemplo da vida real que eleva o consumo do uso de recursos por parte do SO.

\subsection{Outros Conceitos Indiretamente Relacionados a Abstração de Processos}

Nesta seção, apresentaremos o tópico de device drivers e virtualização. Esses são temas indiretamente relacionados às abstrações de processos e que são tratados aqui para auxiliar o leitor na leitura dos próximos capítulos. Vale observar que esses conceitos representam poderosas ferramentas para expandir as abstrações de processos.

\subsubsection{Device Drivers}

Um SO é repleto de elementos que buscam manipular e ocultar a complexidade de lidar com o hardware, portanto, esse é um dos motivos pelos quais esse tipo de software é consideravelmente grande e complicado. Para tornar esse cenário ainda mais desafiador, é preciso levar em consideração que um SO deve fornecer suporte para uma infinidade de dispositivos. A forma como os drivers interagem com o Kernel deve ser projetada com muito cuidado visando reduzir a complexidade e o acoplamento. $\mathrm{O}$ design adotado na maioria dos SOs é uma abordagem flexível na qual o código para um dispositivo é mantido isolado em um driver.

O isolamento fornecido por um device driver é interessante, uma vez que ele fornece um mecanismo e não uma política (RUBINI e CoRBET, 2001). Entenda por mecanismo a capacidade que deve ser fornecida e, por política, a forma com que a capacidade deve ser usada. Esse separação é interessante pois limita o que um driver deve fazer e, por sua vez, simplifica a implementação. Um exemplo disso é o Direct Rendering Management do Linux, que fornece várias capacidades, dentre elas, a operação de trocar framebuffers primários e secundários; contudo, é a aplicação que deve controlar tal operação.

Por fim, é interessante ressaltar que alguns sistemas fornecem a ideia de módulos carregáveis (loadable modules), que significa que, em tempo de execução, é possível carregar um novo device driver. Esse tipo de funcionalidade torna o SO mais leve e configurável. Os módulos são extremamente flexíveis do ponto de vista da implementação uma vez que são um código separado do núcleo do SO e respeitam a interface definida pelo mesmo.

\subsubsection{Virtualização}

A ideia de oferecer a abstração de máquinas virtuais dentro de uma mesma máquina é um aspiração de longa data, como o emblemático trabalho de Popek e Goldberg demonstra (PopeK e GoldBerg, 1974). Ele foi publicado em 1974 e indicava os requisitos necessários para que a terceira geração de processadores fornecessem virtualização completa. Naquele 
período, se tinha noção de algumas das vantagens que a virtualização por software e hardware poderia entregar. Dentre os inúmeros benefícios da virtualização, destacam-se a possibilidade de executar aplicações legadas de um SO antigo, recursos que facilitam o processo de desenvolvimento de software, serviços de nuvem, checkpoints, migração de processos, isolamento, dentre outras.

O elemento central da virtualização é o hypervisor (também conhecido como Virtual Machine Monitor (VMM)), que é responsável por criar a ilusão de múltiplas máquinas em um mesmo hardware físico (TANENBAUm e Bos, 2015). Essas máquinas virtuais executam sobre o mesmo hardware e tem a capacidade de executar diferentes SOs. Existe a ideia de máquina convidada (guest) e máquina anfitriã (host). A primeira refere-se ao SO que está executando sobre o VMM e a segunda refere-se à máquina que está executando sobre o hardware com privilégios.

Um dos objetivos da virtualização consiste em permitir que um SO inicialize como se estivesse em uma máquina real. Para que isso seja possível, é preciso emular o hardware de forma que o guest não perceba que está em um ambiente simulado e, ao mesmo tempo, de forma eficiente. Em 1974, POPEK e GOLDBERG (1974) sugeriram alguns requisitos para que os hardwares pudessem oferecer suporte completo para virtualização, amplamente implementados nos processadores modernos. Os autores também destacam três dimensões que devem ser consideradas para fornecer a virtualização completa no nível dos processadores: segurança, fidelidade e eficiência.

No que tange o assunto segurança, o VMM deve ter total controle sobre os recursos virtualizados. Uma opção é utilizar um interpretador que intercepta cada instrução e realiza exatamente o que a instrução precisa. Algumas instruções podem ser executadas diretamente, mas outras não. Por exemplo, não deve ser possível para a máquina guest desativar as interrupções de toda a máquina (TANEnBAum e Bos, 2015). Para contornar tal situação, o SO guest deve ter a ilusão de que as interrupções estão desativadas.

Do ponto de vista da fidelidade, o comportamento do programa em execução na máquina virtual deve ser idêntico ao seu comportamento se ele estivesse executando diretamente no hardware. Na prática, existem várias complicações associadas a esse requisito que levam à categorização das instruções utilizadas pela CPU em três grupos de diferentes:

- Instruções sensíveis: CPUs que fornecem user mode e kernel mode apresentam instruções comuns para ambos os modos de operação, mas que têm comportamentos diferentes dependendo de cada modo de operação no qual a instrução é executada;

- Instruções privilegiadas: São instruções que geram uma trap quando executadas no modo usuário, mas que não geram trap em modo Kernel;

- Instruções de controle de fluxo sensíveis: São aquelas que tentam mudar a configuração de algum recurso do sistema.

Se um programa tentar fazer algo em modo usuário que não deveria ser capaz de fazer, o hardware deve capturar essa ação; em outras palavras, Popek e Goldberg mostraram que uma máquina é virtualizável se o conjunto de instruções sensíveis é um subconjunto das instruções privilegiadas. Apesar de parecer um conceito simples, foram necessários 
vários anos para que as CPUs incorporassem tais funcionalidades e assim oferecessem um adequado suporte de hardware para a virtualização.

O uso de técnicas de virtualização já era conhecido muito antes de 1998, contudo nenhuma das abordagens utilizadas naquele período tinha total suporte para a virtualização em hardware que atendesse os três tipos de instruções indicado por PoPEK e GOLDBERG (1974). O suporte completo para a virtualização em hardware foi resolvido apenas em 2005 pela Intel (Uhlig et al., 2005) com uma tecnologia chamada Virtualization Technology (VT-x). A AMD tem uma solução parecida chamada Secure Virtual Machine (SVM). A ideia básica é criar um invólucro no qual a máquina virtual pode executar um $\mathrm{SO}$ guest. $\mathrm{O}$ SO continua em execução até que provoque uma trap que faça o VMM ter que lidar com a situação. O conjunto de instruções que provocam uma trap é controlado por um conjunto de bits ao qual o VMM tem acesso. A extensão VT-x torna possível a execução clássica de uma máquina virtual baseada em interrupção-e-emulação (TANEnBAUm e Bos, 2015).

Do ponto de vista da eficiência, a virtualização deve fazer com que a maior parte do código executado pelo SO guest não sofra interferência do VMM. Uma das abordagens utilizadas antes de se ter o hardware de virtualização foi a adoção de técnicas na qual o hypervisor interceptava as instruções e as reescrevia em tempo de execução com uma sequência de código considerada segura. Esse mecanismo permitia substituir instruções sensíveis, mas não privilegiadas. Tal técnica ficou conhecida como tradução binária e demostrou-se extremamente eficiente devido ao seu sofisticado mecanismo de cache.

\section{A Tecnologia VT-x}

UHLIG et al. (2005) apresentaram a tecnologia de virtualização adotada pela Intel para fornecer a virtualização completa no nível do processador. A Figura 2.17 ilustra os elementos que compõem a tecnologia VT-x e a forma como eles interagem. Dentre as inovações apresentadas, dois novos modos de operação introduzidos nas CPUs merecem destaque: VMX non-root e VMX root.

O VMX non-root é o modo de operação no qual a máquina guest executa, enquanto o VMX root é o modo de operação utilizado pelo VMM. É interessante observar que os dois modos têm suporte para os quatro níveis de privilégios fornecidos pelos processadores Intel; isto permite que a máquina guest, ao tentar executar uma instrução privilegiada em algum desses níveis, forneça informações para o VMM. Os software em execução como VMX non-root (p.ex., uma máquina com Debian) pode tentar acessar um dos modos privilegiados, contudo o modo non-root não tem privilégios reais para executar instruções que exigem permissões maiores que a sua; nesses casos, o VMM entra em ação para intermediar a situação.

A Figura 2.17 mostra as transições VM exit e VM entry. A transição VM exit ocorre quando o controle é transferido do guest para o VMM, fazendo com que o estado da máquina guest seja salvo e o estado do host seja carregado para que o VMM decida como tratar a interrupção. No sentido oposto, ocorre a transição VM entry: nesse caso, o VMM transfere o controle para a máquina guest, salvando o estado do host e carregando o estado anterior do guest. Todas as informações referentes à virtualização são mantidas em uma estrutura de dados chamada virtual-machine control structure (VMCS) que tem por função gerenciar as transições entre a VM entry e VM exit. 


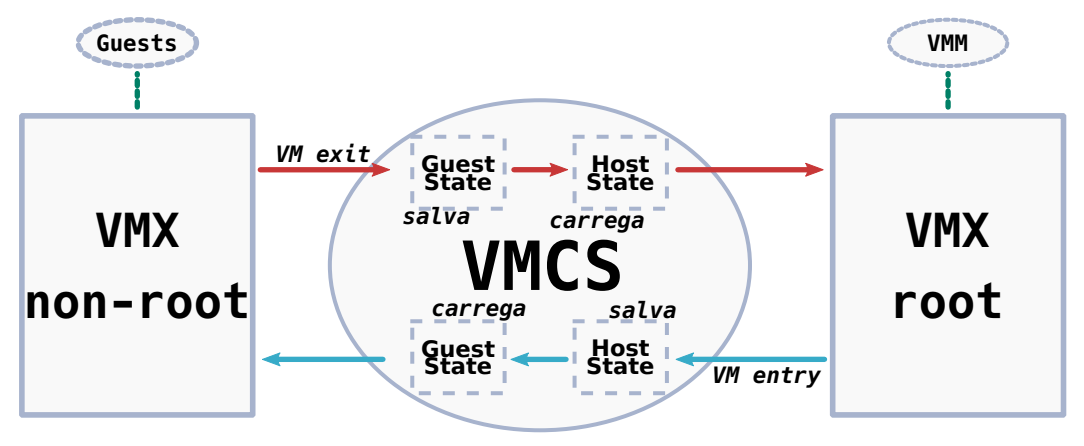

Figura 2.17: Fluxo do comportamento da tecnologia VT-x

Na prática as CPUs Intel fornecem diversas instruções para utilizar o VT-x. Em especial, o VMCALL faz com que VM Exit ocorra incondicionalmente, transferindo o controle para o VMM; por sua vez, o VMM decide o que fazer. Para a melhor compreensão do conteúdo dos próximos capítulos desta dissertação, destacamos apenas um pequeno subgrupos de instruções que normalmente são expostas para as máquinas guest por meio do VT-x de forma segura e isolada, são elas (INTEL, 2018):

Exceções: São tipos especiais de transferência de controle; elas alteram o fluxo normal de execução do programa para atender algum evento externo ou reportar erros para situações excepcionais. Em resumo, exceções manipulam condições detectadas pelo processador no decorrer da execução de uma instrução;

- LIDT: Carrega o valor que indica a localização de um endereço base para ser carregado no registrador que mantém a referência para a tabela global de descritores ou a tabela de interrupções;

- LTR: Carrega um segmento específico que aponta para o segmento de estado de um processo. Essa instrução só pode ser executada em modo privilegiado;

- IRET: Devolve o controle para um programa ou procedimentos após a manipulação de uma exceção ou interrupção;

- STI: Ajusta a flag IF em um registrador EFLAGS, depois de ajustado, o processador começa a responder a interrupções externas;

- CLI: Limpa a flag de interrupção.

Memória Virtual: Máquinas virtuais precisam lidar com o gerenciamento da memória, para isso, elas precisam fazer uso de instruções de manipulação da memória em conjunto com um recurso chamado de Extended Page Tables (EPT) - discutiremos a seguir;

- MOV CRn: Esse tipo de instrução é usada para manipular bits dos registradores, no contexto das memórias virtuais, os registradores CR2 e CR3 são dois importantes elementos. O primeiro é usado para identificar faltas de página e o segundo contém o endereço físico base de uma hierarquia de página em conjunto com duas flags de controle;

- INVLPG: Invalida entradas na TLB; 
- INVPCID: Invalida entrada nas TLBs e caches de página.

Modos Privilegiados: Operações realizadas em modos privilégiados.

- SYSCALL: Chamada rápida para o modo privilegiado;

- SYSRET: Trabalha em conjunto com a instrução SYSCALL devolvendo a execução do SO para o modo de usuário;

- SYSEXIT: Devolve de forma rápida a execução para a aplicação no espaço de usuário.

Por fim, o VT-x trabalha com uma tecnologia chamada de Tabelas de Páginas Estendidas (EPT) que é uma extensão feita sobre as MMUs. O EPT é um mecanismo de paginação aninhada que trata cada endereço físico da máquina guest como um endereço virtual na máquina host, inserindo multiníveis na tabela de páginas da máquina host. Note que toda a manipulação é feita com o auxílio do hardware, o que torna todo o processo de tradução eficiente.

\subsection{Considerações Finais}

Neste capítulos, buscamos apresentar os diversos temas ligados direta e indiretamente às abstrações de processos com o objetivo de tornar a leitura desta dissertação mais simples. No próximo capítulo, apresentaremos diversos trabalhos na qual acreditamos representar o estado da arte nas abstrações de processos e que ainda não atingiram os SOs de produção. 



\section{Capítulo 3}

\section{Trabalhos Analisados}

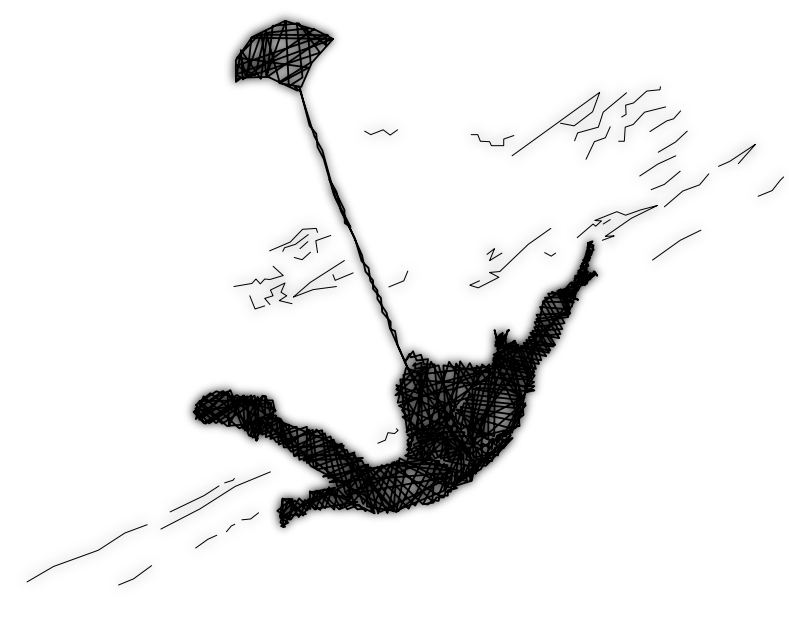

Este capítulo tem como objetivo destacar as principais pesquisas recentemente realizadas com o objetivo de expandir as abstrações de processos. Para a seleção dos trabalhos aqui apresentados, o autor levou em consideração os seguintes aspectos: quantidade de citações dos trabalhos, implementação funcional e pesquisas que tenham a abstração de processos como objeto de estudo. Por uma questão de organização, este trabalho considerou três tipos de implementação funcional: Implementação Estrutural Leve, Implementação Estrutural Pesada e Implementação Independente.

Chamamos de Implementação estrutural leve toda proposta que não altera diretamente o núcleo do SO. Isso faz com que a proposta tenha uma chance maior de ser incorporada em um SO de produção e, ao mesmo tempo, gera pouco impacto geral no SO. Normalmente, implementações leves utilizam artifícios de device drivers (Veja 2.9.1), o que torna simples de desenvolver e testar novas propostas.

As Implementações Estruturais Pesadas são aquelas que alteram diretamente o núcleo do SO. Essa abordagem traz vantagens e desvantagens que devem ser consideradas antes de serem adotadas. Por um lado, alterações diretas no núcleo são mais flexíveis em termos de possibilidade de acesso aos recursos disponíveis do SO. Por outro lado, alterações no núcleo são arriscadas, uma vez que podem afetar toda a estabilidade do sistema, e são extremamente complexas de serem feitas, uma vez que demandam profundo conhecimento do SO em questão.

As Implementações Independentes são aquelas que se propõem a criar um SO totalmente novo, visando demonstrar um ou mais conceitos. Essas abordagens têm poucas chances de serem adotadas diretamente, contudo apresentam conceitos e ideias que podem ser interessantes para serem estendidas para SOs atuais. Nesta dissertação trataremos especificamente do Exokernel devido ao seu grande impacto (Seção 3.9), contudo, trabalhos como o Singularity (Aiken et al., 2006) e o Corey (Boyd-Wickizer et al., 2008) também influenciaram esta dissertação.

Em resumo, este capítulo busca fornecer uma visão geral sobre o estado da arte das abstrações de processos. Além disso, esta seção visa proporcionar as bases para a discus- 
são apresentada no Capítulo 6, tema central deste trabalho. Os trabalhos apresentados adiante, se encaixam em pelo menos uma das características de implementação discutidas acima.

\subsection{Dune}

Como discutido na Seção 2.9.2, o conceito de virtualização já é amplamente conhecido e adotado pela indústria; dentre os recentes avanços, destaca-se a virtualização via hardware proporcionada pelos processadores modernos. O mecanismo de virtualização é normalmente utilizado fornecendo abstrações para a criação de máquinas virtuais. Com esse conceito em mente, BELAY et al. (2012) decidiram dar outra utilidade para esses recursos de hardware: fornecer características adicionais para processos ao invés de máquinas virtuais.

Os autores defendem que uma ampla variedade de aplicações pode tirar proveito do acesso a certos recursos que são apenas disponíveis ao núcleo. Dentre as aplicações que podem comprovadamente ganhar algum desempenho ao obter acesso direto ao hardware, destacam-se:

- Coletor de Lixo (Garbage Collector - GC): O GC pode ganhar desempenho caso tenha como controlar diretamente o hardware de paginação, como CLICK et al. (2005) demostraram em seu trabalho;

- Migração de Processos: Programas no espaço de usuário podem tirar proveito do acesso direto às faltas de páginas e chamadas de sistemas para implementar novas técnicas de migração de processos.

Não obstante, fornecer o acesso direto aos recursos de hardware de forma segura e gerenciável não é uma tarefa trivial, uma vez que requer mudanças na forma como o espaço de usuário e o espaço do núcleo interagem. Além disso, alterações no núcleo são consideradas invasivas e perigosas, uma vez que uma modificação feita de forma errada pode comprometer toda a estabilidade do sistema. Outra alternativa para dar acesso de hardware para aplicações é por meio de execução em uma máquina virtual; assim uma aplicação consegue acesso seguro aos recursos de hardware através da interface de virtualização. Uma desvantagem dessa abordagem é que ela tem pouca integração com o SO da máquina hospedeira, o que impede o processo de obter ganhos de desempenho.

BelAy et al. (2012) oferecem uma alternativa que consiste em utilizar a abstração de virtualização disponível nos processadores modernos de forma a fornecer um novo tipo de processo que executa no chamado Dune Mode (modo Dune). Tal modo é um estado irreversível no qual o processo indica explicitamente que quer entrar; nesse modo, o processo passa a ter acesso direto, por meio dos recursos de virtualização, a modos de operação com maior privilégio, registradores de memória virtual, tabelas de páginas, interrupções, exceções e vetores de chamada de sistema. Para auxiliar a aplicação no espaço de usuário a interagir com tais recursos, os autores criaram uma biblioteca chamada libDune que dá apoio à utilização das novas funcionalidades.

Dentre as vantagens que essa pesquisa promete, destacam-se o fato de que o modo Dune mantém a compatibilidade com os processos, i.e., a aplicação não precisa ser fortemente 
modificada. Quando um processo faz uma chamada de sistema, ele dispara uma instrução chamada SYSCALL, contudo, aplicações que manipulam recursos de virtualização utilizam a VMCALL para manter o isolamento. O Dune utiliza o recurso do VMCALL para tirar o máximo de isolamento fornecido pelo hardware de virtualização. Além disso, devido ao fato de que o Dune não tem por objetivo fornecer máquinas virtuais, ele consegue ser mais simples e rápido. As aplicações que se adequam ao uso desse modelo podem obter melhorias de desempenho e isolamento, como veremos adiante.

Para implementar o Dune, os pesquisadores utilizaram processadores Intel com suporte para a tecnologia VT-x e parte do código do KVM já disponível no núcleo do Linux. Na Seção 2.9.2 apresentamos o VT-x e algumas instruções importantes para o contexto da virtualização, agora introduzimos os três tipos de instruções privilegiadas que o Dune fornece para os processos:

- Exceções: As instruções LIDT, LTR, IRET, STI e CLI são expostas diretamente para os processos. Note que emulação, depuração e rastreamento de desempenho são atividades que podem tirar proveito dessa característica, uma vez que o Dune pode reduzir consideravelmente a sobrecarga ao tratar exceções diretamente. Isso se deve ao fato que o Dune consegue passar as exceções diretamente para o hardware de forma segura (encapsulado pelo hardware de virtualização);

- Memória Virtual: As instruções MOV CRn, INVLPG e INVPCID são oferecidas para o processo Dune. $\mathrm{O}$ acesso flexível à memória virtual pode ser benéfico para aplicações que fazem checkpointing, GC, compressão de dados nas páginas e utilizam memória compartilhada distribuída. O Dune traz melhorias para o acesso à memória virtual expondo as entradas da tabela de páginas para as aplicações. Isso permite que elas controlem a tradução de endereços, as permissões de acesso, bits globais e que elas modifiquem/acessem as páginas com simples referências. Por fim, o Dune também dá a habilidade de controlar as invalidações da TLB manualmente, o que pode ser vantajoso para alguns tipos de aplicações;

- Modos privilegiados: As instruções SYSRET, SYSEXIT, IRET permitem que o Dune exponha os modos privilegiados de forma segura. O Dune expõe esse modos de forma eficiente e segura por que o VMX non-root utiliza o seu próprio conjunto de anéis privilegiados (Veja 2.9.2).

A Figura 3.1 ilustra a arquitetura do Dune. O Dune estende o Kernel como um módulo que habilita o VT-x, colocando-o no modo VMX root. Assim, processos usando Dune têm acesso seguro e garantido para hardware privilegiado utilizando o modo VMX non-root. O módulo Dune intercepta transições do tipo VM exit (Seção 2.9.2), o único motivo para o processo acessar o kernel e realizar qualquer ação. Repare que o Dune é aplicado de forma seletiva aos processos que de fato precisam dele, o que significa que um processo que não usa o Dune não é afetado. A transição de um processo normal para o modo Dune ocorre por meio de uma chamada de ioctl no dispositivo /dev/dune e, ao entrar nesse modo, o processo não pode retornar ao modo anterior. Sempre que um processo Dune faz um fork(), o processo filho não inicia em modo Dune, contudo pode reentrar caso queira.

Na Seção 2.9.2, discutimos diversas propriedades dos VMMs. Com o objetivo de deixar 


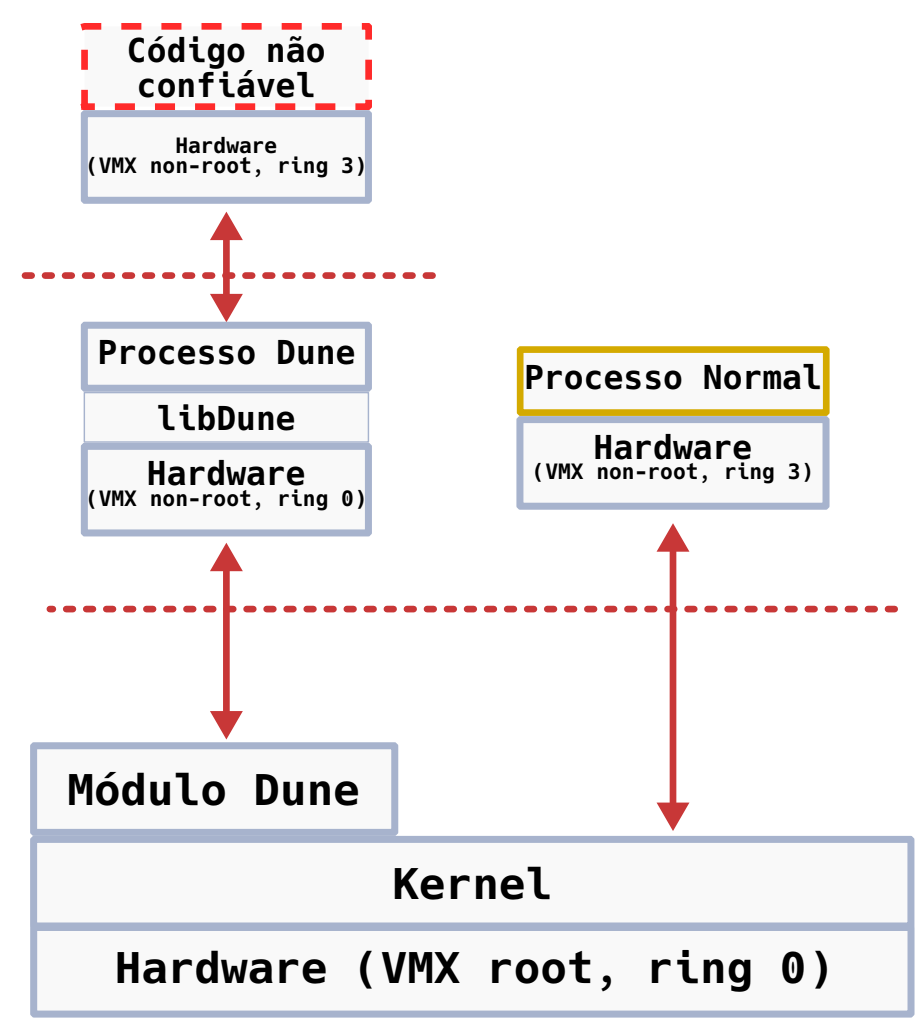

Figura 3.1: Arquitetura do Dune (BELAY et al., 2012)

claras as diferenças entre o VMM e as características de hardware expostas pelo Dune, destacamos as principais diferenças:

- No Dune, o mecanismo de hypercall invoca system calls comuns do Linux;

- Apenas características de hardware que podem ser acessadas diretamente, sem a intervenção do VMM, são disponíveis para a aplicação. Nos casos em que não é possível executar uma dada operação, Dune devolve o controle para o SO;

- Podemos reduzir as diferenças de estados entre o guest e o host, uma vez que processos usando Dune têm uma interface próxima da de hardware;

- No Dune, é preciso configurar o EPT para refletir o endereço do espaço de usuário.

Em resumo, o Dune é um trabalho que se destaca por sua arrojada decisão de tentar dar outras utilidades para um recurso de hardware bem consolidado e heterogêneo. Além disto, a forma como os autores propuseram fazer o Dune se mostra versátil uma vez que é mantido a compatibilidade com as aplicações atuais, essa característica permite a adoção de tal proposta em larga escala. Durante este trabalho, replicamos os resultados publicado pelos autores e também contribuímos com os mesmos na forma de envio de melhorias código para o projeto. 


\subsection{Shreds}

Existe uma categoria de ataques chamada "abusos intra-processos de conteúdo de memória”, na qual o invasor busca acessar determinado tipo de conteúdo sensível na memória (p.ex., dados secretos) ou uma região de código crítica (p.ex., funções privilegiadas) (CHen et al., 2016). O roubo desse tipo de dados acontece por meio da introdução de algum código injetado ou por meio de alguma biblioteca maliciosa que permite acessar alguma região da memória não protegida da vítima. Note que bibliotecas maliciosas são especialmente perigosas, uma vez que elas podem executar funções privilegiadas que são de fato parte do processo como, por exemplo, a função dlopen. Por fim, se o atacante conseguir o acesso à memória, ele pode ler todos os dados buscando por outras informações.

Chen et al. (2016) defendem que o problema de segurança referente aos ataques intraprocessos decorrem da falta de controle fino e eficiente do conteúdo sensível da memória; além disso, argumentam que seria benéfico se tais funcionalidades fossem disponibilizadas para os programadores. Para resolver tal problema, os autores apresentam uma nova abstração de processos que cria uma nova unidade de execução chamada shred, que tem associado a si um fragmento de memória protegida denominado shred-private pool (s-pool). O tamanho do segmento de memória criado é variável, dependendo da necessidade da aplicação. Além disso ele se comporta de forma a existir apenas durante o momento em que é necessário para um pedaço da aplicação. A implementação do shreds é baseada em três pilares: uma API para o usuário conseguir utilizar facilmente as funcionalidade oferecidas, um conjunto de ferramentas de compilação que verifica a correta utilização dos shreds (S-compiler) e um módulo Linux que faz o gerenciamento da memória (S-driver).

Shreds foi projetado buscando três propriedades que visam garantir segurança:

- Acesso exclusivo para s-pool: Um s-pool só é acessível para o shred associado a ele;

- controle de vazamentos na entrada e saída: Dados carregados em um s-pool não podem ser copiados ou exportado sem que seja executada uma operação de limpeza;

- Execuções não desviáveis: O fluxo de execução não pode ser alterado para fora do shred.

Para melhor entender o comportamento dos shreds, veja a Figura 3.2, ilustrando uma aplicação que lida com uma senha (dado sensível) e o código que manipula tal dado. A aplicação possui uma thread que se comporta da forma padrão, contudo, ao ter que lidar com um dado sensível, ela faz uma chamada para uma função da API fornecida pelo shred, shred_enter(). Ao realizar a chamada para essa função, o fluxo de execução entra em um modo seguro em que o shreds gerencia o acesso à memória e garante que os dados são isolados do restante da aplicação. Por fim, após realizar a operação na região protegida, a aplicação do usuário chama shred_exit(). Para utilizar a proposta dos autores, é preciso alterar as aplicações alvo.

A API fornecida pelo shreds consiste em apenas quatro funções:

- shred_enter(): Muda o fluxo de execução da thread atual e cria uma cópia da pilha atual do processo em uma região de memória segura (pool); 


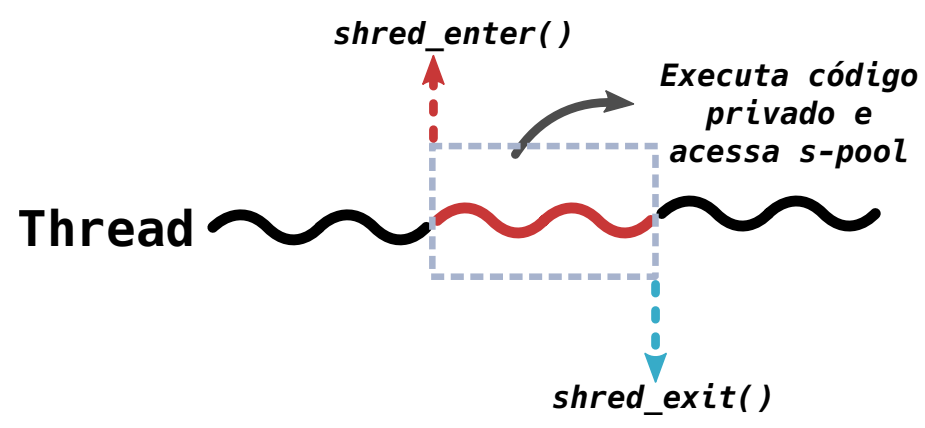

Figura 3.2: Funcionamento geral do shreds

- shred_exit(): Suspende o shred chamado, revoga as permissões de acesso da thread atual sobre o $s$-pool e recupera a pilha de execução original;

- spool_alloc(): Aloca memória para o s-pool associado à thread;

- spool_free(): Apaga a memória alocada.

Para garantir que as regras de utilização da API sejam seguidas, o S-compiler realiza verificações e instrumentações para evitar falhas que abram brechas de segurança.

Para este trabalho, a parte mais importante do shred é o $S$-driver, que consiste em um módulo do Linux responsável por gerir os shreds e s-pools. A implementação dessa técnica é baseada em domínios de memória do ARM (Seção 2.2.3). Contudo, dado que essa tecnologia não foi projetada para os propósitos sugeridos pelo shreds, ela apresenta duas limitações:

- O ARM fornece apenas 16 domínios, o que impede que se crie um domínio para cada $s$-pool, uma vez que seu número pode crescer de forma indeterminada;

- O controle de acesso à memória é extremamente limitado.

A solução adotada pelos autores foi implementar um mecanismo que multiplexa os domínios e introduz identidades dentro da lógica de acesso. Para permitir que uma aplicação tenha várias shreds, o $S$-driver utiliza os domínios de forma temporária, rotacionando as identidades de segurança para o s-pool. Toda vez que uma shreds inicia ou retoma a sua execução em uma $C P U_{i}$ o $S$-driver atribui um $s$-pool associado a um domínio $D_{0} m_{i}$. Isso faz com que uma shred consiga acessar o seu s-pool enquanto outras threads concorrentes não. Quando o shred finaliza ou tem a sua execução parada em favor de outro processo, o $S$-driver muda o domínio, prevenindo que outro processo consiga acessar a região de memória. Note que o driver permite ou rejeita o acesso a um s-pool baseado na CPU; isso faz com que, mesmo que um código malicioso consiga executar em paralelo com o shred, ele não consiga ter acesso ao s-pool sem que seja disparada uma falha de domínio.

Uma das funcionalidades fornecidas pelo shread é a habilidade de permitir fazer cópias de dados para regiões de memória não protegidas de forma segura (p.ex., atribuir dados de um s-pool para uma variável local). Note que, para realizar tal procedimento, é preciso acessar uma pilha regular que pode ter sido atacada e conter um código mal-intencionado, o que violaria toda proteção fornecida pelo s-compiler e $S$-driver. Para prevenir que dados sejam vazados via pilha, o $S$-driver cria uma pilha segura para cada shred alocada partindo 
do s-pool associado a si.

Em síntese, o shred apresenta-se como um projeto inovador ao tentar utilizar um recurso disponível em hardware porém pouco utilizado. Além disso, a sua implementação leve faz com que tal solução seja flexível e elegante uma vez que não exige uma mudança generalizada nas aplicações atuais com o objetivo de manter a compatibilidade.

\subsection{Wedge}

Existe um fundamento proposto em 1975 chamado de "Princípio do Menor Privilégio" que diz:

"O princípio do menor privilégio implica dividir o código em compartimentos, cada um dos quais executa com os privilégios mínimos necessários para completar sua tarefa. Essa abordagem não apenas limita o dano que um ataque pode causar, mas também pode evitar que os bugs vazem acidentalmente informações confidenciais." (SAltzer e Schroeder, 1975)

Apesar desse princípio ter sido apresentado em 1975 e ser amplamente aceito, nota-se que várias aplicações que tem acesso à Internet (um ponto de acesso para o mundo) não buscam atender a esse fundamento e acabam abrindo potenciais pontes de vazamento de dados ou falhas de segurança. Alguns pesquisadores defendem que esse problema surge do fato de que os SO atuais garantem privilégios por padrão. Isso significa que impor limites requer mais esforço por parte do programador e também está sujeito a erros.

A chamada de sistema fork() ilustra a característica de garantir privilégios por padrão. Quando o processo pai cria um filho, este inicia como uma cópia praticamente exata do pai. Se o programador desejar restringir o nível de acesso do processo filho, é preciso realizar uma série de operações manuais e, muitas vezes, algum aspecto acaba sendo ignorado.

BitTAu et al. (2008) buscaram resolver tal problema mudando o princípio atual, de garantir privilégio por padrão, para negar privilégios por padrão. Nessa abordagem, o programador deve indicar explicitamente que deseja garantir permissões adicionais. Os autores alteraram o GNU/Linux para que ele adotasse a remoção de permissões por padrão e chamaram o modelo proposto por eles de Wedge. Esse sistema fornece um conjunto de primitivas de programação para permitir a criação de componentes com semântica de negação de permissões por padrão, tornando o acesso mais restrito. Para isso, Wedge oferece um esquema simples e flexível de marcação (tagging) das permissões de acesso à memória, permitindo que o programador aloque objetos na memória de acordo com essa informação.

Wedge permite que o programador crie um número arbitrário de componentes, cada um sem privilégios por padrão, mas oferece mecanismos que permitem o controle fino. Nesse sentido, Wedge busca se assemelhar às primitivas atuais para facilitar a sua adoção e para que seja simples a introdução delas em aplicações legadas. A proposta é constituída por três primitivas: sthread, tagged memory e callgates. $\mathrm{O}$ acesso a todas essas primitivas é feito via chamadas de sistema. 
Uma sthread pode ser comparada com uma thread fornecida pela biblioteca pthread, definindo um compartimento dentro de uma aplicação. O programador pode então atribuir permissão de acesso para a memória e outros recursos por meio dessas sthreads. Elas consistem de uma thread de controle e políticas de segurança associadas, que especificam:

- As marcações de memória que a sthread pode acessar e a permissão sobre cada uma (leitura, leitura-escrita e copy-on-write);

- Os descritores de arquivo que a sthread pode acessar e as permissões sobre cada (leitura, escrita, leitura-escrita);

- Os callgates que a sthread pode chamar;

- O Unix user id, o diretório raiz, e o contexto SELinux.

Normalmente, quando uma cópia da memória é feita o SO apenas realiza a duplicação quando o recurso é modificado (copy-on-write); nesse contexto uma nova sthread não mantém as permissões de acesso por padrão, a não ser pela memória ainda intocado do copy-on-write. Note que o novo componente não tem permissão para acessar qualquer outra memória ou mesmo descritor de arquivo do pai, contudo o pai pode anexar permissões de acesso ao filho durante a sua criação. Uma sthread só pode criar um filho com permissão igual ou menor do que a sua. Para a implementação, os autores criaram sthreads como uma variante dos processos do GNU/Linux, só que, ao invés de herdar as informações do pai, ela apenas herda as regiões de memória e tabela de descritores asseguradas pela política de segurança.

No Wedge é preciso seguir alguns passos para alocar memória. O passo inicial consiste em criar uma tag que contém as permissões de acesso à região de memória que se deseja alocar. Em seguida, o programador deve utilizar uma chamada específica do Wedge para fazer a alocação; essa função espera uma tag que contém as permissões. Quando alguma alocação de memória ocorre, o programador deve marcar a memória com uma única tag; as permissões de acesso a essa memória são garantidas em termos delas. Essa operação aloca um segmento de memória e armazena um mapa da tag para o segmento. Por exemplo, o programador pode criar uma tag " $\mathrm{t}$ " que define que a memória será apenas para leitura. $\mathrm{O}$ programador expressa os privilégios de memória em termos das tags que são atribuídas para a memória em tempo de alocação.

Um callgate é uma porção de código que executa em um nível de privilégio (normalmente) diferente de quem o chamou. Como um sthread sempre executa com o menor privilégio possível, sempre que for preciso executar algo em um nível de permissão maior, será preciso chamar um callgate para executar a operação. Para criar e usar um callgate, é necessário indicar um ponto de entrada, um conjunto de permissões e argumentos confiáveis fornecido pelo responsável em criar o callgate. Wedge garante que os argumentos passados e criados não podem ser adulterados pelo processo que o utilizará. Além disso o callgate herda o sistema de arquivos raiz e o id do usuário que o criou. As permissões do callgate precisam ser um subconjunto de quem o criou. Depois que um callgate foi criado, a sthread privilegiada pode criar um filho com menos privilégios mas com acesso ao callgate criado. Quando o filho tenta acessar o callgate, uma nova sthread é criada e a execução é levada para o ponto de entrada que foi registrado. 
Para a implementação dos callgates, a função sc_cgate_add() adiciona permissões para o ponto de entrada cgate com as permissões e os argumentos confiáveis, e todos esses dados são salvos no núcleo para evitar acessos indevidos. Um callgate é invocado por meio da função cgate(), que faz com que o núcleo verifique as permissões. De forma geral, a API do Wedge é composta por diversas funções; destacamos apenas algumas:

- sthread_create(sthread_t, sc_t, cb_t, void *arg): Cria uma nova sthread;

- tag_t tag_new(): Cria uma nova tag;

- tag_delete(tag_t): Remove uma tag;

- smalloc(int sz, tag_t tag): Aloca memória baseada na informação de tamanho e na tag;

- $\operatorname{sfree}(\operatorname{void} \star x)$ : Libera a memória previamente alocada com o smalloc()

- sc_cgate_add(sc_t sc, cg_t cgate, sc_t *cgsc, void *arg): Adiciona permissões para chamar um callgate;

- cgate(cg_t cb, sc_t *perms, void *args): Invoca um callgate.

Em suma, o Wedge revive e explora um importante conceito: negar acesso por padrão ("Princípio do Menor Privilégio"). Note que a implementação pesada exigida pelo Wedge faz com que a sua solução seja extremamente poderosas e de certa forma expansível. Por outro lado, o Wedge exigiria mudanças complicadas nos SOs atuais além de demandar alterações em diversas aplicações. Por fim, o Wedge é um projeto auspicioso uma vez que esse pode trazer diversos benefícios de segurança sem degradar o desempenho geral dos SOs.

\subsection{Resource Container}

BANGA et al. (1999) argumentam que as abstrações de SO têm recebido grandes contribuições para melhorar questões de desempenho, mas que pouca atenção tem sido dada para o gerenciamento de recursos. Como exemplo, os autores mostram como a gerência de recursos é um elemento crítico para conter ataques como o Denial-of-Service Attack, que basicamente consiste em fazer com que todos os recursos da máquina sejam consumidos. Eles também assumem que a raiz dos problemas de gestão de recursos encontra-se no modelo atual dos SOs de propósito geral, em que primitivas de escalonamento e de gerência de recursos estendem-se por todo o núcleo. Esse acoplamento torna complicado o processo de permitir que uma aplicação controle os seus próprios recursos.

Para ilustrar as questões referentes à gestão de recursos nos SOs, a Figura 3.3 mostra 4 cenários diferentes. O primeiro cenário consiste em uma aplicação executar em user space que não necessita de qualquer recurso diretamente controlado pelo Kernel e, portanto, cujo consumo de recursos não se estende para o Kernel. O segundo cenário representa uma aplicação que precisa utilizar recursos do Kernel para terminar alguma de suas tarefas (p.ex., um software que usa recursos de rede). Note que parte da aplicação consome recursos dentro do user space; contudo, a outra parte da aplicação se expande para o Kernel. O terceiro cenário mostra múltiplos processos cooperando para concluir uma tarefa sem 


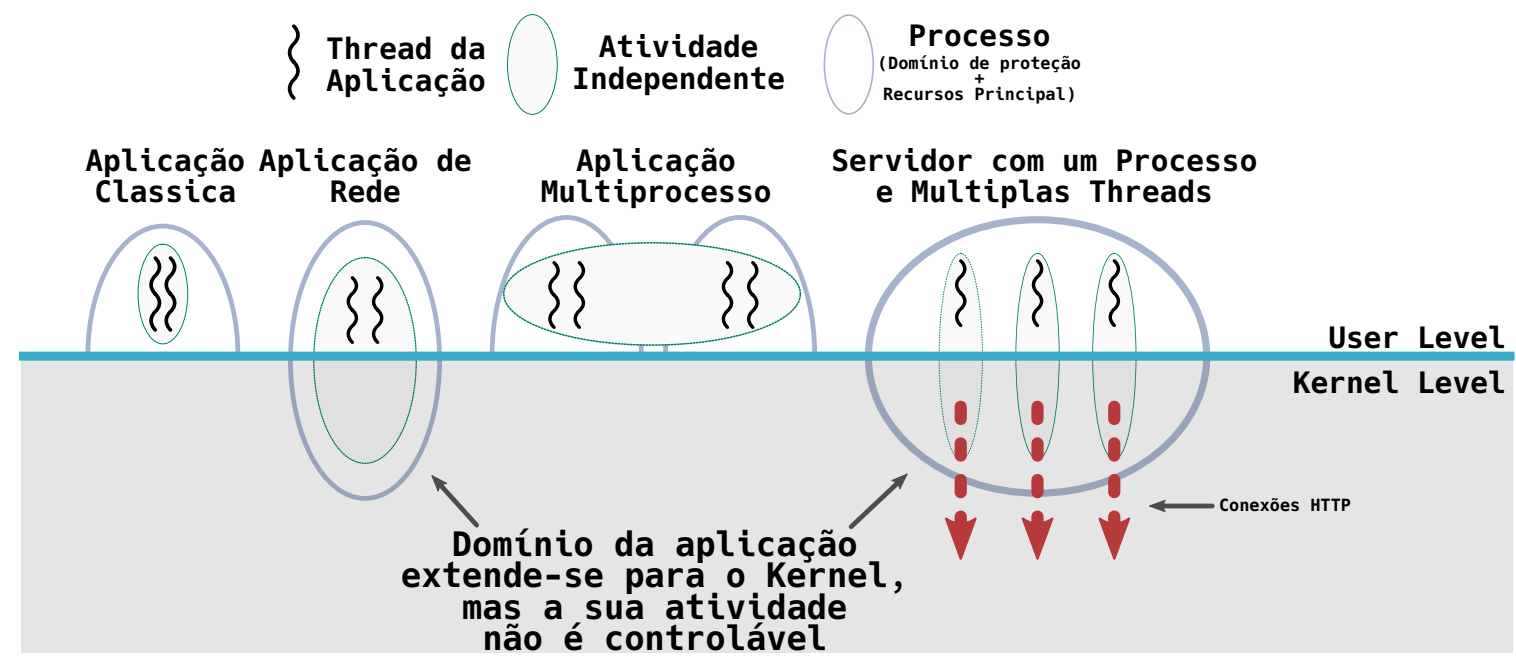

Figura 3.3: Cenários das aplicações

precisar do Kernel. Por fim, temos uma aplicação com um único processo que dispõe de múltiplas threads que, além de utilizar recursos no user space, também demanda recursos oriundos do Kernel. Repare como sistemas tradicionais têm pouco ou nenhum controle sobre os recursos consumidos; esses casos podem levar o escalonador a fazer contagens imprecisas levando-o a comportar-se de forma inadequada.

Inspirados pela falta de uma separação clara do gerenciamento de recursos por parte dos SOs, BANGA et al. (1999) sugeriram a criação de uma nova abstração chamada Resource Container $(R C)$. Este é uma entidade que logicamente contém todos os recursos utilizados pela aplicação para completar uma determinada atividade. Seus atributos são usados para fornecer parâmetros de escalonamento, limites de recursos e QoS para rede. A ideia é que o núcleo cuidadosamente manipule esses recursos, tal qual CPU e memória, consumidos por um RC. O escalonador pode acessar as informações provenientes dos RCs e utilizá-las para melhorar o processo de escalonamento.

A adição do RC cria uma clara distinção entre o domínio da proteção e o de recursos, além de fornecer um controle fino sobre os recursos. O RC fornece um mecanismo para ligar os recursos a uma thread, de forma dinâmica e sob controle da aplicação (isso também é chamado de resource binding). Note que isso permite que múltiplas threads sejam associadas a inúmeros RCs simultaneamente, mas por padrão, uma thread começa com um RC herdado do processo pai. A aplicação poder religar-se a qualquer outro RC caso exista a necessidade.

Uma das implicações diretas do RC é que uma aplicação pode associar informações a uma atividade ao invés de a uma thread ou processo, permitindo que o escalonador forneça informações diretas para a atividade.

A alocação de atributos está diretamente associada com um modelo de escalonamento relacionado com cada $\mathrm{RC}$ em um sistema. Uma thread é normalmente escalonada de acordo com os atributos do $\mathrm{RC}$ ao qual é limitada. Contudo, se uma thread é multiplexada entre vários contêineres, o escalonamento torna-se custoso para cada mudança de binding. $\mathrm{Na}$ prática, a thread deve ser escalonada com base na combinação entre alocação de recursos 
e uso de RC. Para isso, o modelo define um scheduler binding entre cada thread e um conjunto de contêineres sob o atual sendo multiplexado.

É interessante observar que os contêineres formam hierarquias, ou seja, o uso de um recurso usado por um contêiner filho é restringido pelos parâmetros do contêiner pai. Por exemplo, se o contêiner pai tem $70 \%$ dos recursos garantidos, então os contêineres filhos não podem extrapolar esse limite.

Para se utilizar RCs, os autores sugerem uma API com as seguintes características:

- Criar um novo contêiner: Por padrão, um contêiner é criado como parte do fork() e é visível para a aplicação na forma de um descritor de arquivos;

- Ajuste do contêiner pai: Um processo pode mudar quem é o seu contêiner pai;

- Liberar o contêiner: Um processo pode liberar a sua referência para um contêiner usando close();

- Compartilhar contêiner entre processos: Quando um processo recebe uma referência para um contêiner, ele pode usar o recurso como um resource context. Isto permite mover uma aplicação ou computação entre vários domínios de proteção;

- Atributos do contêiner: Uma aplicação pode ler e ajustar atributos de um contêiner;

- Uso de informações dos contêineres: Uma aplicação tem diversos níveis de acesso às informações do $\mathrm{SO}$;

- Binding threads para um contêiner: Uma thread pode fazer o binding para uma contêiner a qualquer momento;

- Restaurar o scheduler binding

- Binding de socket ou arquivo para um contêiner: Um processo pode fazer o bind de um socket ou arquivo para um contêiner, assim o consumo subsequente dos recursos do kernel ficam no contêiner.

Resumidamente, o Resource Container é um projeto na qual podemos encontrar as suas ideias no GNU/Linux na forma dos cgroups. Note que o Resource Container propõe conceitos que vão além daqueles disponíveis pelo o Linux, como por exemplo, permitir que os algoritmos de escalonamento recebam algum tipo de informação adicional da aplicação. Apesar de ser uma implementação pesada, os benefícios que tal técnica traz são consideravelmente importante para os SOs atuais.

\subsection{Nooks}

SwIFT et al. (2003) conduziram uma pesquisa motivada pela busca por adicionar mais confiabilidade e resiliência aos SOs de produção. O principal problema que os autores buscam resolver são as constantes falhas geradas pela expansão dos SOs por meio dos programas que controlam um dispositivo, também conhecidos como modules ou device drivers (Seção 2.9.1). O artigo apresenta diversas evidências relacionadas às falhas geradas pelas extensões feitas nos SOs e sugere uma nova abordagem chamada Nooks. 
Nooks é uma nova camada que se interpõe entre o Kernel e suas extensões. Essa camada comporta-se como um subsistema responsável por tratar as operações passadas via kernel para os módulos e vice-versa; o controle feito sobre cada parte representa uma camada a mais de verificação que adiciona mais segurança e confiabilidade para o SO. Para fornecer a separação e controle dentro do SO, Nooks apresenta o conceito de lightweight kernel protection domain (LKPD). Essa abstração permite isolar partes da memória no nível do Kernel e atribuir diferentes permissões de leitura e escrita para a região. Note que todo o controle entre as regiões de memória e a comunicação entre o kernel com as extensões ocorre no domínio do kernel, não tendo relação direta com o user space.

O projeto de Nooks foi totalmente guiado por dois princípios fundamentais:

1. Nooks deve ser resistente a falhas e não tolerante a falhas;

2. Nooks deve ser projetado para evitar erros e não para evitar abusos.

Esses dois princípios são importantes para deixar clara a área de atuação desta técnica e para guiar os três objetivos principais que o Nooks busca atender:

1. Isolamento: $\mathrm{O}$ Nooks precisa ser capaz de isolar as extensões presentes no Kernel de forma a evitar falhas. Consequentemente, ele precisa ser capaz de detectar falhas antes que outras partes do SO sejam afetadas;

2. Recuperação: A arquitetura precisa dar suporte para a recuperação da aplicação em caso de falhas;

3. Compatibilidade com versões anteriores: Nooks deve ser compatível com as extensões já existentes e usadas.

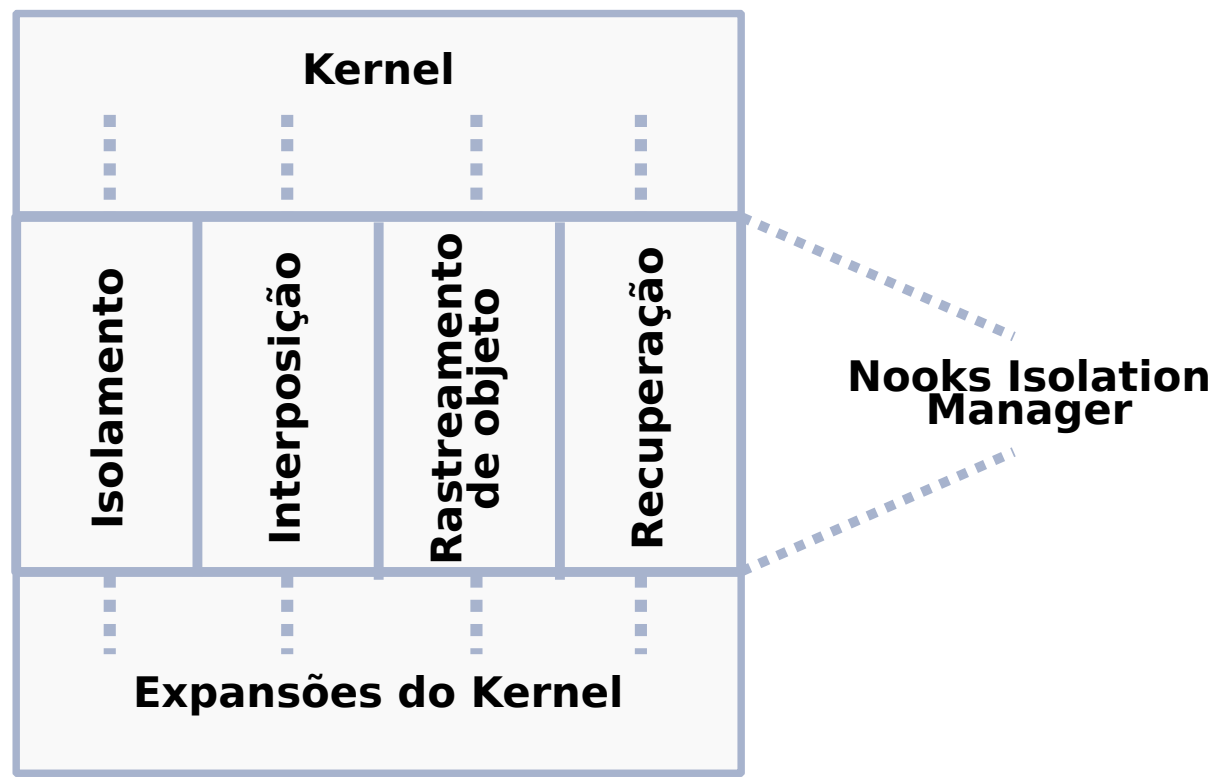

Figura 3.4: Visão geral da arquitetura do Nooks (SWIFT et al., 2003)

A Figura 3.4 ilustra de forma geral a arquitetura de Nooks. Note que a comunicação entre o Kernel e as extensões (e vice-versa) precisa passar pelo Nooks. Esse intermédio é conduzido pelo Nooks Isolation Manager (NIM), que é o responsável por implementar os 
objetivos do projeto. Nooks precisa estender-se em parte para o Kernel e em parte para as extensões. No Kernel, é preciso alterar aquelas funções que são disponibilizadas para as extensões ou que interagem com os módulos. Felizmente, esse tipo de função pode ser detectado por algum padrão que, por sua vez, pode ser abstraído para um script. Além disso, esse tipo de modificação precisa ser feito uma única vez. Do ponto de vista dos módulos, no geral, são poucos os casos que precisam ser alterados diretamente, uma vez que eles fazem uso dos recursos fornecidos pelo Kernel. Normalmente, módulos que exportam estruturas de dados para o Kernel e o espaço de usuário também precisam ser alterados.

O Nooks fornece isolamento por meio do LKPD: toda extensão adicionada ao SO executa dentro do seu próprio LKPD que, por sua vez, é chamado de contexto de execução. Os domínios utilizam o mesmo nível de proteção fornecido pelo processador para o Kernel, com a diferença de que o acesso de escrita para certas porções é limitada e gerenciada pelo NIM. Nesse sentido, podemos dividir o esquema de isolamento de Nooks em duas partes: o gerenciador de memória e o Extension Procedure Call (XPC).

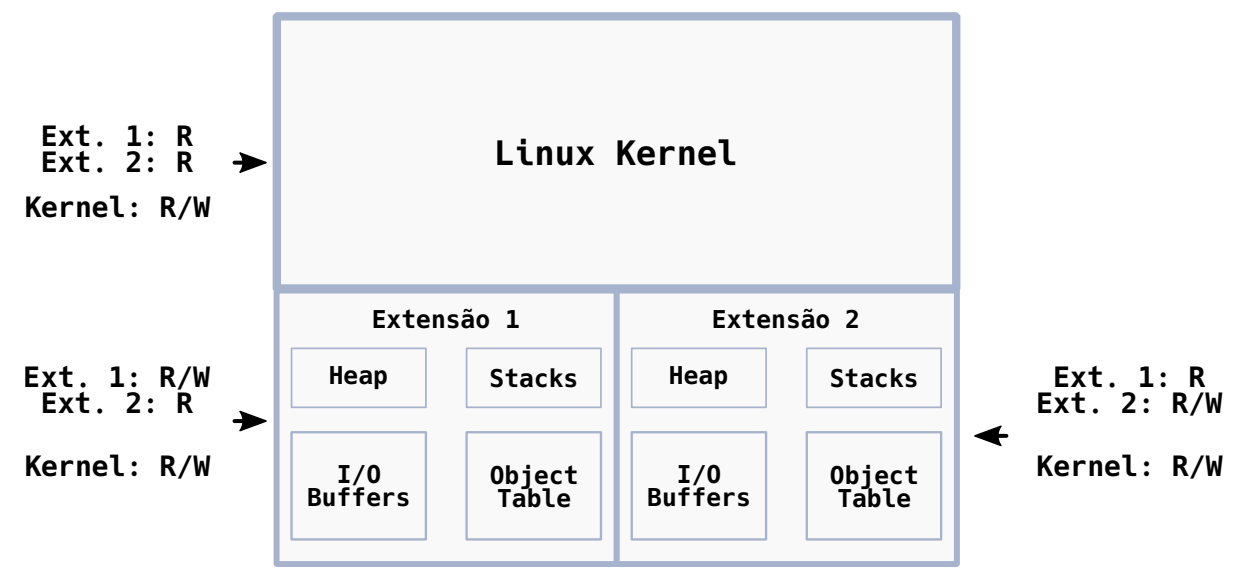

Figura 3.5: Acesso à memória do Nooks (SWIFT et al., 2003)

O gerenciador de memória de Nooks é responsável por alocar, desalocar e manipular os LKPDs. A Figura 3.5 ilustra o kernel address space: note que o Kernel tem permissão de escrita e leitura sobre toda a memória, mas os LKPDs mostrados só têm acesso de leitura e escrita a si mesmos. A leitura de outras regiões de memória de dentro de um LKPD depende do controle de acesso feito pelo NIM mas, no geral, só é permitida a leitura de outras regiões da memória.

O outro mecanismo de isolamento fornecido pelo Nooks é o XPC, que atua como um serviço de transferência de controle criado para isolar as operações feitas dentro do Kernel. A transferência de controle pode acontecer em duas vias: do Kernel para a extensão (nooks_driver_call) e da extensão para o Kernel (nooks_kernel_call). Essas funções esperam três argumentos: um ponteiro para a função que será executada, uma lista de argumentos e o domínio em que será executada. Toda vez que a rotina de transferência é chamada, o contexto da pilha que realizou a chamada é salvo e o Page Table para o novo domínio alvo carregado.

Um dos objetivos do Nooks é o de ser usado em SOs de produção. Para isso, ele tem de se integrar com o SO de forma a causar o menor impacto possível nas extensões. Por isso, 
Nooks isola as extensões com XPC e também implementa um mecanismo de rastreamento de estruturas de dados chamado object-tracking (parte do NIM). O object-tracking tem três recursos básicos: (1) manter uma lista de estruturas de dados do Kernel que são manipuladas por uma extensão, (2) controlar todas as modificações para essas extensões e (3) fornecer informações de objetos para limpeza de dados quando a extensão falhar. O rastreamento dos objetos começa com o armazenamento de todos os objetos em uso por uma extensão e em seguida é feita uma associação entre o Kernel e as versões das extensões.

Por fim, Nooks possui um mecanismo de recuperação que busca detectar falhas de software quando uma extensão é chamada de forma inapropriada ou se uma extensão está consumindo muitos recursos. A estratégia de recuperação é subdividida em duas partes: recovery management e user-mode agent. O primeiro é responsável por desalocar recursos e, se necessário, realocá-los. O segundo é quem coordena a ação de recuperação e é definido no espaço de usuário. Note que a flexibilidade do agent-mode permite várias possíveis formas de recuperação, sendo a mais direta forçar a remoção da extensão, seguida da reinserção e em seguida prosseguindo com a execução da aplicação.

Nooks utilizou uma base de dados de inserção de falhas em módulos para validar a sua eficácia, conseguindo tratar $99 \%$ dos casos. Além disso, os autores também validaram o trabalho da perspectiva do desempenho e notaram que, na maioria dos casos, os gastos com a estrutura são compensados pelas vantagens.

\subsection{Mondrian Memory Protection e Mondrix}

Witchel, CAtes et al. (2002) buscaram explorar técnicas para realizar controle fino sobre à memória, com o objetivo de adicionar mais confiabilidade e segurança para os SOs. Os autores discutem os problemas associados com a decisão usual de se promover isolamento por meio da separação do espaço de endereçamento dos processos, que por sua vez faz com que todas as threads de um processo compartilhem um mesmo domínio de proteção. Além disso, o modelo de paginação comumente adotado impõe um tamanho fixo de página. Logo, o menor compartilhamento possível é o de uma página, que tem o mesmo nível de permissão para todos os elementos contidos nela. Os autores argumentam que, apesar das vantagem oferecidas pelo modelo atual, muitos aspectos de segurança e estabilidade do sistema são comprometidos. Dois exemplos são apontados pelos autores; o primeiro ilustra o caso do servidor Apache, que pode carregar vários plugins externos, contudo, se algum código malicioso ou defeituoso for carregado ele comprometerá toda a estabilidade do servidor (em alguns casos quebrando a aplicação). Outro exemplo refere-se ao acesso de ponteiros em outros domínios da memória (por exemplo, acesso do espaço de usuário para o do Kernel), que atualmente não são permitidos, sendo necessário realizar operações de cópias.

Os autores defendem que mecanismos de controle fino do acesso à memória podem trazer grandes benefícios em termos de segurança, confiabilidade e, em certos casos, desempenho. Nesse sentido, Witchel, CATes et al. (2002) propuseram uma abordagem que permite o controle de acesso à memória no nível do tamanho das palavras de dado. Para isso é apresentado um novo tipo de abordagem baseada em hardware e software chamado Mondrian Memory Protection (MMP) (WitcheL, CATEs et al., 2002). Além disso, 


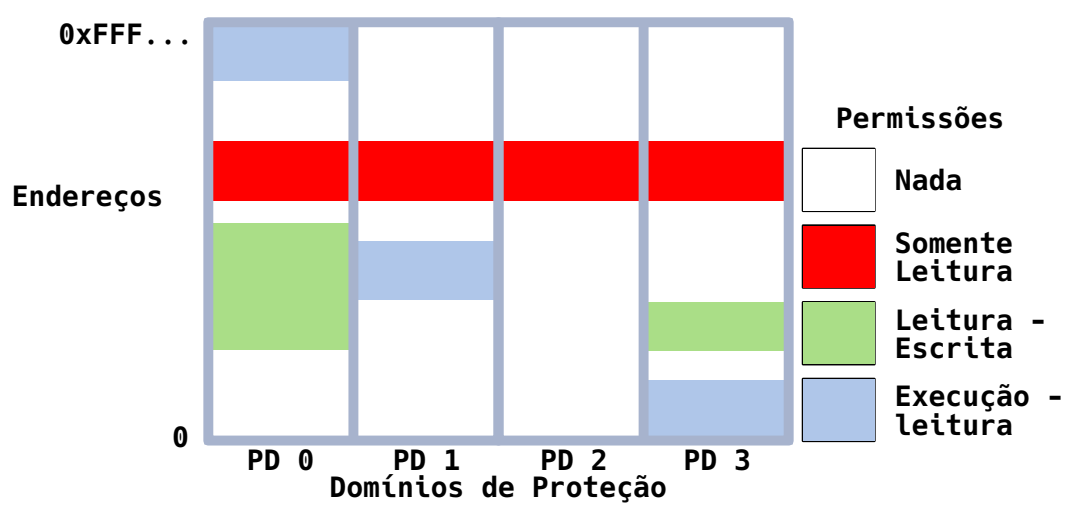

Figura 3.6: Representação dos domínios de proteção do Mondrix (WITCHEL, RHEE et al., 2005)

uma implementação prática chamada Mondrix (Witchel, RheE et al., 2005) foi feita no GNU/Linux. A Figura 3.6 resume a representação de memória que o MMP busca atingir. Repare que não existem porções de memória específica; a memória é dividida em diversos compartimentos chamados Protection Domains (PD). Um PD é definido como um contexto que determina a permissão para executar um código. Cada PD é independente do espaço de endereçamento e pode conter múltiplas threads, mas cada thread só pode pertencer a um único PD. O projeto do MMP é guiado por três requisitos:

1. Diferente: Cada PD diferente pode ter um domínio distinto para a mesma região de memória;

2. Pequeno: A granularidade de compartilhamento deve ser menor do que uma página;

3. Revogável: Um PD é dono da sua própria região de memória e pode mudar a forma como outros domínios veem a sua memória.

Os autores afirmam que MMP tem a semântica da segmentação (Seção 2.2.2) sem os problemas associados a ela. MMP fornece controle fino sobre a proteção dos dados compartilhados, utiliza endereçamento linear, é compatível com o conjunto de instruções existentes, não necessita de registradores de segmentos, possui um mecanismo simples de revogação de permissões e não tem ponteiros marcados. Para que MMP possa garantir o controle de acesso à memória, ele precisa verificar as permissões de acesso feitas por cada operação de load/store; isto claramente consome mais recursos computacionais. Por isso, MMP é uma solução que também depende da utilização de um hardware personalizado.

Da perspectiva do software, Mondrix (Witchel, RheE et al., 2005) sugere a utilização de um novo elemento chamado de Supervisor de Memória, dividido em duas partes: uma parte superior, responsável pelo controle do acesso; e parte inferior, responsável por escrever nas tabelas de permissão. A parte superior é a mais importante, sendo responsável por manter e controlar as políticas, pela interface com o Kernel, por rastrear objetos compartilhados e por implementar grupos de permissão. As definições de permissão da memória são descritas por três elementos:

1. Permissão de Acesso: As permissões de acesso são definidas pelo seguinte conjunto de elementos: permissão do domínio, gates, tabela de pilha;

2. Dono da Memória: Define quem tem autoridade sobre a região de memória (domínio). 
Note que o espaço de endereçamento é contínuo e sem sobreposição, logo, cada região tem apenas um dono;

3. Permissões Exportadas: É possível exportar as permissões de acesso, permitindo que outras regiões chamem códigos fora do seu domínio. Contudo, a exportação pode ser controlada, de forma que outros trechos que acessem o código tenham uma visão limitada da região.

Dados esses elementos, o Supervisor de Memória atua tomando as decisões referentes ao acesso a uma dada região da memória.

Um aspecto interessante de se notar do Supervisor de Memória é a sua separação lógica do alocador de memória. Mondrix permite que o Kernel escolha qual alocador de memória deseja utilizar; isso é possível porque um domínio solicita memória para o alocador e o Supervisor só estabelece as permissões para a memória solicitada.

O Supervisor também é responsável por revogar permissões quando uma região de memória é liberada, além de manter o rastreamento de qual domínio tem acesso a qual região de memória. O Supervisor ainda gerencia o acesso à pilha das threads (uma thread só pode controlar pilha que estão no seu domínio), cria e destrói proteções de domínio e também válida as políticas de acesso.

\subsection{SpaceJMP}

Toda vez que um processo é criado, ele inicializa diferentes estruturas de dados relacionadas à sua execução. Um dos elementos fundamentais dos processos é o espaço de endereçamento virtual (Virtual Address Space - VAS), que é completamente acoplado aos processos. Normalmente, os VASes são maiores que a memória física e são totalmente isolados de outros processos. Se um processo precisar compartilhar dados com outros processos, será necessário criar e gerenciar uma região de memória compartilhada que permita a escrita e/ou leitura por outros processos. O modelo convencional de VAS não dá suporte para o compartilhamento de estruturas de dados entre processos com base em ponteiros; normalmente, é necessário serializar os dados, o que tem se tornado um incômodo.

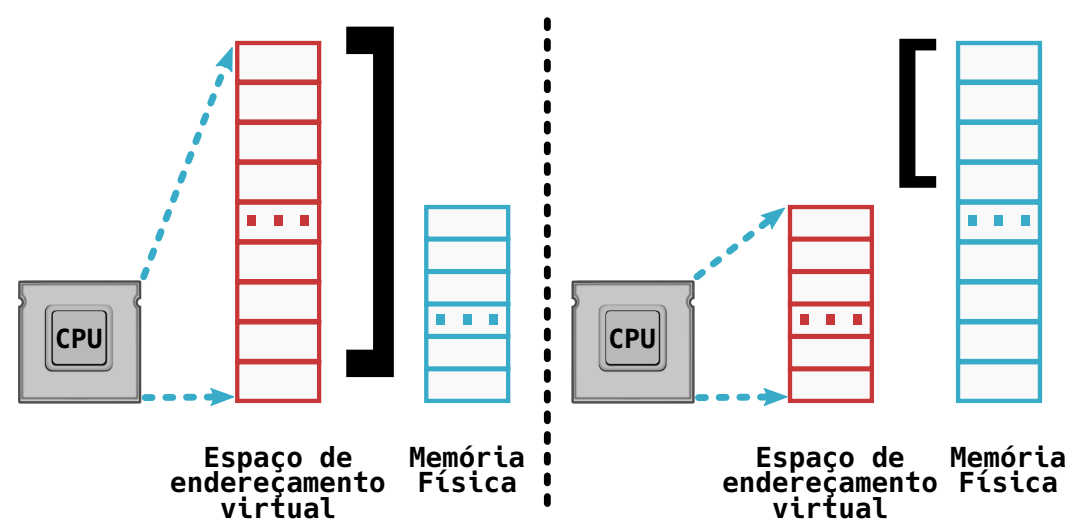

Figura 3.7: VAS e Memóra Física 
No início dos anos 1990s, os processadores tinham poucos bits para o VAS, mas que eram suficientes para endereçar toda a memória física disponível na época. Apesar disso, durante esse período, o tamanho da memória cresceu consideravelmente e os processadores não foram mais capazes de endereçar diretamente todo o endereço de memória disponível (Crowley, 1996). A Figura 3.7 exemplifica o problema mencionados acima: a parte da esquerda ilustra uma CPU com bits suficientes para o VAS, que consegue endereçar todo o espaço de endereçamento físico da memória. O lado direito da figura representa uma situação na qual o VAS é menor do que a memória física. Assim, um único processo não é capaz de acessar toda a memória física disponível, impondo um limite ao processo quanto ao tamanho que ele pode ter. Essa situação não é uma novidade: enquanto a indústria não produzia novos processadores com bits extras para elevar o tamanho da VAS, os desenvolvedores tiveram que utilizar vários artifícios para superar o problema de bits insuficientes. Hoje em dia, esse problema está sob controle, uma vez que os processadores atuais possuem um grande espaço de endereçamento. Contudo, estamos no início de uma geração da computação conhecida por data-centric, que será dominada por grandes memórias não-voláteis (Milojicic e Roscoe, 2016). Assim, simplesmente incrementar o total de bits para o VAS nas CPUs não sanará tão facilmente esse problema, pois elevar o número de bits na VAS tem impactos na produção, desempenho e consumo de energia (El HajJ, Merritt, Zellweger et al., 2016).

Um dos problemas do modelo de processos atual é a representação das estruturas de dados baseadas em ponteiros fora dos limites dos processos. A serialização de dados ou ponteiros especiais podem ser empregados para resolver este problema, contudo, ambos os métodos são incômodos, ineficientes e, em muitos casos, confusos (El HaJj, MerRitT, ZELlWEger et al., 2016). O segundo problema está associado com a tarefa de coordenar o compartilhamento de memória entre vários processos, uma vez que esta é uma tarefa complicada e tediosa.

Para tentar resolver os problemas citados, El HajJ, Merritt, Zellweger et al. (2016) propuseram uma técnica chamada SpacefMP. Os autores propõem desacoplar o VAS dos processos e permitir que um único processo tenha Múltiplos VAS (MVAS) associados a si. Nesse contexto, o VAS é promovido para um objeto de primeira-classe no SO e dá ao processo a habilidade de gerir os muitos VAS.

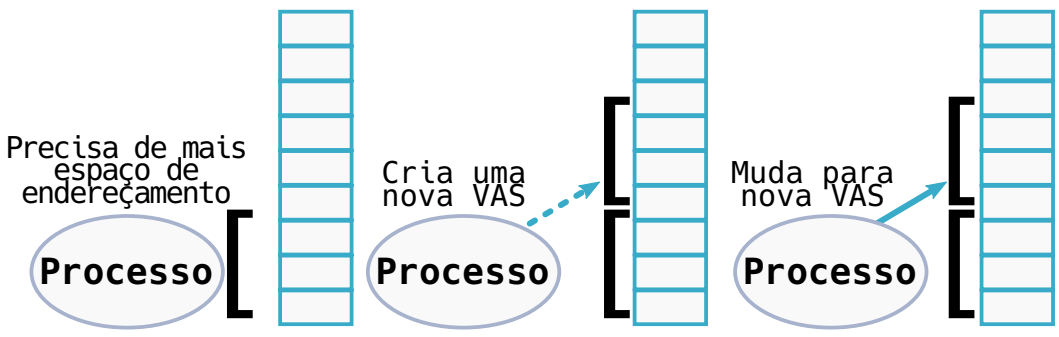

Figura 3.8: Resolvendo o problema de endereçar memórias físicas grandes

A Figura 3.8 ilustra como MVAS resolve o problema de endereçar memórias físicas maiores do que o VAS. Basicamente, todo processo pode criar múltiplas VAS e alternar entre eles. Se os processos precisarem de mais memória do que o disponível, basta criar um novo espaço de endereçamento com o começo apontando para uma região de memória não utilizada e, em seguida, anexar o novo VAS ao processo. O problema da serialização e 
compartilhamento de dados também pode ser simplificado pelo MVAS: basta criar um VAS e permitir que múltiplos processos se anexem a ele.

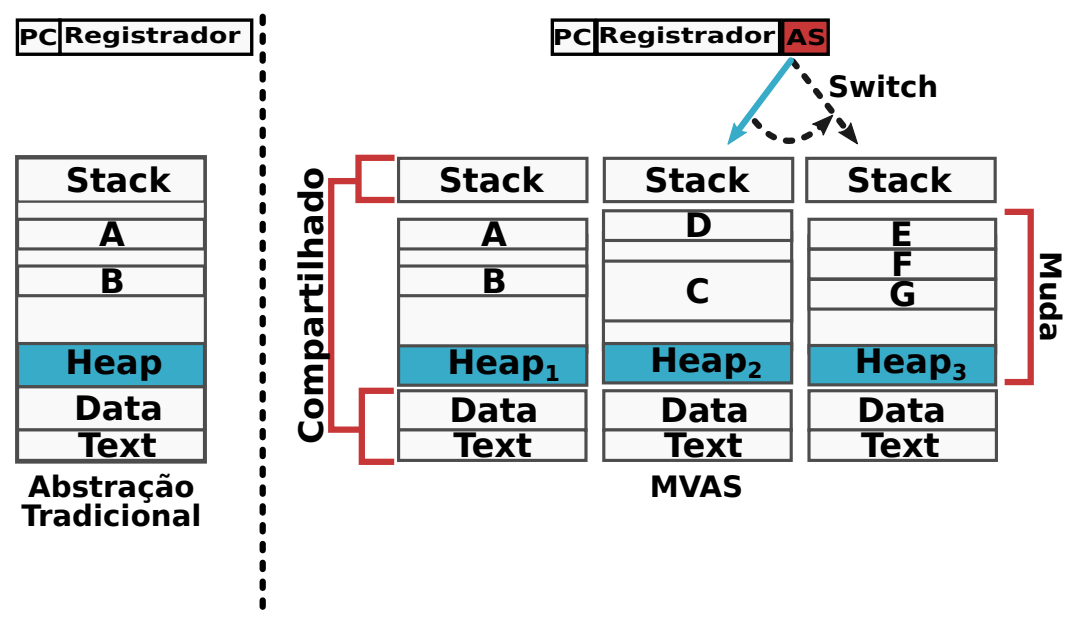

Figura 3.9: VAS e MVAS (EL HAJJ, MERRITT, ZELLWEGER et al., 2016)

A Figura 3.9 ilustra a principal diferença entre um processo com um VAS acoplado para um modelo no qual o VAS é desacoplado (MVAS). O lado esquerdo da Figura mostra um processo tradicional, como explicado na Seção 2.1. O lado direito da figura representa um processo com múltiplos VAS e diferentes informações dentro de cada Heap e segmentos de memória. Nesse novo cenário, a pilha, os dados e os segmentos de texto são compartilhados entre os vários MVAS. Por fim, é importante notar que os processos precisam manter a informação sobre o VAS atualmente em execução.

Os autores da técnica fizeram uma implementação para GNU/Linux. A principal funcionalidade do MVAS foi exposta para o usuário via system calls. A lista a seguir mostra o conjunto de funções expostas para o usuário:

- vas_create(): Cria um novo VAS com o nome indicado;

- vas_delete(): Remove um VAS criado previamente;

- vas_find(): Encontra um VAS de acordo com o nome;

- vas_attach(): Anexa um VAS ao processo;

- vas_detach(): Desanexa um VAS do processo;

- vas_switch(): Muda o VAS atualmente instalado no processo para outro.

A Figura 3.10 ilustra o comportamento das chamadas de sistema implementadas. O topo da figura mostra um processo normal com um VAS padrão associado a si; em seguida, a chamada para a função vas_create() é feita de forma a criar um novo VAS. Após a criação, é preciso anexar o VAS ao processo por meio da chamada de sistema vas_attach(). Por fim, o processo pode mudar entre os VAS por meio da chamada para vas_switch().

O SpaceJMP é um projeto com uma proposta muito interessante: desacoplar o VAS. Essa ideia representa um enorme desafio para ser implementada em SOs de produção, contudo, ela abre precedentes para novos modelos de programação. Em especial, trabalhamos ativamente neste projeto em parceria com a HPe durante esta pesquisa sendo esse 
vas create

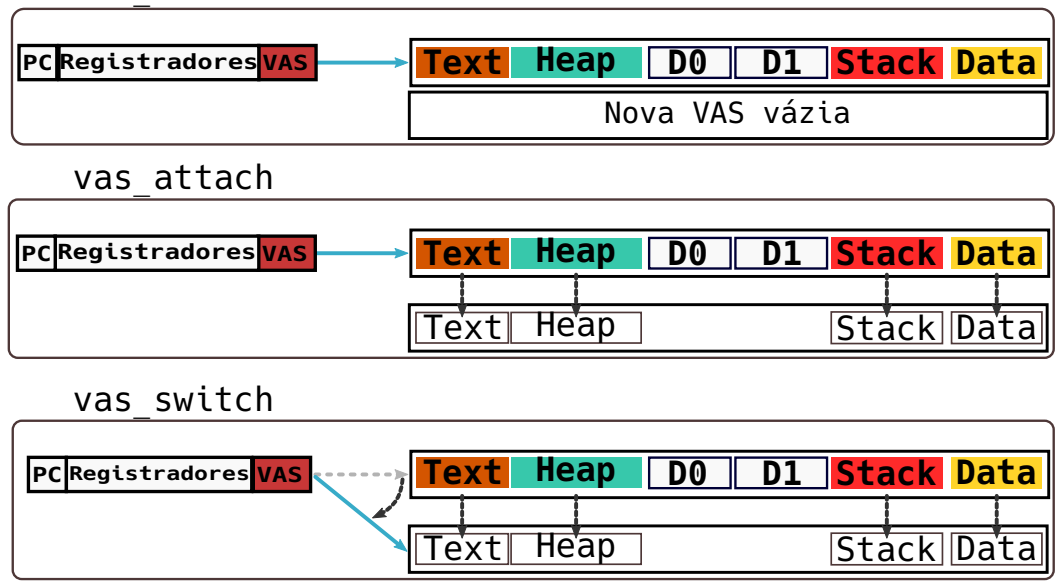

Figura 3.10: System Call disponibilizada pelo SpacefMP (EL HAJJ, MERRITT, ETH et al., s.d.)

um importante trabalho para revelar os desafios em se implementar novas abstrações de processos. Discutiremos com mais detalhes esse trabalho no Capítulo 5; além disso, indiretamente, o SpaceJMP/MVAS foi um dos catalisadores para o parte da pesquisa apresentada no Capítulo 4.

\subsection{Light-weight Contexts}

O fluxo de execução do processo é controlado pelo Program Counter $(P C)$ juntamente com os dados da memória. Por sua vez, o escalonador é a entidade que orquestra quando retirar e inserir um novo processo para execução na CPU. Consequentemente, tanto o PC quando os demais dados do processo são mantidos juntos no nível do kernel.

Litton et al. (2016) afirmam que o desacoplamento do isolamento da memória, estado de execução e separação dos privilégios dos processos trazem benefícios. Com tal ideia em mente, os atores sugerem uma nova abstração de processos chamada de lightweightcontext $(l w C$ ). Basicamente, cada processo pode ter um (lwC root) ou mais lwCs, cada um com o seu próprio mapeamento virtual da memória, descritor de arquivos e credenciais. Opcionalmente, a API do lwC permite controlar quais elementos podem ser compartilháveis ou não entre os lwCs.

Um lwC compreende um mapeamento de memória virtual, uma coleção de mapeamento de páginas, bindings de descritores de arquivos e conjuntos de credenciais; sempre que um novo processo é criado, o sistema cria um novo lwC para ele. A aplicação pode acessar todas as funcionalidades do lwC via espaço do usuário através de chamadas de sistemas que fazem o controle fino dos comportamentos fornecidos.

As chamadas mais interessantes são $\operatorname{lwCreate()}$ e lwSwitch(). O lwCreate() tem uma semântica similar ao da chamada de sistema fork(); assim que a chamada é feita, o processo pai tem os seus dados duplicados no processo filho. Contudo, ao contrário do fork (), o lwCreate () não cria uma nova thread e nem um novo PID. Ao final da execução da chamada de sistema, o lwCreate() retorna um identificador do novo contexto para o processo pai e, se estiver no processo filho, ele retorna -1. A cópia do estado do processo 
pai na forma do contexto, recebe o nome de snapshot. Depois da criação do processo filho, a aplicação é livre para fazer a troca (com o lwSwitch()) para algum de seus snapshots a qualquer momento.

A Figura 3.11 ilustra a operação de troca entre diferentes lwCs. Um processo pode criar vários lwCs durante a sua execução e em diferentes momentos e pode seletivamente escolher transferir o seu fluxo de execução para outro lwC por meio de uma chamada para lwSwitch(). A mudança da thread é feita pelo SO, que é responsável por mudar automaticamente o mapeamento da memória virtual, as entradas das tabelas de arquivos, o PC e o stack pointer.

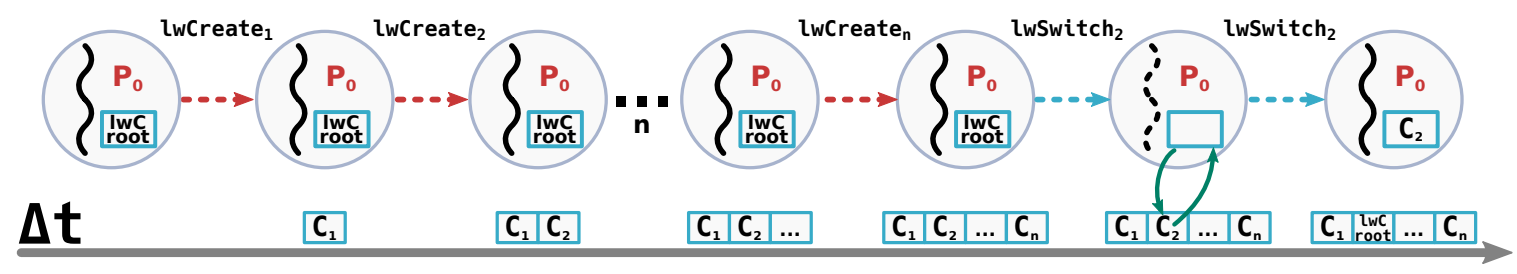

Figura 3.11: Exemplo do comportamento do $l w C$

A interface de lwC também permite que outras operações, como compartilhamento dinâmico ou estático de recursos, controle sobre o acesso as capabilities, emulação de chamadas de sistema e novas camadas de isolamento dentro do processo. Todo o conjunto de chamadas de sistema do lwC fornece um sofisticado modelo de programação que permite novas capacidades tais quais rápido roll-back, isolamento de seções e compartimentos de proteção. A API do lwC é composta das seguintes funções:

- IwCreate(resource-spec, options): Cria um novo contexto de acordo com o estado atual do processo;

- lwSwitch(target, args): Alterna entre os diferentes contextos;

- lwRestrict (1, resource-spec): Permite restringir a forma de acesso ao contexto;

- lwSyscall(target, mask, syscall, syscall-args): Intercepta chamadas de sistema dentro de um contexto permitindo validar permissões de execução.

Os autores demonstram os conceitos do lwC em uma implementação no FreeBSD. As modificações principais foram feitas no gerenciador de memória e estruturas de dados do processo. Seu uso foi demonstrado em adaptações feitas no Apache, Nginx e OpenSSH. Por fim, os autores propõem certos algoritmos que discutiremos no Capítulo 6; esses algoritmos são extremamente interessantes uma vez que representam de forma clara novos modelos de programação.

\subsection{Exokernel}

Introduzimos um trabalho de 1995 chamado de Exokernel que apresenta uma visão de desacoplamento do SO que consideramos moderna e que se alinha com a argumentação que desenvolvemos durante este trabalho. Engler et al. (1995) defendem que os projetos de SOs possuem uma série de desvantagens por terem várias abstrações diretamente programadas 
no núcleo. Os autores argumentam que as abstrações implementadas diretamente no SO possuem sérios impactos no desempenho, reduz consideravelmente a flexibilidade das aplicações e limita as possibilidades de ampliar as funcionalidade disponibilizadas no espaço do usuário. A implementação dessas abstrações diretamente no núcleo do SO são problemática uma vez que: impedem a aplicação de tirar proveito das otimizações que são especificas do seu domínio, as mudanças em tais abstrações são desencorajadas e reduzem as possibilidade do que pode ser feito no espaço de usuário.

Segundo os autores, a fixação das abstrações de alto-nível apresentam as seguintes limitações:

- A degradação do desempenho ocorre uma vez que atender ao maior número de aplicações possível com a mesma abstração tem um custo computacional. Por exemplo, algumas aplicações podem sofrer com o overhead gerado por outras camadas de abstrações;

- As informações de utilização de recursos são escondidas das aplicações, isto dificulta a aplicação ter controle sobre os recursos utilizados;

- As aplicações ficam limitadas a utilizar apenas aquelas interfaces padrão fornecidas pelo SO.

Por fim, com esses problemas em mente e motivados pela antiga observação de que: quanto mais baixo o nível das primitivas (simples), mais eficientemente ela pode ser implementada e maior a amplitude de ação fornecida para abstrações de alto-nível; os autores propuseram uma nova arquitetura de SO chamada exokernel.

Exokernel busca ser um núcleo mínimo que permita multiplexar de forma segura os recursos de hardware e ao mesmo tempo fornecer uma interface de baixo-nível na qual as abstrações do SO podem ser construída sobre ela. Para que seja possível implementar um SO usando este conceito é preciso implementar a chamada biblioteca do SO com acesso aos recursos de baixo nível e com as abstrações construídas nela (p.ex. processos, arquivos, escalonador, etc). Para que a implementação de tal conceito seja possível, os autores os seguintes princípios:

1. Expor o hardware de forma segura: O conceito fundamental do exokernel consistem em exportar de forma segura e controlada o acesso de baixo nível ao hardware, por isto toda implementação do exokernel deve concentrar-se em exportar os privilégios e recursos de máquina. Por isto ele não deve impor abstrações de alto-nível, i.e, o exokernel deve evitar gerir recursos;

2. Expor alocações: Um exokernel deve permitir que uma biblioteca de SO aloque recursos. Além disto, os recursos não devem ser implicitamente alocados uma vez que a biblioteca de SO tem a obrigação de participar de todas as decisões de alocação;

3. Expor nomes: Um exokernel deve exportar nomes físicos. Isto é eficiente uma vez que reduz o nível de indireção, e por sua vez o número de traduções necessárias entre nomes virtuais e físicos. Por fim expor nomes físicos também encapsula atributos de recursos uteis, por exemplo, um sistema de caches fisicamente indexado e diretamente mapeado, tem o nome da página física (i.e. o número da página) determina qual página que conflita; 
4. Expor revogações: Um exokernel deve utilizar um protocolo de revogação de recursos explicitas para que a biblioteca do SO possa gerir os recursos de forma eficiente;

Por fim, além desses princípios o exokernel também deve especificar as políticas para arbitrar a competição entre as bibliotecas do SO. Dado esses princípios o exokernel deve disponibilizar as seguinte tarefas: ligação segura, visibilidade de recursos e protocolo de falha.

A ligação segura (Secure Bindings - SB) é o mecanismo que desacopla a autorização do uso dos recursos. Para implementar o SB é preciso um conjunto de primitivas que a aplicação pode usar para expressar verificações de proteção. Essas podem ser implementadas em hardware ou software, por exemplo, a entrada da TLB é uma primitiva de hardware. Na prática o SB trabalha com o conceito de "baixar o código para o kernel", esse código é chamado para cada acesso ou evento do recurso para determinar o dono e a ação que o Kernel deve tomar. Baixar o código dentro do kernel permite uma thread da aplicação ter controle sobre os eventos. Isto melhora o desempenho uma vez que elimina a camada intermediaria do Kernel e também propícia limitar a aplicação aos seus recursos.

A tarefa de revogação visível é o mecanismo para recuperar os recursos e romper com o SB estabelecidas. Vale observar que este mecanismo pode ser visível ou invisível para a aplicação. Tradicionalmente os SOs realizam a revogação de forma invisível desalocando recursos sem o envolvimento da aplicação. O exokernel utiliza revogação visível para a maioria dos recursos, mesmo o processador é explicitamente revogado ao fim de um tempo de execução determinado de forma que a biblioteca do SO é informada para que possa reagir. O processo de revogação é como um diálogo entre o exokernel e a biblioteca do SO; a biblioteca precisa organizar uma lista de recursos que pode ser desalocado rapidamente.

Por fim, um exokernel pode definir um segundo estágio de revogação no seu protocolo, na qual um pedido se torna um imperativo. Isto ajuda no caso em que a biblioteca do SO falha, então o exokernel pode simplesmente quebrar o SB e informar a biblioteca. Todos as perdas de recursos forçadas são armazenadas em um vetor de recuperação.

\subsection{Considerações Finais}

Neste capítulo buscamos apresentar diversos trabalhos que representam contribuições variadas para a área da abstração de processos. Durante essa pesquisa, vários trabalhos foram analisados, contudo por uma questão prática selecionamos aqueles que trazem propostas diferentes e que podem ser combinadas. No próximo capítulo, faremos uma análise sobre validações de tais trabalhos. 


\section{Capítulo 4}

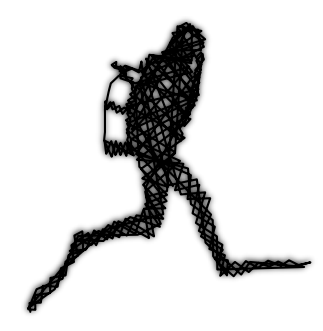

\section{Validação de Novas Abstrações de Processos}

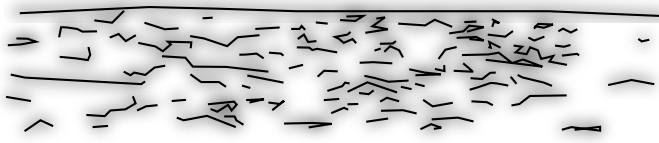

A maioria dos SOs oferecem a infraestrutura necessária para que os processos existam. Eles precisam garantir (1) acesso aos recursos, (2) desempenho, (3) segurança/isolamento e (4) funcionalidades adicionais (p.ex., mutexes). Nesse contexto, melhorias nos SOs devem trazer benefícios em alguma dessas frentes buscando evitar o acréscimo de overhead. Para testar as novas propostas de abstrações, temos as opções de utilizar microbenchmarks e aplicações reais. Aplicações reais são capazes de consumir CPU, realizar diversas operações de leituras e escrita em disco, demandar muita leitura e escrita da memória, gerar intenso tráfego de rede, causar muitas trocas de contexto (pela paralelização), e podem comprometer os caches de memória e disco. Além disso, algumas aplicações possuem necessidades específicas de segurança. Idealmente, qualquer proposta de expandir a abstração de processos deve buscar formas de validação que exercitem todas as características apresentadas.

Na prática, queremos algo que gere uma carga razoável de CPU, disco, rede e paralelismo; além disso, que seja algo relativamente fácil de gerar carga e medir o desempenho. Servidores web, atendem bem esses requisitos: são altamente paralelos, geram bastante $\mathrm{E} / \mathrm{S}$ e tráfego de rede, dependem de algum processamento na CPU e há ferramentas para gerar carga e medir o desempenho. No caso da segurança, faz sentido utilizar aplicações dedicadas, como gnugpg ou openssh, e/ou uma biblioteca, como openssl. Não por acaso, quase todos os trabalhos que avaliamos usam alguma dessas ferramentas para fazer suas validações.

O Capítulo 3 mostrou algumas pesquisas que buscam estender a abstração de processos atual. Apesar dos vários trabalhos demonstrarem algum tipo de benefício, muitos deles ignoram outros aspectos das suas propostas. Por exemplo, uma abordagem que visa isolar dados para evitar vazamento de informações faz testes que buscam por esses tipos de falhas, mas deixam de avaliar se a alteração é viável em um contexto global com uma demanda realista. Adicionalmente, alguns desses trabalhos baseiam-se fortemente em microbenchmarks, que podem evidenciar um resultado desejado sem revelar um efeito 
colateral da alteração. Assim, surge a questão: como avaliar de maneira mais completa e efetiva uma nova abstração? A resposta advém indiretamente dos diversos trabalhos estudados. A ampla maioria das propostas apresentadas no Capítulo 3 alteraram uma ou mais aplicações de uso cotidiano com o objetivo de demonstrar alguma vantagem da alteração na abstração de processo sugerida. Contudo, sistematizar quais aplicações e microbenchmarks podem ser adotadas ainda é um questão pouco discutida; por esse motivos levantamos e respondemos as seguintes perguntas:

QP3: "Quais aplicações podem ser utilizadas para avaliar as novas abstrações adicionadas a um SO?”

QP4:. "Qual conjunto de microbenchmarks pode ser utilizado para auxiliar a entender os impactos de uma nova característica adicionada às abstrações de processos?"

Defendemos que uma das formas mais eficientes para validar uma nova extensão da abstração de processos é por meio de aplicações já consagradas, amplamente adotadas por diversos sistemas e que exercitam várias partes do SO. Por esses motivos, buscamos extrair tais aplicações, dos trabalhos estudados no Capítulo 3, que auxiliam na demonstração de que uma nova proposta de abstração de processos é viável ou não. Buscamos três características: estresse que a aplicação pode gerar, possíveis falhas de segurança e áreas para otimização. Aplicações que consomem muitos recursos de hardware são ideais para comprovar que uma nova extensão é escalável. Por outro lado, várias propostas de novos mecanismos no processo prometem melhorias de segurança e, por esse motivo, sistemas reais que já apresentaram alguma falha de segurança são desejáveis para esse tipo de validação. Algumas pesquisas propõem novos mecanismos dos quais alguns tipos de aplicações podem se beneficiar, como por exemplo, novas formas de compartilhamento de memória e otimizações. Nesses casos, é interessante utilizar alguma aplicação do tipo adequado para a validação.

Outra perspectiva sobre a validação é representada pelos microbenchmarks, que tem por objetivo mensurar e prover formas para analisar uma única característica do objeto de estudo; além disso essa é uma importante ferramenta que auxiliam no estudo dos impactos das alterações. Esses testes são vantajosos durante as etapas iniciais da implementação da nova abstração, uma vez que são rápidos e podem ajudam durante o processo de desenvolvimento. Um conjunto de microbenchmarks pode ser usado para indicar que a nova abstração traz vantagens, contudo, dado o seu alto nível de especialização, ele não consegue revelar possíveis efeitos colaterais ou interferências com outras funcionalidades.

A análise feita sobre as aplicações e microbenchmarks foram originadas dos diversos experimentos realizados pelos pesquisadores que mostramos no Capítulo 3. Além disso, durante esse trabalho, foram conduzidos experimentos que auxiliaram na elaboração das ideias apresentadas nesse capítulo. Esse capítulo pode ser dividido em duas partes: aplicações e microbenchmarks. Primeiramente apresentamos programas que são favoráveis para serem adaptados de forma a utilizar as novas abstrações de processos e, assim, servirem como mecanismo de validação para as propostas. Tentamos ilustrar as características gerais das aplicações de forma a fornecer ideias de possíveis adaptações (discutimos algumas 
delas no Capítulo 6) e também prover ferramentas para o leitor avaliar os trabalhos desse campo. Por fim, apresentamos uma discussão sobre os potenciais microbenchmarks que podem ser utilizados para validar novas extensões nos processos.

\subsection{Servidores Web}

Muitos sistemas possuem máquinas dedicadas a uma aplicação específica com o objetivo de entregar estabilidade, velocidade e estabilidade. Nesses casos, é desejável que a CPU esteja ocupada a maior parte do tempo e use a memória de forma eficiente para evitar desperdício de recursos. Servidores web são aplicações que operam com um desempenho próximo do ótimo utilizando boa parte dos recursos das máquinas para servir páginas web. A principal responsabilidade do servidor web é entregar dados solicitados, que podem vir de um arquivo ou ser gerados especificamente para cada requisição. Uma requisição pode ser divida em três etapas: esperar por uma requisição (request) do usuário, processar a requisição e responder ao usuário.

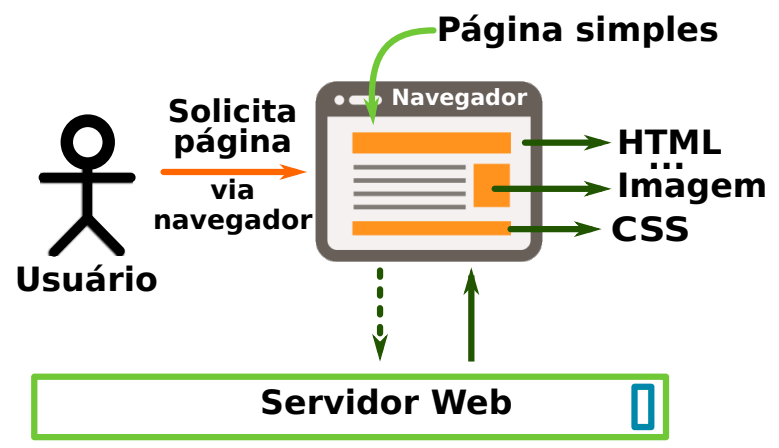

Figura 4.1: Do cliente para o servidor Web. Note que o navegador solicita em paralelo os demais arquivos necessários para a construção da página.

A Figura 4.1 busca exemplificar uma situação simples na qual o cliente solicita uma página web para um servidor. Inicialmente, o cliente (digamos, um navegador web) comunicase com o servidor através do protocolo HTTP para fazer uma solicitação; por sua vez, o servidor responde devolvendo os dados solicitado que contém todas as instruções básicas necessárias para construir a página (HTML). O navegador abre o arquivo HTML retornado, converte o conteúdo e verifica se precisa de mais informações para construir a página solicitada; é comum que a página precise de outros arquivos como CSS, imagens, javascript, etc. Se mais arquivos forem necessários, então o navegador os solicita para o servidor de forma paralela ou serial. O exemplo ilustra de forma simplificada como uma requisição acontece e como múltiplas requisições podem ser geradas para construir uma simples tela. Um exemplo real pode ser considerado da caracterização da carga gerada sobre o site da copa do mundo de 1998 (tenha em mente que hoje as cargas que um servidor precisar suportar são ainda maiores), na qual foi gerado uma média de 10796 requisições/min (ARLITT e Jin, 2000). Um servidor web tem que responder a milhares de usuários e as estratégias utilizadas para lidar com tal volume são as mais variadas.

Dado a enorme demanda que os servidores web precisam suportar, eles buscam diversas técnicas que otimizem a utilização dos recursos. Uma das melhorias disponíveis em alguns 
servidores web nasce da observação de que cada página a ser apresentada para o cliente necessita realizar múltiplas conexões para obter os vários arquivos que a compõem. Esse mecanismo de abrir e fechar conexões constantemente impacta no desempenho uma vez que eleva a latência, tempo gasto abrindo e fechando conexões. Uma possibilidade para minimizar esse impacto é utilizar o mecanismo de keep-alive, que mantém uma conexão aberta durante as atividades do usuário. Por exemplo, a Figura 4.2 mostra um caso que não utiliza keep-alive e outro que utiliza. O primeiro caso ilustra uma situação padrão na qual uma requisição é realizada e, por sua vez, são abertas e fechadas diversas outras conexões de rede para obter cada um dos arquivos necessários para construir a página. O segundo caso ilustra a técnica de keep-alive, cujo o objetivo é reduzir a latência e o uso de CPU no servidor mantendo a conexão aberta por um intervalo de tempo. Esse mecanismo pode melhorar a experiência do usuário ao acessar o site em casos que um servidor esteja recebendo um elevado número de requisições. Contudo, outro aspecto do keep-alive é que ele pode elevar o consumo de memória no servidor, gerando outro tipo de problema em um servidor sobrecarregado. Esses dois mecanismos são importantes elementos a serem considerados durante a realização de experimentos, uma vez que eles modificam o comportamento geral do servidor em certas situações (retomaremos esse tópico no Capítulo 5).

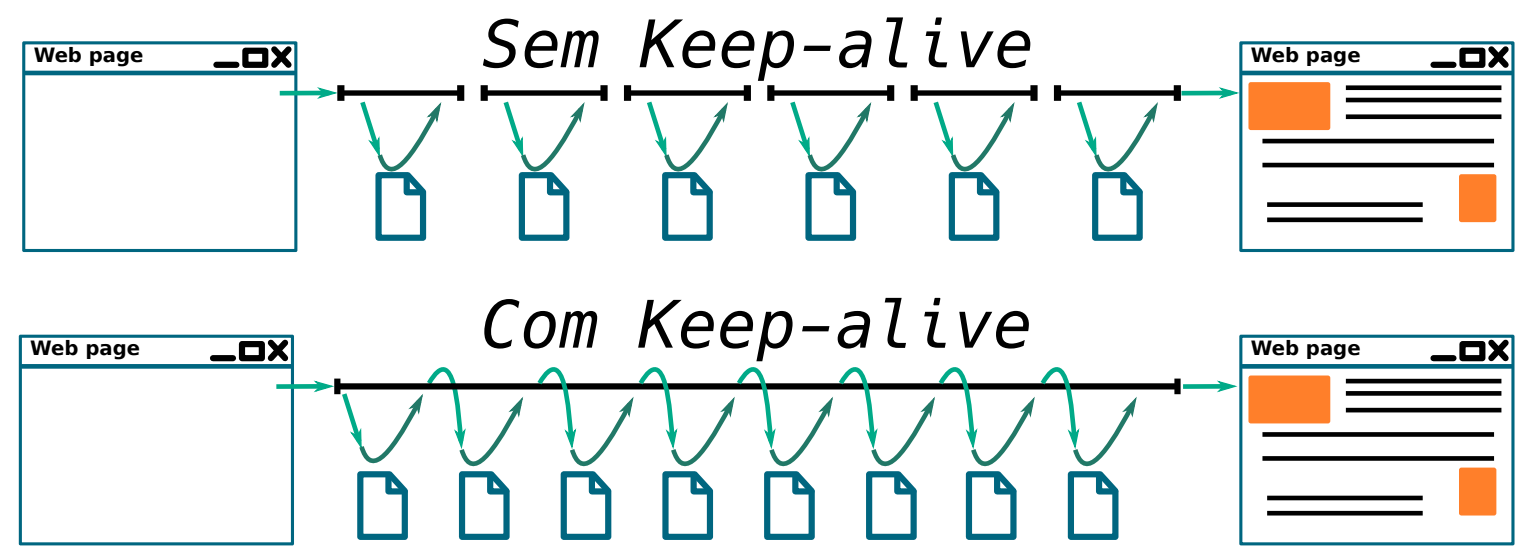

Figura 4.2: Exemplo de uma conexão feita sem keep-alive e outra com keep-alive

Existem muitos servidores web disponíveis no mercado, contudo, dois deles são especialmente relevantes para o contexto deste trabalho: gginx $^{1}$ e Apache Httpd ${ }^{2}$. O primeiro é conhecido pelo seu bom desempenho para entregar arquivos estáticos, enquanto o segundo é conhecido pela sua enorme estabilidade e comodidade. Ambos são amplamente usados, extremamente configuráveis, confiáveis e suportam grandes cargas de requisições. Trabalhos como Light-weight Contexts e shreds fizeram uso desses servidores nos seus experimentos.

\subsubsection{Servidor Apache HTTPD}

O servidor Apache HTTPD, também conhecido como HTTP Daemon (HTTPD) é licenciado com a licença Apache 2.0 e mantido pela fundação Apache. O Apache HTTPD ${ }^{3}$

\footnotetext{
${ }^{1}$ https://www.nginx.com/

${ }^{2}$ https://httpd.apache.org/

${ }^{3}$ Usaremos HTTPD e Apache como sinônimos nesse texto.
} 
foi projetado para executar em vários SOs; essa restrição fez com que fosse necessário adotar estratégias para fazer o HTTPD multiplataforma e mantendo um bom desempenho. Uma característica importante do HTTPD é a sua forte separação em módulos para manipular processos/threads e outros elementos; o conjunto de todos os módulos constituem a arquitetura do projeto. O Apache utiliza a biblioteca Apache Portable Runtime (APR), cuja a intenção é ser utilizada como uma interface portável para as tarefas comuns de programação (p.ex.: alocação de memória, manipulação de tempo, etc). Por fim, o HTTPD implementa um módulo especial chamado Multi-Processing Module (MPM), responsável por manter o processamento das requisições e a lógica de manipulação de processos/threads. O MPM é uma boa fonte de comparação entre diferentes modelos de processos.

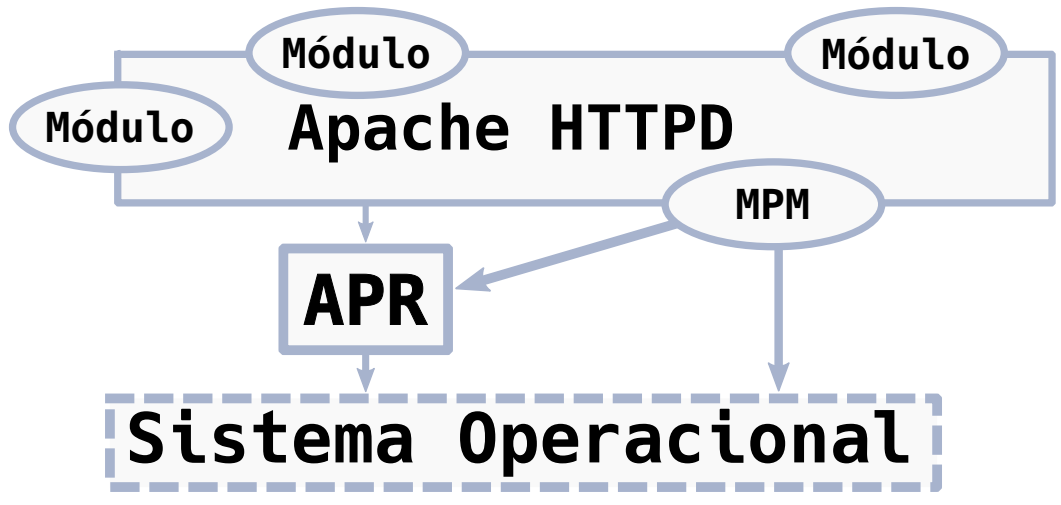

Figura 4.3: Arquitetura do servidor Apache HTTP (KEW, 2007)

A Figura 4.3 é uma visão de alto nível da arquitetura do Apache. O topo da imagem representa os elementos do núcleo do Apache responsáveis por juntar os demais componentes necessários para o seu funcionamento. Ao redor do núcleo, existe um grande número de módulos anexados que podem ser conectados ao projeto. Esses módulos facilitam o processo de adicionar e remover elementos do núcleo, normalmente como bibliotecas dinâmicas. Módulos na forma de bibliotecas dinamicamente ligadas fornecem flexibilidade, um bom desempenho e portabilidade entre diferentes SOs (p.ex., Windows e Linux podem ter diferentes implementações para o mesmo módulo). A Figura 4.3 também ilustra o MPM como um componente diretamente conectado ao SO, porque o MPM manipula os elementos de paralelização e cada SO precisa implementar essa parte de acordo com as suas próprias particularidades. A última parte da imagem mostra a biblioteca APR, que se posiciona entre o núcleo do HTTPD e o SO.

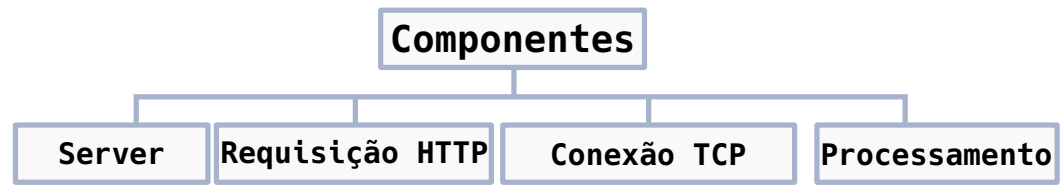

Figura 4.4: Componentes do Servidor Apache HTTP

Alguns módulos são essenciais para o funcionamento do HTTPD, uma vez que eles representam os elementos básicos das estruturas de dados que são usadas por todo o código. A Figura 4.4 mostra alguns componentes fundamentais usadas pelo HTTPD. O módulo server é responsável por criar uma estrutura de dados para a requisição toda vez 
que o HTTPD aceita uma nova conexão. O módulo HTTP é encarregado de preencher uma estrutura de dados de requisição e o módulo de conexão TCP constrói a estrutura de dados que mantém as informações da conexão. Normalmente, não é preciso se preocupar com módulos relacionados aos detalhes do HTTP, uma vez que o Apache ajusta todos os elementos necessários e também entrega uma estrutura de dados pronta para ser utilizada.

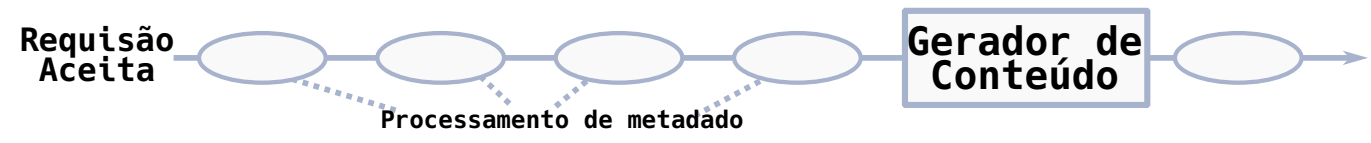

Figura 4.5: Gerador de Conteúdo (KEW, 2007)

Outros dois aspectos da arquitetura do Apache são o Content Generator (Gerador de Conteúdo) e as fases de processamento das requisições. O Content Generator pode ser visto como o núcleo do Apache, uma vez que ele é responsável pelas operações de escutar por requisições e devolver respostas; existe exatamente um gerador de conteúdo por requisição. No Apache, um módulo pode registrar um content generator de forma simples (basta ajustar o httpd.conf) e, se nenhum estiver disponível, ele utiliza o gerador padrão que simplesmente mapeia um arquivo para uma requisição (KEw, 2007). O content generator pode processar toda a requisição sozinho, contudo o Apache divide a request em várias fases como pode ser visto na Figura 4.5. Alterações nessas fases podem ser extremamente proveitosas para testar novas abstrações de processos.

\section{MPM}

O módulo Multi-Processing (MPM) é um elemento especial dentro do Apache. Como a Seção 4.1.1 introduziu, o MPM funciona como uma interface entre o HTTPD e o SO. O MPM tem três características principais para qualquer instância do Apache: deve ser único, é obrigatório e tem uma implementação específica para o SO alvo. O HTTPD fornece pelo menos um módulo MPM por SO; por exemplo, Windows utiliza mpm_winnt e Linux tem três opções diferentes. Cada uma delas pode ser classificada como baseada em processos ou em threads. São elas: Prefork, Worker e Event. Esses módulos constituem bons pontos para comparar threads e processos usando as novas abstrações, uma vez que apenas um ponto isolado do Apache é alterado; isso faz com que o comportamento padrão do HTTPD seja conservado e assim a comparação entre diferentes abordagens ocorra de forma mais justa. Em outras palavras, alterar o módulo de multi-processamento do Apache conserva o ambiente de teste e fornece comparações mais precisas.

Prefork: foi a primeira estratégia adotada pelo HTTPD e é totalmente baseado em processos. A Figura 4.6 ilustra os três passos realizados pelo Prefork. O Apache inicia com um processo responsável por gerir os filhos que serão encarregados de manipular uma requisição por vez. Em seguida, ao receber uma requisição, o processo de controle identifica um processo filho que esteja ocioso e repassa a requisição para ele, que se encarrega da tarefa de tratar a solicitação. Caso não exista nenhum processo filho disponível para manipular a requisição, o processo de controle cria novos processos filhos. Repare que o processo de controle comporta-se como um balanceador de carga. 


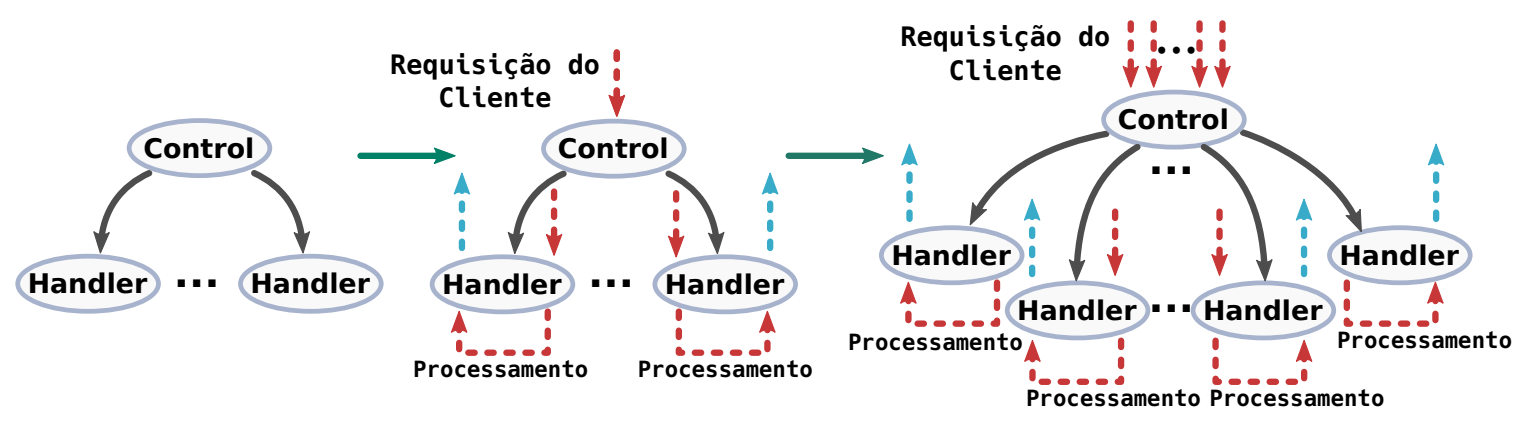

Figura 4.6: Prefork

Prefork é uma boa opção para servidores web que não são compatíveis com threads (p.ex., pela utilização de aplicações legadas escritas em PHP) e é a melhor opção de MPM para isolar requisições recebidadas pelo Apache. Contudo, Prefork consome muita memória e CPU, o que não é desejável em um servidor sob forte demanda.

Worker : é uma solução híbrida, uma vez que seu design é baseado em processos e threads. Esse módulo tem um processo de controle que também é responsável por criar processos filhos e controlar o balanceamento da carga entre eles. Ao contrário de Prefork, Worker não cria instâncias de processos filhos para manipular requisições feitas pelos clientes: ao invés disso, cada filho possui várias threads para realizar o tratamento das requisições. Comumente, o HTTPD tem que manipular uma grande carga de requisições e, nesses casos, o processo de controle age criando novos filhos (cada um com um conjunto de threads) para suportar a carga. Repare que Worker utiliza threads para manipular as requisições, fazendo com que o total de processos filhos criado seja relativamente pequeno (comparado com o Prefork) e, consequentemente, o consumo de memória seja reduzido. O HTTPD tem um arquivo de configuração que permite um controle fino de todos os parâmetros relacionados ao número máximo de processos filhos, o total de threads por filho, dentre outros.

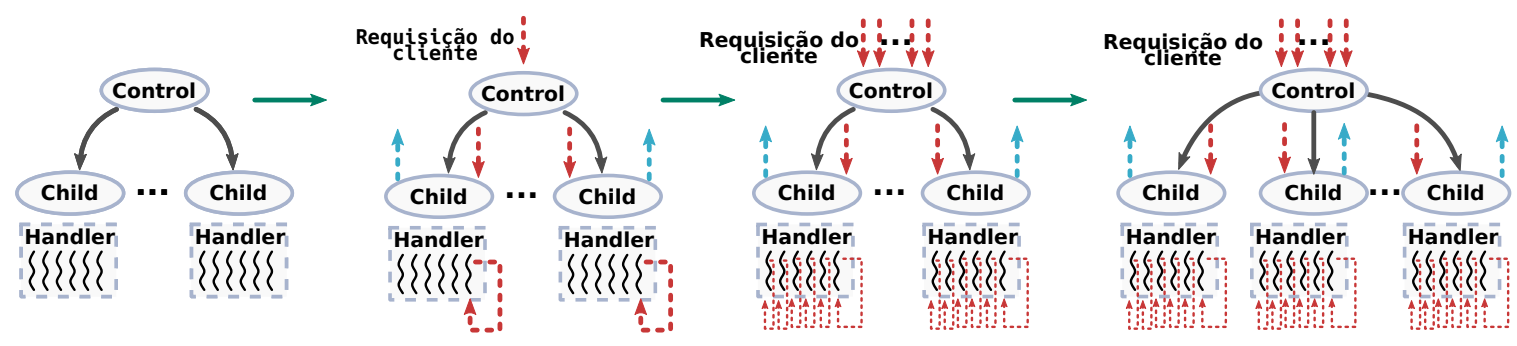

Figura 4.7: Worker

A Figura 4.7 é um exemplo de como o Worker funciona. Quando o Apache inicia, ele tem um processo de controle e alguns processos filhos que mantêm um grupo de threads paradas. A segunda parte da figura representa o caso em que o HTTPD recebe um grande número de requisições e o processo de controle cria mais filhos para suportar a carga. O Worker consome menos memória que o Prefork e, consequentemente, é melhor em casos nos quais o servidor está sobrecarregado. A mistura de processo e thread adiciona estabilidade para todo o sistema.

Event: O módulo Event é baseado em threads e é o padrão na última versão do Apache. A 
Figura 4.8 ilustra o comportamento básico de Event. A forma na qual Event opera é similar à do Worker, contudo esse mecanismo diferencia-se por dois elementos extras: mecanismo de manipulação do keep-alive e separação da responsabilidade de transmitir os dados para o cliente. O processo extra, incumbido de enviar as informações para o cliente, comunica-se com as diversas threads que manipulam as requisições e tomam para si a responsabilidade de enviar os dados processados.

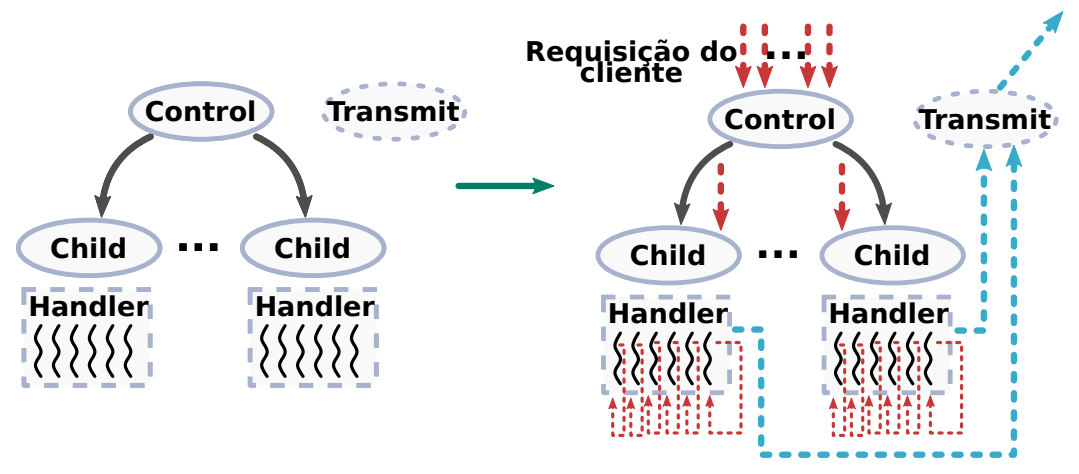

Figura 4.8: Event

\subsubsection{Nginx}

Assim como o Apache HTTPD, Nginx é um servidor web, contudo ele diferencia-se de muitas formas dos servidores web tradicionais. A sua principal característica é o seu excelente desempenho para atender requisições, principalmente aquelas relacionadas a arquivos estáticos. Além disso, o Nginx é comumente usado como um reverse-proxy; ele recebe uma requisição do usuário, por sua vez ele repassa a requisição para uma aplicação específica responsável por realizar o processamento (p.ex. Puma, PHP-FPM, etc). Quando o dado é processado pela aplicação, ela devolve o resultado para o Nginx, que repassa os dados para o usuário (SonI, 2016). A Figura 4.9 ilustra o funcionamento geral do Nginx; note que, neste exemplo, a requisição do usuário chega ao servidor criptografada por meio do protocolo SSL (vide Seção 4.2.1). Em seguida, o Nginx trata a solicitação transformando-a em HTTP; por fim, o processo termina repassando-a para algum serviço.

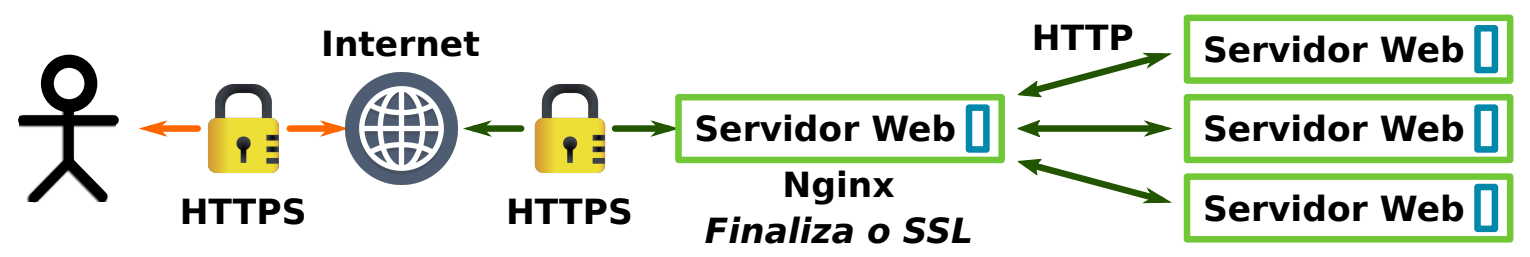

Figura 4.9: Nginx comportando-se como reverse-proxy (SONI, 2016)

A grande maioria dos servidores web, inclusive o Apache, busca tirar o máximo de proveito dos recursos de hardware utilizando um elevado número de threads e processos. Essa abordagem é relativamente simples de ser implementada e traz bons resultados, contudo também tem alguns problemas. Dentre as desvantagens, o modelo baseado em threads/processos gera uma grande quantidade de operações que bloqueiam e, consequentemente, geram trocas de contexto. Além disso, a abordagem baseada em threads/processos 
consome uma elevada quantidade de recursos (p.ex. memória, descritores de arquivos e CPU), degradando o desempenho da aplicação em situações de elevada demanda.

O Nginx utiliza uma outra abordagem de servidor web, baseada na ideia de eventos; esse mecanismo, é uma técnica baseada em requisições de E/S assíncronas. Por uma questão histórica o Apache não faz uso desse método pois as operações de E/S assíncronas não funcionavam bem nas suas primeiras versões no Linux. A estratégia de eventos parte do princípio de que deve-se evitar ao máximo a troca de contexto e, assim, tirar o máximo de proveito da CPU com processamento útil. Por esse motivo, Nginx cria apenas três tipos de processos (Inside NGINX: How We Designed for Performance and Scale 2015):

- Processo mestre, que faz operações privilegiadas como ler arquivos de configuração e acessar portas;

- Processo de cache de disco, que carrega dados do disco fazendo cache na memória;

- Processo gestor de cache, que gerencia o cache e que realiza verificações sobre ele periodicamente;

- Processos Worker, que fazem o trabalho de manipular conexões, ler e escrever em disco e comunicar-se com os clientes.

Nginx recomenda um Worker por núcleo da $\mathrm{CPU}$, o que permite tirar grande proveito dos eventos.

Na prática, o sistema de eventos é eficiente pois gera poucos bloqueios (comparado com o modelo que utiliza threads/processos), uma vez que não espera a aplicação terminar o que está fazendo para iniciar outra atividade. Por exemplo, se o worker estiver atendendo uma requisição e, em um determinado momento, precisar recuperar uma informação do disco, ele não bloqueia, mas simplesmente vai fazer outra tarefa e salva o evento referente à busca no disco para retornar a ele depois (mais precisamente, quando surgir um evento). O sistema de eventos faz com que um único worker execute múltiplas tarefas de forma sequencial sem bloqueio e, consequentemente, com poucas trocas de contexto.

\subsection{Ferramentas de Comunicação Criptografada}

Como mostrado no Capítulo 3, algumas das novas propostas de abstrações de processos levam melhorias de segurança para o espaço de usuário. Nesse sentido, aplicações que envolvem mecanismos de criptografia ou que têm algum requisito especial de segurança representam bons casos de uso para validar novas abstrações. Esse tipo de software costuma ser desenvolvido por uma comunidade de especialistas na área de segurança, o que significa que levar melhorias a esse tipo de ferramenta não é uma tarefa trivial. Por uma questão de simplicidade e abrangência selecionamos dos diversos trabalhos discutidos no Capítulo 3 , duas ferramentas amplamente utilizadas: OpenSSH e OpenSSL.

\subsubsection{OpenSSL}

Antes de discutir o pacote OpenSSL, é importante apresentar de forma geral o protocolo Secure Sockets Layers (SSL). O principal objetivo de SSL é fornecer um conjunto de 
protocolos criptográficos que permita a comunicação segura em rede. É uma ferramenta de uso cotidiano, e diversas aplicações críticas à missão dependendo dele, o que o torna um constante alvo de ataques (existem mais de 200 CVEs reportadas para essa ferramenta $\left.^{4}\right)$.

O SSL utiliza um mecanismo chamado handshake, que nada mais é do que um processo de negociação entre o cliente e o servidor de uma conexão de rede, de forma a criar uma conexão segura entre ambos. A Figura 4.10 descreve de forma geral os passos da negociação. $\mathrm{O}$ processo de handshake começa com o cliente mandando uma mensagem do tipo "Oi, sou o cliente" para o servidor; nessa mensagem, o cliente informa a versão do SSL que está usando, os algoritmos de criptografia e os métodos de compressão que ele sabe manipular. O servidor, por sua vez, responde com "Oi, sou o servidor", dizendo qual algoritmo usar (selecionado da lista que o cliente mandou), um ID da sessão, um certificado digital e a sua chave pública. Com o certificado, o cliente consulta uma Autoridade Certificadora (Certificate Authority - $C A$ ) que valida se o servidor é valido ou não, estabelecendo a confiança sobre o servidor. Depois que o cliente recebe a validação da CA, ele começa a etapa de troca de chaves, na qual o cliente envia uma chave secreta compartilhável. O cliente criptografa essa chave com a chave pública fornecida pelo servidor antes do envio e termina enviando uma mensagem de fim. O servidor decriptografa a mensagem do cliente e utiliza a chave enviada para criptografar uma mensagem de fim para ser enviada para o cliente. Quando o handshake termina, o servidor e o cliente podem enviar mensagens que são simetricamente criptografadas com a chave compartilhada (RISTIC, 2013).

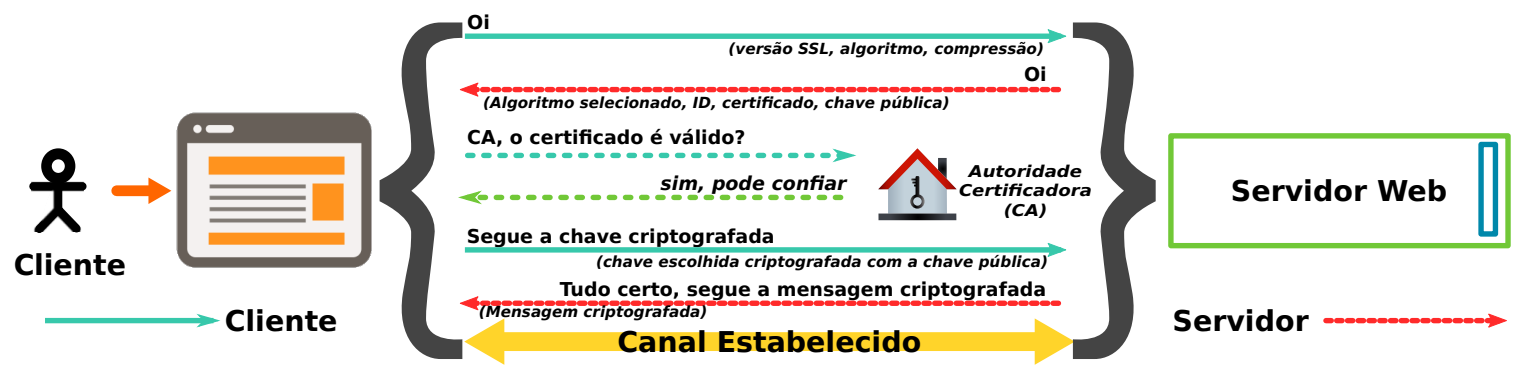

Figura 4.10: Do cliente para o servidor Web

O OpenSSL é uma implementação livre do protocolo SSL que inclui várias funções criptográficas e utilitárias. A Figura 4.11 mostra uma visão geral da arquitetura do OpenSSL. O EVP crypto API são funções de alto nível que fornecem recursos para derivação de chaves, hash seguro, código de autenticação de mensagens, criptografia/decriptografia de algoritmos simétricos/assimétricos, dentre outros. A arquitetura também fornece uma pilha de manipulação de erros e uma interface abstrata para lidar com E/S.

Dado a sua versatilidade e constante aprimoramento, o OpenSSL tornou-se uma das ferramentas mais utilizadas por diversos projetos consagrados. Dentre eles destacamse:

Apache-SSL/mod_ssl: módulo do Apache que fornece suporte para utilizar protocolos de criptografia;

\footnotetext{
${ }^{4}$ https://cve.mitre.org/cgi-bin/cvekey.cgi?keyword=OpenSSL
} 


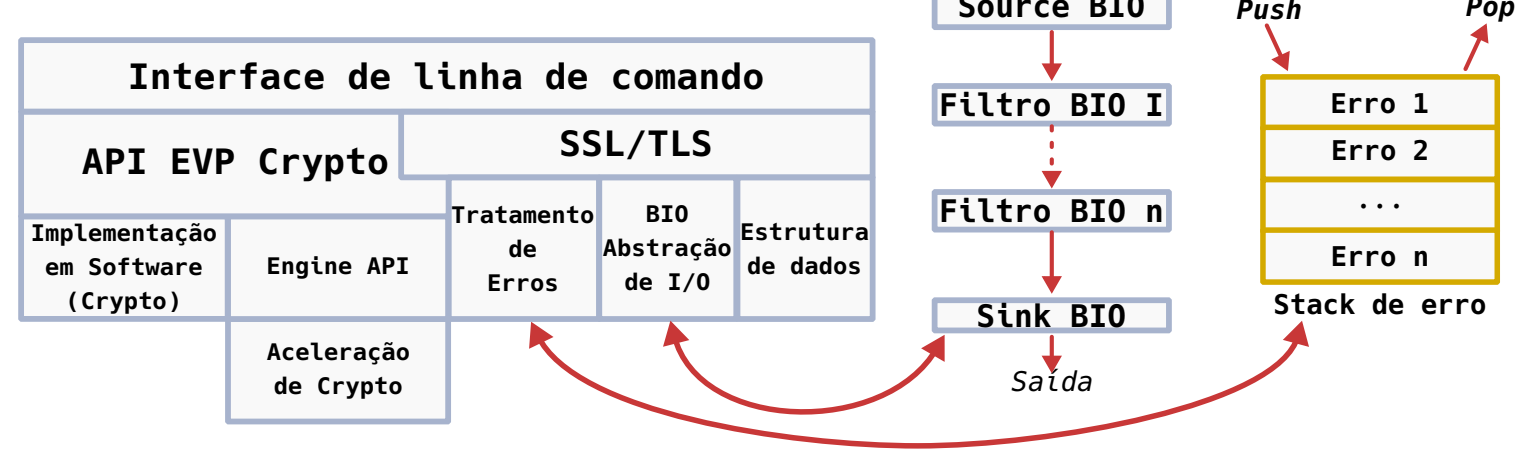

Figura 4.11: Arquitetura do OpenSSL (Crypto With OpenSSL 2008)

Net::SSLeay: módulo Perl que funciona como uma interface para as operações fornecidas pelo OpenSSL sendo amplamente utilizado por diversas aplicações escritas em Perl;

cURL: software que fornece uma biblioteca e ferramentas de linha de comando para transferir dados usando diversos protocolos (p.ex., FTP, HTTP, HTTPS, GOPHER e DICT);

Samba: popular sistema de compartilhamento de arquivos integrado com vários clientes;

OpenSSH: conjunto de utilitários que fornece um canal seguro de comunicação em rede (discutiremos sobre essa ferramenta na próxima seção).

As aplicações citadas acima representam apenas algumas das ferramentas que utilizam o OpenSSL, note que alterações nessa biblioteca impactam diretamente em uma ampla variedade de ferramentas. Dado a sua vasta utilização, várias vulnerabilidades foram encontradas e catalogadas na forma de Vulnerabilidades e Exposições Comuns (Common Vulnerabilities and Exposures - CVE). A CVE é um sistema que fornece de forma pública e metodológica, informações sobre uma vulnerabilidade conhecidas. Dentre as CVEs registradas do OpenSSL destacamos apenas duas com o objetivo de ilustrar como abrações de processos podem demonstrar melhorias na prática, segue:

Heartbleed: Das versões 1.0.1 até 1.0.1f do OpenSSL é possível encontrar uma falha de segurança chamada de Sagramento do Coração; essa falha nasce de um erro de implementação, em uma extensão chamada de heartbeat (batida do coração). O heartbeat é um mecanismo que permite ao cliente manter a conexão segura por mais tempo, para isso o cliente solicita um byte de informação toda vez que tenta manter a conexão ("batimento do coração"). Contudo, o OpenSSL cegamente acreditava no valor solicitado sem realizar qualquer tipo de validação; isso permitia que alguém solicitasse mais dados da memória do que o permitido ("sangramento do coração"). Essa falha permite que um agressor consiga roubar ou vazar informações como nomes e senhas de usuários; em casos extremos, pode ser possível recuperar a chave privada usada pelo OpenSSL ${ }^{5}$.

CCS Injection Vulnerability: As versões 0.9.8za, 1.0.0m e 1.0.1h do OpenSSL são com-

\footnotetext{
${ }^{5}$ https://cve.mitre.org/cgi-bin/cvename.cgi?name=CVE-2014-0160
} 
prometidas com essa falha. Essa vulnerabilidade pode ser explorada por um atacante que fique entre o cliente e o servidor. Basicamente, o agressor captura as requisições feitas durante o handshake (Figura 4.10) e manipula a chave que será usada para criptografar o tráfego. Essa falha ocorre devido a fraquezas no método de gerar chaves ${ }^{6}$.

Propostas de extensão da abstração de processos que pretendem trazer melhorias de segurança, podem utilizar versões comprometidas do OpenSSL e tentar mostrar que a nova abstração resolve um problema real. O pesquisador pode consultar a longa lista de CVEs, selecionar um dos problemas, replicar e em seguida resolver a falha utilizando a sua proposta. Dado a ampla utilização do OpenSSL, fica claro o impacto de propostas que tragam melhorias de segurança para tal ferramenta.

\subsubsection{OpenSSH}

Uma das tarefas mais comuns do dia-a-dia de muitos desenvolvedores e administradores de sistemas, consiste em acessar servidores em diversos locais do mundo e configurar uma determinada aplicação. Na prática, boa parte dos profissionais de TI faz uso de conexões seguras na Internet por meio do protocolo Secure Shell (SSH). Existem diversas implementações desse protocolo, mas para este trabalho discutiremos o OpenSSH.

A Figura 4.12 apresenta uma visão geral da arquitetura do OpenSSH. Primeiramente, repare que as três camadas correspondentes às camadas SSH encontram-se sobre a camada $\mathrm{TCP} / \mathrm{IP}$, que consiste em uma conexão não segura. A primeira camada se chama sshtransport e é responsável por realizar operações criptográficas, pela proteção contra ataques e por reverificar chaves de tempos em tempos. Logo após a primeira camada temos o ssh-userauth, que é responsável pela autenticação: se tudo der certo durante a autenticação, então a troca de chaves acontece e a conexão segura é estabelecida. Por fim, a camada ssh-connection estabelece um canal seguro e fica responsável por gerir a multiplexação de múltiplas conexões e redirecionamentos (STAHNKE, 2005; VenkATACHALAM, 2007).

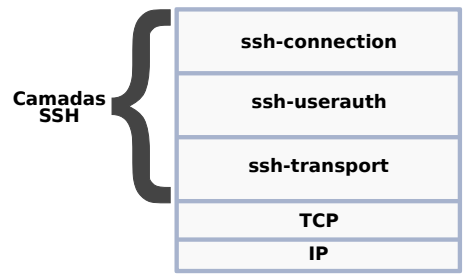

Figura 4.12: Camadas SSH (VENKATACHALAM, 2007)

Dada a enorme importância do OpenSSH, ele é alvo de constantes ataques e, consequentemente, recebe diversas melhorias do ponto de vista do desenvolvimentos e de adoção de novas técnicas mais seguras. Como resultado, algumas CVEs foram criadas e resolvidas no OpenSSH. Dentre as CVEs destacamos:

Escalada de privilégios: Das versões 6.8 até a 6.9 do OpenSSH, existiu uma vulnerabilidade conhecida como escalada de privilégios (privilege escalation). Este tipo de vulnerabilidade descreve um cenário na qual um atacante é capaz de enganar o

\footnotetext{
${ }^{6}$ https://cve.mitre.org/cgi-bin/cvename.cgi?name=CVE-2014-0224
} 
sistema de forma a fazer com que ele ofereça permissões extras ou de outro usuário. Era possível realizar esse ataque por meio da opção TIOCSTI passada para a função ioctl(), que permitia injetar caracteres dentro do terminal do usuário e assim executar qualquer comando ${ }^{7}$.

Recuperação de Texto Simples contra cifras CBC: Quando o OpenSSH utiliza algoritmo de criptografia em bloco em modo Criptografia de Blocos Encadeados (Cipher Block Chaining $(C B C)$ ), fica relativamente simples para um atacante remotamente recuperar pedaços de textos de blocos criptografados em uma sessão SSH. Essa vulnerabilidade foi mitigada na versão 5.2 do OpenSSH${ }^{8}$.

Do ponto de vista do uso de tal aplicação para validar propostas de abstrações de processos, destacamos que ela pode ser usada para demonstrar ganhos de segurança e controle de acesso à memória. Uma abordagem é partir de uma versão antiga do OpenSSH, que não tem a correção para alguma vulnerabilidade, e demonstrar que a nova abstração sugerida consegue resolver o problema.

\subsection{Outras Aplicações}

As propostas de novas abstrações de processos podem levar benefícios para outras áreas além das mostradas nas Seções 4.1 e 4.2. Por esse motivo, apresentamos algumas ferramentas que são de ampla utilização no mercado e que podem ser utilizadas na validação da utilidades de algumas das novas abstrações mencionadas no capítulo 3.

\subsubsection{Redis}

Fazer alguns sistemas capazes de operar em grande escala não é uma tarefa trivial e exige constantes ajustes. Como resultado dessa necessidade, surgiu o sistema Redis, que implementa a ideia de utilizar um sistema que pode ser um cache e, ao mesmo tempo, um mecanismo de armazenamento de dados utilizando a memória principal (RAM) com o objetivo de levar ganhos de desempenho para a aplicação. O Redis também salva os dados da memória para o disco, o que permite que, posteriormente, ele consiga reconstruir o sistema na memória.

O Redis é conhecido por utilizar como forma de armazenamento o esquema de chavevalor (key-value). Essa técnica permite o armazenamento dos dados na forma de um par que consiste de uma chave identificadora e um valor associado a ela. Quando um valor-chave é salvo, o par passa a estar presente na RAM. No Redis, uma chave tem que ser uma cadeia de caracteres, mas seus valores podem ser de vários tipos diferentes. Dentre as abstrações de dados oferecidas por ele, destacam-se:

- Lista de strings

- Conjunto de strings

- Conjunto de strings ordenadas

\footnotetext{
${ }^{7}$ https://cve.mitre.org/cgi-bin/cvename.cgi?name=CVE-2015-6565

${ }^{8} \mathrm{https}: / /$ cve.mitre.org/cgi-bin/cvename.cgi?name $=$ CVE-2008-5161
} 
- Tabelas de hash na qual a chave e valor são strings

- HyperLogLogs

- Stream de entradas com grupos de consumidores

- Dados Geoespaciais

O tipo utilizado no valor determina qual operação é possível de ser aplicada. De forma geral, o Redis permite realizar operações de alto nível (p.ex., uniões e diferenças).

A Figura 4.13 apresenta uma visão de geral da organização do Redis. Repare que ele fornece uma interface de interação do lado do cliente (via linha de comando ou API) e possui um servidor que é responsável por gerir os dados na memória e em disco. A implementação faz constante uso da criação de processos (via chamada de sistema fork()). Basicamente, toda vez que um armazenamento é necessário, o Redis faz um fork() do processo pai; em seguida, o processo filho dá início ao processo de escrita em disco enquanto o processo pai continua realizando as suas tarefas.

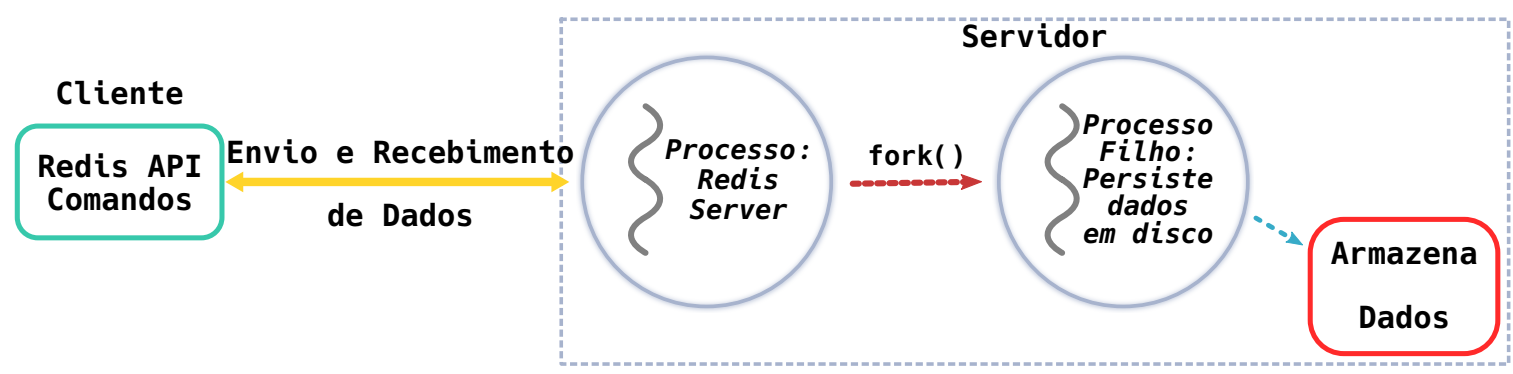

Figura 4.13: Visão geral do funcionamento do Redis

Um dos aspectos mais interessante de Redis, da perspectiva das novas abstrações de processo é o mecanismo de persistência dos dados. Redis pode utilizar três: (Redis Persistence 2018): Relational Database (RDB), Append-Only-File (AOF) e o comando SAVE. RDB faz uma cópia de todos os dados presentes na memória para o disco. Por padrão, Redis escreve os dados a cada dois segundos. Repare que RDB pode causar perda de dados em caso de mau funcionamento; uma alternativa seria configurá-lo para fazer mais escritas, contudo isso elevaria consideravelmente o consumo de memória pela natureza do uso de fork(). AOF registra todas as operações de escrita feitas pelo servidor, logo tudo é persistido. AOF tem o problema de que pode ser mais lento do que RDB, a depender da política de sincronização adotada, e também consumir mais memória. Por fim, o comando SAVE força o servidor a criar um dump dos dados no momento em que foi solicitado.

Do ponto de vista das novas abstração de processos, o Redis pode ser utilizado para testar propostas que visam trazer melhorias para a forma como os dados são compartilhados. Além disso, ele pode ser utilizado para testar formas mais eficientes e confiável de persistir os dados da memória para o disco.

\subsubsection{Coleta Automática de Lixo (GC)}

Várias linguagens de alto nível possuem mecanismos de gerenciamento automático de recursos (p.ex., memória, processamento paralelo, etc.) que garantem a portabilidade da 
aplicação e removem a complexidade de ter que gerenciar recursos de baixo nível. Dentre as vantagens de tais tecnologias, destacam-se o fato de que o programador pode manter o foco nas características da aplicação e também a redução nas chances de erros graves. Java é uma representante desse tipo de linguagem, fornecendo mecanismos de gerenciamento automático da memória e sendo portável para múltiplas plataformas. Por uma questão de simplicidade, iremos adotar Java para as discussões desta seção. Toda a flexibilidade oferecida por Java deve-se ao uso da fava Virtual Machine (JVM), que fornece elementos para a manipulação dos recursos do SO. Um dos principais elementos da JVM é o Coletor de Lixo (Garbage Collector - GC), cuja principal tarefa consiste em abstrair o gerenciamento de memória da aplicação de forma que ela não tenha que lidar com tal aspecto (alocar e desalocar memória). Dado o seu impacto, o GC tem sido alvo de constantes otimizações ao longo dos anos e esse é um elemento que pode se beneficiar de novos recursos oferecidos por extensões às abstrações de processos.

O coletor de lixo é um módulo que é parte da JVM, executando junto com a aplicação. Vários algoritmos de gerenciamento de memória implementado pelo GC, fazem uso de uma técnica chamada de Stop the World (STW) ou Parar tudo (CLICK et al., 2005). O STW é uma operação realizada pela JVM na qual todas as threads da aplicação são suspensas para que o GC execute. Em outras palavras, a única thread executando será a do coletor. Note que o GC requer essa pausa para funcionar; isso é preciso pois seus algoritmos precisam que aplicação não faça nenhuma atualização da memória durante uma das fases do processo de limpeza da memória.

Existem diversos algoritmos que podem ser adotados pelo GC, contudo podemos generalizar três etapas gerais: Marking, Sweep e Compact. A etapa de Marking, também conhecida por pintura, consiste em inspecionar os objetos na memória para verificar quais ainda são considerados "vivos". Para determinar se um objeto está vivo, o GC começa por elementos conhecidos como objetos raiz ou Garbage Collection Roots. Os seguintes componentes são considerados GC roots: variáveis locais, entrada de parâmetros, threads ativas, campos estáticos e referências JNI (GC Algorithms: Basics 2018). Partindo de um GC raiz, o GC atravessa o grafo dos objetos alcançáveis e, para cada elemento que consegue acessar, ele "pinta" a referência como viva. A Figura 4.14 ilustra o algoritmo descrito. No contexto do GC, o processo de parar as threads para que a JVM possa executar a etapa de Marking recebe o nome de safe point (ponto seguro) e essa gera um evento STW. O tamanho da pausa é definido pela quantidade de objetos alcançáveis e seu tamanho no heap.

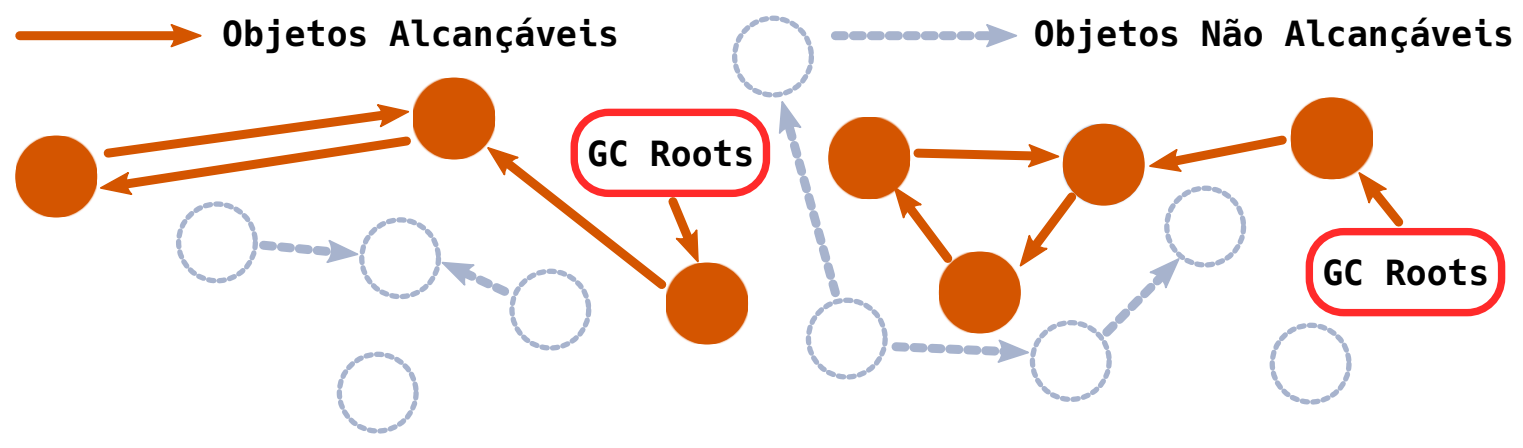

Figura 4.14: Algoritmo de pintura da memória(GC Algorithms: Basics 2018) 
Depois da etapa de pintar os objetos na memória, entra em ação a etapa de remover os objetos que não foram pintados; note que essa etapa pode acontecer em paralelo ou não, dependendo do algoritmo adotado. O processo de remoção pode gerar fragmentação na memória, o que pode representar um problema, uma vez que o GC pode não encontrar espaços de memória grandes o suficiente para outros objetos. Por isso, também existe uma fase de compactação, na qual o GC realoca os objetos pintados para liberar espaço contíguo. Contudo, para que a compactação aconteça corretamente, as referências dos objetos têm que ser atualizadas, uma vez que a posição física dos objetos mudou. O processo de atualizar as referências chama-se remapeamento e precisa examinar toda a memória para realizar os ajustes. Note que a etapa de compactação eleva o tempo de STW. A Figura 4.15 apresenta uma visão da memória durante as três etapas descritas.

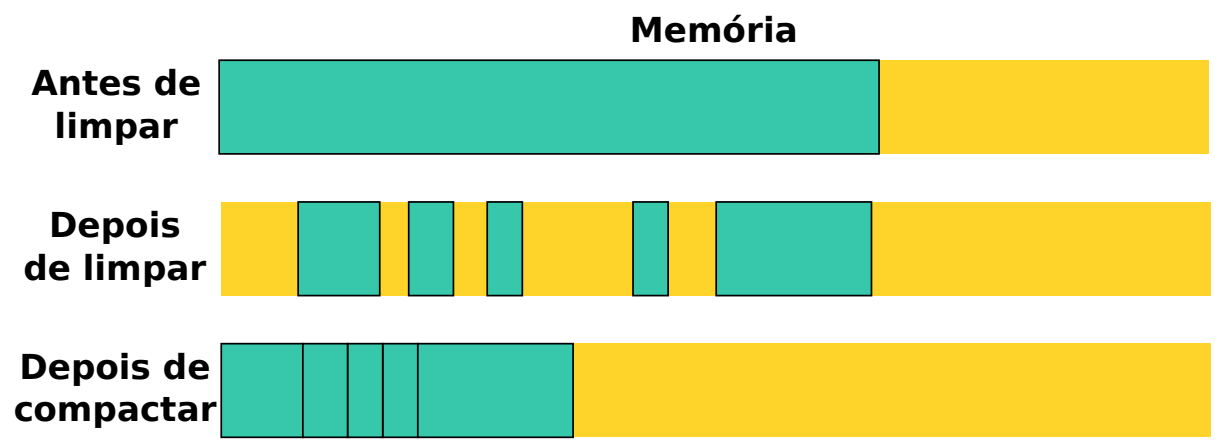

Figura 4.15: Visão da memória durante a aplicação do algoritmo de GC(GC Algorithms: Basics 2018)

Vale salientar que existem diversos algoritmos de GC, cada um com suas vantagens e desvantagens; nosso objetivo nessa seção é apenas ilustrar o potencial de uso de tal aplicação para validar novas abstrações de processos.

\subsection{Discussão Sobre as Aplicações}

Desde o começo deste capítulo até esta seção, apresentamos algumas aplicações destacando o seu funcionamento, estruturas básicas e os recursos exigidos por elas. Contudo, o nosso principal objetivo é verificar quais são os tipos de benefícios e validações que tais aplicações podem fornecer para o avanço das pesquisas em novas abstrações de processos. Cada tipo de aplicação pode ser útil para demonstrar algum aspecto da nova abstração, mas idealmente é interessante evidenciar que as demais aplicações apresentadas também não sofrem com a nova abstração.

Apache e Nginx são aplicações cujo o objetivo é servir requisições feitas pelos usuários, ou seja, são servidores web. Esse tipo de aplicação normalmente oferece opções para que sejam amplamente configuradas de forma a atender os requisitos do usuário da melhor maneira possível. Tais aplicações são especializadas para tirar o máximo de proveito possível dos recursos de hardware, uma vez que servidores web podem lidar com enormes cargas de requisições levando a um ostensivo uso do hardware. Nesse tipo de aplicação, é comum que ocorra um amplo consumo da memória e que a CPU esteja próxima do $100 \%$ de utilização em situações de estresse (muitos usuários acessando). Note que, quanto 
mais tempo uma requisição vive, mais memória é consumida, por isso é desejável que as requisições sejam atendidas o mais rapidamente possível. Por sua vez, o SO tem que manipular diversos aspectos relacionados à memória, processos e arquivos. Por esse motivo, utilizar esse tipo de software como prova de conceito para demonstrar a eficácia de uma nova abstração de processos é algo extremamente desejável. Essas aplicações podem ser utilizadas para mostrar que o comportamento da alteração na abstração de processos em uma situação de alta demanda evidenciando assim o real impacto da nova abstração de processos. Contudo, é importante ressaltar que os testes realizados em tais ferramentas devem gerar uma carga substancial (em alguns casos é preciso alterar as configurações padrão da ferramenta). Esse aspecto é fundamental, uma vez que não existe grande valor em demonstrar algo usando tais ferramentas com uma carga pequena, pois isso pouco ajuda na verificação dos reais impactos gerados pela nova extensão do processo.

Devido ao uso dos módulos de MPM do Apache, é possível testar processos e threads de forma equivalente. Tal característica é interessante para comparar novas abstrações diante de dois modos de execução amplamente utilizados. De forma similar, o Nginx usa outro modelo chamado de event, que também representa outro contexto para validação. Da forma como Apache e Nginx manipulam requisições, podemos dizer que o primeiro fornece um isolamento horizontal enquanto o segundo proporciona isolamento vertical. O isolamento horizontal vem do fato de que um processo cria vários outros e o vertical vem da criação de um único processo por núcleo do processador durante a inicialização. Ambas as formas de isolamento, horizontal e vertical, podem ser úteis para demonstrar que uma nova abstração pode melhorar o isolamento sem degradar o desempenho.

Apache trabalha com diversos plugins que são acoplados ao código principal dinamicamente. Essa junção tem uma boa relação entre desempenho e flexibilidade, mas também eleva as chances de quebrar o Apache. Portanto, o sistema de plugins do Apache fornece um bom elemento de validação para aquelas abstrações que visam trazer isolamento e recuperação.

Várias propostas de extensão da abstração de processos sugerem algum ganho de segurança por meio do controle fino ou isolamento de pedaços da memória. Nesse sentido, OpenSSH e OpenSSL são ferramentas interessantes, já que possuem os requisitos de segurança adequados para a validação das novas abstrações. Em especial, ambas as aplicações tem diversas CVEs associadas a si com correções disponíveis a partir de uma versão específica. Portanto, uma proposta de melhoria na abração de processo que eleva a segurança pode demonstrar o seu real valor em uma dessas aplicações.

Redis, por sua vez, é uma aplicação que trabalha com grandes quantidade de dados na memória e que tem excelente desempenho em situações de forte demanda. Essas características fazem dele uma excelente ferramenta para demonstrar novas técnicas de compartilhamento da memória. Além disso, um dos objetivos de Redis é auxiliar na escalabilidade das aplicações. Por isso, é desejável que ele reaja rapidamente a qualquer problema. Nesse contexto, abstrações de processos novas que tragam melhorias no tempo recuperação de uma aplicação em caso de falha podem usar o Redis com instrumento de validações.

Novas abstrações de processos podem entregar ganhos de desempenho para as aplicações por utilizar algum recurso de hardware ou mesmo fornecer uma nova estrutura de 
dados para a aplicação. Tal otimização pode ser demonstrada em um GC, uma vez que esse tipo de aplicação faz uso de vários algoritmos que dependem de certos dados fornecidos pelo SO. Como exemplo disto, a fase de compactação pode ser otimizada se o endereço virtual for mantido e apenas o endereço físico alterado (CLICK et al., 2005).

A Tabela 4.1 busca resumir quais aplicações podem ser usadas para demonstrar algum aspecto da nova abstração de processos. Note que utilizamos uma escala que vai de nenhum $\boldsymbol{V}$ até três $\boldsymbol{V}$ que indica o quanto uma determinada aplicação pode influenciar na observação de algum dos alvos indicados nas colunas. Além disso, esta seção inteira responde a pergunta RQ3, uma vez que apresenta e discute diversas aplicações. Por fim, repare na Tabela 4.1 que Apache é uma das ferramentas que melhor pode ser usada para demonstrar os aspectos de uma nova abstração de processos. No Capítulo 5 aprofundamos a validação utilizando Apache para testar o MVAS.

\begin{tabular}{|c|c|c|c|c|c|c|}
\hline App & $\begin{array}{c}\text { Controle } \\
\text { fino da } \\
\text { Memória }\end{array}$ & $\begin{array}{c}\text { Consumo } \\
\text { de CPU }\end{array}$ & $\begin{array}{c}\text { Consumo } \\
\text { de Memória }\end{array}$ & Segurança & Recuperação & Otimização \\
\hline \hline Apache & & $\boldsymbol{V}$ & $\boldsymbol{V}$ & $\boldsymbol{V}$ & $\boldsymbol{V}$ & $\boldsymbol{V}$ \\
\hline Nginx & $\boldsymbol{V}$ & $\boldsymbol{V}$ & $\boldsymbol{V}$ & $\boldsymbol{V}$ & $\boldsymbol{V}$ & $\boldsymbol{V}$ \\
\hline OpenSSL & $\boldsymbol{V} \boldsymbol{V}$ & & & $\boldsymbol{V}$ & & \\
\hline OpenSSH & $\boldsymbol{V} \boldsymbol{V}$ & & & $\boldsymbol{V}$ & & \\
\hline Redis & $\boldsymbol{V}$ & & $\boldsymbol{V}$ & & $\boldsymbol{V}$ & $\boldsymbol{V}$ \\
\hline GC & & $\boldsymbol{V}$ & $\boldsymbol{V}$ & & & $\boldsymbol{V}$ \\
\hline
\end{tabular}

Tabela 4.1: Relação aplicações e alvos

\subsection{Microbenchmarks}

Microbenchmarks têm por objetivo mensurar e fornecer meios para analisar uma única característica do objeto de estudo. Eles facilitam o processo de desenvolvimento, mostram o impacto em um único elemento de forma a facilitar a análise e são relativamente simples de serem implementados. Contudo, a principal desvantagem encontra-se no fato de que eles não ajudam a revelar o impacto geral do objeto alvo. Por esse motivo, é interessante trabalhar com um conjunto de microbenchmarks e também com validações usando aplicações (como descrito na Seção 4.4). Expandindo o contexto dos microbenchmarks para o subconjunto da pesquisa sobre abstrações de processos, queremos destacar aquelas validações que lidam com a memória, sobrecargas extra e impactos na utilização de certos recursos de hardware.

No Capítulo 3, apresentamos diversas propostas que buscam de alguma maneira lidar com os mecanismos de acesso à memória. Várias dessas propostas permitem o controle fino da memória ou algum ganho de segurança que os autores normalmente demonstram por meio da alteração de algumas aplicações (p.ex., OpenSSL ou OpenSSH). Contudo, alterações no gerenciamento da memória podem incorrer em erros e em problemas de desempenho. Nesse sentido, alguns microbenchmarks podem ser extremamente oportunos 
para validar o uso de novas abstrações de processos que lidam com a memória. Com base em todos os trabalhos analisados no Capítulo 3, extraímos os seguintes itens:

Medir tempo gasto com novos mecanismos de alocação de memória: Algumas propostas criam mecanismos de alocação de memória contendo características novas, por isso é interessante comparar os mecanismos propostos pelo pesquisador utilizando como base a forma padrão de alocação (p.ex., malloc() e calloc()). Tendo os valores base extraídos das operações já consolidadas e os valores coletados do modelo proposto, torna-se possível ter um critério para compreender o real impacto da mudança. Vale observar que esse tipo de microbenchmark precisa ser feito com múltiplas cargas de tamanhos variados; no mínimo, espera-se cargas na ordem dos KBs, MBs e GBs.

Medir tempo gasto com operações de leitura e escrita: Mensurar o tempo de leitura e escrita em memória usando os mecanismos padrão é importante para obter o custo de acesso base. Tal informação deve ser utilizada para comparar com novas propostas de abstrações de processos que adicionam camadas extras para acessar a memória (p.ex., Nooks e Wedge). Novamente, é importante que várias cargas de trabalho sejam utilizadas.

Algumas propostas sugerem a adição de novas chamadas de sistema que adicionam novos modelos de programação (p.ex., lwC e MVAS). Apesar de as chamadas de sistema serem relativamente rápidas, elas adicionam overhead. Por isso, é desejável que o pesquisador identifique alguma syscall padrão que tenha algum nível de similaridade com a nova chamada que ele está propondo; assim, ele pode realizar medições do tempo total gasto com a chamada padrão para ter um valor base para comparar com a nova chamada. Contudo, existem casos em que a nova chamada representa algo totalmente novo e em que não faz sentido comparar com qualquer outra chamada já existente. Independentemente de existir ou não uma chamada base, é desejável que o pesquisador execute microbenchmarks que possam aferir:

Tempo total gasto na chamada: Espera-se que o tempo total da chamada seja medido, considerando-se cenários em que a chamada é feita dezenas, centenas e milhares de vezes. Esse tipo de parametrização é importante na validação do comportamento da chamada sob diferentes cargas.

Tempo total gasto na chamada em um contexto de concorrência: Testes realizados no contexto de concorrência auxiliam na validação de como novas chamadas se comportam. Novamente, espera-se que tal teste execute a nova chamada diversas vezes.

Quantidade de trocas de contexto: As novas instruções podem fazer com que o número de trocas de contexto aumente, por isso é valioso medir tal aspecto referente à nova chamada.

Várias propostas propõem um novo hardware (p.ex., Mondrix) ou uma mudança na forma como um dispositivo é usado, o que torna importante validar alguns aspectos de uso. Contudo, para a questão do microbenchmark vamos considerar apenas os aspectos referentes à reutilização do hardware de virtualização, uma vez que consideramos que tal técnica tem amplas chances de ser adotada (discutimos esse aspecto com mais detalhes no 
Capítulo 6). Nesse contexto, dois elementos devem ser medidos:

Custos de operações que executam VM Entry e Exit: Chamadas que utilizam recursos de virtualização têm custos para entrar e sair do kernel. Mensurar tal custo é útil para analisar em quais contextos vale a pena ou não utilizar os recursos de virtualização.

Medir o uso de EPT: Quando se utiliza a EPT, espera-se que o total de TLB misses se eleve, uma vez que, em muitos casos, é preciso procurar por dois níveis de chamadas (Belay et al., 2012). Portanto, torna-se interessante medir o tempo total gasto quando a EPT é usada sob diferentes cargas.

Por fim, é importante ressaltar que vários dos microbenchmarks devem utilizar recursos estatísticos para derivar seus resultados. Por exemplo, espera-se que cada experimento execute múltiplas vezes e a sua média ou mediana e intervalo de confiança sejam calculados. Além disso, a combinação de múltiplos microbenchmarks pode auxiliar consideravelmente na validação de uma nova proposta de abstração.

\subsection{Discussão}

Recapitulando o objetivo deste Capítulo por meio das perguntas de pesquisa:

QP3: "Quais aplicações podem ser utilizadas para avaliar as novas abstrações adicionadas a um SO?"

QP4:. "Qual conjunto de microbenchmarks pode ser utilizado para auxiliar a entender os impactos de uma nova característica adicionada às abstrações de processos?"

Para responder a primeira pergunta, fizemos uma jornada da Seção 4.1 até a 4.4 analisando diversas aplicações amplamente consolidadas. Em especial, a Seção 4.4 apresentou uma discussão sobre as vantagens em se utilizar as aplicações para validar as novas abstrações de processos. A Tabela 4.1 buscou relacionar as aplicações e as áreas que elas auxiliam a validar.

Para responder a segunda pergunta, revisitamos todos os trabalhos e buscamos compilar um conjunto de microbenchmarks que auxiliam no processo de validação. A combinação de múltiplos microbenchmarks auxilia mostrando o impacto da alteração de forma mais abrangente, contudo, esse tipo de validação sozinho não é capaz de revelar os impactos gerais de uma nova abstração.

Em um cenário ideal, a combinação das validações utilizando as aplicações discutidas em conjunto com os microbenchmarks representa uma boa cobertura sobre os impactos de uma nova abstração. Por fim, é importante relembrar que tais validações devem buscar utilizar cargas de trabalho relevantes para tornar claros os impactos da nova abstração. 


\section{Capítulo 5}

\section{Estudo de Caso}

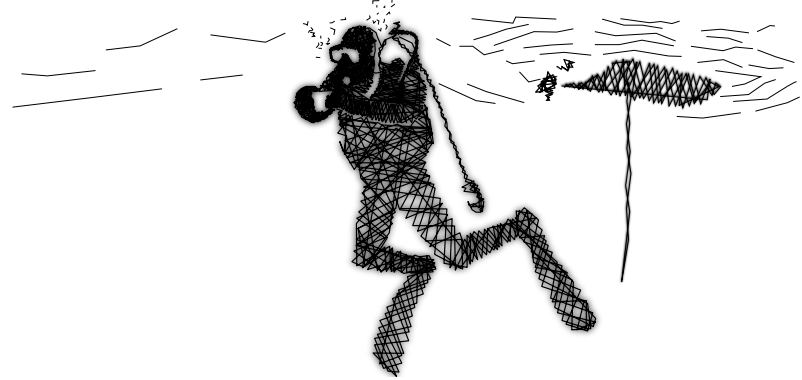

Neste estudo de caso, nós buscamos atingir três objetivos: (1) garantir a reprodutibilidade dos resultados, (2) construir uma estrutura que possa ser estendida para outros cenários e (3) validar os problemas associados a novas abstrações de processos. Utilizamos uma estrutura para preparar o ambiente (deploy) que é responsável por configurar todas as máquinas alvos envolvidas nos experimentos. Para automatizar tal passo, decidimos utilizar a ferramenta Ansible ${ }^{1}$ para controlar a implantação dos experimentos uma vez que esta é amplamente utilizada e é relativamente simples de se utilizar. Adicionalmente, temos um grupo de scripts projetados para estressar diferentes cenários ${ }^{2}$, esses scripts são baseados em uma ferramenta chamada Apache Benchmark Tool (ab) que por sua vez tem configurações específicas para testar diferentes aspectos do SO e de um servidor HTTP. Temos uma coleção de programas para processar todos os dados gerados durante a execução do experimento e produzir os gráficos. Neste capítulo, apresentamos alguns experimentos e buscamos validar os benefícios da abordagem utilizando Múltiplos Endereços Virtuais (MVAS); ou seja, esse capítulo tem como objetivo testar parte do que foi apresentado no Capítulo 4.

\subsection{Metodologia}
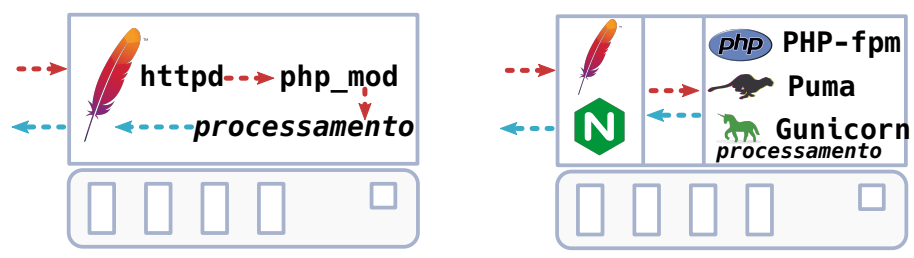

Figura 5.1: Visão geral da organização de aplicações utilizando servidores Web

Atualmente podemos encontrar um grande número de arquiteturas que pode ser utilizada por um sistema web. A Figura 5.1 ilustra duas arquiteturas diferentes. A primeira mostra uma situação na qual uma página web é totalmente manipulada pelo Apache

\footnotetext{
${ }^{1}$ https://www.ansible.com/

${ }^{2}$ https://github.com/LSS-USP/web_server_benchmark
} 
HTTP Server (httpd). Basicamente, o httpd manipula uma solicitação e a passa para um módulo específico responsável por executar um software (p.ex.: uma página web em PHP é executado por um módulo PHP chamado $\left.p h p \_m o d\right)$. A segunda arquitetura é um exemplo de página web escrita em Ruby on Rails que é composta por duas camadas: (1) um servidor web para manipular as requisições que chegaram dos clientes (pode ser o Apache ou Nginx), (2) um servidor de aplicação responsável por executar um programa (no exemplo da figura, temos o PUMA que é especializado em executar código Ruby). Esses exemplos, ilustram que podemos ter diferentes formas de organizar as aplicações.

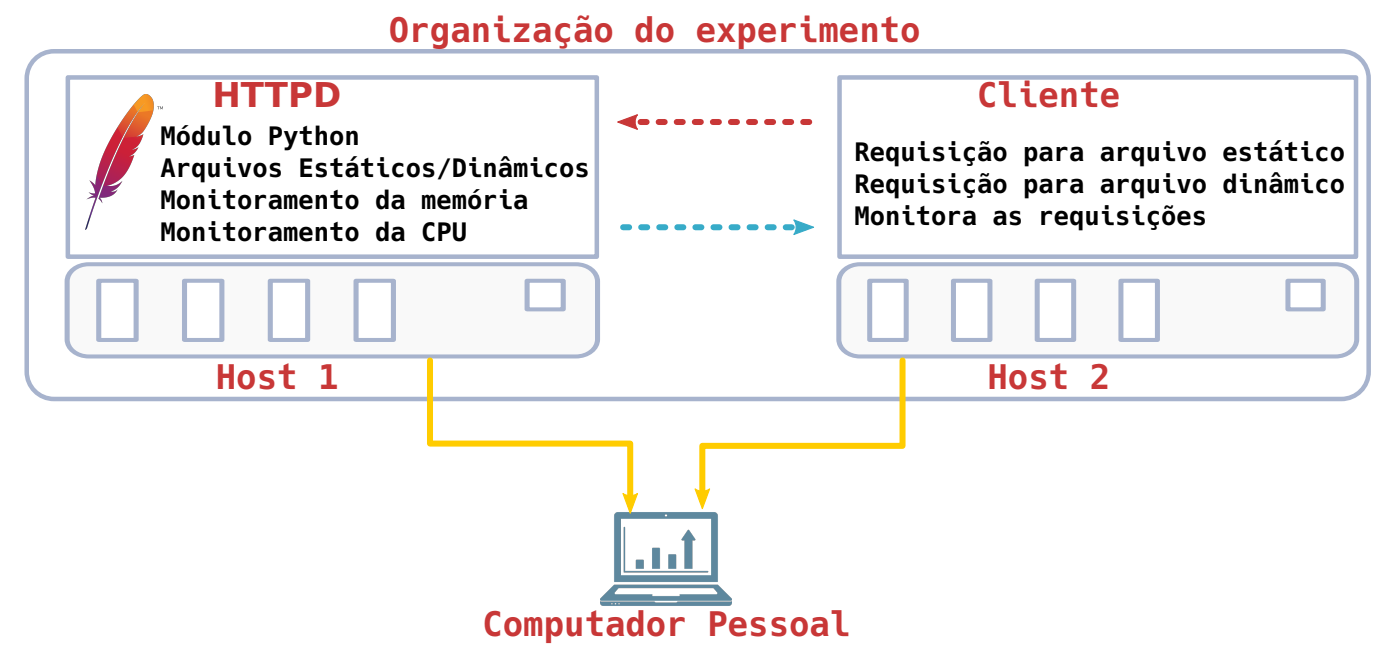

Figura 5.2: Arquitetura do experimento

A Figura 5.2, ilustra de forma geral a estrutura utilizada para conduzir os experimentos com MVAS. Note que a figura indica duas máquinas virtuais (Host 1 e Host 2), uma com um servidor web configurado para dar suporte para uma grande carga de requisições geradas por uma segunda máquina, que por sua vez, é responsável por simular um grande número de clientes concorrentes. Ambas as máquinas são conectadas via conexão Gigabit Ethernet, uma vez que queremos simular múltiplos cliente fazendo requisições sem ter que se preocupar com questões de sobrecarga da rede.

Nos experimentos, queremos simular uma situação na qual o httpd terá que lidar com uma grande carga que gere pressão na aplicação e assim eleve a utilização de recursos de hardware. Com essa ideia em mente, conduzimos dois experimentos empíricos com o objetivo de determinar qual seria a configuração ideal para o Host 1. Primeiro, investigamos as principais características das diferentes estrategias de MPM e notamos que o Prefork impõe um grande consumo de memória; por isso, a quantidade de memória foi escolhida com base no Prefork uma vez que se espera que as estratégias de Worker e Event consumam menos memória. Em segundo lugar, conduzimos um pequeno conjunto de experimentos com diferentes cargas de trabalho e monitoramos a utilização de recursos. Analisamos os logs e concluímos que a forma mais rápida de tornar evidente a diferença entre as estratégias é utilizando poucos núcleos e ter um bom tamanho de memória. Consequentemente, decidimos utilizar uma máquina de 13GB de memória RAM e 2 núcleos. Note que 13GB é um tamanho selecionado visando dar suporte para um grande número de requisições quando o httpd é configurado para utilizar o Prefork. Finalmente, é importante ressaltar que o Host 1 tem uma ferramenta configurada para monitorar a utilização de memória e 
CPU $\left(\right.$ Collectl $\left.^{3}\right)$, dados posteriormente recuperados para análise.

A segunda máquina, tem uma coleção de scripts que utiliza a ferramenta de Benchmark do Apache (ab) para gerar diferentes testes; a Figura 5.2 ilustra a máquina que é responsável por produzir diferentes cargas. Todas as requisições são monitoradas e salvas em arquivos.

Por fim, o computador pessoal exerce duas funções: orquestrar os experimentos em ambos os Hosts e processar os dados recuperados de ambas as máquina. O computador pessoal possui as regras para iniciar os experimentos e recuperar os dados; além disso, ele é o responsável por processar todos os dados recuperados.

\subsection{Customizações no Servidor Apache e no GNU/Linux}

Uma das principais características do httpd é a sua habilidade de ser facilmente ajustado por meio de arquivos de configuração. Da perspectiva de um usuário avançado, o Apache HTTP Server pode ser mais flexível e adaptável para diferentes contextos. Apesar de toda a flexibilidade e capacidade do httpd, ele vem com uma configuração conservadora por padrão para evitar que os usuários não experientes causem algum tipo de dano ao seu próprio ambiente. Consequentemente, é necessário configurar o httpd para suportar grandes cargas de requisições. Da mesma forma, o GNU/Linux também vem configurado de maneira conservadora e esse também possibilita um elevado grau de personalização. Portanto, um usuário avançado que desejar fazer com que o Linux entregue o melhor desempenho possível para cada hardware, precisa personalizar vários arquivos internos (em alguns caso, até recompilar o Kernel). Nesse trabalho, nós queremos simular uma situação que se assemelhe a de um servidor web que manipule uma elevada carga de requisições, por isso, fizemos diversas otimizações no servidor Apache e no Linux.

Em nossos experimentos, utilizamos e comparamos: Prefork, Worker e Event. Todas as estratégias de MPM tem um arquivo de configuração específico associado a si, na qual cada um permite algum tipo de ajuste fino. Seguem os principais parâmetros disponíveis para configurar esse tipo de MPM:

StartServers: Espera um inteiro positivo que representa o total de processos que serão iniciados junto com o httpd. O valor padrão varia de acordo com o MPMs adotado (MPM StartServer 2019);

MinSpareServers: Espera um inteiro positivo e ajusta o número mínimo de processos ociosos. É importante ter um conjunto de processos desocupados para o caso em que o httpd receba uma grande carga de requisições em um curto intervalo de tempo, os filhos ociosos podem ser usados para tentar tratar as novas requisições. O processo pai compara o total de filhos com o valor contido em MinSpareServers. Se tiver apenas alguns filhos ociosos, então o processo pai cria novos filhos (MinSpareServers Directive 2019);

\footnotetext{
${ }^{3}$ http://collectl.sourceforge.net/ Acessado dia 03/07/2018
} 
MaxSpareServers: Espera um valor positivo inteiro e configura o número máximo de processos ociosos. Repare que MinSpareServers e MaxSpareServers trabalham juntos controlando o total de recursos sendo utilizado pelos filhos (MaxSpareServers Directive 2019);

MaxRequestWorkers: Ajusta o número total de requisições servidas pelo httpd. Se o número total de requisições é maior que o MaxRequestWorkers, então toda nova requisição será enfileirada. O tamanho da fila no Apache HTTP Server é configurada no parâmetro ListenBacklog (MPM MaxRequestWorkers 2019);

ListenBacklog: Indica o tamanho máximo da fila. Esse valor tem relação com o tamanho da fila TCP definida pleo GNU/Linux (ListenBackLog Directive 2019);

ServerLimit: Eleva o número máximo de processos permitidos pelo httpd (ServerLimit Directive 2019);

MinSpareThreads: Espera um inteiro positivo que representa o número mínimo de threads ociosas. Se tem muitas requisições para o servidor e não tem threads ociosas o suficiente para manipular toda a carga, o processo filho cria mais threads até que alcance um número de threads maior do que o valor especificado nesse parâmetro. Por padrão, o httpd ajusta um valor de 75 para esse parâmetro (MinSpareThreads Directive 2019);

MaxSpareThreads: Espera um inteiro positivo que representa o número máximo de threads que podem ficar ociosas. Se o httpd tem mais threads ociosas do que o valor especificado nesse parâmetro, então o processo pai mata os filhos excedentes. Por padrão, esse valor é ajustado para 100 (MaxSpareThreads Directive 2019);

ThreadLimit: Espera um inteiro positivo que representa um limite superior de threads por processo (ThreadLimit Directive 2019);

ThreadPerChild: Espera um inteiro positivo que represente o total de thread por processo filho (ThreadsPerChild Directive 2019);

\begin{tabular}{|c|c|c|c|}
\hline Parameter & Event & Worker & Prefork \\
\hline \hline ServerLimit & 6000 & 6000 & 5000 \\
\hline StartServer & 10 & 10 & 1000 \\
\hline MinSpareThreads & 512 & 512 & - \\
\hline MaxSpareThreads & 1024 & 1024 & - \\
\hline ThreadLimit & 64 & 64 & - \\
\hline ThreadPerChild & 64 & 64 & - \\
\hline MaxRequestWorkers & 5120 & 5120 & 5000 \\
\hline MinSpareServers & - & - & 500 \\
\hline MaxSpareServers & - & - & 1500 \\
\hline
\end{tabular}

Tabela 5.1: Configuração adotada para o MPM

Definir os valores para cada um dos parâmetros citados acima não é uma tarefa trivial, por isso, fizemos de forma incremental diversos testes para encontrar a configuração que melhor utiliza os recursos das máquinas que tínhamos. A Tabela 5.1, ilustra os resultados 
finais após os nossos testes e que definem as customizações que utilizamos para configurar o httpd para os experimentos. Nossa configuração permite que o Apache responda a uma elevada quantidade de requisições, o que torna o experimentos próximo de uma situação realista. Nossas customizações no GNU/Linux e httpd permite que boa parte do hardware seja utilizado.

\begin{tabular}{|c|c|}
\hline Parâmetros & Valores \\
\hline \hline Max queue events & 1048576 \\
\hline Max user instances & 1048576 \\
\hline Max user watches & 1048576 \\
\hline Max map count & 262144 \\
\hline TCP max syn backlog & 8096 \\
\hline TCP syncookies & 0 \\
\hline
\end{tabular}

Tabela 5.2: Configurações feitas no Kernel

Também é necessário customizar o GNU/Linux uma vez que as configurações padrão deste são feita para evitar o consumo de todos os recursos de hardware (p.ex.; o Linux limita uma aplicação como o httpd). A Tabela 5.2 mostra todas as configurações feita no GNU/Linux para esse experimento (tais valores foram derivados de forma experimental, assim como a Tabela ??). Observe que o GNU/Linux estabelece um limite de arquivos que podem ser abertos por meio dos File Descriptor (FD), tal situação representa um problema quando o httpd precisa manipular uma grande quantidade de requisições uma vez que cada uma mantém um FD. Para superar esse problema, elevamos a quantidade total de FDs permitidos pelo Linux (na Tabela 5.2, o parâmetro Max map count), tal alteração permite que o httpd manipule um maior número de requisições. Além disso, o GNU/Linux tem uma coleção de arquivos de configuração que previne alguns ataques de rede bem conhecidos. No nosso caso, precisamos desabilitar o SYN Flood Protection (Tabela 5.2, TCP syncookies) uma vez que essa configuração evita que o SO manipule uma quantidade gigantesca de requisições feitas de uma mesma máquina. Por fim, o tamanho padrão da fila TCP é pequena para esse estudo de caso, portanto, nós elevamos consideravelmente o seu tamanho (na Tabela 5.2, TCP max syn backlog, Max queue events, e Max user instances).

Resumindo, fizemos ajustes finos no httpd e GNU/Linux para que esses suportassem cargas de requisições elevadas. Essas configurações são importantes para o contexto desses experimentos uma vez que desejamos colocar o httpd sob pressão para mostrar o comportamento do MVAS em tal situação.

\subsection{Cenários}

É comum encontrar aplicações executando no httpd que também trabalham com banco de dados. Normalmente, esse tipo de aplicação tem que esperar para que uma operação retorne algum dado. Esse cenário pode ser facilmente expandido para uma situação na qual grandes quantidades de requisições são feitas e o banco de dados fica ocupado. As vezes, os servidores de aplicações também apresentam estratégias de cache, o que gera um cenário completamente novo. Com essas questões em mente, é preciso decidir qual tipo de experimentos queremos conduzir. Esta seção descreve os cenário adotados. 


\begin{tabular}{|c|c|c|}
\hline & Pequeno & Grande \\
\hline \hline Estático & $70 \mathrm{~Kb}$ & $120 \mathrm{~Kb}$ \\
\hline Dinâmico & $80 \mathrm{~Kb}$ & $120 \mathrm{~Kb}$ \\
\hline
\end{tabular}

Tabela 5.3: Tamanho dos arquivos para serem transferidos

Nossos experimentos foram compostos por dois cenários diferentes, separados por dois tipos de arquivos: estático e dinâmico. Utilizamos dois arquivos estáticos com texto puramente HTML de tamanhos distintos. A Tabela 5.3 mostra os arquivos adotando, em especial, os tamanhos dos arquivos são baseados em valores de um relatório publicado em 2015 que indica que um arquivo HTML tem em média 66KB (State of the Web 2019). Para os arquivos dinâmicos, foi escrito um pequeno código em Python que gera uma saída diferente para cada requisição. Nós decidimos por essa estratégia com os arquivos dinâmicos para evitar os sistemas de cache. Finalmente, os arquivos dinâmicos são importantes em um cenário em que a CPU deve ser mantida ocupada por um período maior de tempo e com o tamanho dos arquivos afetando isso.

O httpd entrega arquivos estáticos HTML com pouca utilização de hardware uma vez que esses arquivos não necessitam de processamento. Essas características são desejáveis para mostrar a diferença entre o Prefork, Event e Worker ao se utilizar o MVAS dentro do Apache com um tipo de requisição que demandam pouca CPU. Por outro lado, os arquivos dinâmicos são utilizados para experimentos que usam muita CPU e são usados para simular uma situação na qual uma requisição tem que esperar por processamento. Essa situação gera sobrecarga na $\mathrm{CPU}$ e, consequentemente, consome uma enorme quantidade de memória, uma vez que os processos vivem por mais tempo (até o fim do processamento).

\begin{tabular}{|c|c|c|}
\hline Casos & Requisiçõoes & Concorrência \\
\hline \hline Arquivos estáticos & 60000 & 20000 \\
\hline Arquivos dinâmicos & 5000 & 600 \\
\hline
\end{tabular}

Tabela 5.4: Carga principal aplicada

A Tabela 5.4 ilustra a carga aplicada nos experimentos. Para os arquivos estáticos, aplicamos a maior carga de requisições com o maior nível de concorrência; já para os arquivos dinâmicos, aplicamos uma carga de requisições menor com pouca concorrência. Nosso objetivo com essas configurações foi examinar em um ambiente sem alteração nas abstrações de processos, qual a diferença em utilizar uma abordagem baseada em processos e outras usando threads. Tendo essa clara distinção entre as estratégias, passamos a ter um cenário base para comparações com novos cenários que utilizam alterações nas abstrações de processos. Por fim, vale observar que estamos ignorando os casos nas quais as requisições fazem uso de keep-alive. 


\subsection{MVAS Dentro do GNU/Linux e Apache HTTP Server}

O SpaceJMP (El HajJ, Merritt, Zellweger et al., 2016) foi a primeira implementação do conceito de MVAS e está disponível para os SOs DragonFlyBSD e Barrelfish. Em 2016 os pesquisadores envolvidos com o SpaceJMP decidiram implementar o MVAS no núcleo Linux com a intenção de estender o trabalho original e enviar a modificação como uma sequência de patches para os mantenedores do Kernel. Como resultado, em Agosto de 2016, foi lançado a primeira versão do MVAS para o Linux ${ }^{4}$ por um dos pesquisadores.

Para utilizar a atual implementação do MVAS no Linux, nós trabalhamos em um fork feito da branch original mantida por Till Smejkal (o criador da implementação do MVAS no Linux). Till é alundo de Doutorado em Ciência da computação e criou a implementação do SpaceJMP no Linux durante o seu estágio de pesquisa na HPe sob a supervisão de Dejan Milojicic. Parte deste trabalho foi parte da nossa cooperação com a HPe. Durante nossos trabalhos, tivemos que aprender como compilar, customizar e instalar a versão do Kernel com MVAS. Para essas atividades, utilizamos o Debian com o Kernel fornecido pelo Till.

MVAS é acessível por meio de chamadas de sistema e também possui algumas informações que permitem auxiliar na depuração de problemas. Adicionalmente, estudamos parte da implementação da MVAS para conseguir melhorar os experimentos e também colaborar com o mantenedor. Durante muito tempo, a pesquisa foi conduzida em conjunto com Till Smejkal, Ranjan Sarpangala e o laboratório da HPe (responsáveis pela pesquisa). Contudo, tal implementação foi abandonada uma vez que não se mostrou viável e nem escalável.

\subsubsection{MVAS Dentro do Apache HTTP Server}

Uma requisição tem um ciclo de vida curto dentro do httpd uma vez que é criada e destruída frequentemente. As informações sobre um cliente e as suas conexões são armazenadas dentro de uma estrutura de dados para manter as informações sobre as requisições. Note que, da perspectiva da segurança, é desejável adicionar o maior nível de isolamento possível para cada requisição, contudo da perspectiva do httpd o tratamento das requisições deve ser mantido leve. Embora o modelo baseado em processos isole todas as requisições mantendo um desempenho aceitável, ele gera um grande consumo de memória (Seção 4.1.1). Por outro lado, a estratégia baseada em threads tem melhor desempenho mas não proporciona um isolamento completo uma vez que parte da memória é compartilhada com outras threads.

O modelo do MVAS tem um mecanismo para criar múltiplos espaços de endereçamento virtual, todos inteiramente isolados e com um comportamento que gera persistência de dados (Seção 3.7). Nossa hipótese sobre a utilização do MVAS era a de que ele poderia ser utilizado como uma solução híbrida na qual fornecesse o mesmo nível de isolamento de um processo com um desempenho aproximado ao das threads. Com tal ideia em mente,

\footnotetext{
${ }^{4}$ https://github.com/I3nkz/linux/tree/mvas Acessado dia 03/07/2017
} 
alteramos o ciclo de vida das requisições do Apache com a intenção de verificar a nossa hipótese.

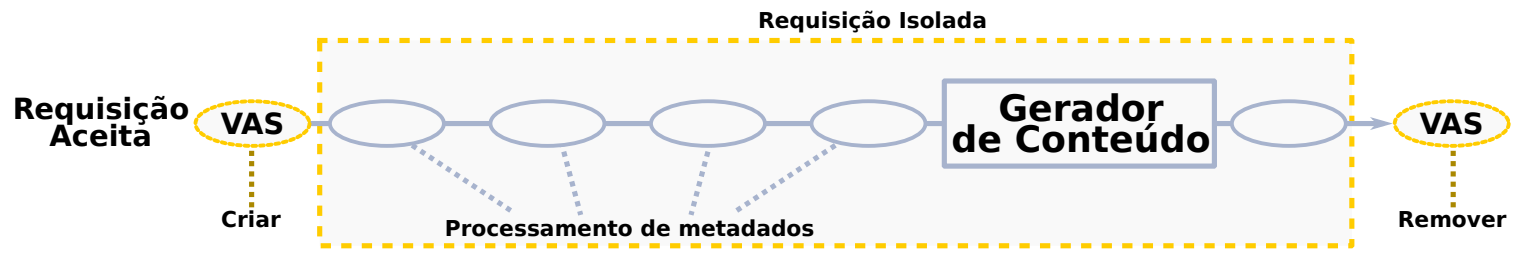

Figura 5.3: httpd com MVAS

A Figura 5.3 mostra a nossa abordagem para adicionar o MVAS dentro do httpd. Antes da estrutura de dados da requisição ser construída no Apache HTTP Server, nós temos que criar um novo VAS, anexá-lo na thread atual e mudar para o novo VAS. Depois, todo o ciclo de vida da requisição vai ser realizada da forma usual, mas dentro de uma nova VAS (totalmente isolado). Quando uma requisição termina, procedemos com a limpeza das informações relacionadas ao VAS. Essa abordagem garante o total isolamento de qualquer requisição.

Nós identificamos as exatas funções que mantém todo o ciclo de vida de um requisição e aplicamos MVAS para isola-las totalmente uma das outras. Essas funções são:

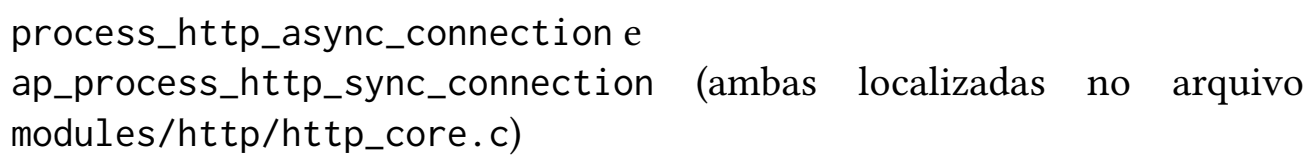

Os módulos MPM invocam uma dessas funções para manipular um ciclo de vida de uma requisição, por esse motivo, adicionar MVAS nessas funções elimina a complexidade relacionada ao código. Contudo, adicionar o MVAS eleva a sobrecarga geral para atender as requisições.

O Código 5.1 é um trecho extraído de nossa implementação do MVAS dentro do Apache HTTP Server. Repare que a função create_isolate_vas() é projetada para dar suporte para a criação de uma nova VAS dentro do Apache HTTP. O código também chama as funções ap_process_http_async_connection e ap_process_http_sync_connection, ambas isoladas dentro de uma nova VAS. No começo de cada uma dessas funções é criado uma nova VAS, anexada ao processo atual e finalmente mudada para uma nova VAS depois que o httpd cria a requisição. No fim do ciclo de vida, nós removemos a VAS. Nossa implementação ainda precisa de melhorias, mas já é funcional. Finalmente, todo o código fonte das nossas modificações está disponível no Github em https://github.com/LSS-USP/ httpd-experiment/commit/aa9e74a3a1157e4345f4bbe977a3e6bd39445e9f.

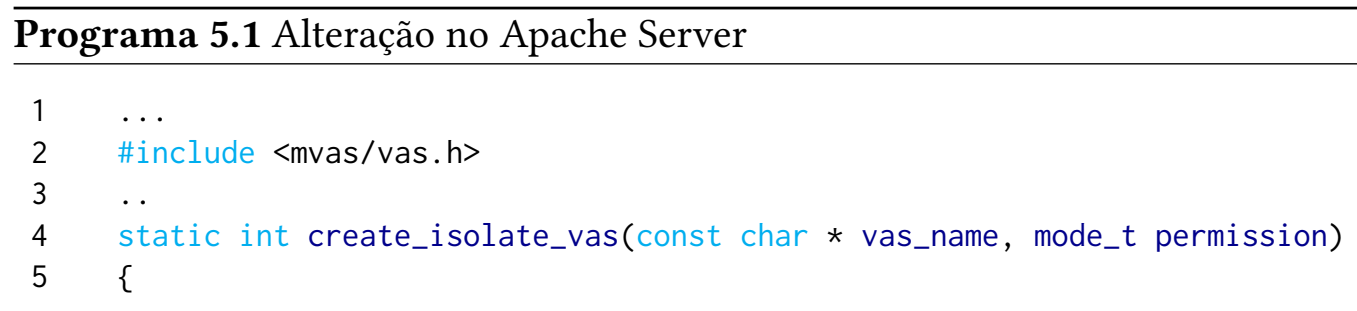




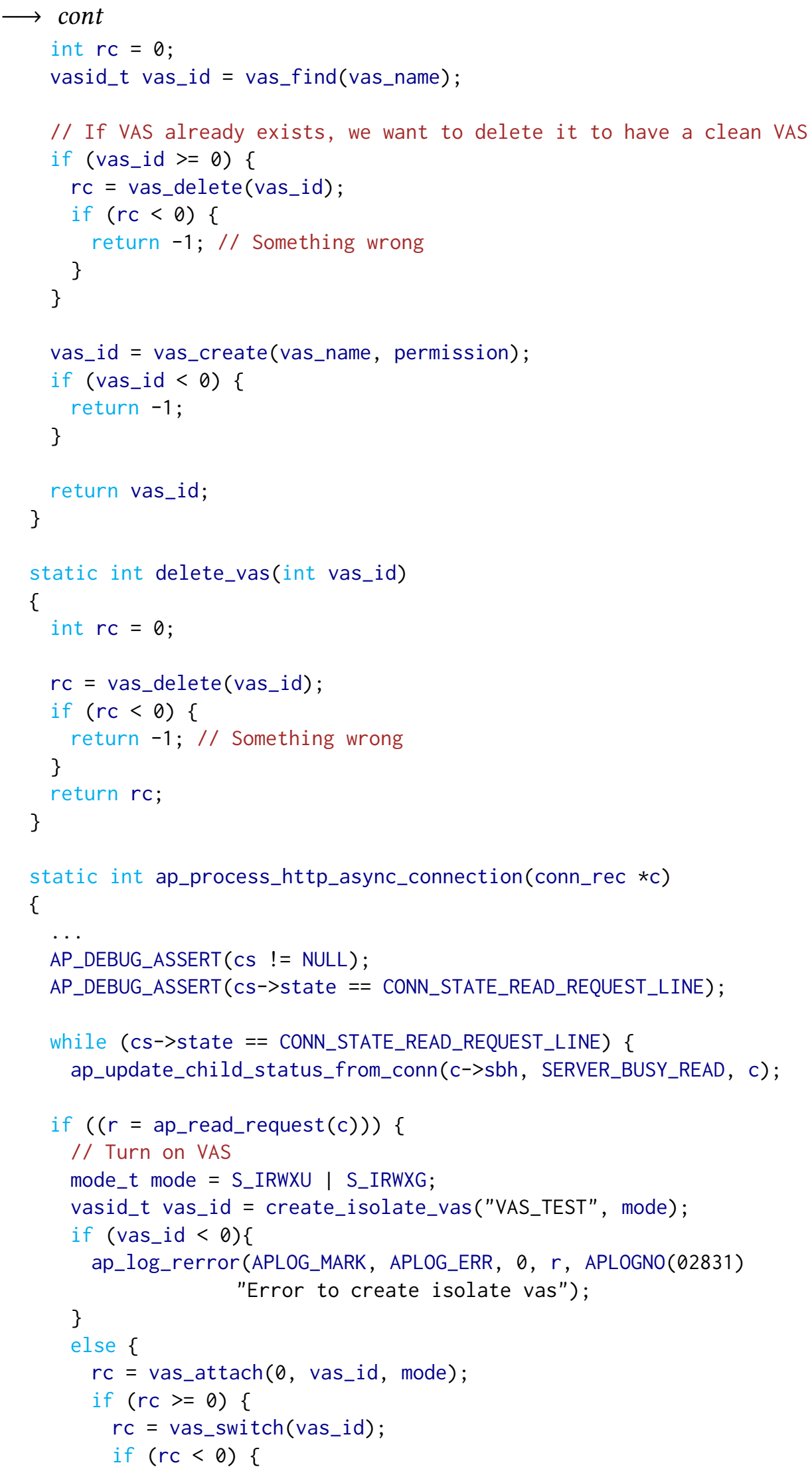




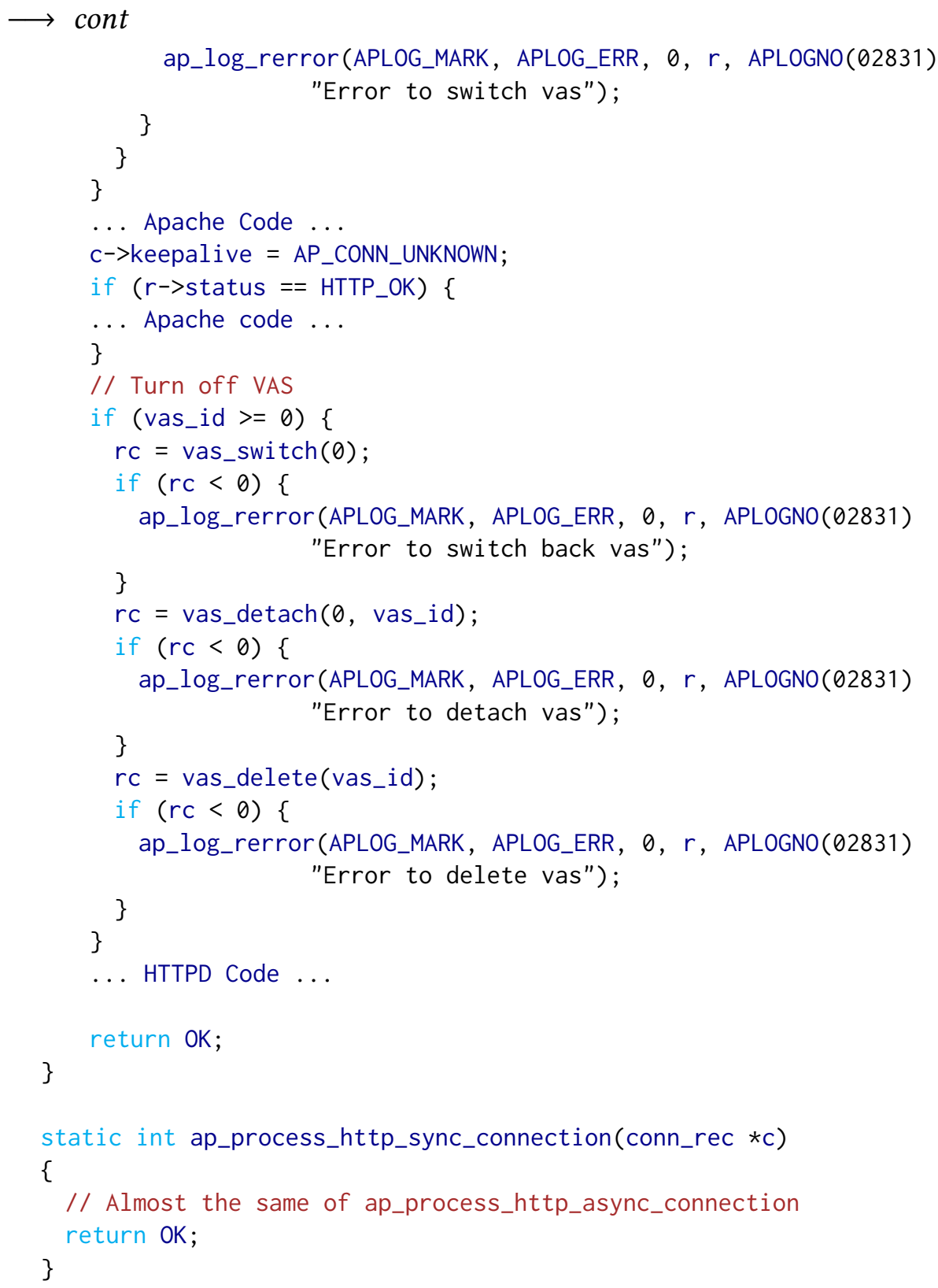

cont

ap_log_rerror(APLOG_MARK, APLOG_ERR, 0, r, APLOGNO(02831)

"Error to switch vas");

\}$^{3}$

Esperamos que o MVAS adicione mais latência, contudo, queremos investigar se a sobrecarga extra é tolerável ou não. O objetivo principal desse experimento é verificar se o MVAS pode ser utilizado como uma substituição à estratégia baseada em processos.

\subsection{Resultados}

O método proposto na Seção 5.1 busca evidenciar, de forma clara, sistemática e replicável, as diferenças entre as estratégias baseadas em processos e threads. Por isso, o primeiro passo desses experimentos consiste em deixar claro a diferença entre as estratégias de MPM, para que em seguida, com os resultados e a estrutura utilizada, possamos expandir os experimentos para a versão do Apache que utiliza MVAS. 


\subsubsection{Existe alguma diferença significativa de desempenho entre o apache HTTP trabalhando com processos e threads?}

Nesse primeiro cenário, temos o httpd com as alterações explicadas na Seção 5.2, mas sem as modificações do MVAS. Responder essa pergunta traz vantagens: (1) deixa claro a diferença entre processos e threads no Apache, (2) temos o comportamento base para comparar com o MVAS e (3) validamos a nossa metodologia.

\begin{tabular}{|c|c|c|}
\hline Nome & Núcleo & Memória \\
\hline M1 & 2 & $13 \mathrm{~Gb}$ \\
\hline M2 & 2 & $4 \mathrm{~Gb}$ \\
\hline
\end{tabular}

Tabela 5.5: Hardware

Na Seção 5.1 e 5.3, detalhamos a nossa metologia e a configuração básica que seguimos. Duas máquinas foram utilizadas, uma chamada de M1 e a outra de M2 como a Tabela 5.5 mostra. Repare que nós decidimos utilizar apenas alguns núcleos e memórias grandes uma vez que essas condições são melhores para revelar o comportamento do httpd.

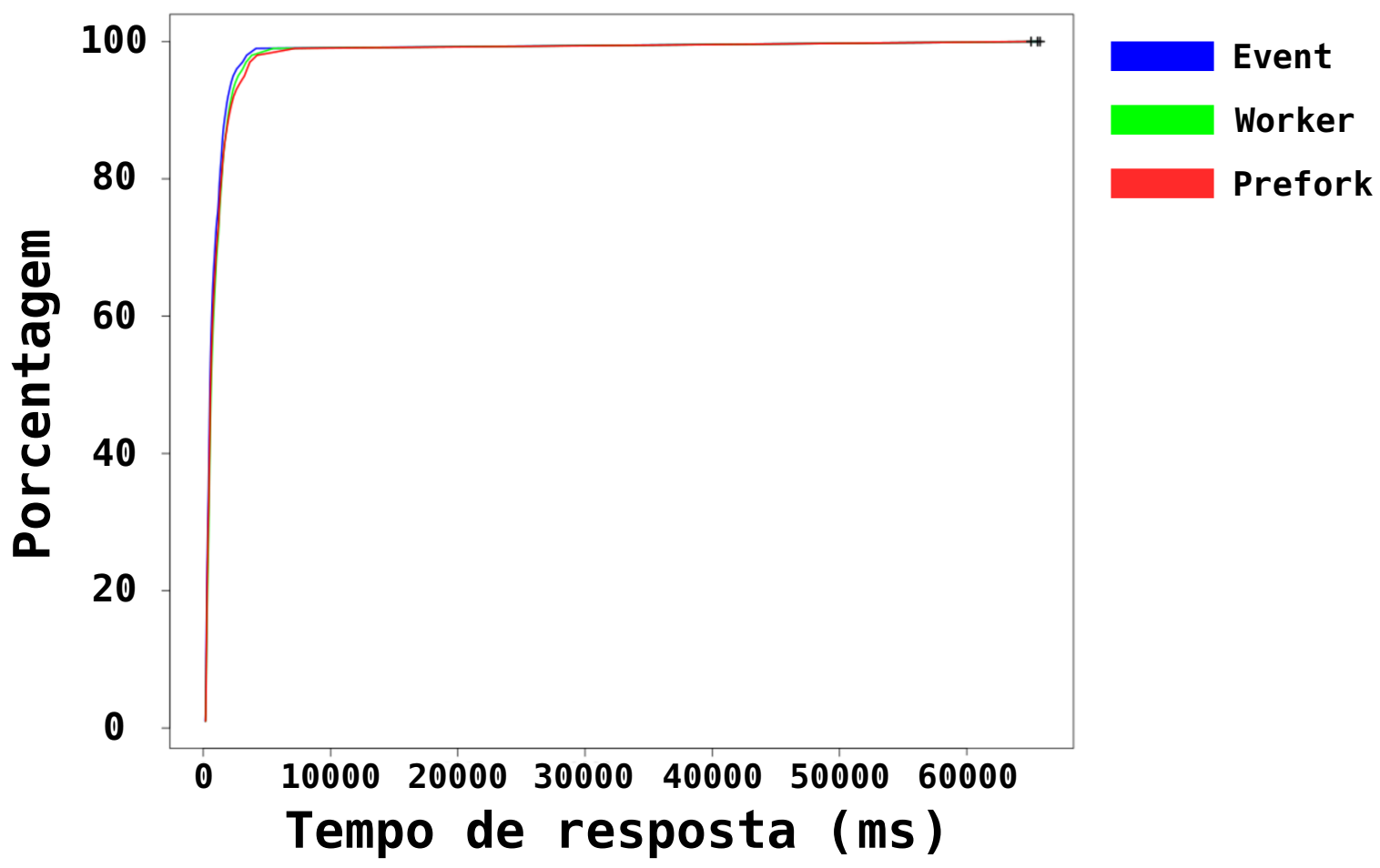

Figura 5.4: Arquivos estáticos: tempo gasto para servir o percentual de requisições

O gráfico na Figura 5.4 mostra o percentual de requisições no eixo y; no eixo x temos o tempo gasto para atender o percentual de requisições (Apache ab 2019). A Figura 5.4 mostra o cenário na qual são servidos arquivos estáticos, recebendo um total de 60000 requisições com até 20000 requisições em paralelo. Além disso, o gráfico ilustra o Prefork, Worker e Event juntos para tornar mais simples de visualizar a diferença.

Analisando a Figura 5.4, é possível perceber que o tempo de resposta foi praticamente o mesmo para todas as estratégias. Em uma primeira análise, esse resultado pode parecer frus- 


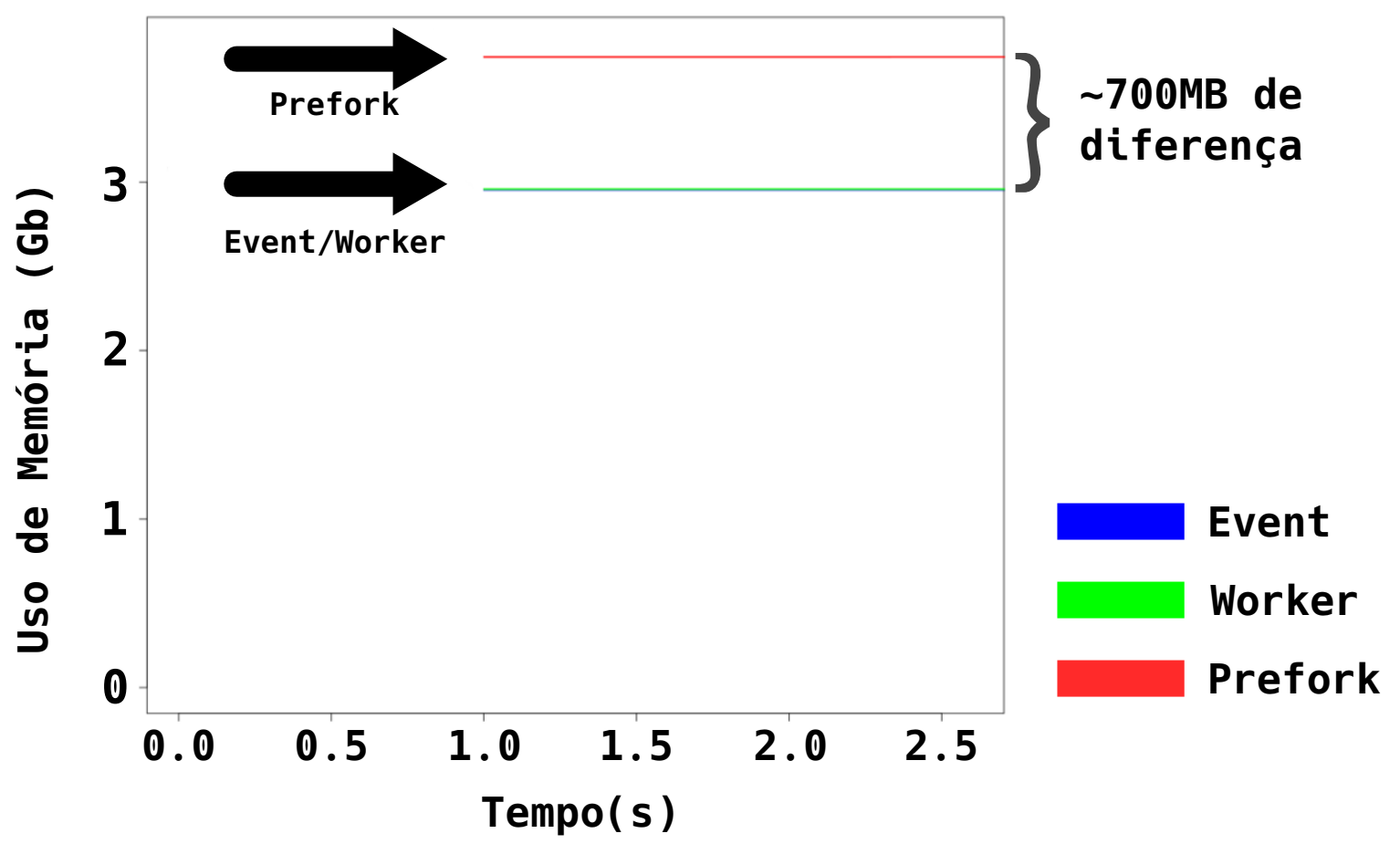

Figura 5.5: Arquivos estáticos: $O$ consumo de memória necessário para atender todas as requisições

tante uma vez que é de se esperar que o Prefork responda um número menor de requisições. Contudo, a Figura 5.5 apresenta o mesmo experimento sob a perspectiva do consumo de memória. Repare que o prefork utiliza aproximadamente $3.7 \mathrm{~Gb}$ e o event/worker precisam de $3 \mathrm{~Gb}$ para atender a todas as requisições. Esse resultado evidência uma desvantagem do prefork em um cenário simples. Por fim, é importante ressaltar que um dos motivos de threads e processos terem o mesmo tempo de resposta nesse cenário vem do fato de que a troca de contexto para threads e processos é o mesmo no GNU/Linux (Love, 2010).

A Figura 5.6 mostra um cenário com arquivos dinâmicos. Nesse caso, a diferença entre processos e threads são muito mais claras. O prefork é mais lento do que o Event e Worker, a diferença é próxima de 42 segundos o que é inaceitável em um cenário real. Para entender melhor esse caso, a Figura 5.7 mostra o consumo de memória e explicita o enorme gasto de memória do prefork quando comparado com o Event e Worker. Essa situação pode ser examinada da perspectiva do SO. Basicamente o Apache tem que criar muitos processos filhos por requisição e manter eles vivos até que o processamento termine. Consequentemente, o Apache tem um enorme número de processos vivos e consumindo memória. Por outro lado, threads compartilham dados com os processos pai, o que reduz o total de memória gasta, assim, mantendo as threads vivas com um custo menor.

Podemos concluir que os experimentos tornam as diferenças claras entre processos e threads dentro do httpd. Os dois cenários descritos são suficientes para servir como critério para mostrar a diferença entre os MPMs. O atual resultado fornece informações básicas necessárias para o restante dos experimentos. 


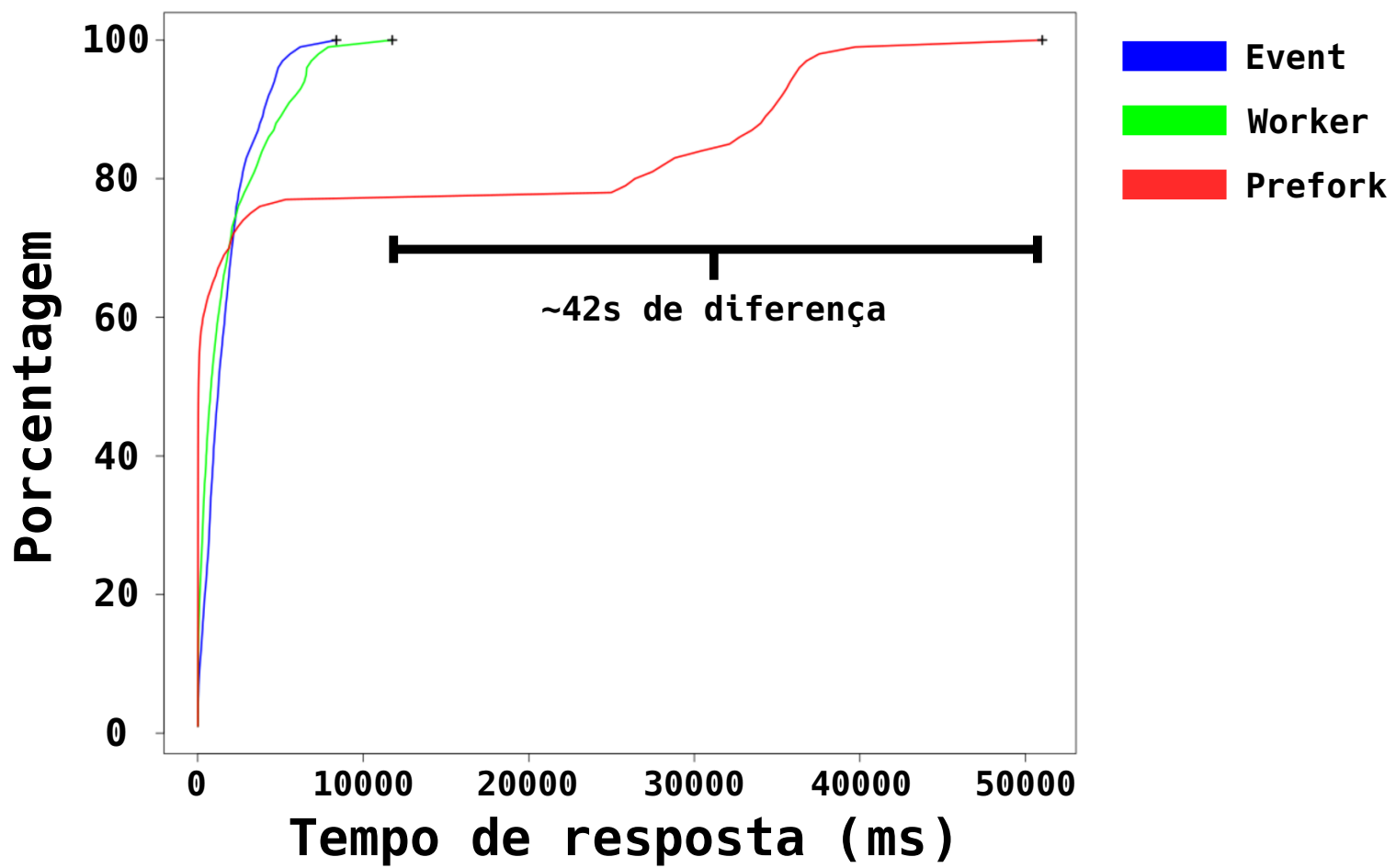

Figura 5.6: Arquivos Dinâmicos: Tempo gasto por percentual de requisições

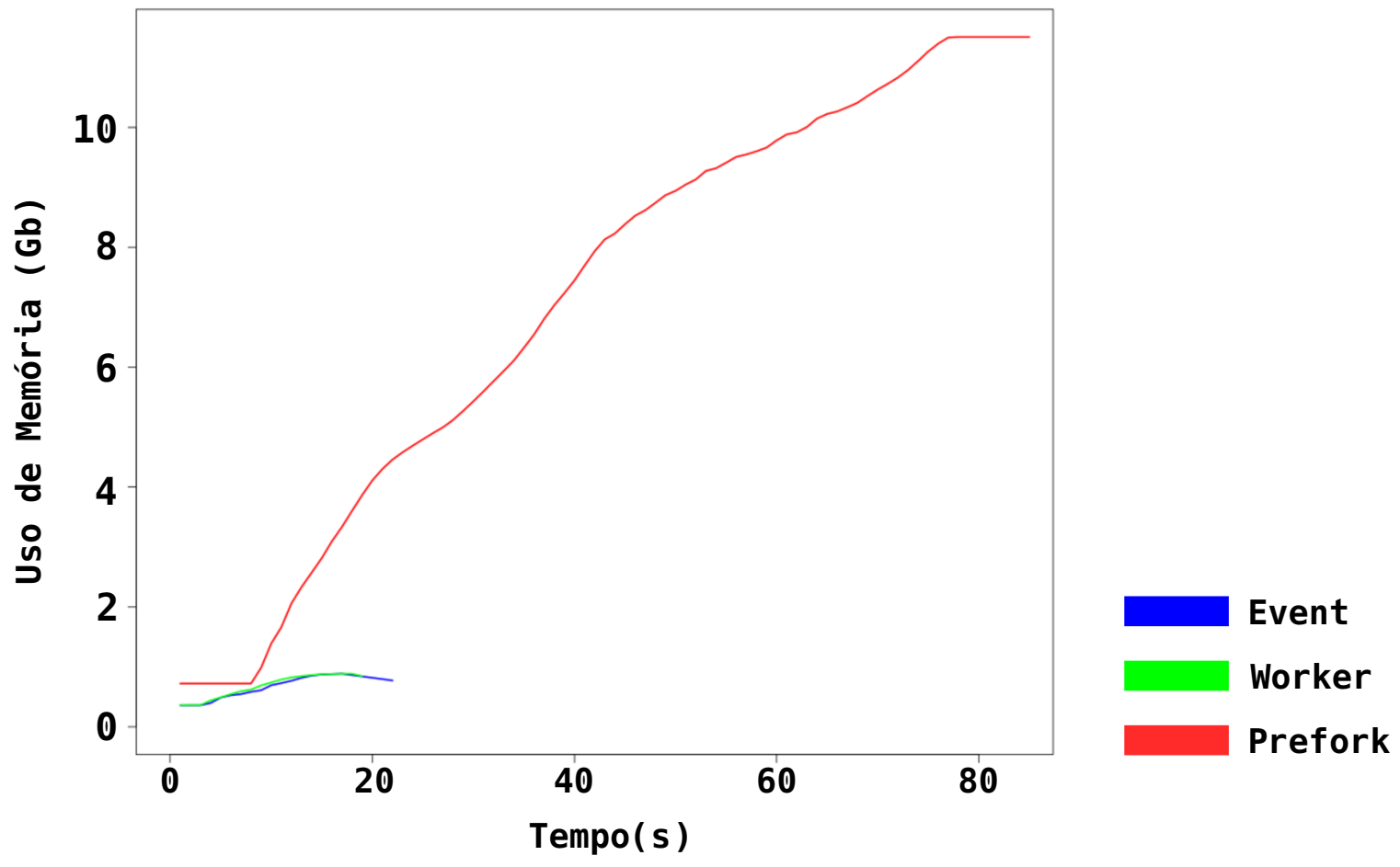

Figura 5.7: Arquivos Dinâmicos: Consumo de memória necessário para servir as requisições 


\subsubsection{Qual a Diferença de Desempenho do Apache Utilizando MVAS Quando Comparado com as Estratégias Baseadas em Processos e Threads?}

A segunda parte das validações tiveram como principais objetivos estudar o comportamento do kernel Linux com MVAS e com o Apache fazendo uso dos seus recursos. Como explicado na Seção 5.4, já temos a versão modificada do httpd utilizando MVAS. Instalamos a versão do httpd e executamos o benchmark novamente. Contudo, nossos experimento apontaram três problemas: (1) MVAS não funciona bem com múltiplas threads, (2) existem problemas de alocação de memória e (3) existe uma enorme sobrecarga nas operações do MVAS.

Para o primeiro problema, nós conversamos diretamente com o autor do MVAS para tentar identificar o que estava acontecendo. Depois de várias verificações na implementação, o autor detectou problemas nas heurísticas de manipulação dos segmentos de memória. Basicamente, MVAS tem problemas relacionados a alocação de pilha. Infelizmente, resolver esse problema requer mudar praticamente toda a implementação atual do MVAS e essa possibilidade foi, por hora, abandonada.

Para o segundo problema, é preciso recorrer à fundamentação teórica e revisitar como o Linux aloca memória. Na Seção 2.2.4 discutimos o processo de alocação da memória em sistemas Linux e na Figura 2.14 ilustramos o segmento heap para um programa. Repare da primeira parte da Figura 2.14 que o heap é mapeado para a memória física. Em seguida, o programa pede por mais memória para o SO por meio da função malloc(). O Linux então estende o tamanho do heap e fornece uma nova referência para a memória imediatamente e então espera que o programa tente escrever algo na memória. Assim, depois de uma tentativa de escrita na memória o kernel realmente aloca memória física para o programa. Com essa ideia em mente, é possível perceber que o MVAS tem que manipular esse tipo de situação e esse é um problema complicado para o MVAS resolver. Infelizmente, o MVAS falha em mapear essa situação e, a cada mudança no VAS, o SO perde a referência para a memória física.

\subsection{Discussão Sobre os Experimentos}

Durante a análise das diversas propostas de ampliação das abstrações de processos, notamos que os dois principais métodos de validação consistem em utilizar aplicações e microbenchmarks. Como já discutimos no Capítulo 4, o uso de aplicações é desejável uma vez que elas podem ser amplamente utilizadas para verificar o impacto geral de uma modificação nas abstrações de processos. Apesar de vários pesquisadores terem feito uso de tal abordagem, notamos que nenhum deles realizou experimentos utilizando cargas expressivas. Por exemplo, os trabalhos que alteraram o Apache realizavam testes com algumas poucas dezenas de requisições para arquivos estáticos; por exemplo, o Light-weight Contexts faz testes com cargas irrisórias (Vide Capítulo 3. Tais testes não evidenciam a real natureza da alteração feita na abstração de processo pois a aplicação modificada não é demandada de forma a exercitar o sistema sob pressão.

Esta pesquisa surgiu de uma parceria com a HPe que tinha por objetivo levar o Spa- 
ceJMP para o Linux por meio do MVAS. Para isso era necessário demonstrar que o MVAS funcionaria bem no Linux. Por isso, ficamos responsáveis por trabalhar nas validações de tal técnica. Como demostrado ao longo deste capítulo, tal técnica não é escalável da forma como foi feita. Isso é interessante de se observar uma vez que tal resultado dialoga com a argumentação construída no Capítulo 4; por meio do uso de uma aplicação real foi demonstrado que uma nova abstração pode não escalar em um sistema real. Note que esse resultado não significa que desacoplar a VAS é uma ideia ruim, apenas ilustra que os estudos referentes a tal ideia ainda precisam avançar.

Repare que nos experimentos, nós utilizamos uma abordagem na qual criamos o nosso benchmark do zero; essa decisão foi tomada de forma natural uma vez que o nosso principal objetivo era inserir o MVAS dentro do Apache. Contudo, dada a complexidade em se construir benchmarks (TARASOv et al., 2011), o melhor cenário a longo prazo consiste na adoção de uma ferramenta bem consolidada de benchmark, como PHORONIX ${ }^{5}$ ou LMbench $^{6}$.

Durante este trabalho, também buscamos replicar os resultados apresentados pelo Dune; também colaboramos com os desenvolvedores do Dune por meio do envio de correções na implementação original deles (patches). Os microbenchmarks apresentados pelos pesquisadores comportam-se perfeitamente como reportado, mas não foi possível replicar os resultados com as aplicações pois parte do código não estava mais disponível. O Dune é uma das propostas com maior potencial de ser incorporada nos SOs modernos, contudo a sua implementação é insegura e não escalável. O principal motivo para isso está no fato do Dune interceptar os endereços das chamadas de sistemas. Tal abordagem não funciona desde o momento que o Kernel adotou o sistema de aleatorização dos endereços de chamadas conhecido por KASLR (Gruss et al., 2017).

Portanto, o principal objetivo deste capítulo era apresentar evidências e uma visão prática da validação de uma nova abstração de processo usando uma aplicação amplamente conhecida. Além disso, buscamos deixar claro a importância de utilizar cargas de testes relevantes.

\footnotetext{
${ }^{5}$ https://www.phoronix-test-suite.com/

${ }^{6} \mathrm{http}: / /$ www.bitmover.com/Imbench/
} 



\section{Capítulo 6}

\section{Análise Sobre Abstrações de Processos}

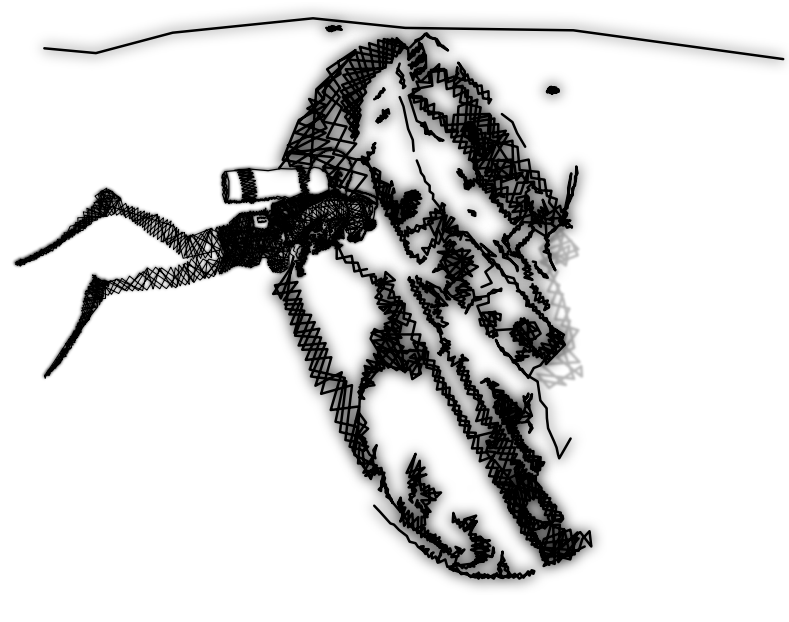

No Capítulo 3, introduzimos os principais trabalhos que orbitam em torno de novas abstrações de processos e, a partir de tais pesquisas, pretendemos desenvolver neste capítulo uma reflexão sobre suas principais características. Para isso, realizamos diversas análises sobre o estado da arte da pesquisa em processos e apresentamos um modelo teórico que visa fornecer uma perspectiva para a nova geração de abstrações de processos. Como resultado, responderemos as seguintes questões de pesquisa:

QP1: "Quais são as características desejáveis para a próxima geração de abstrações de processos?"

QP2: "Quais são os principais desafios em se implementar a próxima geração de abstrações de processos?"

Este trabalho se diferencia dos trabalhos apresentados no Capítulo 3 por buscar uma visão unificada sobre as novas extensões nas abstrações de processos e por levar em conta SOs de uso cotidiano, em especial o GNU/Linux. Esse último critério torna-se relevante para futuras investigações na área, uma vez que, se tais abstrações alcançarem SOs de ampla utilização, o impacto e o crescimento da área serão significativos.

\subsection{Potenciais e Dificuldades Para a Adoção de Novas Abstrações de Processos}

Quando a academia faz uma nova proposta para sistemas que estão no "estado da prática”, ela deve ser genérica o bastante para ser utilizada por múltiplas linguagens de programação e deve também considerar questões referentes a compatibilidade, melhor uso do hardware disponível e confiabilidade. Assim, apesar dos avanços trazidos pelas 
pesquisas em SO, elas estão limitadas às diferentes restrições existentes nos SOs utilizados tanto em produção quanto em projetos de pesquisa.

SOs usados em produção demandam rigorosa validação para manter o sistema estável em uma variedade de configurações. Espera-se que um SO maduro busque prevenir acessos ilegais à memória, impossibilitar a violação de APIs, evitar consumo excessivo de recursos e impedir erros de sincronização ou locking. Essas características precisam ser garantidas pelo SO (Witchel, RheE et al., 2005), porém, como esperado, tais restrições dificilmente são atendidas por propostas de pesquisas devido ao foco dos pesquisadores em um único problema, desconsiderando assim outros impactos. Por esse motivo, para que um novo componente sugerido a partir de uma pesquisa acadêmica chegue aos SOs atuais, é importante garantir que as aplicações que já existem não sofram impactos negativos em termos de desempenho e de uso.

Outra perspectiva que deve ser considerada é o contínuo desenvolvimento de novos recursos de hardware. Por exemplo, frequentemente observam-se componentes que são especializados em um nicho e que, ao longo do tempo, chegam ao usuário final, tornando-se comuns. Um caso simples que ilustra tal evolução é o uso de hardware especializado para virtualização, uma vez que esses existiam apenas para servidores e hoje estão disponíveis para a maioria dos usuários comuns. Tais recursos representam um novo leque de opções não exploradas, inclusive possíveis melhorias para as atuais abstrações de processos.

Entretanto, para incorporar novos recursos de hardware à abstração de processos, não se deve descartar que tal recurso pode não estar disponível para alguns usuários. Por essa razão, qualquer mudança nos processos para adicionar suporte a novos recursos de hardware deve levar em consideração todo tipo de situação. De modo inverso, propostas para melhorar uma abstração de processos podem sugerir mudanças no hardware e promover avanços no estado da arte dos chips modernos. Claro que a evolução do hardware necessita de cautela para evitar quebra de compatibilidade binária com aplicações legadas. Infelizmente, é preciso ter em mente que as alterações de hardware e suas limitações fazem com que propostas que dependem de tal evolução sejam difíceis de serem adotadas, e tornam a ampla adoção de uma determinada melhoria às vezes impraticável.

Algumas das novas abstrações de processos propostas por pesquisadores têm enorme dependência com outras tecnologias experimentais. Se, por um lado, isso traz vantagens para as tecnologias em desenvolvimento, por outro, reduz a chance de adoção de uma nova abstração de processos por um SO de produção devido à dependência dessa abstração de tecnologias instáveis.

Encontrar um bom balanceamento entre academia e indústria de forma a levar benefícios para os usuários não é uma tarefa trivial. Nesse sentido, novas propostas de mudanças na abstração de processos devem considerar as limitações citadas nessa seção para que possam atender aos requisitos de qualidade exigidos pelos SOs de uso cotidiano. Infelizmente, afirmar que uma proposta da academia pode ser adotada ou não pela indústria é uma tarefa complexa dada a enorme quantidade de variáveis envolvidas em tal análise. Mesmo assim, para posicionar o leitor em termos do estado da arte e da prática, buscamos estabelecer um "potencial de adoção" de uma nova proposta. Com base nos critérios apresentados, definimos um conjunto de variáveis que auxilia na definição das chances de uma pesquisa ser adotada pela indústria: 
1. Dependência Técnica: indica se o trabalho é construído levando-se em consideração outras tecnologias não estabilizadas. Consideramos tal aspecto um problema para a adoção da nova técnica.

2. Dependência de Compatibilidade: refere-se às propostas que exigem alterações na semântica das aplicações em espaço de usuário para que elas possam tirar proveito de alguma melhoria.

3. Dependência de Compilador: propostas que dependem de alterações no compilador. Nesses casos, consideramos que a adoção torna-se mais complicada uma vez que dois projetos precisam ser alterados.

4. Implementação Pesada: consideramos as implementações pesadas mais complicadas, uma vez que necessitam realizar mudanças no núcleo do SO, o que dificulta a adoção.

5. Implementação Independente: refere-se a propostas de novas implementações, claramente de difícil adoção.

6. Hardware Novo: indica que a proposta depende de um hardware novo que só existe em algum contexto específico ou mesmo que ainda não foi implementado.

7. Característica Específica de Hardware: refere-se a propostas de utilização de algum hardware bem consolidado para algum propósito diferente do original.

A Tabela 6.1 tenta apresentar o potencial de adoção de cada uma das propostas citadas no Capítulo 3 de acordo com as variáveis discutidas nesta seção. Na tabela, temos uma marcação indicada pelo simbolo $\boldsymbol{*}$ que significa que uma determinada proposta possui a limitação indicada na coluna correspondente. Se a proposta não contém tal restrição, então ela é marcada com o simbolo $\boldsymbol{V}$. Por uma questão de simplicidade, para definir o potencial de adoção, atribuímos zero para cada $\boldsymbol{*}$ e um para $\boldsymbol{V}$. Por fim, toda vez que a opção "Hardware Novo" é marcada, consideramos que a proposta também requer características específicas de hardware; para as variáveis referentes à implementação, consideramos que quando uma proposta parte de uma implementação independente, ela também é considerada pesada.

\begin{tabular}{|c|c|c|c|c|c|c|c|}
\hline \multirow{2}{*}{ Trabalho } & \multicolumn{3}{|c|}{ Dependência } & \multicolumn{2}{|c|}{ Implementação } & \multicolumn{2}{|r|}{ Hardware } \\
\hline & Técnica & Compatibilidade & Compilador & Pesada I & Independente & Novo & o Característica \\
\hline Dune & $\checkmark$ & $\checkmark$ & $\checkmark$ & $\checkmark$ & $\checkmark$ & $\checkmark$ & $\boldsymbol{x}$ \\
\hline Shreds & $\checkmark$ & $\boldsymbol{x}$ & $\boldsymbol{x}$ & $\checkmark$ & $\checkmark$ & $\checkmark$ & $\boldsymbol{x}$ \\
\hline Wedge & $\checkmark$ & $\boldsymbol{x}$ & $\checkmark$ & x & $\checkmark$ & $\checkmark$ & $\checkmark$ \\
\hline $\begin{array}{l}\text { Resource } \\
\text { Container }\end{array}$ & $\checkmark$ & $\boldsymbol{*}$ & $\checkmark$ & * & $\checkmark$ & $\boldsymbol{V}$ & $\checkmark$ \\
\hline Nooks & $\checkmark$ & $\boldsymbol{*}$ & $\checkmark$ & $\boldsymbol{*}$ & $\checkmark$ & $\checkmark$ & $\checkmark$ \\
\hline Mondrian & $\checkmark$ & $\boldsymbol{x}$ & $\checkmark$ & $\boldsymbol{*}$ & $\checkmark$ & $\boldsymbol{x}$ & $\boldsymbol{*}$ \\
\hline SpaceJMP & $\checkmark$ & $\boldsymbol{x}$ & $\boldsymbol{x}$ & $\boldsymbol{x}$ & $\checkmark$ & $\checkmark$ & $\checkmark$ \\
\hline LwC & $\checkmark$ & $\bar{x}$ & $\checkmark$ & $\bar{x}$ & $\checkmark$ & $\checkmark$ & $\checkmark$ \\
\hline Exokernel & $\boldsymbol{x}$ & $\boldsymbol{x}$ & $\boldsymbol{x}$ & $\boldsymbol{x}$ & $\boldsymbol{x}$ & $\checkmark$ & $\checkmark$ \\
\hline
\end{tabular}

Tabela 6.1: Potencial de adoção 


\subsection{Extração de Conceitos Derivados das Pesquisas em Abstrações de Processos}

Todas as pesquisas apresentadas no Capítulo 3 configuram o estado da arte no que se refere às abstrações de processos. Infelizmente, nenhuma delas encontra-se no código principal de qualquer SO de uso cotidiano. Parte desse problema vem dos fatos apresentados anteriormente na Seção 6.1, contudo outros aspectos que contribuem para que tais propostas não estejam presentes nos SO modernos vêm da falta de unificação e sistematização de tais ideias. Ao analisar cada uma das propostas, notamos que todas elas propõem direta ou indiretamente algum nível de desacoplamento entre os elementos presentes no SO. Tal observação nasce da abordagem radical tomada pelos criadores do Exokernel, que levaram o nível de desacoplamento do SO ao extremo. Apesar de o Exokernel ser um sistema de difícil adoção em termos práticos, ele nos alerta sobre as vantagens da redução de dependências entre os elementos do $\mathrm{SO}$ e as possibilidades que ela pode levar ao espaço de usuário. Tendo isso em mente, revisitamos de forma breve alguns dos trabalhos apresentados no Capítulo 3 sob a ótica do desacoplamento e seus potenciais benefícios.

Iniciamos analisando o projeto Dune. Esse projeto traz uma nova perspectiva de uso dos recursos de virtualização disponibilizados pelas CPUs modernas que, consequentemente, traz dois benefícios diretos: otimização e flexibilidade. Ao utilizar os recursos de virtualização para acelerar certas tarefas, o Dune promoveu avanços em um setor difícil de ser otimizado. Além disso, tais melhorias facilitam certas implementações no espaço de usuário, pois removem a necessidade de códigos com técnicas avançadas que visam trazer melhorias de desempenho; em outras palavras, a proposta do Dune pode melhorar a legibilidade de alguns códigos. Os avanços citados foram factíveis graças ao desacoplamento da virtualização, que possibilita entregar melhorias de desempenho no espaço de usuário de maneira relativamente simples (do ponto de vista da aplicação) e também fornece ganhos de segurança.

Já o projeto Nooks se distancia um pouco da abstração de processos, uma vez que busca tornar o núcleo do SO mais resiliente. Contudo, ao criar mecanismos que reagem de forma a reduzir as chances de o sistema quebrar, tal proposta apresenta o desacoplamento dos recursos, de forma a fornecer mecanismos para que os processos possam se recuperar ou tomar ações em casos de falhas. Adicionalmente, essa técnica cria um interessante mecanismo de comunicação entre as extensões do Kernel e os seus drivers, permitindo que o SO se "defenda" de problemas que ocorram com um código que foi acoplado ao seu núcleo.

De forma mais direta e sistemática, o Resource Container sugere o controle fino do gerenciamento de recursos e consequentemente o desacoplamento do gerenciamento de recursos de tal elemento. De certa maneira, essa proposta já pode ser encontrada incorporada nos SOs atuais, sob a forma de contêineres no Linux, mais especificamente, como o cgroups $^{1}$. A principal contribuição do Resource Container vem da sua capacidade de permitir que a própria aplicação tome conta da sua execução. Ainda que parte das ideias apresentadas por esse trabalho estejam presentes em alguns SOs, as implementações ainda

\footnotetext{
${ }^{1}$ cgroups é uma funcionalidade fornecida pelo Linux que permite limitar e isolar recursos de uma coleção de processos.
} 
são relativamente reduzidas em termos do escopo apresentado na pesquisa.

Uma abordagem alternativa que visa atender uma nova geração de computadores com memórias não voláteis na ordem dos petabytes é o SpaceJMP/MVAS. Os autores sugerem o desacoplamento do VAS dos processos e permitir que eles tenham múltiplos VAS e, de forma reativa, a aplicação torne-se capaz de mudar o VAS atual. Essa abordagem faz com que um processo consiga acessar regiões muito maiores do que aquelas garantidas pelo tamanho de um VAS. Indiretamente, desacoplar um VAS adiciona a possibilidade de criar processos persistentes, isto é, que vivem mesmo após o reboot ou mesmo após um problema. Desacoplar o VAS pode trazer benefícios para aplicações de checkpoints, melhorar o gerenciamento de bibliotecas, e elevar o nível de isolamento e compartilhamento.

O projeto Light-weight Context $(\mathrm{lwC})$ indiretamente propõe o total desacoplamento do PC; vale observar que os autores explicitam outros desacoplamentos, contudo, para esse trabalho, acreditamos que o desacoplamento do PC é o que melhor descreve as inovações propostas. Desacoplar o PC leva uma infinidade de possibilidades para o espaço de usuário, uma vez que o processo pode fazer operações semelhantes às do escalonador sem grandes custos e dentro do mesmo intervalo de execução do processo. lwC tem como principal característica um robusto e interessante modelo de programação que permite às aplicações no espaço de usuário utilizarem novos paradigmas de desenvolvimento. Isso cria diversas oportunidades para desenvolver novos tipos de manipulações, tal como criar snapshots do estado atual do processo e depois reverter o processo para o estado anterior. Dado os múltiplos snapshots (contextos), é possível fazer com que um processo em execução mude para uma outro contexto com diferentes restrições de acesso a memória permitindo isolar trechos de código sensível. Ao contrário do que parece, isso não é como utilizar threads ou processos independentes. Por não haver dependência do escalonador para mudar o contexto do processo (o que é razoavelmente caro), a própria aplicação pode escolher quando e qual contexto manipular e fornecer, assim, um controle fino para os programadores (o que pode melhorar o desempenho e a segurança).

De modo geral, percebemos que vários dos trabalhos analisados têm preocupação com o gerenciamento e acesso a memória; em especial, vários deles questionam o tratamento dado à memória pelos SOs atuais. A abordagem de utilizar um único espaço de endereçamento por processo tem se provado eficiente ao longo dos anos, porém, apesar do seu sucesso, essa não é uma abordagem à prova de falhas e ainda carece de melhorias. Primeiramente, a abordagem de isolar os processos por meio do espaço de endereçamento linear melhora a confiabilidade do sistema e a segurança. Entretanto, um processo não tem uma forma de restringir o seu próprio acesso ao seu segmento de memória, o que pode ser útil para reduzir os riscos de falhas de segurança ocasionados por binários de terceiros. Em segundo lugar, o controle do compartilhamento de memória acontece no tamanho de uma página e cria a oportunidade para explorar falhas, tais quais buffer e stack overflow ou mesmo o compartilhamento de bibliotecas comprometidas. Com essa preocupação, os trabalhos Wedge, shreds e mondrix/mondrian buscam trazer melhorias para essas fragilidades.

Analisando as abstrações de processos da perspectiva da segurança, o projeto Wedge retoma uma antiga premissa que defende o princípio do menor privilégio. Ela afirma que precisamos mudar a lógica atual de conceder permissão por padrão para uma ideia de negar permissão por padrão. Essa mudança de paradigma torna supostamente possível a redução 
das chances de ataques e vazamento de dados, uma vez que o programador precisa indicar explicitamente o que será exposto. Tal pesquisa indiretamente propõe o desacoplamento dos privilégios da abstração de processos. Além disso, ela mantém a compatibilidade entre aplicações novas e legadas, sendo uma opção de uso ao programador.

Entrando um pouco mais nas questões de proteção e controle-fino da memória, destacamos o shreds e o mondrix/mondrian. shreds nasce com a ideia de evitar ataques conhecidos como abusos intra-processos de conteúdo da memória. Os autores defendem que o acesso a certas regiões da memória de um processo que esteja executando em espaço de usuário merece proteção especial. Em tal proposta, os autores utilizaram um recurso específico dos processadores ARM em conjunto com um mecanismo de gerenciamento da região de memória (Seção 2.2.3). Essa proposta entrega mais flexibilidade, segurança e controle ao acesso da memória.

$\mathrm{Na}$ mesma linha de fornecer controle fino sobre a memória, os autores do Mondrix propuseram, de forma mais radical, um mecanismo de controle do acesso à memória no nível das palavras de dados. Para isso, os autores sugerem alterações no hardware e no $\mathrm{SO}$ de forma a controlar todo acesso com a menor granularidade possível. Indiretamente, shreds e mondrix são propostas de desacoplamento do controle de memória.

\subsection{Bead: Um Modelo Teórico Para a Próxima Geração de Abstrações de Processos}

Neste trabalho discutimos as abstrações de processos partindo do conhecimento já estabelecido e consolidado pela indústria até chegar ao estado da arte de novas propostas para melhorar o conceito de processo. Durante toda a pesquisa, percebemos que as diversas propostas giram em torno do desacoplamento de elementos do processo, contudo, não existe uma tentativa de organizar as diversas ideias propostas. Nesse sentido, observamos e analisamos diferentes propostas de desacoplamento que representam o estado da arte, acreditando que várias das ideias apresentadas podem atingir o "estado da prática" e assim pavimentar novos ramos de pesquisas. Como resultado dessa pesquisa, compilamos os diversos trabalhos estudados em um modelo que busca elevar o grau de desacoplamento dentro das abstrações de processos.

Para exemplificar a proposta de desacoplamento deste trabalho, faremos uma analogia com a evolução do modelo atômico. Começamos por um dos primeiros modelos atômicos aceitos pela comunidade científica, proposto por Dalton, que afirmava que um átomo era uma esfera maciça e indivisível. Em seguida, Thomson propôs outro modelo no qual os átomos eram compostos por partículas positivas e negativas, o que indicava a divisibilidade dos átomos. Posteriormente, Rutherford refinou o modelo, propondo um esquema em que o átomo possui um núcleo e os elétrons giram em torno desse núcleo formando um sistema semelhante ao modelo planetário. O modelo atômico continua sendo evoluído e sofisticado, contudo a principal lição que tiramos disso para o nosso contexto é o constante refinamento do modelo e os avanços que vêm junto com ele.

Seguindo a analogia do modelo atômico, podemos considerar que as abstrações de processos estão em um estágio equivalente ao modelo de Thomson. A abstração de processo 
não é mais um bloco sólido e indivisível; ela possui um leve grau de desacoplamento, uma vez que no passado notou-se a vantagem em se desacoplar o PC e a Pilha, possibilitando múltiplos fluxos de execução no mesmo processo (threads). Seguindo esse raciocínio e buscando avançar o modelo atual, apresentamos o modelo bead ${ }^{2}$ que consiste em buscar um elevado grau de desacoplamento dos elementos da abstração de processos.

\begin{tabular}{|c|c|c|c|c|c|c|}
\hline Vantagem & $\begin{array}{c}\text { Novos } \\
\text { modelos de } \\
\text { programação }\end{array}$ & $\begin{array}{c}\text { Persistência } \\
\text { de processos }\end{array}$ & $\begin{array}{c}\text { Controle } \\
\text { fino de } \\
\text { privilégios }\end{array}$ & Segurança & Recuperação & Otimização \\
\hline \hline PC & $\boldsymbol{V}$ & & & & & $\checkmark \checkmark$ \\
\hline VAS & $\boldsymbol{V}$ & $\boldsymbol{V}$ & & & $\checkmark \checkmark$ & \\
\hline $\begin{array}{c}\text { Resource } \\
\text { Management }\end{array}$ & $\checkmark$ & & & & $\checkmark \checkmark \checkmark$ & $\checkmark$ \\
\hline $\begin{array}{c}\text { Controle de } \\
\text { acesso a } \\
\text { memória }\end{array}$ & & & $\checkmark \checkmark \checkmark$ & $\checkmark \checkmark$ & & \\
\hline Virtualização & & & & $\boldsymbol{V}$ & & $\checkmark \checkmark \checkmark$ \\
\hline Privilégios & $\boldsymbol{V}$ & & $\boldsymbol{V} \boldsymbol{V}$ & $\boldsymbol{V}$ & & \\
\hline
\end{tabular}

Tabela 6.2: Relação desacoplamento benefício

Como apresentado na Seção 6.1, para que os desacoplamentos propostos nas pesquisas sejam absorvidos pelos SOs atuais é preciso considerar diversos aspectos. Em especial, destacamos que as abordagens que seguem uma implementação leve e que atendem as propostas de desacoplamento destacadas na Tabela 6.2 são preferíveis. Essa tabela mostra as propostas de desacoplamento na vertical e os benefícios que elas podem trazer aos SOs. Por fim, utilizamos uma escala de zero a três $\boldsymbol{V}$, que indica o quanto de benefício um determinado desacoplamento pode levar para uma área.

A Figura 6.1 busca mostrar de forma visual o modelo de abstração de processos proposto por este trabalho. Na parte central da figura temos os três elementos fundamentais para o uso dos processos: PC, Pilha e contexto de E/S. Nas camadas mais externas temos o VAS, que é um elemento importante para que os processos em SOs de propósito geral funcionem de forma apropriada (dada sua importância, ele ocupa boa parte da representação da abstração). Em seguida notamos diversos elementos que orbitam a abstração atual de processos. Eles podem ser vistos como elementos menos importantes para o correto funcionamento da abstração, mas são fundamentais para diversas aplicações modernas. Note na Figura a presença de "??", esse foi inserido na imagem com o objetivo de simbolizar outros desacoplamentos que não detectamos ou que venham a surgir no futuro. Por fim, no canto direito da figura, destacamos apenas os dois principais elementos envolvidos na criação das threads; repare que threads podem ser vistas como desacoplamentos do PC e da pilha.

\footnotetext{
${ }^{2}$ Bead em inglês, refere-se às pequenas contas que compõem um colar ou pulseira. Normalmente, existe uma ampla variedade de tais objetos.
} 


\section{Abstração de processos}

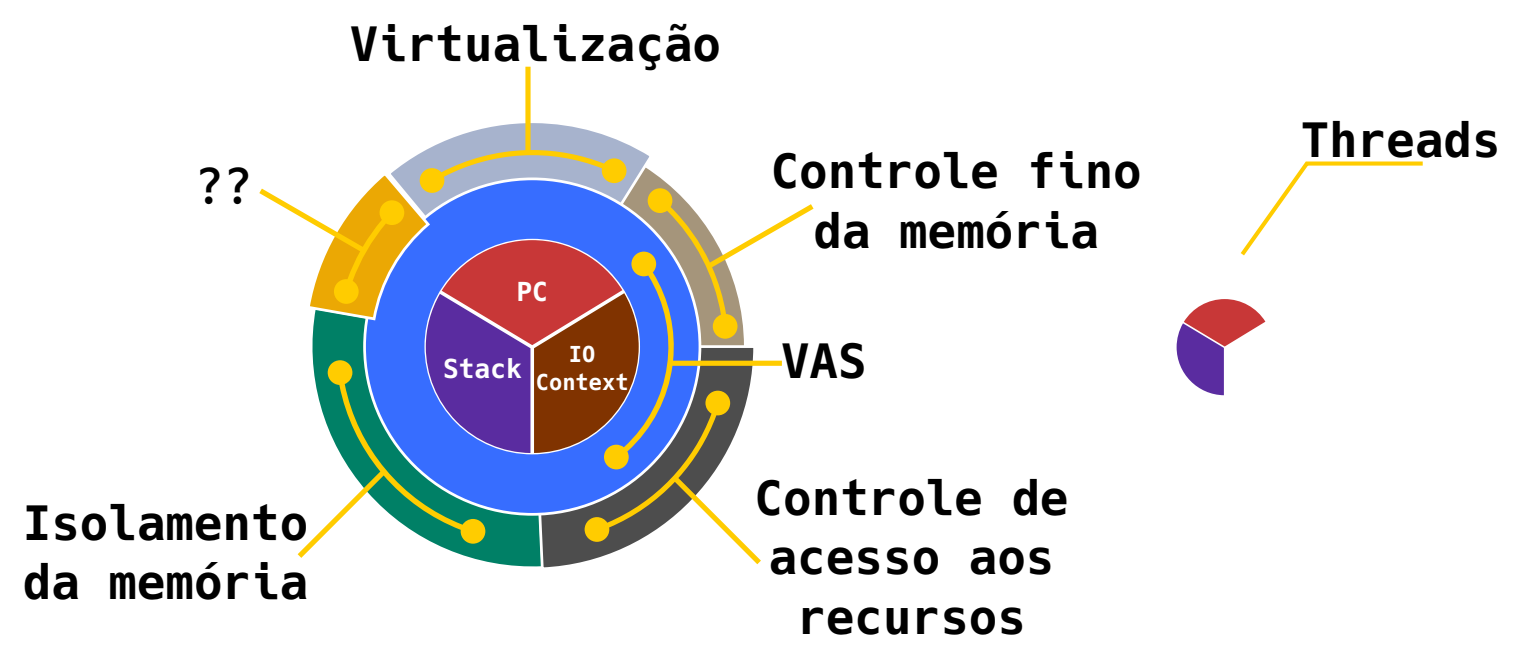

Figura 6.1: Decomposição do processo

\subsubsection{A API Bead}

Nesta subseção discutiremos a proposta de API do Bead, que tem por objetivo fornecer uma visão do funcionamento desse modelo; note que a implementação do Bead consiste em um trabalho futuro. Em termos de API e implementação, queremos manter os critérios para adoção descritos na Seção 6.1 e, ao mesmo tempo, fornecer uma API unificada que possa ser utilizada no espaço de usuário. Para que tal modelo possa ser implementado, é preciso usar uma abordagem que caminha entre uma implementação estrutural leve e pesada. Implementação pesada significa que será necessário inserir códigos intermediários nas atuais abstrações de processo para que esses forneçam mecanismos externos e permitam às extensões atuar sobre o núcleo do SO. Tal abordagem visa manter a compatibilidade com as aplicações já existentes sem forçar mudanças nas aplicações no espaço do usuário. Implementação leve é quando queremos o maior grau de desacoplamento possível como também facilidade para futuras expansões no modelo.

Como mostrado no Capítulo 3, cada proposta de extensão na abstração de processo sugere uma API para o seu contexto específico. Nesse sentido, buscamos absorver as técnicas utilizadas pelos trabalhos anteriores e combinamos as principais chamadas dentro do bead. A seguir, apresentamos cada uma das operações fornecidas, uma breve descrição sobre o seu comportamento e o trabalho do qual foi derivada. Observe que o conjunto dessas operações pode ser abstraído para uma biblioteca no espaço do usuário e que a combinação das várias operações possibilita a criação de novos modelos de programação (discutiremos padrões de utilização na próxima seção).

BEAD_SET_CONFIG: Essa operação atua diretamente nas configurações referentes às abstrações de processos. Ela espera que o programa indique explicitamente quais desacoplamentos utilizar. Se nenhuma informação for passada, assume-se um conjunto de configurações padrão compatível com a maioria das aplicações atuais. As configurações do que será desacoplado são feitas por meio desse comando. 


\section{- Parâmetros:}

Espera uma estrutura de dados padrão que encapsula todas as informações referentes aos desacoplamentos desejados.

\section{- Retorno:}

Se todas as configurações solicitadas pelo usuário forem suportadas, então a função devolve o status 0 . Se alguma das operações falhar, o status é um valor positivo construído por meio de manipulações binárias na qual cada bit significa uma falha que ocorreu ${ }^{3}$.

\section{- Referência:}

Essa operação surge da necessidade de unificar as diversas propostas, por isso não tem referência direta a nenhum trabalho.

BEAD_GET_CONFIG: Essa operação atua recuperando as configurações referentes às abstrações de processos.

\section{- Parâmetros:}

Espera uma estrutura de dados padrão que será utilizada para preencher as informações.

\section{- Retorno:}

Devolve 0 se tudo ocorrer como esperado, ou um valor negativo de status de erro.

\section{- Referência:}

Operação criada no contexto deste trabalho.

BEAD_NEW_CONTEXT_INSTANCE: Essa chamada comporta-se de forma similar ao fork(), pois faz uma cópia idêntica dos elementos do processo pai, porém diferencia-se dela por não criar uma nova thread e compartilhar o mesmo PID do processo pai. Na prática, essa função também pode receber alguns parâmetros que alteram o seu comportamento padrão.

\section{- Retorno:}

Se estiver no processo que invocou a operação, então um descritor do novo contexto é devolvido. Caso contrário, se estiver dentro de um contexto criado, devolve -1 .

\section{- Referência:}

Chamada baseada em lwCreate(), proposta pelo lwC.

BEAD_SWITCH: Dentre as operações mais comuns observadas nos diversos trabalhos, destaca-se o mecanismo de troca de alguma propriedade dentro do processo. Nesse

\footnotetext{
${ }^{3}$ Definir o significado para cada bit, representa um nível de detalhe que pode varia de SO para SO. Por isso, não especificamos tais valores.
} 
contexto, a operação BEAD_SWITCH unifica operações de mudanças dentro do processo. Destacam-se os casos da troca de contexto e de entrada em regiões mais seguras da memória. A operação pode esperar um descritor que referencia uma instância de um contexto que seja válida. Com base no descritor recebido, essa chamada transfere a thread de execução do processo que invocou tal chamada para a instância de contexto criada anteriormente. Outra utilização dessa operação é a troca da execução de uma área menos segura para outra mais segura por meio da operação BEAD_ENTER_CONTEXT.

- Parâmetros:

- Descriptor: Descritor do contexto alvo

\section{- Retorno:}

Se algo der errado, essa função devolve um valor negativo informando o erro.

\section{- Referência:}

Chamada baseada em lwSwitch(), proposta pelo lwC.

BEAD_VIRTUALIZATION_MODE: A chamada para essa operação faz com que o processo entre em modo de virtualização, i.e., faz uso dos recursos de virtualização disponíveis. Essa função pode ter o seu comportamento alterado via parâmetro ou via configurações externas. Dentre as possíveis configurações, encontra-se a possibilidade de restringir qual operação de virtualização deseja-se utilizar.

- Parâmetros:

- Options: Recebe opções que determinam o modo de virtualização.

\section{- Retorno:}

Se algo der errado, essa função devolve um valor negativo informando o erro.

\section{- Referência:}

Chamada baseada em dune_entry(), do Dune.

BEAD_ENTER_COMPARTMENT: Essa operação faz com que a thread em execução tenha associada a si um compartimento ao qual apenas ela tem acesso. Isso auxilia contra ataques intra-processos. Nenhuma outra thread do processo tem acesso a qualquer dado do compartimento e o mesmo vale para os dados dentro do compartimento (i.e., o compartimento é isolado). Devido ao isolamento oferecido por essa técnica, tornase necessária uma função especial para realizar a alocação de memória dentro do compartimento. Essa operação trabalha em conjunto com a operação BEAD_SWITCH.

\section{- Retorno:}

Devolve 0 se tudo ocorrer bem, ou um código de erro se algo der errado.

\section{- Referência:}

Chamada baseada em shred_enter(), proposta pelo Shred.

BEAD_EXIT_COMPARTMENT: Essa função sai do compartimento atual. 


\section{- Retorno:}

Devolve 0 se tudo ocorrer bem, ou um código de erro se algo der errado.

\section{- Referência:}

Chamada baseada em shred_exit(), proposta pelo Shred.

BEAD_ALLOC_COMPARTMENT: Essa operação é responsável por alocar memória dentro de um compartimento e tem o seu funcionamento similar ao da função malloc(). Uma vez que a memória é alocada utilizando essa operação, ela é acessível apenas dentro da thread que solicitou entrar no compartimento. Esse mecanismo de isolamento de memória faz com que as páginas do próprio processo tenham o seu acesso restrito a uma thread.

\section{- Parâmetros:}

- tamanho: Tamanho em bytes que se deseja alocar.

\section{- Retorno:}

Devolve um ponteiro para a região de memória alocada. Em caso de erro, o valor NULL é devolvido.

- Referência:

Chamada baseada no Shred.

BEAD_FREE_COMPARTMENT: A operação de liberar o compartimento alocado simplesmente reverte a operação feita por BEAD_ALLOC_COMPARTMENT.

\section{- Parâmetros:}

- Ref: Ponteiro para a memória previamente alocada.

\section{- Retorno:}

Não devolve nada.

\section{- Referência:}

Chamada baseada no Shred.

\subsubsection{Padrões de Utilização}

As operações indicadas na Seção 6.3.1 podem ser entendidas como funções ou constantes utilizadas para determinar o procedimento que deve ser feito ${ }^{4}$. Para manipular as diversas operações fornecidas pelo bead, utilizaremos uma função central (beadctl()) responsável por gerenciar as chamadas de sistema solicitadas pelo usuário. Essa função receberá dois valores como parâmetro: (1) uma constante representando a operação do bead solicitada e (2) uma estrutura de dados padronizada (bead_data). O beadctl() atua de forma seletiva sobre as operações solicitadas como pode ser visto no Pseudocódigo 6.1 - ao longo deste capítulo, adotaremos essa função como padrão. Note que ela se comporta

\footnotetext{
${ }^{4}$ Entendemos que tal decisão deve ser tomada pelo próprio desenvolvedor.
} 
como um adaptador chamado no espaço de usuário e que, por sua vez, faz o pedido direto para o Kernel (essa função é análoga ao IOCTL presente no Linux).

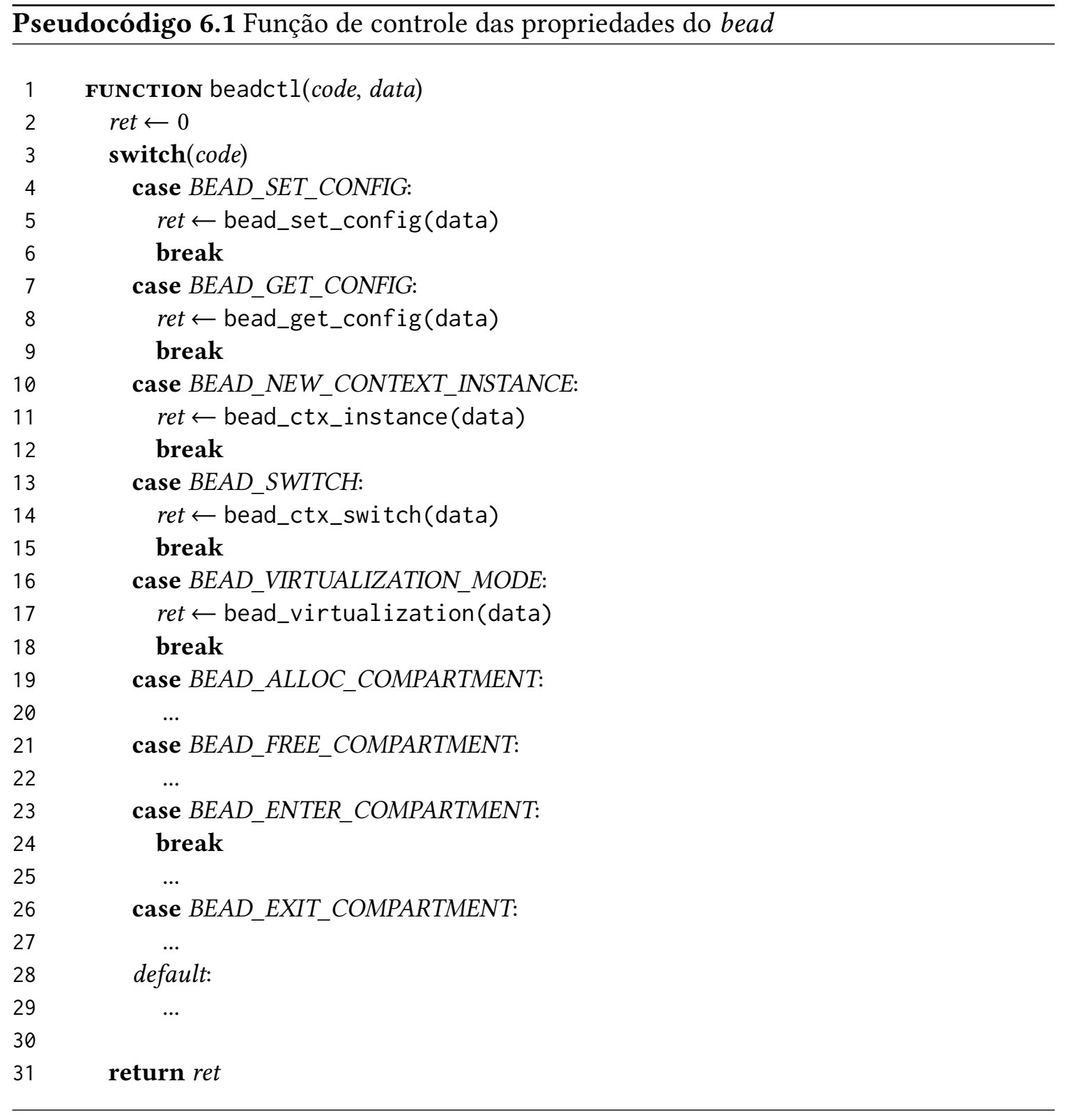

Para passar dados do espaço de usuário para o kernel (e vice-versa), definimos uma estrutura de dados para realizar a troca de informações de forma padronizada. O Pseudocódigo 6.2 ilustra uma potencial estrutura de dados para realizar a troca de informação do espaço de usuário para o kernel. Note que essa estrutura de dados nasce com o objetivo de simplificar as chamadas de função, unificar as diferentes propostas e facilitar a comunicação.

Introduzimos nesta seção alguns dos possíveis padrões de utilização do bead. Nosso objetivo é ilustrar como tal API pode levar benefícios para as aplicações, principalmente em termos de novos modelos de programação. Apresentamos alguns usos elementares, mas que servirão de apoio para outros padrões mais sofisticados. Além de mostrar o 
Pseudocódigo 6.2 Estrutura de dados utilizada pelo bead para troca de dados do espaço de usuário com o de kernel (vice-versa)

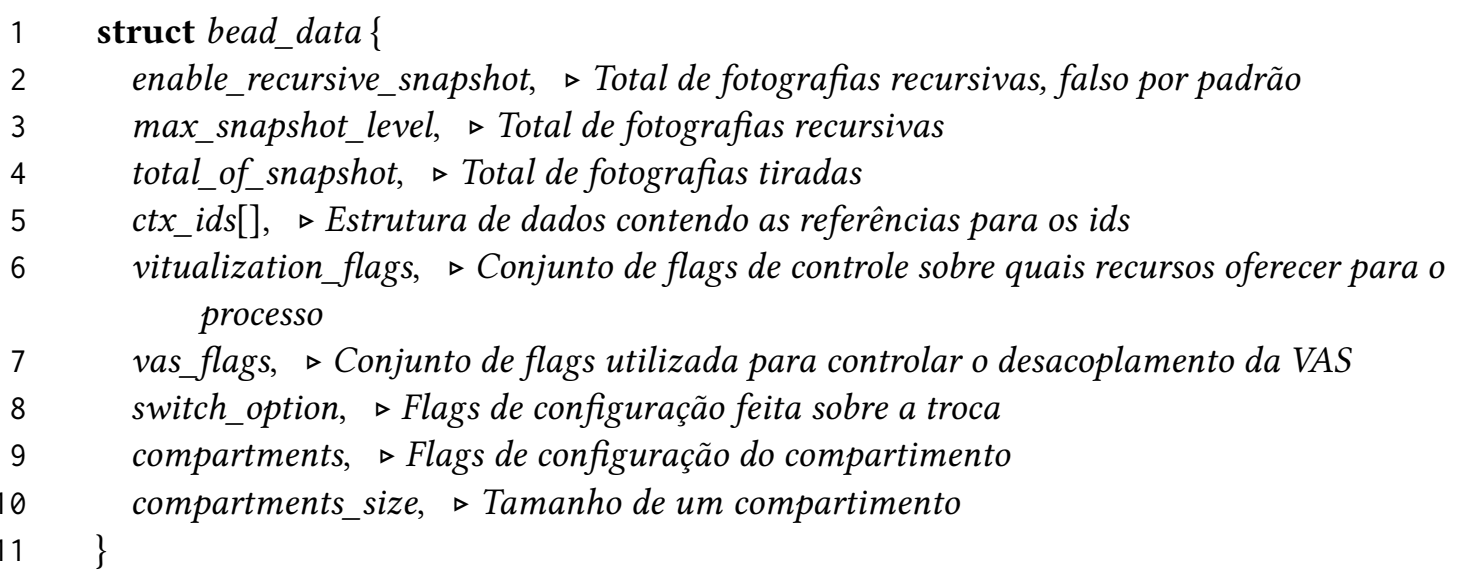

pseudocódigo, também discutimos o potencial uso de determinado padrão em aplicações reais ${ }^{5}$.

\section{Padrão Configuração}

Uma das operações mais comuns presentes nos trabalhos discutidos no Capítulo 3 é a possibilidade de configurar certas funcionalidades. A maioria dos projetos realiza tal procedimento por meio de parâmetros passados para as funções. Dado que o bead busca unificar as diversas propostas e ampliar a decomposição das abstrações de processos, faz-se necessário um mecanismo simplificado para ajustes de configuração. O Pseudocódigo 6.3 mostra a manipulação das operações BEAD_SET_CONFIG e BEAD_GET_CONFIG, que tem por objetivo lidar com as diferentes opções de desacoplamentos do processo.

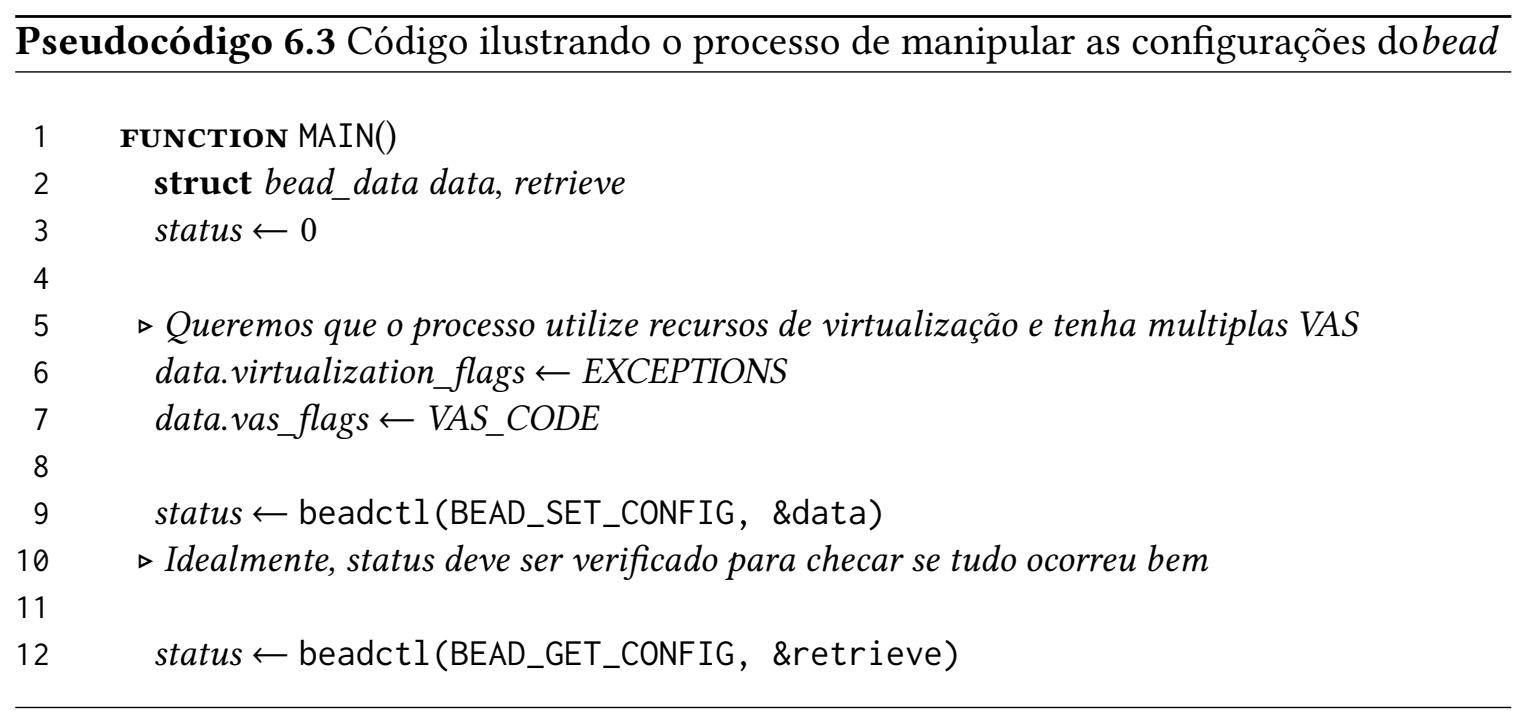

O Pseudocódigo 6.3 ilustra de forma geral o processo de utilização das operações

\footnotetext{
${ }^{5}$ Vale observar que nem todos os padrões apresentados nesta seção têm aplicação direta nas aplicações atuais.
} 
de ajuste e recuperação da configuração. A estrutura bead_data padroniza a comunicação entre o espaço de usuário e o Kernel. Vale acrescentar que esse tipo de operação pode ser facilmente encapsulada e explorada em bibliotecas no espaço do usuário (p.ex., libbead).

A operação BEAD_SET_CONFIG recebe uma estrutura de dados do tipo bead_data. Por sua vez, essa estrutura deve ser preenchida no espaço de usuário de forma a conter as propriedades de desacoplamento que o programador deseja explorar. Por exemplo, se o programador deseja utilizar recursos de virtualização e de desacoplamento do VAS, ele pode preencher os campos VITUALIZATION_FLAGS e VAS_FLAGS da estrutura bead_data para, em seguida, chamar a função beadctl(), passando tal informação como parâmetro. A opção BEAD_SET_CONFIG é uma operação de baixo nível que vai preencher estruturas internas do Kernel referentes aos processos. Essa função pode ser chamada a qualquer momento durante a execução do processo, tornando flexível o ajuste de algumas configurações.

A operação BEAD_GET_CONFIG permite recuperar as configurações feitas nos processos. Se o programador não tiver feito nenhuma alteração, então o Kernel utiliza uma configuração padrão que é compatível com a abstração atual de processos - isso permite manter a compatibilidade com as aplicações atuais. Essa operação é de baixo nível e devolve uma estrutura de dados do tipo bead_data preenchida pelo Kernel com as configurações atuais.

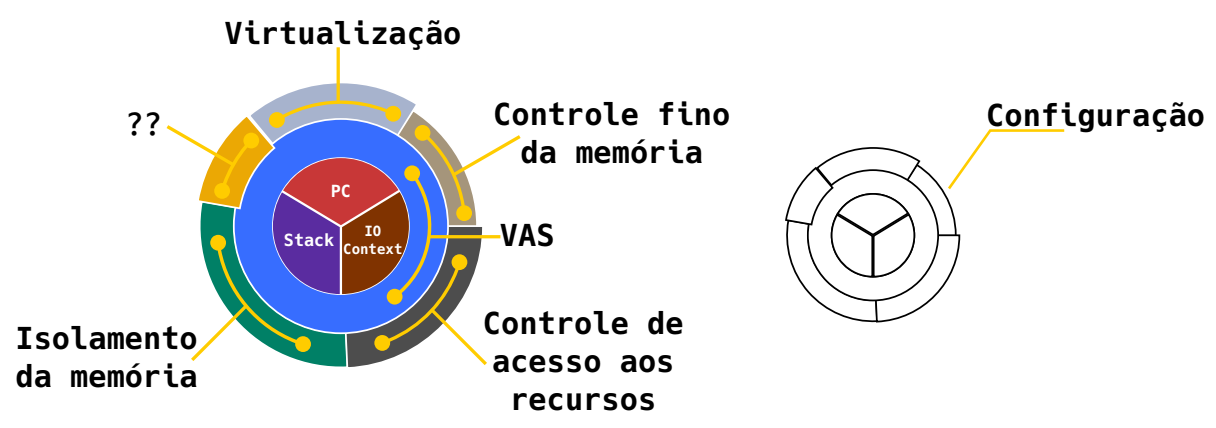

Figura 6.2: Ilustração do padrão configuração

A Figura 6.2 fornece uma visão geral sobre os elementos afetados pelo padrão configuração. Ele representa as fronteiras entre os diversos componentes da abstração de processos. Esse padrão também pode ser expandido para dar suporte a mecanismos sofisticados que permitem à aplicação em espaço de usuário passar informações sobre como o bead deve proceder em determinadas situações. Uma aplicação poderia fazer uso de algum padrão consolidado, por exemplo, o BSD Packet Filter (MCCANNE e JACOBSON, 1993), e assim dizer para o núcleo do SO como agir de forma similar a como o Resource Container sugere (Seção 3.4).

\section{Padrão Fotografia}

O $l w C$ introduz a funcionalidade snapshot (utilizaremos o termo fotografia), duplicando as informações do processo de forma similar ao fork(). O snapshot () diferencia-se do fork(), uma vez que ele não cria uma nova thread e nem um novo PID (para mais detalhes, veja Seção 3.8). Inspirado por tal funcionalidade, o bead busca oferecer esse recurso e, 
adicionalmente, a possibilidade de ter maior controle sobre a operação de fotografar o processo. O Pseudocódigo 6.4 ilustra o uso dessa operação.

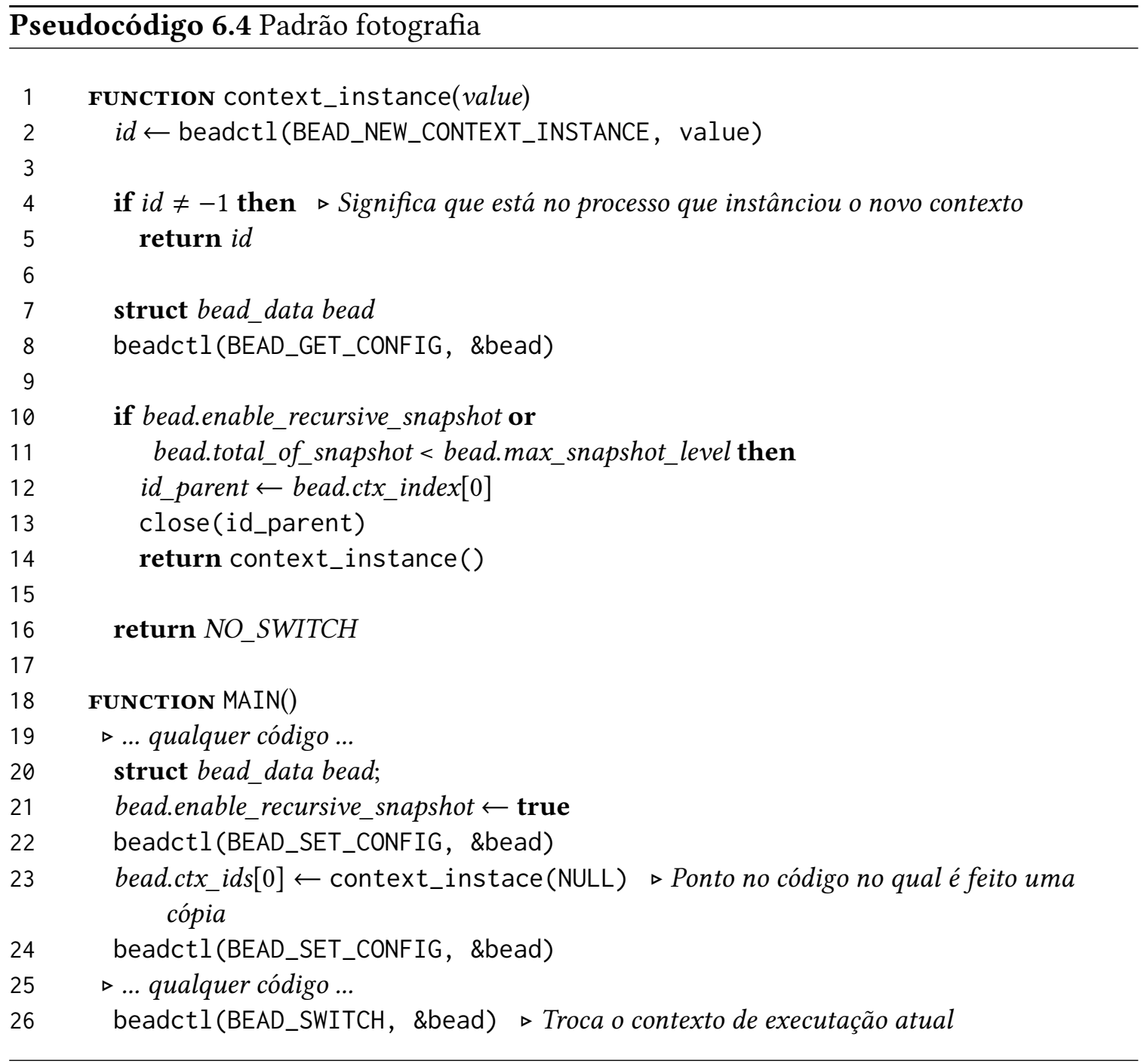

A Linha 18 do Pseudocódigo 6.4 representa o ponto de início de um programa qualquer. Como indicado no comentário, várias operações podem ser realizadas antes de tirar uma fotografia do estado do processo, ou seja, o processo atinge um estado qualquer sem a influência do bead. O programador deve decidir em qual momento da execução do processo ele quer tirar uma fotografia do estado, então ele dá início a tal tarefa seguindo a semântica introduzida pelo bead. Ainda na função $\operatorname{MAIN(),~o~desenvolvedor~pode~configurar~detalhes~}$ da operação de fotografar o estado para que ela seja recursiva em relação ao ponto na qual a fotografia foi tirada ou não ${ }^{6}$. A operação de fazer uma cópia do processo começa no momento em que a função context_instance() é chamada.

A função context_instance() na Linha 1 é responsável pela operação de criar e salvar a cópia do estado. Ela começa realizando uma chamada para a função beadctl() passando a solicitação da operação de BEAD_NEW_CONTEXT_INSTANCE. No momento que essa chamada

\footnotetext{
${ }^{6} \mathrm{O}$ programador pode definir quantas vezes ele quer repetir o processo de fotografar de forma similar a um loop.
} 
termina, uma cópia do estado atual do processo foi feita. Note que o atributo id pode assumir valores diferentes dependendo do contexto no qual o processo está executando. Se a thread do processo estiver no processo pai (aquele que chamou context_instance()) então o id será um identificador da fotografia do processo; do contrário, ela receberá -1. Na primeira execução, a função vai devolver o id para a função MAIN() que, por sua vez, vai prosseguir com a sua execução normalmente. Observe que o id é armazenado em uma estrutura de dados interna para simplificar a recuperação dessa informação em outras fotografias do processo. Quando a Linha 7 for atingida, ocorrerá a troca do estado atual do processo para o estado anteriormente fotografado. Logo que a troca de estados acontece, a Linha 2 retorna -1 , pois a execução do processo acontecerá dentro do estado anterior; o código da Linha 7 em diante dá seguimento a execução.

A Linha 10 ilustra como a troca de contexto pode ser feita de forma recursiva ou limitada por um determinado número de chamadas. Se as condições do if forem atendidas, então recupera-se o id do pai e, em seguida, remove-se as informações do estado por meio da função close(). Por fim, a função context_instance() é chamada recursivamente e uma nova fotografia do processo é tirada; note que o SO deve controlar tal recursividade de forma a evitar sobrecarga no sistema. Se a condição do if falhar, então a troca de contexto encerra devolvendo NO_SWITCH para o espaço de usuário. A aplicação pode realizar o tratamento que julgar necessário com base no retorno.

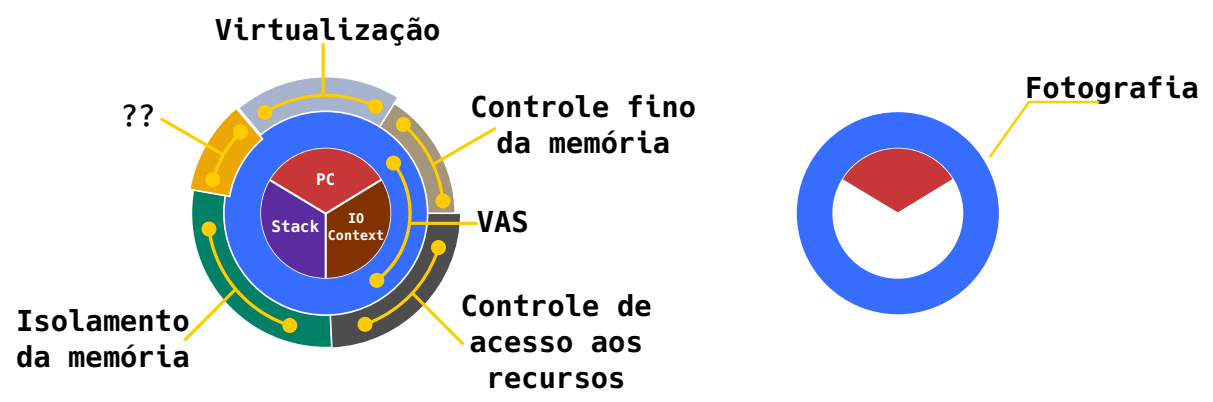

Figura 6.3: Ilustração dos principais elemento envolvidos no padrão fotografia

A Figura 6.3 ilustra os principais elementos envolvidos no padrão fotografia: o VAS e o PC. Durante o processo de criação do novo contexto, o VAS é fotografado e mantido ao longo do tempo; por sua vez, o PC é usado para alternar pelas diferentes fotografias do processo. Esse padrão pode ser útil em alguns cenários; dentre eles, destaca-se a aceleração e isolamento de algumas atividades que necessitam ser inicializadas várias vezes.

Para ilustrar a utilização desse padrão em uma aplicação real, recorremos ao tratamento de requisições feito pelo servidor Apache Httpd (para mais detalhes vide Seção 4.1.1). Para cada requisição, o Apache precisa iniciar uma série de estruturas de dados e, em seguida, proceder com o tratamento da solicitação. Essa etapa inicial pode ser otimizada utilizando o padrão fotografia. Para isso, bastaria que, ao final do procedimento de iniciação, o programador explicitamente tirasse uma foto do estado atual do processo. O Apache procederia normalmente com o tratamento da requisição, contudo, quando o processamento da requisição fosse finalizado, faria uma troca para o contexto anteriormente criado e tiraria uma nova fotografia do estado. Além de evitar a repetição do trabalho de iniciação, esse procedimento poderia ainda melhorar o isolamento entre as requisições. Essa mesma ideia 
é expansível para aplicações menores que têm uma etapa de iniciação reutilizável.

\section{Padrão Virtualização Controlada}

O padrão virtualização controlada nasce do projeto Dune como uma especialização do modo de operação no qual o processo faz uso dos recursos de virtualização. Nesse contexto, quando um processo em execução entra em modo Dune, ele irreversivelmente passa utilizar os recursos de virtualização em sua execução e não pode mais voltar ao seu estado normal (para mais detalhes, veja 3.1). Motivado por tal funcionalidade e buscando elevar o grau de desacoplamento da virtualização, o bead busca dar suporte para funcionalidades similares às do Dune utilizando uma abordagem com maior controle. Veja o Pseudocódigo 6.5 ilustrando tal forma de utilização.

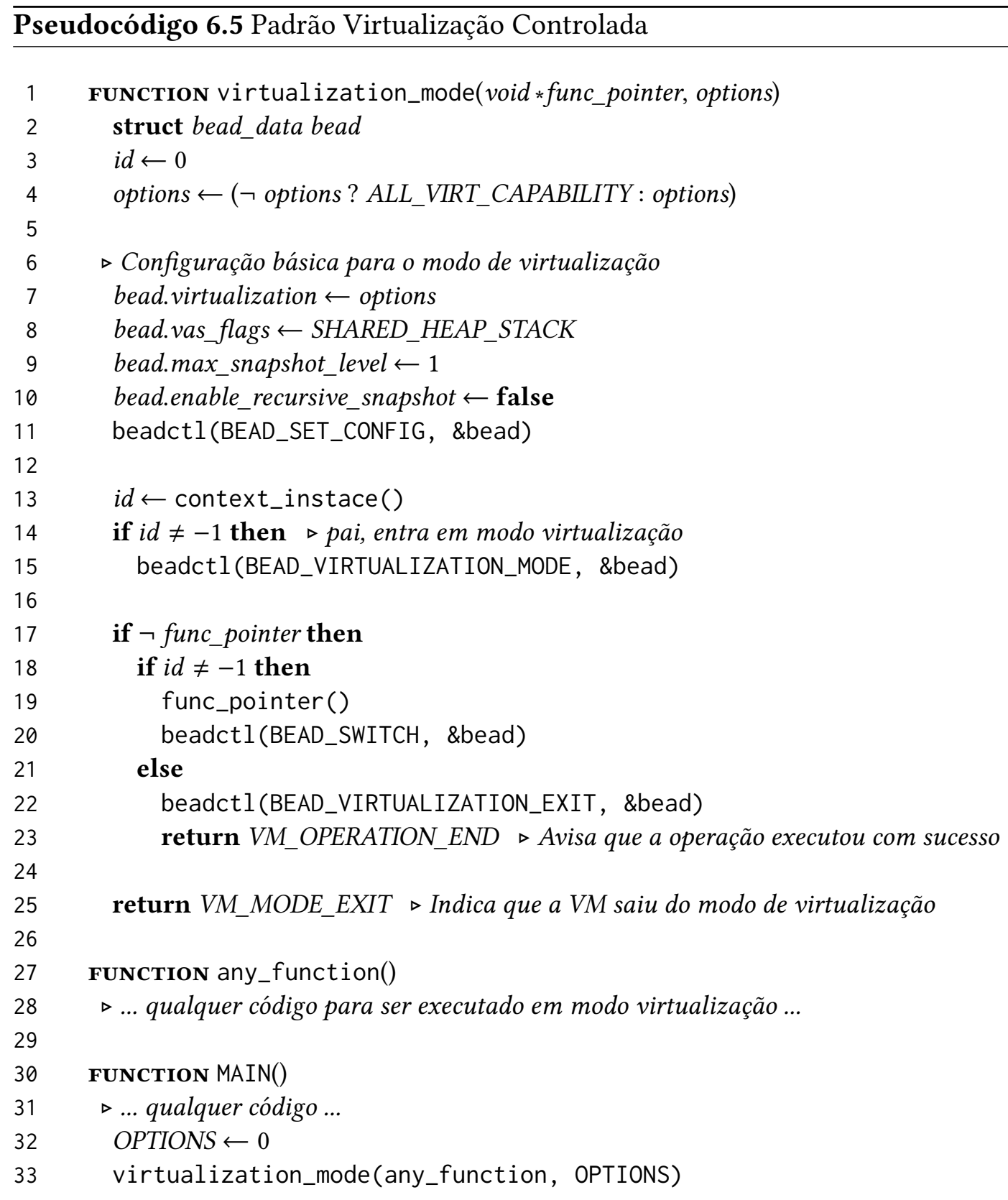


O Pseudocódigo 6.5 começa a execução na Linha 30. Como indicado no comentário, logo após a função MAIN(), notamos que a semântica do programa não sofre alteração. A Linha 33 ilustra uma chamada para a função virtualization_mode() que espera por um ponteiro para uma função que será executada em modo de virtualização; se uma referência nula for passada no parâmetro, todo o processo vai executar em modo virtualização. Na Linha 27, temos um exemplo de como poderia ser o protótipo da função ${ }^{7}$. Quando a função virtualization_mode() começa a executar, a primeira tarefa dela consiste em configurar os elementos da virtualização, como pode ser visto da Linha 7 até a Linha 11 (seguindo o padrão configuração). Os parâmetros de virtualização podem aceitar diversos argumentos, permitindo o controle fino dos recursos de virtualização (não definimos esse nível de detalhamento, pois pode haver diversas formas de implementar tal recurso); por padrão, vamos supor que o processo quer utilizar todos os recursos de virtualização disponíveis.

$\mathrm{Na}$ Linha 13 é feita uma cópia do estado atual do processo. Se tudo ocorrer bem, o bead entra em modo de virtualização nas linhas subsequentes. Note que, na Linha 17, é realizada uma verificação no ponteiro da função passada por parâmetro, o que faz com que essa função assuma duas formas de execução diferentes. Se um ponteiro para função for passado, ela executará em modo virtualização e ao final da execução ocorrerá um retorno para o estado anterior da aplicação, na Linha 20. Em seguida, no estado restaurado, o else da Linha 21 será executado de forma a desabilitar as funcionalidades de virtualização e devolverá um código de fim da operação (VM_OPERATION_END). Se virtualization_mode() receber um ponteiro nulo para a função, significa que o programador quer que todo o processo execute em modo de virtualização (similar ao modo Dune).

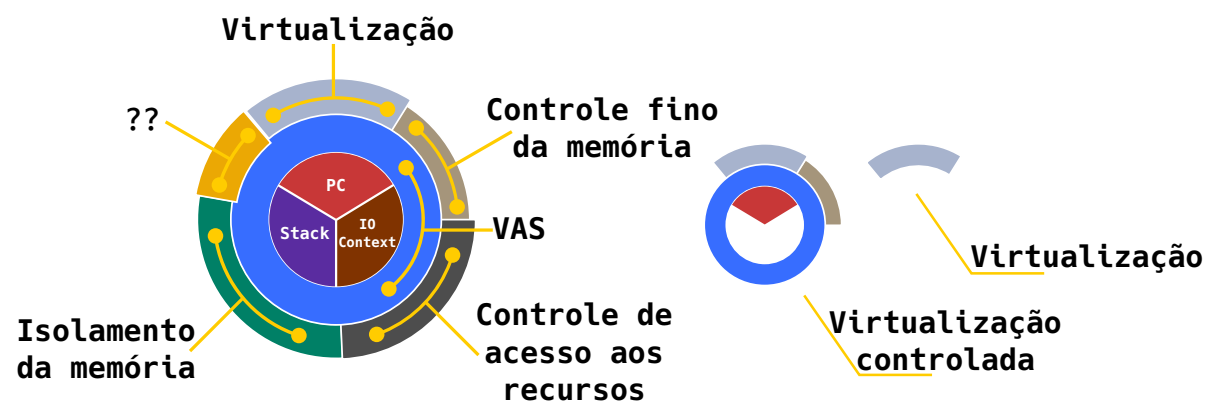

Figura 6.4: Ilustração dos elementos envolvidos no padrão virtualização

A Figura 6.4 mostra os elementos alvos para o desacoplamento das características de virtualização de um processo. O padrão virtualização pode comportar-se como uma extensão do padrão fotografia (Seção 6.3.2) ou simplesmente reagir de forma a executar durante todo o tempo em modo virtualização. Esse padrão pode ser utilizado em alguns contextos; dentre eles, em ferramentas de depuração e interceptação de erros. Em especial, aplicações como Garbage Collectors (GC) podem se beneficiar de tais recursos, uma vez que é possível utilizar as funcionalidades fornecidas pela virtualização para otimizar tarefas. Os algoritmos de compactação de memória são potenciais alvos de otimização utilizando recursos de virtualização: a compactação adotada pelo GC pode fazer uso dos recursos

\footnotetext{
${ }^{7}$ Note que esse é apenas um exemplo para a demonstração de uso. Em uma implementação real, tal protótipo de função pode conter diversos parâmetros ou outra assinatura.
} 
de acesso direto às páginas de memória fornecido pelos mecanismos de virtualização. Em poucas palavras, quando o GC compacta a memória, ele precisa varrer todas as referências usadas pelo programa em execução e atualizar os endereços para as novas posições pós compactação (Seção 4.3.2). Utilizando mecanismos de virtualização, é possível intervir diretamente nas referências das aplicações, mantendo o endereço virtual e alterando apenas o mapeamento para o endereço físico novo. Isso é possível pois os recursos de virtualização permitem o acesso direto às suas páginas de memória e, assim, o GC poderia atuar diretamente sob tais valores.

\section{Padrão Persistência}

Parte do padrão persistência nasce indiretamente da proposta do MVAS, que permite que um processo tenha múltiplas VASes que, por sua vez, persistem além do tempo de execução padrão do processo. Nesse contexto, o bead fornece um mecanismo similar no qual o contexto do processo pode ser salvo somente para leitura e, assim, ser usado como base por outros processos do mesmo tipo. O Pseudocódigo 6.6 ilustra de maneira geral como esse padrão trabalha. Por questão de simplicidade, nós representamos duas execuções diferentes de processos no mesmo pseudocódigo (ilustrado na Linha 15 e 22).

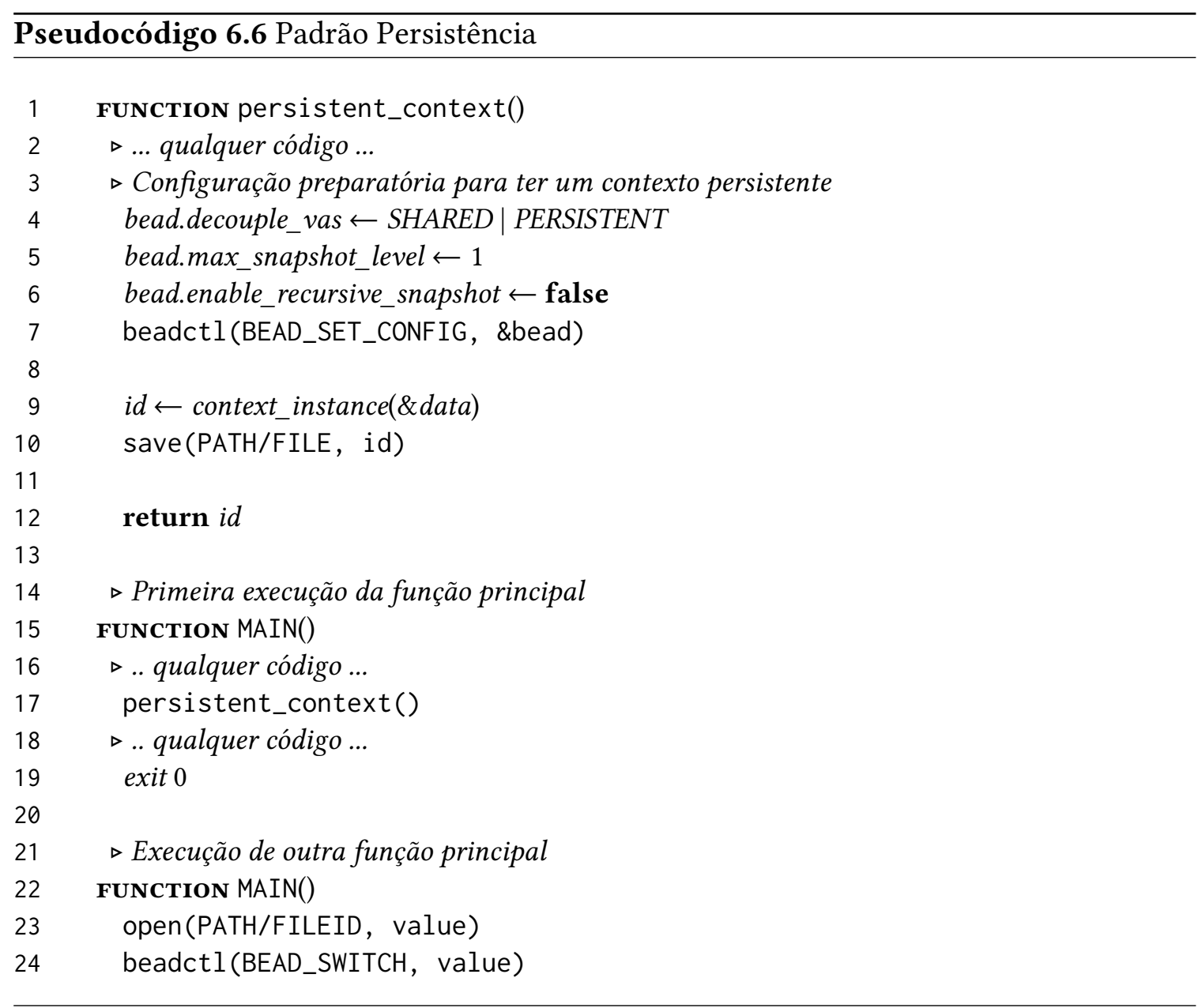

Na Linha 15 do Pseudocódigo 6.6, temos o processo que criará um novo contexto persistente, isto é, o contexto do processo viverá além do tempo de execução do processo 
que o criou. O primeiro passo da função consiste em realizar a configuração sobre o contexto que será criado, por isso é preciso passar duas flags específicas: SHARED e PERSISTENT. A combinação dessas duas flags faz com que o bead crie um contexto persistente gerenciado pelo núcleo do SO que pode ser utilizado por outras aplicações. Idealmente, para que o padrão persistência funcione corretamente, o SO deve armazenar diversos metadados sobre os processos para que ele tenha mecanismos de validação durante a tentativa de carregar um estado (posteriormente). Na Linha 9, notamos que foi passada uma variável data para a função context_instance(). Isso é feito uma vez que um identificador especial é criado e salvo em data. Dessa forma, o processo pode passar o identificador da maneira que achar melhor. No exemplo, simplesmente salvamos o identificador em um arquivo.

Quando o novo processo indicado na Linha 22 inicia, ele abre o arquivo contendo o identificador e recupera o valor. Em seguida, a operação de troca de contexto é feita utilizando o valor carregado.

\section{Padrão Atualização em Tempo Execução}

O padrão de Atualização em Tempo de Execução (ATE), ou simplesmente live-patching, nasce do desacoplamento do VAS, PC e da utilização de técnicas que calculam a diferença entre dois arquivos (diff). Em complemento ao trabalho do SpaceJMP, o bead busca adicionar um nível de controle maior sobre o VAS, permitindo o controle fino em cada um dos seus elementos. A ideia do live-patching já existe e consiste em aplicar patches ${ }^{8}$ sem desligar/reiniciar o sistema; o Kernel Linux já suporta tal funcionalidade, mas empregar esse tipo de atualização em aplicações no espaço do usuário ainda é um desafio.

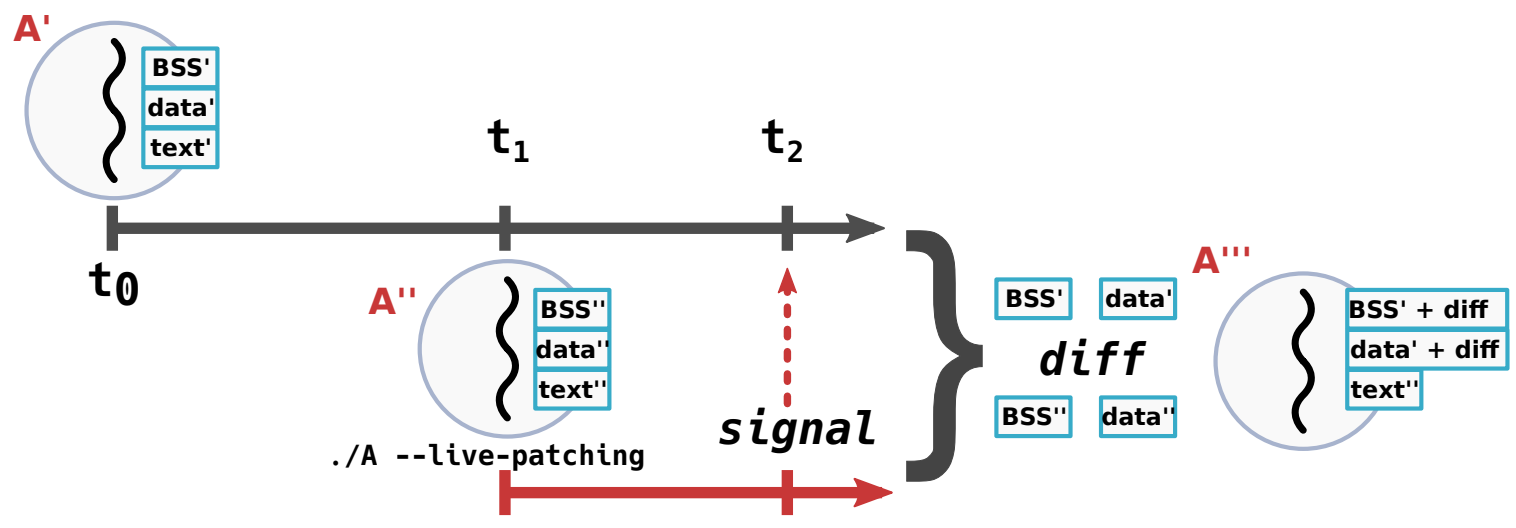

Figura 6.5: Funcionamento do padrão atualização em tempo de execução

Buscando uma possível solução para este problema, a Figura 6.5 ilustra de forma geral o padrão ATE. Na ilustração temos um processo chamado de $A^{\prime}$ que é o alvo da atualização em tempo de execução; ainda na figura, repare a linha do tempo indicando a execução de $A^{\prime}$. No período de tempo $t_{1}$, uma instância idêntica do processo $A$ é iniciada e recebe o nome de $A^{\prime \prime}$. Repare que o processo $A^{\prime \prime}$ recebe a flag --live-patching como parâmetro durante a sua inicialização, isso significa que $A^{\prime \prime}$ vai iniciar em um estado especial; por fim uma fotografia persistente é feita. Quando tal estado é atingido $A^{\prime \prime}$ envia um sinal para $A^{\prime}$, que por sua vez manipula o sinal recebido. Dentro da operação de tratamento do sinal,

\footnotetext{
${ }^{8}$ Um pedaço de software que visa consertar ou melhorar algum programa.
} 
$A^{\prime}$ faz com que uma operação de troca (BEAD_SWITCH) com a flag DIFF para a fotografia de $A^{\prime \prime}$ aconteça. Essa troca ocorre fazendo uma operação que calcula a diferença (diff) do segmento de BSS e Data de $A^{\prime}$ com $A^{\prime \prime}$; por fim, é feito uma troca do segmento de texto de $A^{\prime} \operatorname{com} A^{\prime \prime}$.

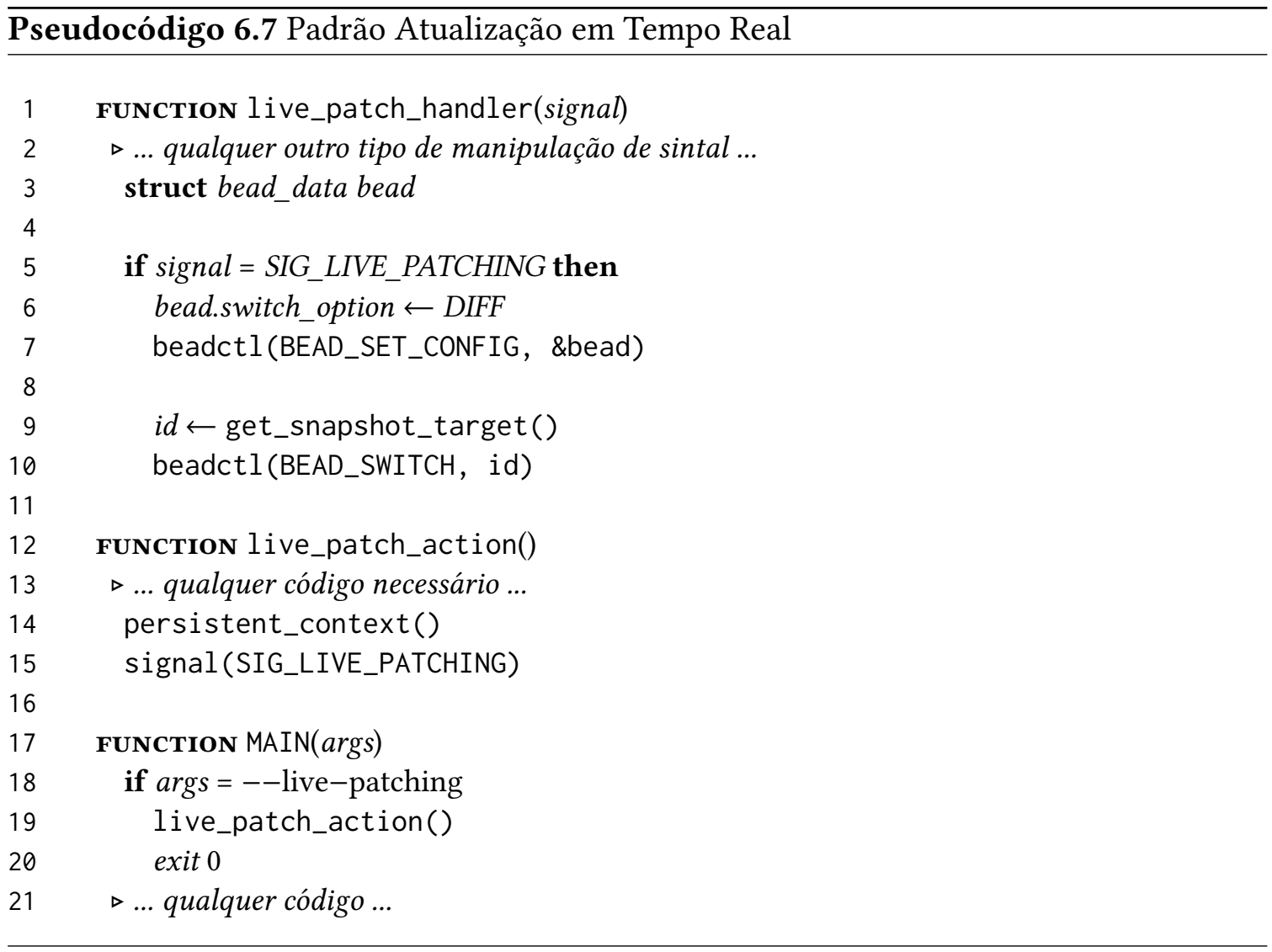

O Pseudocódigo 6.7 ilustra como seria uma possível implementação do padrão ATE. A função MAIN() de algum programa qualquer precisaria ser alterada para aceitar o parâmetro --live-patching ${ }^{9}$ como a Linha 18 ilustra. Se o parâmetro --live-patching for recebido, uma função especial deve entrar em ação para por o software em um estado considerado seguro pela aplicação para em seguida tirar uma fotografia persistente do estado atual; por fim, ela deve enviar um sinal para o processo que será atualizado. Quando o sinal chegar para a aplicação, a função live_patch_handler() deve ser executada de forma a tratar o sinal e, como a Linha 6 indica, o bead deve ser configurado para realizar a atualização. A Linha 9 mostra uma função que deve buscar a fotografia persistente referente ao processo, note que essa função pode ser implementada de várias maneiras visando garantir segurança e consistência; para esse pseudocódigo, apenas considere que ela devolverá o identificador da fotografia tirada do processo na Linha 18. Por fim, o processo faz a atualização por meio da operação de BEAD_SWITCH previamente configurada.

\footnotetext{
${ }^{9} \mathrm{O}$ nome do parâmetro poderia ser qualquer um que o programador queira adotar.
} 


\section{Padrão Compartimento}

O padrão Compartimento nasce dos conceitos apresentados pelo shred, que busca apresentar uma técnica para evitar ataques intra-processos baseada em um recurso de hardware subutilizado. Essa ideia é fundamentada em um novo recurso fornecido por várias CPUs que permite definir domínios de acesso dentro da memória do processo (Seção 2.2.3). O principal objetivo do compartimento dentro do próprio processo consiste em adicionar maior nível de isolamento e dificultar/impedir ataques que ocorram dentro do processo.

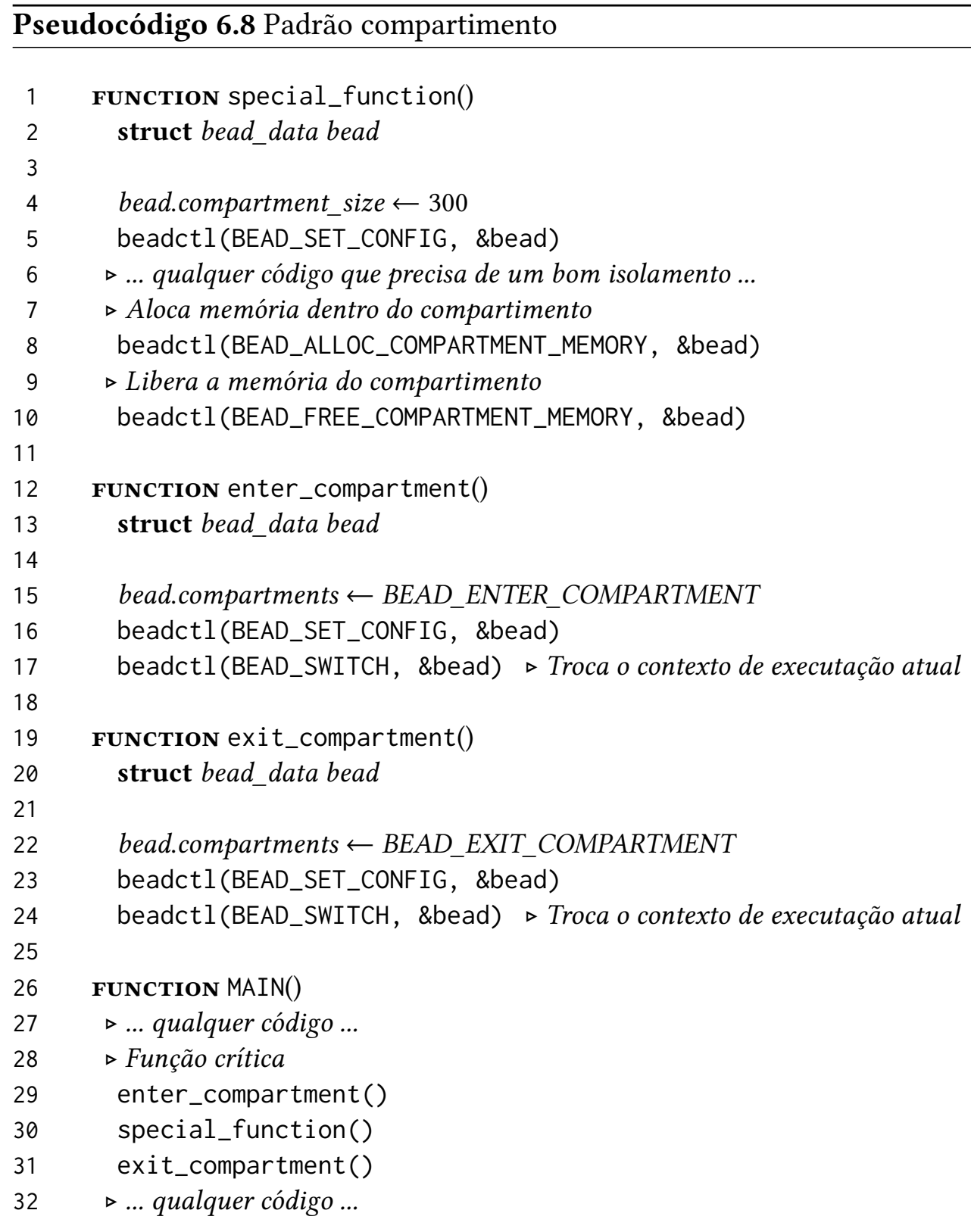

O Pseudocódigo 6.8 ilustra como esse padrão se comporta. O exemplo começa na Linha 26, onde a semântica do código original não sofre alteração. Em um determinado trecho de uma aplicação, pode ser necessário executar uma operação sobre dados sensíveis (p.ex., senhas), portanto, é desejável que o acesso a tal informação seja o mais restrito possível. 
Nesse contexto, a Linha 29 ilustra a operação enter_compartment() que é responsável por mudar o fluxo de execução do processo para o compartimento. Em seguida, na Linha 15, podemos acompanhar o processo de configuração necessário para criar o compartimento. Se tudo ocorrer bem, o processo passa a executar dentro de um compartimento isolado das demais threads.

A operação BEAD_ENTER_COMPARTMENT foi introduzida na Seção 6.3.1. Ela foi utilizada no processo de configurar o compartimento e a operação de troca foi utilizada para entrar em tal modo (vale destacar que esse é um uso diferente da operação de troca). Dentro do compartimento, não é possível utilizar as operações de alocação de memória padrão, uma vez que é preciso utilizar o recurso de controle de acesso fornecido pelo hardware. Nesse sentido, o bead fornece a operação BEAD_ALLOC_COMPARTMENT_MEMORY, responsável por alocar memória e impedindo a qualquer thread externa ter acesso a ela. A Linha 8 é responsável por alocar memória dentro do próprio compartimento. Por fim, para remover a memória alocada basta chamar a função BEAD_FREE_COMPARTMENT_MEMORY.

Quando todas as operações sobre dados sensíveis tiver acabado, o programador pode solicitar ao bead para sair do compartimento. A Linha 19 ilustra a função que faz a operação de sair do compartimento.

\section{Outras Possibilidades de Padrões}

Os padrões ilustrados na Seção 6.3.2 são apenas algumas das possibilidades ao se usar a API do bead, note que outros padrões podem surgir da utilização dos recursos de desacoplamento dos processos. Em especial, é importante ressaltar que alguns recursos de hardware modernos podem ser utilizados para dar maior controle de acesso à memória. Tais recursos podem significar uma alternativa a propostas como a do Mondrian (Seção 3.6), que exigem a alterações no hardware da CPU.

Em 2015 a Intel lançou um novo recurso chamado de Extensões de Proteção de Memória ou simplesmente MPX (Memory Protection Extensions). Essa extensão adiciona um novo conjunto de registradores, instruções e uma tabela de limites; o objetivo principal dessa alteração consiste em inserir novos mecanismos de segurança para a verificação dos ponteiros utilizado pelas aplicações. O MPX adiciona proteções na forma como um ponteiro é acessado com o objetivo de evitar acessos não permitidos a certas regiões da memória (R. InTEL, 2019). Note que essa tecnologia, de certa forma, é similar ao que foi proposto pelo Mondrian e representa uma alternativa para implementar o nível de controle fino sugerido pelos pesquisadores. A tecnologia MPX ainda é pouco explorada e tem alguns problemas de desempenho como demonstrado por OlEKSENKo et al. (2018); contudo, essa tecnologia ainda mostra-se promissora para ser explorada do ponto de vista das abstrações de processos.

Ainda no campo do desacoplamento do isolamento e do controle fino da memória, citamos uma nova tecnologia presente nos processadores da Intel e que recebe o nome de Software Guard Extensions (SGX). O objetivo dessa nova tecnologia consiste em criar formas para que as aplicações possam executar códigos que exigem maior proteção de forma isolada dentro da CPU (Costan e Devadas, 2016). Repare que esse conjunto de instruções se interpõe entre a proposta feita pelo Mondrix (Seção 3.6) e Shreds (Seção 3.2), adicionando assim novos mecanismos de isolamento de códigos considerados sensíveis. 


\subsubsection{A Biblioteca libbead}

$\mathrm{Na}$ Seção 6.3.2, procuramos evidenciar o comportamento de baixo nível do bead de forma a explicitar o desacoplamento das abstrações de processos. Na prática, não esperamos que os usuários do bead utilizem os padrões da forma descrita na Seção 6.3.2, uma vez que elas representam operações de baixo nível. Idealmente, a implementação do bead deve vir acompanhada de uma biblioteca (chamaremos de libbead neste texto) que se comporte como uma camada de abstração sobre as operações de baixo nível e assim facilite a utilização nos novos recursos oferecidos pelo bead. Note que tal biblioteca deve prover os padrões descritos da Seção 6.3.2.

O padrão fotografia (Seção 6.3.2) poderia ser encapsulado em duas funções: beadGetContext() e beadSwitch(). A função beadGetContext() espera alguns parâmetros de configuração que definem a forma como a fotografia deve operar e em seguida salva o contexto. Posteriormente, o desenvolvedor precisaria realizar o beadSwitch() para o contexto novo. O Pseudocódigo 6.9 ilustra como pode ser usada a operação descrita na Seção 6.3.2, da perpectiva de um usuário da libbead.

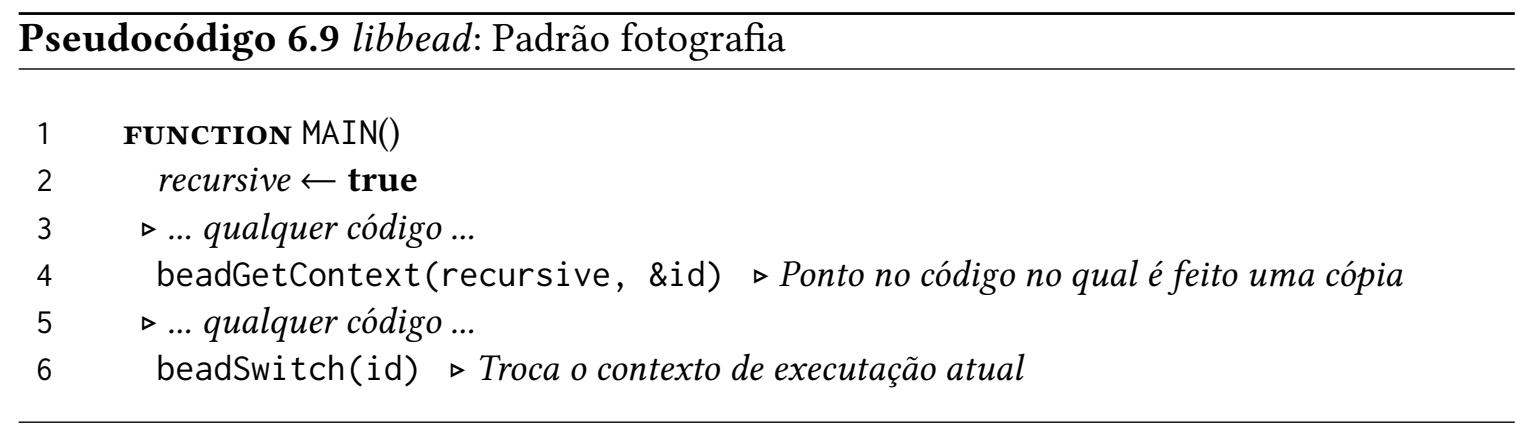

Outra funcionalidade que poderia ser consideravelmente simplificada pela libbead é a operação de virtualização controlada apresentada na Seção 6.3.2. O Código 6.10 ilustra como a libbead pode simplificar a tarefa de usar os recursos de virtualização. Note que a função beadVirtualMode() espera um conjunto de parâmetros de configuração e uma função para ser executada em modo virtualização; se NULL for passada no último parâmetro, todo o processo vai executar em modo de virtualização.

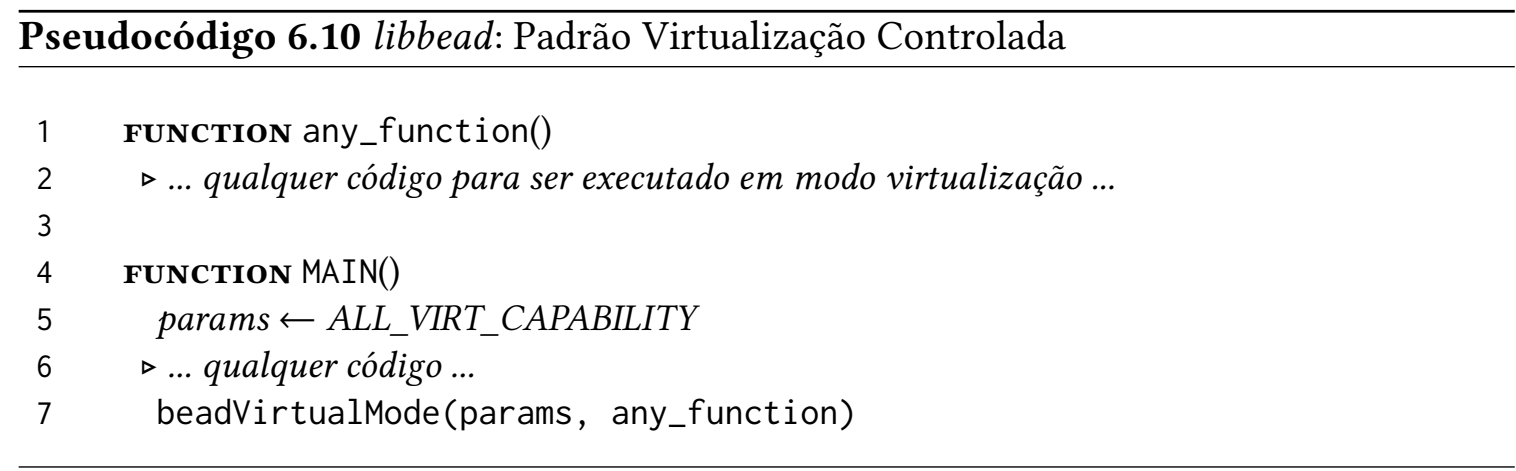

Em termos de utilização do padrão de atualização em tempo de execução (Seção 6.3.2), a libbead representa uma enorme simplificação. O Pseudocódigo 6.11 ilustra o padrão ATE da perspectiva do libbead, note que precisamos apenas da função 
beadInstallLivePatching() para adicionar suporte para a atualização em tempo de execução. Essa função instala no processo um mecanismo que o leva para um estado quiescence (VANDEWOUdE et al., 2007) que pode permitir a atualização em tempo de execução. Na Seção 6.3.2 foi descrito em detalhes o comportamento do padrão ATE, lembre-se que essa técnica precisa tratar o recebimento do pedido de atualização feito no espaço de usuário; note que mesmo utilizando a libbead, ainda é preciso realizar o pedido de atualização.

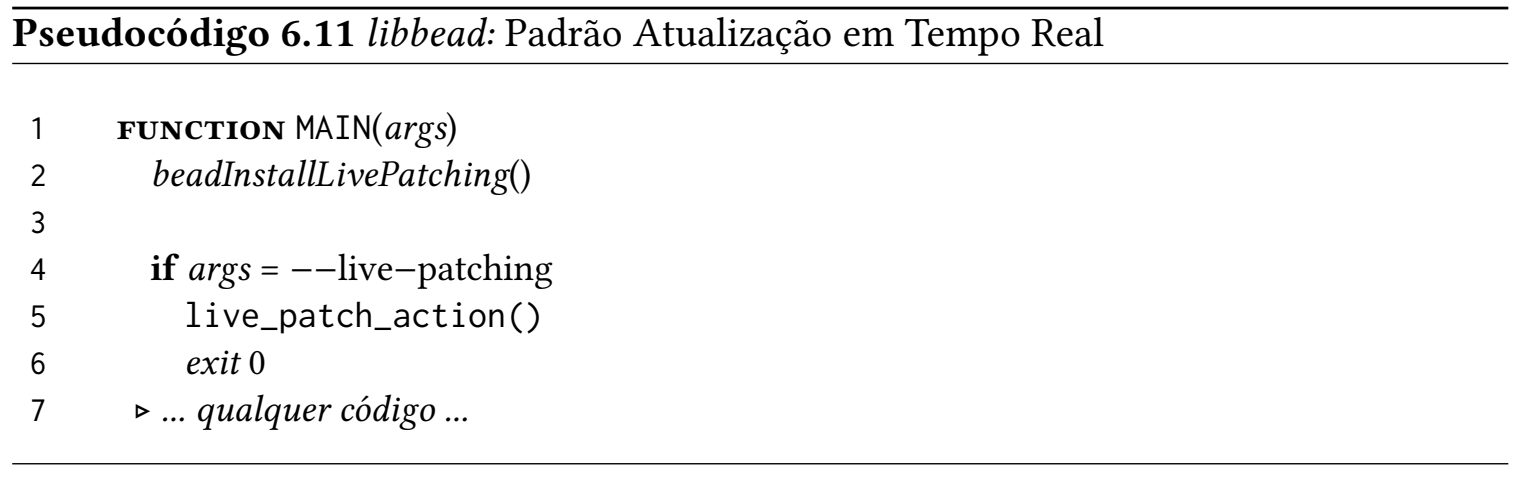

Por fim, o mais importante a se notar sobre a libbead é que ela comporta-se como uma camada de abstração para as operações de baixo nível. Essa biblioteca deve tornar simples o processo de utilização do bead, assim como a 1 ibc ${ }^{10}$ e a 1 ibdrm ${ }^{11}$ fazem para seus respectivos sistemas.

\subsection{Sumário}

Neste capítulo, os nossos objetivos consistiram em responder as seguintes questões de pesquisa:

QP1: "Quais são as características desejáveis para a próxima geração de abstrações de processos?"

QP2: "Quais são os principais desafios em se implementar a próxima geração de abstrações de processos?"

Para responder a primeira questão de pesquisa, fizemos uma análise da Seção 6.2 até a 6.3 discutindo as diversas características desejáveis para a próxima geração de abstração de processos. Em especial, a Tabela 6.2 apresenta uma visão centralizada dos diversos desacoplamentos passíveis de serem adotados. Além disso, a Figura 6.1 ilustra graficamente como a nova geração de abstrações de processo pode se organizar levandose em consideração os diversos desacoplamentos sugeridos. Por fim, introduzimos na Seção 6.3 um modelo teórico chamado de bead que tem por principal objetivo mostrar uma unificação dos diversos trabalhos e ilustrar os potenciais usos dessa nova técnica.

Para responder a segunda questão de pesquisa, realizamos uma ampla discussão na Seção 6.1 que busca dialogar com o Capítulo 4. Em especial, com base em certos cri-

\footnotetext{
${ }^{10}$ https://www.gnu.org/software/libc/

${ }^{11}$ https://01.org/linuxgraphics/community/libdrm
} 
térios, criamos a Tabela 6.1 mostrando o potencial de adoção de novas abstrações de processos.

Por fim, destacamos que levar avanços para as abstrações de processos atuais significa abrir novos campos de pesquisa e reaquecer os projetos de SO modernos. Note que um SO monolítico, como o Kernel Linux, pode mudar completamente o seu design para modelos mais flexíveis e desacoplados tendo como ponto inicial a evolução dos processos. 


\section{Capítulo 7}

\section{Conclusões}

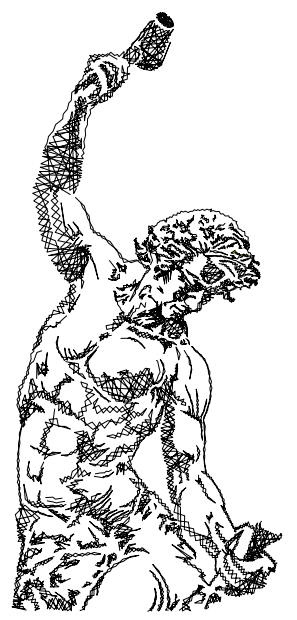

Ao longo deste trabalho investigamos diversos aspectos referentes às abstrações de processos. Começamos revisitando conceitos já consolidados (Capítulo 2) para que em seguida pudéssemos expandir a visão sobre os processos (procuramos apresentar diferentes perspectivas sobre esse conceito). No Capítulo 3 elencamos e resumimos diversos trabalhos relacionados as abstrações de processos fornecendo assim um panorama geral sobre as pesquisas já realizadas. Buscamos o estado da arte e suas intersecções com o estado da prática utilizando a implementação do MVAS como estudo de caso (Capítulo 5). Além disso, durante este trabalho, interagimos com a indústria por meio do Kernel Linux e com uma parceria com a HPe (tal parceria durou apenas alguns meses). Por várias vezes tentamos consertar o MVAS, juntamente com alguns funcionários da HPe, não atingindo exito em tal tarefa; contudo, extraímos dessa experiência diversas ideias nas quais refinamos no decorrer deste mestrado.

Durante o aprofundamento na pesquisa sobre novas abstrações de processos percebemos que, por vários anos, a academia vem buscando inovações nesse campo, mas tais progressos não chegam aos SOs de uso cotidiano. Como o Capítulo 4 discute, parte disso vem do fato de que algumas propostas negligenciam aspectos importantes que precisam ser considerados para avançar sistemas usados em produção. Por exemplo, é fundamental que as novas gerações de abstração de processos levem em consideração aplicações amplamente adotadas. No Capítulo 4, evidenciamos um subconjunto de aplicações que podem servir como alicerce para demonstrar o uso e potencial de adoção de uma nova abstração. Além disso, não basta levar ganhos em uma área ao custo de fazer com que outras partes da aplicação sejam afetadas negativamente, é preciso fazer uma análise geral dos impactos gerados por novas abstrações. Como exemplo, o estudo de caso apresentado no Capítulo 5 revelou como uma determinada proposta pode comprometer todo o sistema. Por fim, muitos dos trabalhos analisados não realizam testes de estresse consistentes, o que não revela a real natureza dos impactos.

Por outro lado, notamos da análise dos diversos trabalhos que não há uma tentativa de unificar as propostas, normalmente cada trabalho busca apresentar-se como diferentes de todos os outros já feitos. Após o estudo das diversas propostas, notamos que a melhor forma de levar os avanços sugeridos pelos pesquisadores para os SOs de uso cotidiano é buscando 
unificar as pesquisas e adaptando elas para as necessidades atuais. No Capítulo 6 buscamos mostrar tal aspecto apontando um caminho para a próxima geração de abstrações de processos. Qualquer tentativa de avançar o estado da prática também deve buscar o menor impacto possível nos SOs.

Os anos 80 e 90 representaram o período áureo da pesquisa em SO; parte disso deve-se ao fato de que tal área era muito jovem e carente de novas definições. Com o natural amadurecimento da área tornou-se cada vez mais complicado e menos atraente realizar pesquisa em SOs; pode-se dizer que hoje, o interesse por tal área é relativamente morno quando comparado com outras áreas. Parte desse momento dormente da pesquisa em SO pode ser fundamento no distanciamento entre indústria e academia ou ainda na falta de novos paradigmas em SO. Este trabalho é uma modesta tentativa de discutir novos caminhos para a pesquisa em SO com a esperança de contribuir de forma a inspirar novos e velhos pesquisadores a olhar essa área com mais interesse.

\subsection{Trabalhos Futuros}

Este trabalho teve como objetivo estudar e colocar em evidência um campo de pesquisa com pouca visibilidade. Dentre os trabalhos futuros que identificamos, nós destacamos: escrever um survey sobre o estado da arte das abstrações de processos, a criação de um sistema de validações de abstrações de processos que funcione de forma automatizada e a implementação da abstração de processos da próxima geração proposta no Capítulo 6.

Como podemos observar no Capítulo 3, diversos pesquisadores vem colocando esforços para fazer com que as abstrações de processo evoluam. Além disso, as abstrações de processos adotadas na prática também distinguem-se daquelas apresentadas na bibliografia padrão. Por esse motivo, faz-se necessário um levantamento profundo e detalhado das pesquisas referentes às abstrações de processos. Acreditamos que um survey com tal temática traria novas perspectivas de pesquisa para a área de SO. Além desse trabalho, o Capítulo 4 apontou a falta de um trabalho que apresente uma taxonomia das aplicações de forma similar ao que é feito na biologia. Tal taxonomia pode ser útil para generalizar certas características das aplicações e assim facilitar a seleção de subgrupos de software para serem utilizadas em outros trabalho (p.ex., o Capítulo 4 poderia ter feito uso de tal taxonomia).

$\mathrm{O}$ assunto tratado no Capítulo 4 em conjunto com a experiência adquirida sobre o núcleo Linux e os experimentos realizados (Capítulo 5), revelaram a necessidade de uma ferramenta automatizada para testar falhas de segurança. Seria interessante construir um software que de forma sistemática tente explorar as falhas de segurança já catalogadas e assim verificar se alguma regressão aconteceu. Por exemplo, o openSSL apresentou a vulnerabilidade Heartbleed nas versões 1.0 .1 e que foram corrigidas. Nesse contexto seria interessante ter um teste que verifique se tal ataque ainda é possível. Note que tal ferramenta seria extremamente valiosa na demonstração da utilidade de novas abstrações de processos. Uma determinada proposta poderia utilizar uma versão comprometida de uma determinada aplicação junto com o teste que explora uma falha e assim demonstrar que a sua proposta de extensão da abstração de processos resolve algum problema de segurança. 
A Seção 4.5 abordou o tema dos microbenchmarks tendo como foco as validações para novas abstrações de processos. Nesse contexto, seria interessante a construção de um arcabouço de microbenchmark automatizado que possa ser utilizado para validar as novas abstrações. Tal ferramenta tem que ser simples de ser alterada para que seja possível validar as diferentes propostas sem grandes esforços de implementação.

Por fim, o trabalho futuro mais interessante consiste em implementar a nova geração de abstrações de processos apresentada no Capítulo 6. Tal implementação em um Kernel monolítico pode significar um avanço de como os SO modernos são organizados e abrir caminhos para uma nova geração de SOs. Além disso, novos paradigmas, técnicas e padrões de projetos podem emergir com a nova geração de abstrações de processos.

\subsection{Outras Contribuições deste Mestrado}

Durante este mestrado, busquei investir na minha formação passando pelas seguintes áreas: ensino, pesquisa, orientação e desenvolvimento. Nesse sentido, segue o resumo de outras contribuições que tive durante o mestrado:

1. Publicações como autor principal:

- Siqueira, Rodrigo et al. Continuous delivery: building trust in a large-scale, complex government organization. IEEE Software, v. 35, n. 2, p. 38-43, 2018.

- The Next-Generation OS Process Abstraction - IEEE Computer - (Aguardando para submeter)

2. Publicações como co-autor:

- Wen, Melissa et al. FLOSS Project Management in Government-Academia Collaboration. In: IFIP International Conference on Open Source Systems. Springer, Cham, 2018. p. 15-25. - (Prêmio de melhor artigo)

- Meirelles, Paulo et al. Brazilian Public Software Portal: an integrated platform for collaborative development. In: Proceedings of the 13th International Symposium on Open Collaboration. ACM, 2017. p. 16.

- BelinAssi, Giuliano AF et al. Optimizing a Boundary Elements Method for Stationary Elastodynamic Problems implementation with GPUs. WSCAD-WIC 2017, p. 51. - (Prêmio de segundo melhor artigo da WSCAD-WIC)

- Wen, Melissa et al. Leading successful government-academia collaboration using FLOSS and agile values. In: Journal of Systems and Software - (Aguardando Revisão)

3. Trabalhos relacionados a orientandos:

- Giuliano A. F. Belinassi: Auxiliei na orientação do Giuliano no seu TCC, e na produção do artigo: Optimizing a Boundary Elements Method for Stationary Elastodynamic Problems implementation with GPUs (Prêmio de segundo melhor artigo na WSCAD-WIC). Durante o mestrado dele, eu tenho auxiliado na definição do tema e na construção de experimentos. 
4. Contribuições para Software livre:

- Kernel Linux:

- VKMS: Fui um dos autores do driver VKMS

- IIO: Ajudei a fundar o grupo de estudo de Kernel na USP. Esse grupo já colaborou movendo mais de três drivers da staging do Linux para a árvore princípal. Veja: https://flusp.ime.usp.br.

- Tenho mais de 30 contribuições de código no repositório principal do Linux

- Debian:

- Mantenedor de alguns pacotes, em especial do Dia

- Promovi diversos eventos sobre o Debian em São Paulo e em Brasília

5. Apresentações:

- Linuxdev-br: Da linuxdev-br ao GSoC: Displays Virtuais no Kernel (https: //youtu.be/S0hBHiiTDjA)

- XDC18: VKMS (https://youtu.be/ber_9vkj_-U)

- The 14th International Conference on Open Source Systems: FLOSS Project Management in Government-Academia Collaboration

6. Outros:

- Participei do programa Google Summer of Code 2018 sob o guarda-chuva da Xorg Foundation. Trabalhei em conjunto com uma desenvolvedora para criar as bases de um novo driver chamado VKMS (para mais detalhes, veja https: //siqueira.tech/report/gsoc-final-report/) 


\section{Referências}

[Apache ab 2019] Apache $a b$. URL: https://httpd.apache.org/docs/2.4/programs/ab.html (acesso em 02/01/2019) (citado na pg. 81).

[GC Algorithms: Basics 2018] GC Algorithms: Basics. URL: https://plumbr.io/handbook/ garbage-collection-algorithms (acesso em 06/11/2018) (citado nas pgs. 65, 66).

[ListenBackLog Directive 2019] ListenBackLog Directive. URL: https://httpd.apache.org/ docs $/ 2.4 / \mathrm{mod} / \mathrm{mpm}$ _common.html\#listenbacklog (acesso em 02/01/2019) (citado na pg. 74).

[MaxSpareServers Directive 2019] MaxSpareServers Directive. URL: https://httpd.apache. org/docs $/ 2.4 / \mathrm{mod} /$ prefork.html\#maxspareservers (acesso em 02/01/2019) (citado na pg. 74).

[MaxSpareThreads Directive 2019] MaxSpareThreads Directive. URL: https : / / httpd . apache.org/docs / 2.4/mod/mpm_common. html\# maxsparethreads (acesso em 02/01/2019) (citado na pg. 74).

[Memory Layout And The Stack 2018] Memory Layout And The Stack. URL: http://www. dirac.org/linux/gdb/02a-Memory_Layout_And_The_Stack.php (acesso em 06/11/2018) (citado nas pgs. 6, 7).

[MinSpareServers Directive 2019] MinSpareServers Directive. URL: https://httpd.apache. org/docs $/ 2.4 / \mathrm{mod} /$ prefork.html\#minspareservers (acesso em 02/01/2019) (citado na pg. 73).

[MinSpareThreads Directive 2019] MinSpareThreads Directive. URL: https://httpd.apache. org/docs $/ 2.4 / \mathrm{mod} / \mathrm{mpm} \_c o m m o n . h t m l$ minsparethreads (acesso em 02/01/2019) (citado na pg. 74).

[MPM MaxRequestWorkers 2019] MPM MaxRequestWorkers. URL: https://httpd.apache. org / docs / 2 . 4 / mod / mpm _common . html \# maxrequestworkers (acesso em 02/01/2019) (citado na pg. 74).

[MPM StartServer 2019] MPM StartServer. URL: https://httpd.apache.org/docs/2.4/mod/ mpm_common.html\#startserverslh (acesso em 02/01/2019) (citado na pg. 73). 
[Redis Persistence 2018] Redis Persistence. URL: https://redis.io/topics/persistence (acesso em 06/11/2018) (citado na pg. 64).

[ServerLimit Directive 2019] ServerLimit Directive. URL: https://httpd.apache.org/docs/2. 4/mod/mpm_common.html\#serverlimit (acesso em 02/01/2019) (citado na pg. 74).

[State of the Web 2019] State of the Web. URL: https://httparchive.org/reports/state-ofthe-web?start=2016_07_01\&end=2017_07_01\&view=list (acesso em 02/01/2019) (citado na pg. 76).

[ThreadLimit Directive 2019] ThreadLimit Directive. URL: https://httpd.apache.org/docs/ 2.4/mod/mpm_common.html\#threadlimit (acesso em 02/01/2019) (citado na pg. 74).

[ThreadsPerChild Directive 2019] ThreadsPerChild Directive. URL: https://httpd.apache. org/docs $/ 2.4 / \mathrm{mod} / \mathrm{mpm} \_$common.html\#threadsperchild (acesso em 02/01/2019) (citado na pg. 74).

[Crypto With OpenSSL 2008] Crypto With OpenSSL. 17 de out. de 2008. uRL: https:// www.slideshare.net/guanzhi/crypto-with-openssl (acesso em 06/11/2018) (citado na pg. 61).

[Inside NGINX: How We Designed for Performance and Scale 2015] Inside NGINX: How We Designed for Performance and Scale. 10 de jun. de 2015. uRL: https://www.nginx. com/blog/inside-nginx-how-we-designed-for-performance-scale/ (acesso em 06/11/2018) (citado na pg. 59).

[Aiken et al. 2006] Mark Aiken, Manuel Fähndrich, Chris Hawblitzel, Galen Hunt e James LARUs. "Deconstructing process isolation”. Em: Proceedings of the 2006 Workshop on Memory System Performance and Correctness. MSPC '06. San Jose, California: ACM, 2006, pgs. 1-10. ISBN: 1-59593-578-9. DOI: 10.1145/1178597. 1178599. URL: http://doi.acm.org/10.1145/1178597.1178599 (citado na pg. 29).

[Arlitt e Jin 2000] Martin Arlitt e Tai Jin. "A workload characterization study of the 1998 world cup web site”. Em: IEEE network 14.3 (2000), pgs. 30-37 (citado na pg. 53).

[Bovet e Cesati 2006] Daniel P Bovet e Marco Cesati. Understanding the Linux kernel. $3^{\text {a }}$ ed. O’Reilly, 2006 (citado nas pgs. 5, 20).

[BAnga et al. 1999] Gaurav Banga, Peter Druschel e Jeffrey C. Mogul. "Resource containers: a new facility for resource management in server systems". Em: Proceedings of the Third Symposium on Operating Systems Design and Implementation. OSDI '99. New Orleans, Louisiana, USA: USENIX Association, 1999, pgs. 45-58. ISBN: 1-880446-39-1. URL: http://dl.acm.org/citation.cfm?id=296806.296810 (citado nas pgs. 37,38$)$. 
REFERÊNCIAS

[Belay et al. 2012] Adam Belay et al. "Dune: safe user-level access to privileged cpu features". Em: Proceedings of the 10th USENIX Conference on Operating Systems Design and Implementation. OSDI'12. Hollywood, CA, USA: USENIX Association, 2012, pgs. 335-348. ISBN: 978-1-931971-96-6. URL: http://dl.acm.org/citation.cfm? id $=2387880.2387913$ (citado nas pgs. $30,32,70$ ).

[Bittau et al. 2008] Andrea Bittau, Petr Marchenko, Mark Handley e Brad Karp. "Wedge: splitting applications into reduced-privilege compartments". Em: Proceedings of the 5th USENIX Symposium on Networked Systems Design and Implementation. NSDI'08. San Francisco, California: USENIX Association, 2008, pgs. 309-322. ISBN: 111-999-5555-22-1. URL: http://dl.acm.org/citation.cfm?id=1387589.1387611 (citado na pg. 35).

[BOYD-Wickizer et al. 2008] Silas Boyd-Wickizer et al. "Corey: an operating system for many cores". Em: Proceedings of the 8th USENIX Conference on Operating Systems Design and Implementation. OSDI'08. San Diego, California: USENIX Association, 2008, pgs. 43-57. URL: http://dl.acm.org/citation.cfm?id=1855741. 1855745 (citado na pg. 29).

[Costan e Devadas 2016] Victor Costan e Srinivas Devadas. "Intel sgx explained." Em: IACR Cryptology ePrint Archive 2016.086 (2016), pgs. 1-118 (citado na pg. 109).

[Chen et al. 2016] Yaohui Chen, Sebassujeen Reymondjohnson, Zhichuang Sun e Long Lu. "Shreds: fine-grained execution units with private memory". Em: IEEE Symposium on Security and Privacy (SP). IEEE. 2016, pgs. 56-71. ISBN: 978-1-50900825-4 (citado na pg. 33).

[Crowley 1996] Charles Crowley. Operating Systems: A Design-Oriented Approach. McGraw-Hill Professional, 1996. ISBN: 0256151512 (citado nas pgs. 5, 45).

[Click et al. 2005] Cliff Click, Gil Tene e Michael Wolf. "The pauseless ge algorithm". Em: Proceedings of the 1st ACM/USENIX International Conference on Virtual Execution Environments. VEE '05. Chicago, IL, USA: ACM, 2005, pgs. 46-56. ISBN: 1-59593-047-7. DOI: 10.1145/1064979.1064988. URL: http://doi.acm.org/10.1145/ 1064979.1064988 (citado nas pgs. 30, 65, 68).

[Duarte 2009a] Gustavo Duarte. Anatomy of a Program in Memory. 27 de jan. de 2009. URL: https://manybutfinite.com/post/anatomy-of-a-program-in-memory (acesso em 06/11/2018) (citado na pg. 18).

[Duarte 2009b] Gustavo Duarte. How The Kernel Manages Your Memory. 24 de fev. de 2009. URL: https://manybutfinite.com/post/how-the-kernel-manages-yourmemory (acesso em 06/11/2018) (citado nas pgs. 17, 18).

[Duarte 2014] Gustavo Duarte. System Calls Make the World Go Round. 6 de nov. de 2014. URL: https://manybutfinite.com/post/system-calls (acesso em 03/10/2018) (citado na pg. 20). 
[Engler et al. 1995] D. R. Engler, M. F. KaAshoek e J. O’Toole Jr. "Exokernel: an operating system architecture for application-level resource management". Em: Proceedings of the Fifteenth ACM Symposium on Operating Systems Principles. SOSP '95. Copper Mountain, Colorado, USA: ACM, 1995, pgs. 251-266. ISBN: 0-89791715-4. DOI: 10.1145/224056.224076. URL: http://doi.acm.org/10.1145/224056.224076 (citado na pg. 48).

[El HajJ, Merritt, ETH et al. s.d.] Izzat El HajJ, Alexander Merritt, Gerd Zellweger ETH et al. Large Physical Memory (citado na pg. 47).

[El HajJ, Merritt, Zellweger et al. 2016] Izzat El HajJ, Alexander Merritt, Gerd ZELLWEgER et al. "Spacejmp: programming with multiple virtual address spaces”. Em: Proceedings of the Twenty-First International Conference on Architectural Support for Programming Languages and Operating Systems. ASPLOS '16. Atlanta, Georgia, USA: ACM, 2016, pgs. 353-368. ISBN: 978-1-4503-4091-5. DOI: 10.1145/2872362.2872366. URL: http://doi.acm.org/10.1145/2872362.2872366 (citado nas pgs. $45,46,77)$.

[Gruss et al. 2017] Daniel Gruss et al. "Kaslr is dead: long live kaslr". Em: International Symposium on Engineering Secure Software and Systems. Springer. 2017, pgs. 161176 (citado nas pgs. 17, 85).

[R. INTEL 2019] RB InTEL. Introduction to Intel Memory Protection Extensions. URL: https: //software.intel.com/en-us/articles/introduction-to-intel-memory-protectionextensions (acesso em 22/02/2019) (citado na pg. 109).

[INTEL 2018] InTEL, ed. Intel® 64 and IA-32 Architectures Software Developer's Manual. 2018. URL: software.intel.com/sites/default/files/managed/39/c5/325462-sdm-vol1-2abcd-3abcd.pdf (citado na pg. 26).

[KEw 2007] Nick Kew. The Apache modules book: application development with Apache. Prentice Hall Professional, 2007 (citado nas pgs. 55, 56).

[Limited 2001] ARM Limited. ARM Developer Suite. 2001, pgs. 49-64 (citado na pg. 16).

[Litton et al. 2016] James Litton et al. "Light-weight contexts: an os abstraction for safety and performance". Em: Proceedings of the 12th USENIX Conference on Operating Systems Design and Implementation. OSDI'16. Savannah, GA, USA: USENIX Association, 2016, pgs. 49-64. ISBN: 978-1-931971-33-1. URL: http://dl.acm.org/ citation.cfm?id=3026877.3026882 (citado na pg. 47).

[Love 2010] Robert Love. Linux Kernel Development. $3^{\text {a }}$ ed. Novell Press, 2010 (citado nas pgs. $1,5,82)$.

[McCanne e Jacobson 1993] Steven McCanne e Van Jacobson. "The bsd packet filter: a new architecture for user-level packet capture". Em: Proceedings of the USENIX Winter 1993 Conference Proceedings on USENIX Winter 1993 Conference Proceedings. 
USENIX'93. San Diego, California: USENIX Association, 1993, pgs. 2-2. URL: http: //dl.acm.org/citation.cfm?id=1267303.1267305 (citado na pg. 100).

[Milojicic e Roscoe 2016] Dejan Milojicic e Timothy Roscoe. "Outlook on operating systems”. Em: Computer 49.1 (2016), pgs. 43-51 (citado na pg. 45).

[Oleksenko et al. 2018] Oleksii Oleksenko, Dmitrii KuvaiskiI, Pramod Bhatotia, Pascal Felber e Christof Fetzer. "Intel mpx explained: a cross-layer analysis of the intel mpx system stack”. Em: Proc. ACM Meas. Anal. Comput. Syst. 2.2 (jun. de 2018), 28:1-28:30. ISSN: 2476-1249. DOI: 10 . 1145 / 3224423. URL: http: //doi.acm.org/10.1145/3224423 (citado na pg. 109).

[Popek e Goldberg 1974] Gerald J. Popek e Robert P. Goldberg. "Formal requirements for virtualizable third generation architectures". Em: Commun. ACM 17.7 (jul. de 1974), pgs. 412-421. ISSN: 0001-0782. DOI: $10.1145 / 361011.361073$. URL: http: //doi.acm.org/10.1145/361011.361073 (citado nas pgs. 23-25).

[Patterson e Hennessy 2007] David A Patterson e John L Hennessy. Computer Organization and Design. $4^{\text {a }}$ ed. Morgan Kaufmann, 2007 (citado na pg. 7).

[Rubini e Corbet 2001] Alessandro Rubini e Jonathan Corbet. Linux device drivers. $2^{a}$ ed. O’Reilly Media, Inc, 2001 (citado na pg. 23).

[Ristic 2013] Ivan Ristic. OpenSSL cookbook. 2013 (citado na pg. 60).

[Swift et al. 2003] Michael M. Swift, Brian N. Bershad e Henry M. Levy. "Improving the reliability of commodity operating systems". Em: Proceedings of the Nineteenth ACM Symposium on Operating Systems Principles. SOSP '03. Bolton Landing, NY, USA: ACM, 2003, pgs. 207-222. ISBN: 1-58113-757-5. DOI: 10.1145/945445.945466. URL: http://doi.acm.org/10.1145/945445.945466 (citado nas pgs. 39-41).

[Silberschatz et al. 2010] Abraham Silberschatz, Peter B Galvin e Greg Gagne. Operating System Concepts. $8^{\text {a }}$ ed. Addison-wesley Reading, 2010 (citado nas pgs. 1, $5,7,8,14,19,20)$.

[SonI 2016] Rahul SonI. Introduction to Nginx Web Server. Springer, 2016 (citado na pg. 58).

[SAltzer e Schroeder 1975] Jerome H Saltzer e Michael D Schroeder. "The protection of information in computer systems". Em: vol. 63. 9. IEEE, 1975, pgs. 1278-1308 (citado na pg. 35).

[Stahnke 2005] Michael Stahnke. Pro OpenSSH. Apress, 2005 (citado na pg. 62).

[TARAsov et al. 2011] Vasily Tarasov, Saumitra Bhanage, Erez Zadok e Margo SeltZER. "Benchmarking file system benchmarking: it* is* rocket science." Em: HotOS. Vol. 13. 2011, pgs. 1-5 (citado na pg. 85). 
[Tanenbaum e Bos 2015] Andrew S Tanenbaum e Herbert Bos. Modern Operating Systems. $4^{\text {a }}$ ed. Pearson Education, Inc, 2015 (citado nas pgs. 1, 5, 24, 25).

[Uhlig et al. 2005] Rich Uhlig et al. "Intel virtualization technology". Em: Computer 38.5 (2005), pgs. 48-56. DOI: 10.1109/MC.2005.163 (citado na pg. 25).

[Vandewoude et al. 2007] Yves Vandewoude, Peter Ebraert, Yolande Berbers e Theo D'Hondt. "Tranquility: a low disruptive alternative to quiescence for ensuring safe dynamic updates”. Em: IEEE, 2007, pgs. 856-868 (citado na pg. 111).

[Venkatachalam 2007] Girish Venkatachalam. The OpenSSH Protocol Under the Hood. 1 de abr. de 2007. uRL: https://www.linuxjournal.com/article/9566 (acesso em 06/11/2018) (citado na pg. 62).

[Witchel, Cates et al. 2002] Emmett Witchel, Josh Cates e Krste Asanović. "Mondrian memory protection”. Em: Proceedings of the 10th International Conference on Architectural Support for Programming Languages and Operating Systems. ASPLOS X. San Jose, California: ACM, 2002, pgs. 304-316. ISBN: 1-58113-574-2. DOI: 10.1145/605397.605429. URL: http://doi.acm.org/10.1145/605397.605429 (citado na pg. 42).

[Witchel, Rhee et al. 2005] Emmett Witchel, Junghwan Rhee e Krste Asanović. "Mondrix: memory isolation for linux using mondriaan memory protection". Em: Proceedings of the Twentieth ACM Symposium on Operating Systems Principles. SOSP '05. Brighton, United Kingdom: ACM, 2005, pgs. 31-44. IsBN: 1-59593-079-5. DOI: 10.1145/1095810.1095814. URL: http://doi.acm.org/10.1145/1095810.1095814 (citado nas pgs. 43, 88). 


\section{Índice Remissivo}

A

acerto na TLB (TLB hit), 13

C

chamada de sistema, 19

Chave de Proteção da Memória, 15

Comunicação entre processos, 8

contexto de hardware, 20

D

descritor de arquivo (file descriptor -

fd), 21

E

endereço lógico, 11

endereços físicos, 11

endereço virtual, 11

entrada da tabela de páginas, 13

espaço de endereçamento físico, 11

espaço de endereçamento virtual (Virtual Address Space), 11

F

falta na TLB (TLB miss), 13

frames, 12

G

guest, 24

H

handshake, 60

host, 24

hypervisor, 24

I

Implementação estrutural leve, 29

Implementações Estruturais Pesadas, 29

Implementações Independentes, 29 inode, 21

Instruções de controle de fluxo sensíveis, 24

Instruções privilegiadas, 24

Instruções sensíveis, 24

Interprocess Communication, 8

IPC, 8

K

keep-alive, 54

\section{$\mathbf{M}$}

módulos carregáveis, 23

mapeamento anônimo, 17

Memory-Management Unit (MMU), 11

Memory Protection Extensions, 109

$\mathbf{P}$

páginas, 12

Process Control Block (PCB), 7

\section{S}

Secure Sockets Layers (SSL), 59

Secure Virtual Machine (SVM), 25

segmentação, 14

segmento de dados inicializados, 6

segmento de dados não inicializados, 6

segmento de memória mapeada, 6, 17

segmento de pilha, 7

segmento de texto, 6

segmento do monte (heap segment, 7

Servidores web, 53

sistema de arquivos, 21

Software Guard Extensions (SGX), 109

stack frames, 7

Stop the World (STW), 65 
T

tabela de paginação, 12

tabela de segmentos, 14

tabela global de arquivos, 21

tabela local de arquivos dos processos, 21

tradução binária, 25

translation look-aside buffer (TLB), 13

V

VAS, 11

virtual-machine control structure
(VMCS), 25

virtual bits, 11

Virtual Machine Monitor (VMM), 24

virtual memory area - VMA, 18

VM entry, 25

VM exit, 25

VMX non-root, 25

VMX root, 25

VT-x, 25

Vulnerabilidades e Exposições Comuns

(Common Vulnerabilities and

Exposures - CVE), 61 